Florida International University FIU Digital Commons

9-1-2015

\title{
The Performance and Service Life Prediction of High Performance Concrete in Sulfate and Acidic Environments
}

Shuo Zhang

eric.zhang2729@yahoo.com

DOI: $10.25148 /$ etd.FIDC000151

Follow this and additional works at: https://digitalcommons.fiu.edu/etd

Part of the Civil Engineering Commons, and the Structural Engineering Commons

\section{Recommended Citation}

Zhang, Shuo, "The Performance and Service Life Prediction of High Performance Concrete in Sulfate and Acidic Environments" (2015). FIU Electronic Theses and Dissertations. 2260.

https://digitalcommons.fiu.edu/etd/2260 


\section{FLORIDA INTERNATIONAL UNIVERSITY}

Miami, Florida

THE PERFORMANCE AND SERVICE LIFE PREDICTION OF HIGH

PERFORMANCE CONCRETE IN SULFATE AND ACIDIC ENVIRONMENTS

A dissertation submitted in partial fulfillment of the

requirements for the degree of

DOCTOR OF PHILOSOPHY

in

CIVIL ENGINEERING

by

Shuo Zhang

2015 
To: $\quad$ Interim Dean Ranu Jung

College of Engineering and Computing

This dissertation, written by Shuo Zhang, and entitled The Performance and Service Life Prediction of High Performance Concrete in Sulfate and Acidic Environments, having been approved in respect to style and intellectual content, is referred to you for judgment.

We have read this dissertation and recommend that it be approved.

Ton-Lo Wang

Arindam G. Chowdhury

Arvind Agarwal

Nakin Suksawang

Atorod Azizinamini, Major Professor

Date of Defense: September 1, 2015

The dissertation of Shuo Zhang is approved.

Interim Dean Ranu Jung

College of Engineering and Computing

Dean Lakshmi N. Reddi

University Graduate School

Florida International University, 2015 


\section{DEDICATION}

I dedicate this thesis to my wife. Without her understanding and supports, the completion of this work would not have been possible. 


\section{ACKNOWLEDGMENTS}

First and foremost I would like to especially thank Dr. Nakin Suksawang, for his selfless help and support through my completion of my doctoral study. Dr. Suksawang served as my major advisor for most of time except the last two years. His help, advising, and guidance is highly appreciated.

Especially appreciation also to Dr. Azizinamini for taking me under his gentle but firm direction during the final steps of my doctoral study. I also would like to express my gratitude to my committee members, Dr. Ton-Lo Wang, Dr. Arindam G. Chowdhury, and Dr. Arvind Agarwal for their suggestions and help with my dissertation, for their time, interests, and thought provocative questions.

The field exploration and laboratory experiments performed was funded by the Florida Department of Transportation (FDOT). The support from the FDOT is acknowledged.

Finally, I take this opportunity to express my profound gratitude to my family for their unconditional love and encouragement. My wife, Yuanyuan Fang, always supports my endeavors with great enthusiasm. 


\begin{abstract}
OF THE DISSERTATION
THE PERFORMANCE AND SERVICE LIFE PREDICTION OF HIGH

PERFORMANCE CONCRETE IN SULFATE AND ACIDIC ENVIRONMENTS
\end{abstract}

by

Shuo Zhang

Florida International University, 2015

Miami, Florida

\title{
Professor Atorod Azizinamini, Major Professor
}

Concrete substructures are often subjected to environmental deterioration, such as sulfate and acid attack, which leads to severe damage and causes structure degradation or even failure. In order to improve the durability of concrete, the High Performance Concrete (HPC) has become widely used by partially replacing cement with pozzolanic materials. However, HPC degradation mechanisms in sulfate and acidic environments are not completely understood. It is therefore important to evaluate the performance of the HPC in such conditions and predict concrete service life by establishing degradation models.

This study began with a review of available environmental data in the State of Florida. A total of seven bridges have been inspected. Concrete cores were taken from these bridge piles and were subjected for microstructural analysis using Scanning Electron Microscope (SEM). Ettringite is found to be the products of sulfate attack in sulfate and acidic condition.

In order to quantitatively analyze concrete deterioration level, an image processing program is designed using Matlab to obtain quantitative data. Crack 


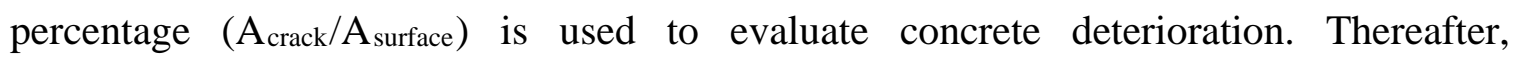
correlation analysis was performed to find the correlation between five related variables and concrete deterioration. Environmental sulfate concentration and bridge age were found to be positively correlated, while environmental $\mathrm{pH}$ level was found to be negatively correlated.

Besides environmental conditions, concrete property factor was also included in the equation. It was derived from laboratory testing data. Experimental tests were carried out implementing accelerated expansion test under controlled environment. Specimens of eight different mix designs were prepared. The effect of pozzolanic replacement rate was taken into consideration in the empirical equation. And the empirical equation was validated with existing bridges.

Results show that the proposed equations compared well with field test results with a maximum deviation of $\pm 20 \%$. Two examples showing how to use the proposed equations are provided to guide the practical implementation. In conclusion, the proposed approach of relating microcracks to deterioration is a better method than existing diffusion and sorption models since sulfate attack cause cracking in concrete. Imaging technique provided in this study can also be used to quantitatively analyze concrete samples. 


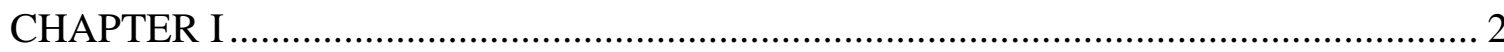

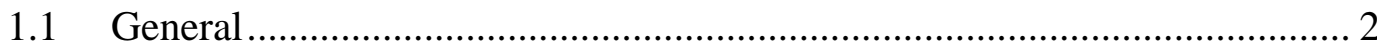

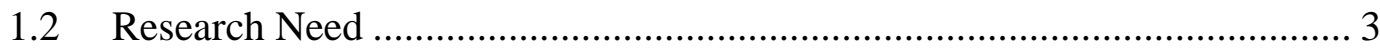

1.3 Objectives and Scope................................................................................ 5

1.4 Organization of Dissertations ................................................................. 5

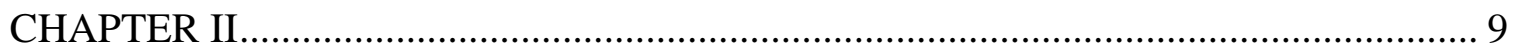

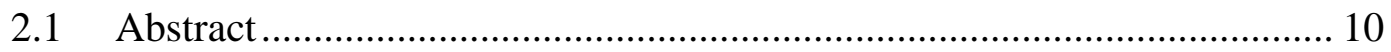

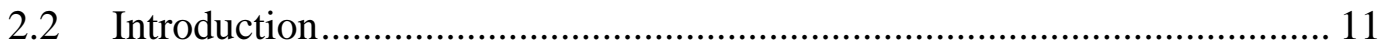

2.3 Description of Tests .............................................................................. 13

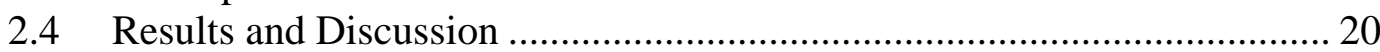

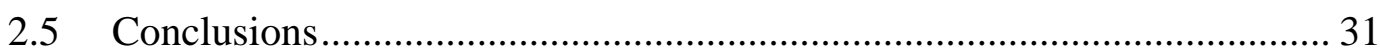

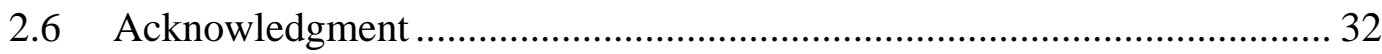

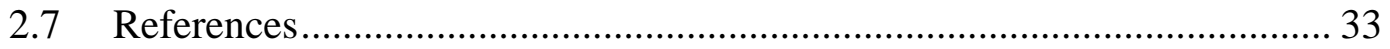

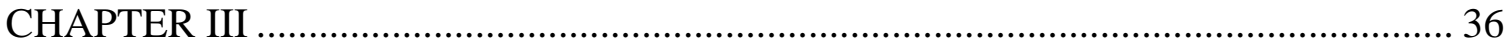

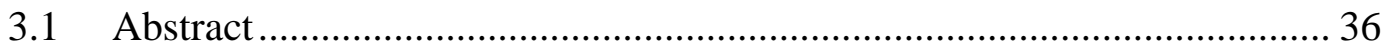

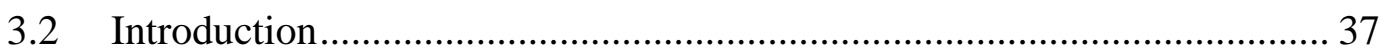

3.3 Laboratory Studies ...................................................................................... 38

3.4 Accelerated Sulfate Resistance Test .......................................................... 41

3.5 Modulus of Rupture Test ........................................................................ 42

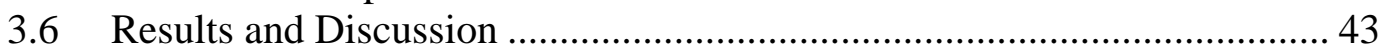

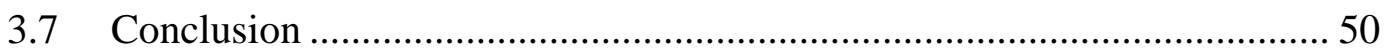

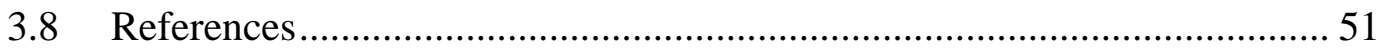

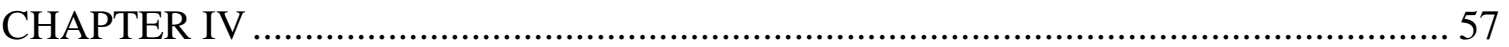

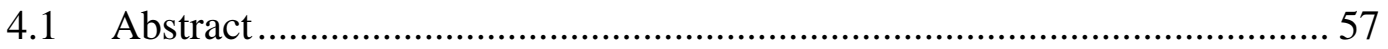

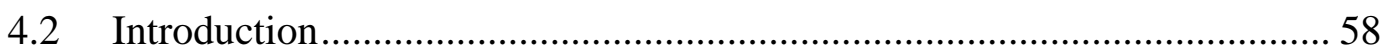

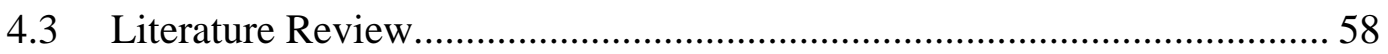

4.4 Theories and Considerations ........................................................................ 60

$4.5 \quad$ Finite Element Analysis .............................................................................. 77

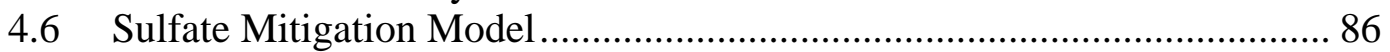

4.7 Comparative Study with In-Service Concrete Piles..................................... 104

4.8 Application Scopes and Limitations ……………….................................. 107

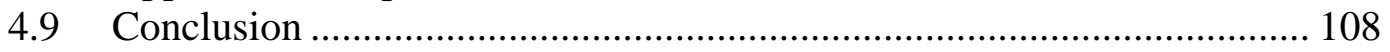

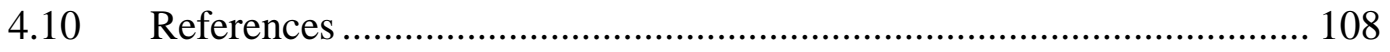

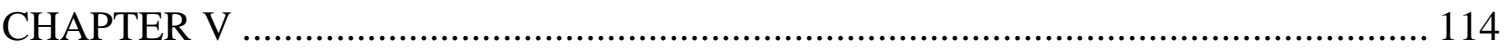

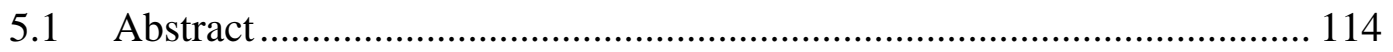

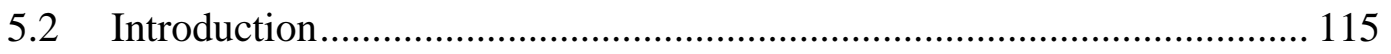

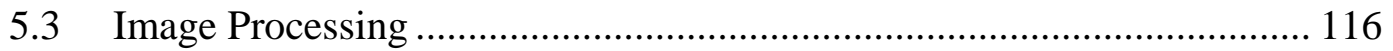

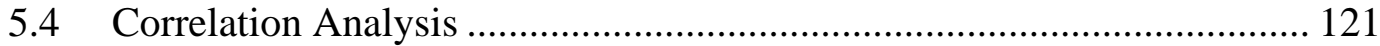




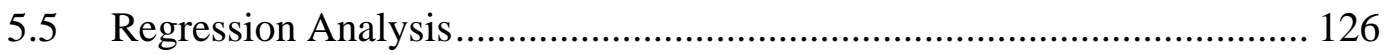

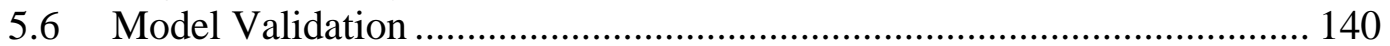

5.7 Conclusion and Practical Implementation ............................................. 141

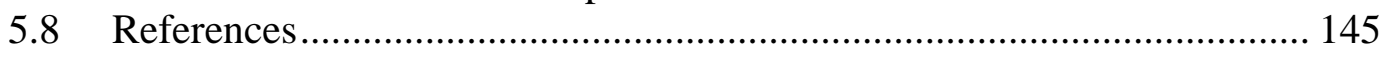

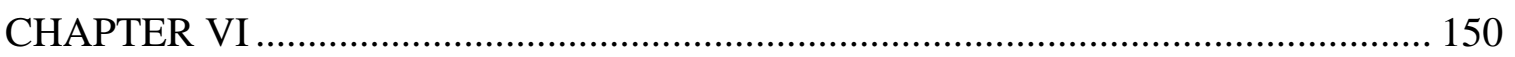

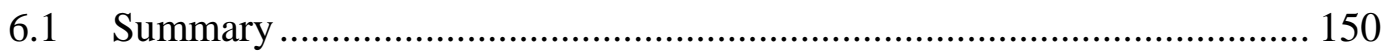

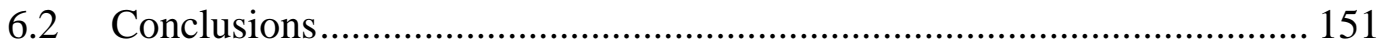

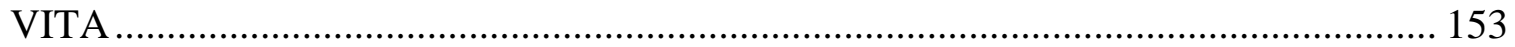




\section{LIST OF TABLES}

TABLES

PAGE

Table 2-1 List of inspected field bridges ................................................................ 13

Table 3-1 Cement binders mixes, w/cm ratio, and concrete mixes ............................... 39

Table 4-1 Hydraulic diffusivities of concrete represented by Eq. 4.8 ........................... 63

Table 4-2 Difference diffusion expression for same materials..................................... 63

Table 4-3 Permeability of cement-based materials........................................................ 65

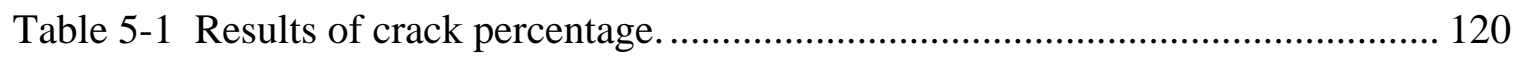

Table 5-2 Expansion rate constants of pozzolanic materials in magnesium and

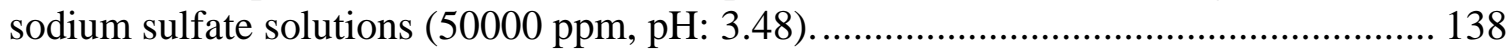

Table 5-3 Expansion rate constants of pozzolanic materials in magnesium and

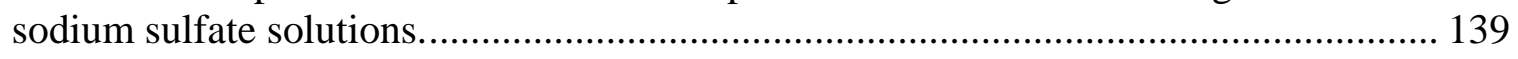




\section{LIST OF FIGURES}

FIGURE

PAGE

FIGURE 2.1. Drilling locations of core samples (a) and 2-in. diameter core samples (b). 15

FIGURE 2.2. Typical backscattered electron image. ................................................ 16

FIGURE 2.3. EDS spectrum of (a) ettringite and (b) nearby cement paste...................... 19

FIGURE 2.4. EDS mapping of ettringite particles within concrete. ............................ 20

FIGURE 2.5. surface scaling and concrete core samples conditions of (a and c)

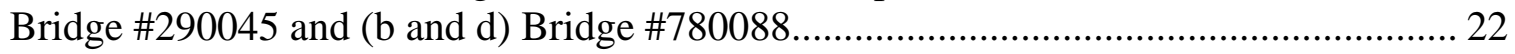

FIGURE 2.6. Steel corrosion revealed from (a) Bridge \#720476 and (b) Bridge \#740033.

FIGURE 2.7. Concrete core samples condition of Bridge \#290045 (a) and \#780088 (b). 24

FIGURE 2.8. Sulfate distribution within concrete of (a) Bridge \#290045, (b) ............... 26

FIGURE 2.9. Sulfate distribution within concrete of (a) Bridge \#490030, (b) Bridge \#720476, (c) Bridge \#170067, and (d) Bridge \#740033.

FIGURE 2.10. Internal cracks SEM images of bridge \# 290045 (a, b, c) and bridge \# 780088 (d, e, f).

FIGURE 2.11. Internal cracks SEM images of bridge \# 490030 (a, b, c) and bridge \#

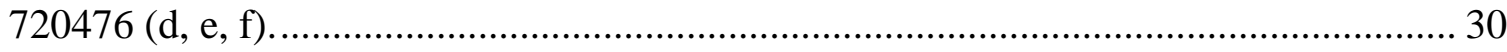

FIGURE 2.12. Relation of crack width versus sulfur atom percentage.......................... 31

FIGURE 3.1. Laboratory environmental control system........................................ 41

FIGURE 3.2. A typical specimen for accelerated expansion test................................. 42

FIGURE 3.3. Fly ash specimens after 1 week of submerging under sodium and magnesium sulfate.

FIGURE 3.4. Specimens with different cementitious materials under sodium and magnesium attack 
FIGURE 3.5. Fly ash cement paste with dry curing, moist curing and compound curing after 6 weeks of submerging in sodium sulfate solution.

FIGURE 3.6. Comparison of expansion of various fly ash specimens under different curing conditions.

FIGURE 3.7. Comparison between different curing conditions (under sodium sulfate attack if not noted).

FIGURE 4.1. Hydraulic diffusivity of concrete (left) and ceramic (right) using exponential expression and power-law expression.

FIGURE 4.2. Variation of water evaporation rate $\left(\mathrm{g} \mathrm{h}^{-1}\right)$ with humidity (Left, humidity factor $\mathrm{H}=1-(\%$ R.H./100) and air speed (Right)

FIGURE 4.3. Water content profiles calculated by Eq. 4.12 and using power-law diffusivity for concrete $\mathrm{w} / \mathrm{c}=0.40$.

FIGURE 4.4. Scanning Electron Microscope image of the surface of fly ash cement (25\% fly ash) after 4 weeks immerged into 50,000 ppm sulfate solution.

FIGURE 4.5. X-ray diffraction analysis of the surface of fly ash cement (25\% fly ash) after 4 weeks immerged into 50,000 ppm sulfate solution

FIGURE 4.6. The FE model used in this study: specimen size, discretization scheme and boundary conditions

FIGURE 4.7. Water content profiles using power-law diffusivity function at a series of elapsed times t for water absorption into concrete having the diffusivity function $\mathrm{D} / \mathrm{m}^{2} \mathrm{~s}^{-1}=2.13 \times 10^{-8} \square^{6.5}$

FIGURE 4.8. Water content profiles using exponential diffusivity function at a series of elapsed times $t$ for water absorption into concrete having the diffusivity function $\mathrm{D} / \mathrm{m}^{2} \mathrm{~s}^{-1}=1.3 \times 10^{-11} \exp (7.4$

FIGURE 4.9. Water content profiles obtained by NMR during capillary absorption of water by a plaster bar (a, b) and water content profiles calculated by FE models and power-law diffusivity analytical solution of concrete

FIGURE 4.10. Water content profiles using exponential diffusion model at different time.

FIGURE 4.11 Water content profiles using power-law diffusion model at different time. 
FIGURE 4.12. Water content profiles of emerged concrete under both side penetrations. Concrete $\mathrm{w} / \mathrm{c}=0.4$. Calculation use exponential diffusivity function, $\mathrm{D}_{0}=1.3 \times 10^{-11} \mathrm{~m}^{2} \mathrm{~s}^{-1}, \mathrm{~B}=7.4$.

FIGURE 4.13. Water content at the depth of steel rebar and in the middle of concrete pile.

FIGURE 4.14. Sulfate reaction products content in form of sulfur weight percentage distribution at different period

FIGURE 4.15. The FE model used in this study: specimen size, discretization scheme and boundary conditions

FIGURE 4.16. Water content profiles contour map of concrete half immerged in water for 1 week

FIGURE 4.17. Water content profiles contour map of concrete half immerged in water for 2 weeks.

FIGURE 4.18. Water content profiles contour map of concrete half immerged in water for 3 weeks.

FIGURE 4.19. Water content profiles contour map of concrete half immerged in water for 4 weeks.

FIGURE 4.20. Water content profiles of concrete half immerged in water for a series of time. Measurements are taken at $50 \mathrm{~mm}$ under water level.

FIGURE 4.21. Water content profiles of concrete half immerged in water for a series of time. Measurements are taken at $50 \mathrm{~mm}$ above water level.

FIGURE 4.22. Water content profiles of concrete half immerged in water for a series of time. Measurements are taken at 3 inch depth from surface. Water level is at 100 mm height.

FIGURE 4.23. Sulfate reaction products distribution of concrete half immerged in water for a series of time at 3-inch below water level.

FIGURE 4.24. Sulfate reaction products distribution of concrete half immerged in water for a series of time at 3-inch depth from surface. Water level is at $100 \mathrm{~mm}$ height

FIGURE 4.25. The FE model used in this study: specimen size, discretization scheme and boundary conditions

FIGURE 4.26. The water content profiles contour map of research domain at the end of 10 years. Analysis concentrates on the left side of domain..... 
FIGURE 4.27. The water content profiles contour map of research domain at the end of 30 years.

FIGURE 4.28. The water content profiles contour map of research domain at the end of 30 years.

FIGURE 4.29. The water content profiles contour map of research domain at the end of 30 years.

FIGURE 4.30. Reduced water content profiles along line 1,500 mm under water level at different time period.

FIGURE 4.31. Sulfur weight percentage along line 1,500 mm under water level at different time period.

FIGURE 4.32. Reduced water content along line 1,500 $\mathrm{mm}$ above water level at different time period.

FIGURE 4.33. Sulfur weight percentage along line 1,500 $\mathrm{mm}$ above water level at different time period.

FIGURE 4.34. Reduced water content along line 3.3 inch depth from the surface at different time period.

FIGURE 4.35. Sulfur weight percentage along line 3.3 inch depth from the surface at different time period.

FIGURE 4.36. Bridge \#490030 on-site picture 105

FIGURE 4.37. Sulfur atom percentage along line $2.500 \mathrm{~mm}$ above water level at different time period. Results come from Finite Element Model. 106

FIGURE 4.38. Compare on sulfur atom percentage between on-site exploration and FE model to a 27-year old bridge at $500 \mathrm{~mm}$ above water level.

FIGURE 5.1. Original concrete SEM image. ........................................................... 117

FIGURE 5.2. Crack enhenced concrete SEM image................................................ 117

FIGURE 5.3. Image processing methodologies. ...................................................... 118

FIGURE 5.4. Crack enhancement program algorithm flowchart................................. 119

FIGURE 5.5. Aggregate identification program algorithm flowchart.......................... 120

FIGURE 5.6. Correlation between crack percentage and sulfur percentage................. 123 
FIGURE 5.7. Correlation between crack percentage and environmental sulfate concentration

FIGURE 5.8. Correlation between crack percentage and environmental pH level........ 123

FIGURE 5.9. Correlation between crack percentage and bridge age.

FIGURE 5.10. Correlation between crack percentage and sample depth.

FIGURE 5.11. Correlation between normalized crack percentage and environmental $\mathrm{pH}$.

FIGURE 5.12. Correlation between normalized crack percentage and bridge age........ 125

FIGURE 5.13. Regression analysis of the relation between sulfur percentage and crack percentage

FIGURE 5.14. Regression analysis of the relation between environmental $\mathrm{pH}$ level and normalized crack percentage.

FIGURE 5.15. Regression analysis of the relation between bridge age and normalized crack percentage

FIGURE 5.16. Correlation between crack percentage and sample depth 128

FIGURE 5.17. Expansion of specimens with fly ash $10 \%$ and $25 \%$ replacements of cement in magnesium $\left(\mathrm{Mg}^{+}\right)$sulfate solution.

FIGURE 5.18. Expansion of specimens with fly ash $10 \%$ and $25 \%$ replacements of cement in sodium $\left(\mathrm{Na}^{+}\right)$sulfate solution.

FIGURE 5.19. Expansion of specimens with silica fume 5\%, 7\% and 9\% replacements of cement in magnesium $\left(\mathrm{Mg}^{+}\right)$sulfate solution.

FIGURE 5.20. Expansion of specimens with silica fume 5\%, 7\% and 9\% replacements of cement in sodium $\left(\mathrm{Na}^{+}\right)$sulfate solution.

FIGURE 5.21. Expansion of specimens with slag 30\%, 50\% and 70\% replacements of cement in magnesium $\left(\mathrm{Mg}^{+}\right)$sulfate solution.

FIGURE 5.22. Expansion of specimens with slag 30\%, 50\% and 70\% replacements of cement in sodium $\left(\mathrm{Na}^{+}\right)$sulfate solution.

FIGURE 5.23. Expansion rate of specimens with fly ash replacements in sodium $\left(\mathrm{Na}^{+}\right)$and magnesium $\left(\mathrm{Mg}^{+}\right)$sulfate solution. 
FIGURE 5.24. Expansion rate of specimens with silica fume replacements in sodium $\left(\mathrm{Na}^{+}\right)$and magnesium $\left(\mathrm{Mg}^{+}\right)$sulfate solution.............................................................. 137

FIGURE 5.25. Expansion rate of specimens with slag replacements in sodium $\left(\mathrm{Na}^{+}\right)$ and magnesium $\left(\mathrm{Mg}^{+}\right)$sulfate solution. ...................................................................... 137

FIGURE 5.26. Correlation between the tested crack percentage and calculated crack percentage. 


\section{LIST OF ACRONYMS/ABBREVIATIONS}

ASTM

EDS

FDOT

FHWA

HPC

SEM

USGS

$\mathrm{w} / \mathrm{cm}$
American Society for Testing and Materials

Energy-Dispersive X-ray Spectroscopy

Florida Department of Transportation

Federal Highway Administration

High-Performance Concrete

Scanning Electron Microscopes

United State Geological Survey

Water-to-Cementitious Ratio 
CHAPTER I

INTRODUCTION 


\section{CHAPTER I \\ INTRODUCTION}

\subsection{General}

High performance concrete (HPC) has multiple definitions. Mehta and Aietcin suggested the term HPC for concrete mixtures that possess the following three properties: high workability, high strength, and high durability.

The Strategic Highway Research Program (SHRP) in the United States defined HPC for highway structures by three requirements, namely a maximum $w / c m$, a minimum durability factor to cycles of freezing and thawing (ASTM C 666, Method A), and a minimum early-age or ultimate compressive strength.

HPC mixtures are essentially composed of the same materials as conventional concrete mixtures. But the proportions are designed or engineered to provide the strength and durability needed for the structural and environmental requirements of the project. HPC is being extensively used now for the fabrication of precast pylons, piers, and girders of many long span bridges in the world.

Acid and sulfate are chemicals that could cause severe damage to concrete structures. They broadly present in environments nationally. Based on the current classification that stated by Florida Department of Transportation (FDOT), environmental conditions are classified using the terms negligible, moderate, severe, and very severe. However, questions have been raised of the combination attack of both acid and sulfate, which is whether or not current environmental classification still valid when more than one hazardous chemicals appear in the environment. 
The FDOT has provided comprehensive guidelines and specifications on HPC mixtures that account for the environmental impact. These guidelines are designed to ensure a minimum 75-year service life of the design of reinforced concrete structures. However, the prediction of concrete service life has been done usually using chloride diffusion models that developed based on Portland cement concrete instead of HPC. Since the HPC has different composition compare to Portland cement concrete, the degradation process may be governed by other mitigation methods other than chloride diffusion.

This research mainly focuses on the performance of HPC in sulfate and acidic environments. Finite Element Method (FEM) is used in modeling concrete degradation process and concrete service life is predicted using this model with data supported from field inspection and laboratory experiments.

\subsection{Research Need}

The fundamental theory for improving the durability performance of concrete, particularly the increase in chemical resistance, is by lowering its permeability. The addition of pozzolanic and other cementitious materials as well as lowering the $w / \mathrm{cm}$ ratio can significantly reduce permeability but cannot totally eliminate the diffusion process of chemical attack in concrete. Thus, in addition to the use of HPC, specifications on concrete cover are provided to prevent corrosion of the steel reinforcement based on environmental classification and are designed to provide a minimum 75-year design service life of reinforced concrete structures. 
The specifications are based on years of research and implementation but with an emphasis on coastal environment where chloride and sulfate are the two dominating compounds that deteriorate concrete. Less known, however, are other environmental conditions that also exist, particularly the exposure to both low $\mathrm{pH}$ and moderate sulfate environment. Based on the current FDOT classification, bridges exposed to both low $\mathrm{pH}$ and sulfate environment would be in the moderately aggressive environmental classification range because the $\mathrm{pH}$ is above 5.0 and the sulfate content is below 1500 ppm. It should be noted that despite the current specification describing low pH as a level below 5.0, concrete does suffer from deterioration when the $\mathrm{pH}$ level is below 6.5 [Mehta and Monteiro, 2006; Mindes et al, 2003].

The problem with the exposure to both low $\mathrm{pH}$ and moderate sulfate environment is their failure mechanism is not well established. It is possible that the combination of low $\mathrm{pH}$ and sulfate could potential lead to significant deterioration of the concrete structures. Therefore, there is a need to investigate the impact on HPC in low $\mathrm{pH}$ and moderate sulfate environment.

Besides this particular environment, sulfate transport mechanism is not clear under such condition. Chloride diffusion model is widely adopted in calculation of concrete service life. But as well as concrete cover specification, it mostly concentrates on coastal environment. Therefore, there is a need to further explore sulfate transport mechanism in low pH and sulfate environment. A new concrete service life model should be made based on sulfate migration instead of chloride diffusion only. 


\subsection{Objectives and Scope}

To better fulfill the goal of this research, which is to evaluate HPC performance in sulfate and acidic environments, establish sulfate transport model, and predict concrete service life, objectives of this research are listed below.

1. Determine the potential risk of significant deterioration of HPC in low $\mathrm{pH}$ and sulfate environments.

2. Identify the concentration of sulfate and $\mathrm{pH}$ for deterioration of HPC to occur.

3. Evaluate degradation degree of in-situ concrete bridge piles.

4. Evaluate sulfate resistance of HPC with different cementitious materials.

5. Establish sulfate migration model.

6. Evaluate time scale of HPC degradation.

\subsection{Organization of Dissertations}

The current dissertation is written in the format of 'Thesis Containing Journal Papers.' The dissertation contains four (4) manuscripts, out of which, one under review, one submitted, and two will be submitted to scholarly journals. In addition, a general introduction chapter appears at the beginning and a general conclusion chapter appears at the end of dissertation.

The first paper, under review of Transportation Research Board, presents inspection results of piles of seven bridges using micro-structural analysis method. This study is conducted to learn the sulfate-induced deterioration of in-situ concrete piles and their resistivity to sulfate and acidic environmental conditions. It is observed that the 
deterioration of concrete piles under acidic sulfate combination attack exceeds expectation. Sulfate penetration is revealed to be much severe in such conditions that with the existing of comparative low $\mathrm{pH}$ (lower than 7.0) and moderate sulfate contents (over $150 \mathrm{ppm}$ ). Ettringite is found to be the production of sulfate attack in such condition. It is concluded from this study that acidic sulfate attack will result of extensive internal cracks to in-situ concrete bridge piles.

The second paper, submitted to Construction and Building Materials, presents the results of an experimental investigation carried out to evaluate sulfate resistance properties of concrete mixtures with pozzolanic materials. A total of 15 mixtures with different mix designs were prepared. Accelerated sulfate resistance test and modulus of rupture test were carried out. The degree of sulfate attack was evaluated using expansion tests and loss of strength. Compression test results indicate that even under the same sulfate concentration, magnesium sulfate is more aggressive than sodium sulfate. Moreover, regardless the type of sulfate, the addition of pozzolanic materials significantly increased the resistance to sulfate attack.

The third paper, to be submitted to Cement and Concrete Composite, presents the approach of computational modeling sulfate absorption based model using Richards Equation and it's validated with other scholars' data and experimental data. From these computations, it was concluded that under acidic condition, sulfate penetration could be described using absorption based model. Durability concerns have been focused on the modeling of external sulfate attack. A literature review has exposed the different aspects trying to explain the mechanisms underlying this complex phenomenon. A model has been developed based on a finite element method by implying absorption-reaction 
equation. After extrapolation of the short-term to the long term case, the output of the model is validated by comparing it to experimental results.

The fourth paper, presents the empirical model developed using field exploration data and laboratory data to predict the development of concrete cracks. An image processing program is designed using Matlab to process the Scanning Electron Microscope (SEM) images and obtain crack percentage $\left(\mathrm{A}_{\text {crack }} / \mathrm{A}_{\text {surface}}\right)$. Correlation analysis were implemented between related variable(s) and concrete deterioration. Environmental sulfate concentration, bridge age, environmental $\mathrm{pH}$ level and concrete properties were found to be related with the development of concrete cracks. The empirical equations were concluded and validated with field bridges testing data. In conclusion, the proposed approach of relating microcracks to deterioration is a better method than existing diffusion and sorption models since sulfate attack cause cracking in concrete. Imaging technique provided in this study can also be used to quantitatively analyze concrete samples. 


\section{CHAPTER II}

STUDY OF SULFATE-INDUCED DETERIORATION OF IN-SITU CONCRETE BRIDGE FOUNDATIONS 


\title{
CHAPTER II
}

\section{STUDY OF SULFATE-INDUCED DETERIORATION OF IN-SITU CONCRETE BRIDGE FOUNDATIONS}

\author{
Shuo Zhang \\ Graduate Student \\ Department of Civil \& Environmental Engineering, \\ Florida International University \\ 10555 W Flagler Street, Miami, Florida 33174 \\ Tel: (305)298-1112 Fax: (305)348-2802; E-mail: szhan002@fiu.edu
}

\author{
Nakin Suksawang \\ Assistant Professor \\ Department of Civil Engineering \\ Florida Institution of Technology \\ 150 W University Blvd, Melbourne, Florida 32901
}

Tel: (321)674-7504 Fax: (321) 674-7565, E-mail: nsuksawang@fit.edu

Word count: 3,549 words text +14 tables/figures x 250 words (each) $=7049$ words

Submission Date 


\subsection{Abstract}

This paper presents test results of seven bridge piles using micro-structural analysis method. This study is conducted to learn the sulfate-induced deterioration of insitu concrete piles and their resistivity to sulfate and acidic environmental conditions. The testing program addressed concrete deterioration due to sulfate penetration and expansion. Scanning Electron Microscope (SEM) with energy-dispersive X-ray spectroscopy (EDS) is used to characterize micro-crack development and chemical composition. It is observed that the deterioration of concrete piles under acidic sulfate combination attack exceed previous expectation. Sulfate penetration is revealed to be much severe in such conditions that with both existing of comparative low $\mathrm{pH}$ (lower than 7.0) and moderate sulfate contents (over $150 \mathrm{ppm}$ ). Ettringite is found to be the production of sulfate attack at such condition. Micro-cracks were evaluated using 100 times magnification SEM images. Cracks are found to be connected through formed ettringite particles and aggregate/cement interface. Maximum crack width is found to be $7.35 \mu \mathrm{m}$ at depth of 3.5 inch from surface of bridge \#720476 that constructed in acidic sulfate environment (pH 6.5, sulfate $860 \mathrm{ppm}$ ) in 1984. Comparatively, bridge under severe acid attack (bridge \#290045, pH 4.2, built in 1977), although endures severe surface scaling, concrete internal cracks are revealed to be less than $2.69 \mu \mathrm{m}$. It is concluded from this study that acidic sulfate attack will result of extensive internal cracks to in-situ concrete bridge piles.

Keywords: Concrete, Sulfate Attack, Acid Attack, Precast Piles, Scanning Electron Microscopic, Energy-Dispersive X-Ray Spectroscopy, Microstructures, Cracks 


\subsection{Introduction}

The most common type of deep foundation is pilling. Piles used for modern bridge construction may be made of concrete, steel, or timber. For corrosive environments, special protection should be considered for the use of steel piles exposed to water in extremely aggressive environments. To achieve a 100 -year design life, the steel piles require coating, increasing steel thickness and filling concrete and rebar for pipe piles. This results in additional costs to protect the pile in corrosive environments that are not present when using concrete piles. Thus, for most of Florida bridges, Precast Prestressed Concrete Piles (PPCP) is the most widely accepted bridge foundation type.

Florida Department of Transportation (FDOT) Design Standards as well as FDOT’s Structures Desgin Guidelines provide comprehensive regulations and guidelines for the use of such concrete piles. The required concrete cover for such piles is 3-inch in order to protect steel rebar. Especially, for substructures facing extremely aggressive environments, the minimum required size for prestressed concrete pile is 24-inch. It is believed that 75-year design life could be achieved by following these guidelines. However, for field bridges, it is unclear if 3-inch concrete cover is sufficient to protect steel rebar or if design service life could be reached based on current deterioration process. Much less researches focus on inspection of in-situ bridge piles than experimental approaches.

One major reason that causes concrete deterioration is sulfate attack. Sulfate attack could result of the formation of gypsum or ettringite and further more crack development. Internal sulfate attack can be reduced by carefully select cement and aggregate. In this research, external sulfate attack is studied as influenced by the factors 
of environmental sulfate concentration, $\mathrm{pH}$ level, concrete internal cracks, wet and dry cycles and so on.

Several researchers have raised criticism of current sulfate attack test method. The effort acid attack is generally ignored. As a matter of fact, the ASTM describes two test methods for accessing hydraulic cement sulfate resistance in sulfate environments (ASTM C452 and ASTM C1012). But neither of them seems to predict field concrete performance adequately. It is the field in deeply need to be studied that in acid- and sulfate- rich environment, how does field concrete perform to resist both acid and sulfate attack, even though concrete design philosophy did not concern the effect of acid nor able to predict long-term concrete performance.

Surface scaling and spalling, weight loss and expansion are also important phenomenon of acid and sulfate attack. They can be used for quantitative analysis. However, for bridges that have been in service for years, most of these quantitative analysis methods don't perform well since there is no "original” data to use. Scanning Electron Microscopy (SEM) has distinct advantages for use of characterization of cement and aggregate microstructures. Quantitative information can be acquired from these data and therefore could be used for analysis of sulfate penetration and evaluation of concrete deterioration.

Extensive preliminary research has been done before selecting inspected bridges. Florida's environmental condition is summarized in FDOT's Bridge Environmental Data, which including nearly 7000 bridges' environmental information. By reviewing this data sheet as well as United States Geological Survey (USGS) database, seven (7) bridges were selected. The inspected concrete information is summarized (Table 2-1). It is to be 
noted that seasonal variations, tidal conditions and recent rainfall conditions may cause the difference between measured value and FDOT record.

Table 2-1 List of inspected field bridges

\begin{tabular}{|c|c|c|c|c|c|c|c|}
\hline $\begin{array}{l}\dot{0} \\
z \\
\text { 됭 } \\
\text { 夏 }\end{array}$ & 尝 & 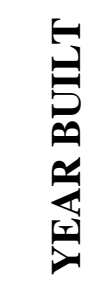 & 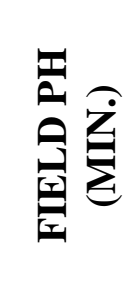 & 氞罢 & 国是 & 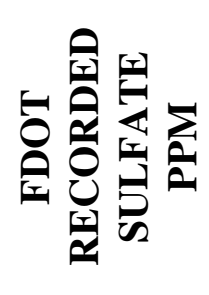 & 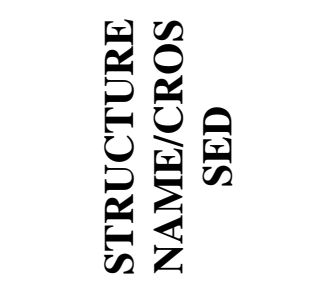 \\
\hline 170067 & Sarasota & 2009 & $\begin{array}{l}7.60 \\
(7.03)\end{array}$ & 5.4 & 55 & 1074 & $\begin{array}{c}\text { SR-72 / } \\
\text { MYAKKA } \\
\text { RIVER } \\
\text { OVERFLOW }\end{array}$ \\
\hline 290045 & Columbia & 1977 & $\begin{array}{c}4.35 \\
(4.23)\end{array}$ & 4.2 & -* & 130 & $\begin{array}{l}\text { CR-250/ } \\
\text { FALLING } \\
\text { CREEK }\end{array}$ \\
\hline 490030 & Franklin & 1986 & $\begin{array}{c}7.61 \\
(6.85)\end{array}$ & 5.9 & 1417 & 552 & $\begin{array}{l}\text { US98 SR-30/ } \\
\text { TURKEY } \\
\text { BAYOU }\end{array}$ \\
\hline 580017 & $\begin{array}{l}\text { Santa } \\
\text { Rosa }\end{array}$ & 1971 & $\begin{array}{c}7.12 \\
(7.02) \\
\end{array}$ & 5.6 & 18 & 4 & $\begin{array}{l}\text { SR-87/EAST } \\
\text { BAY RIVER }\end{array}$ \\
\hline 720476 & Duval & 1984 & $\begin{array}{c}7.53 \\
(7.42)\end{array}$ & 6.4 & 860 & 800 & $\begin{array}{c}\text { I-295 (SR-9A) } \\
\text { NB/TERRAPIN } \\
\text { CREEK }\end{array}$ \\
\hline 740033 & Nassau & 1992 & $\begin{array}{c}7.47 \\
(7.39)\end{array}$ & 6.3 & 750 & 280 & $\begin{array}{l}\text { I-95 SB (SR-9)/ } \\
\text { TIDE CREEK }\end{array}$ \\
\hline 780088 & St. Johns & 1982 & $\begin{array}{l}7.26 \\
(6.81)\end{array}$ & 6.3 & 8 & 220 & $\begin{array}{c}\text { I-95 (SR-9)/ } \\
\text { CANAL CREEK }\end{array}$ \\
\hline
\end{tabular}

Note: *Sulfate content is too low to be measured.

\subsection{Description of Tests}

\subsubsection{General}

A field exploration program was performed which consisted of environmental condition tests, collect of concrete samples in order to understand field environmental conditions and concrete deterioration level. Laboratory testing program was conducted by 
preparing samples, analyzing chemical composition using SEM with EDS. Concrete deterioration level is concluded from visual inspection and micro-crack analysis. Sulfate penetration is determined by measuring sulfur atoms contents in cement particles.

\subsubsection{Environmental Condition Tests}

Environmental condition test was performed on water samples obtained from water body near inspected bridges. The testing performed included $\mathrm{pH}$ and sulfate content. Testing of sulfate content was performed in accordance with the Florida Method of Test for Sulfate in Soil and Water (FM 5-553). Sulfate reagent system - Sulfate, Pocket Colorimeter II Test Kit of Hach Company was used to test sulfate concentration. Testing of $\mathrm{pH}$ was conducted in accordance with the Florida Method of Test for $\mathrm{pH}$ of Soil and Water (FM 5-550). The pH meter and electrode system - Portable pH Test Kit Model 5050T of Hach Company was used for this purpose. Water samples were collected from three (3) locations for each inspected bridges, which are upstream, downstream and near concrete piles. The collected samples were placed in air-tight container and transported to lab for sulfate content test.

\subsubsection{Concrete Core Samples}

Concrete core samples were taken on selected concrete piles. Totally at least four (4) 2-inch diameter core samples were collected from each inspected bridge piles, specifically, two (2) samples were taken above the highest watermark and two (2) samples below watermark (Figure 2.1) Core samples were drilled as deep as possible from existing surface of concrete piles to reinforced steel, which usually has a length of 2 to 4 inch (Figure 2.1). Drilled hole was then patched with cement paste after sampling to 
prevent excessive corrosion due to inspection. Core samples were washed using fresh water and kept in air-tight container and transported to lab for further investigation.

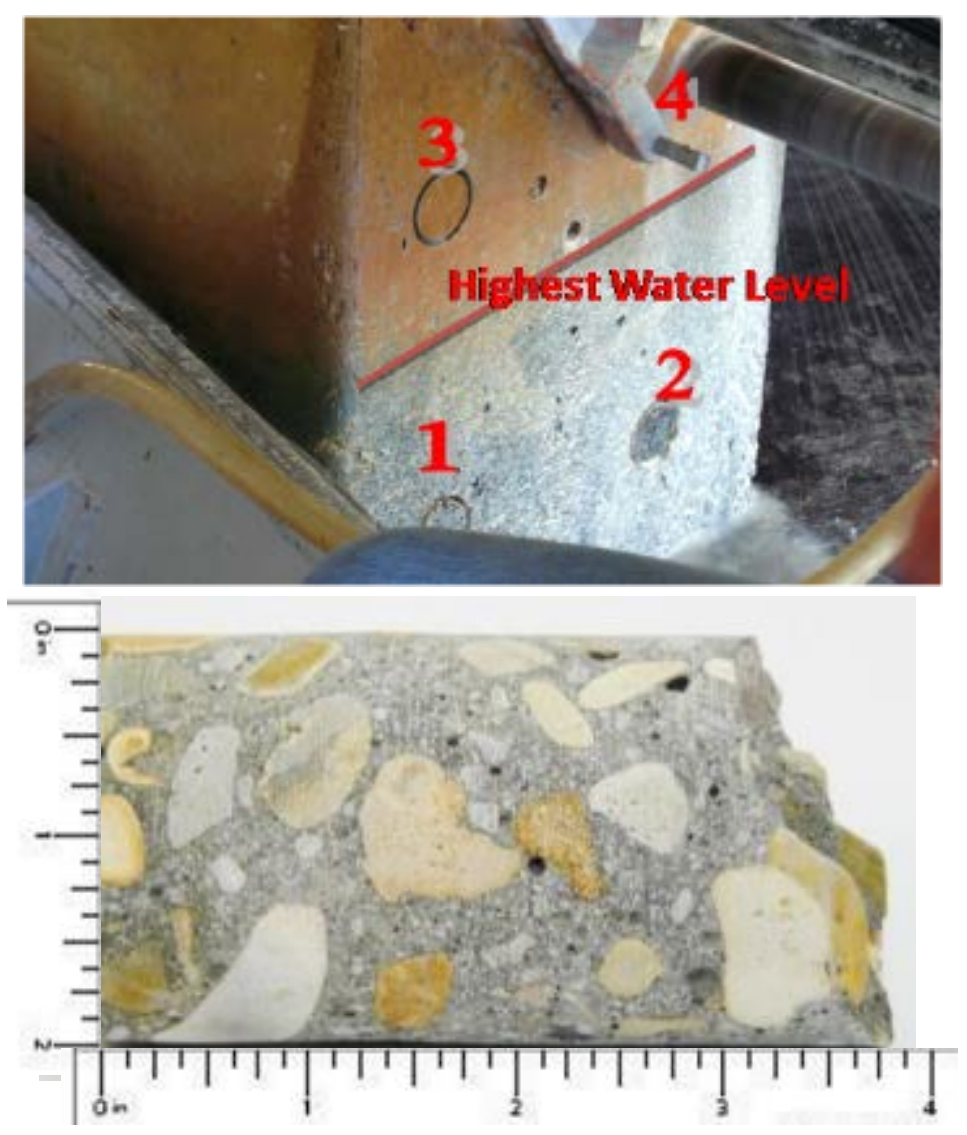

FIGURE 2.1. Drilling locations of core samples (a) and 2-in. diameter core samples (b).

\subsubsection{Sample Preparation}

Concrete core samples collected from inspected bridge piles were firstly visually inspected. Thereafter, these core samples were sliced using concrete saw at depth of every half inch from surface. The concrete slides were then washed using tapped water (sulfate content was tested of less than $10 \mathrm{ppm}$ ), dried and stored separately in air-tight container to prevent cross-contamination. 


\subsubsection{Microstructural Analysis}

After the concrete samples were prepared, JEOL JSM 5900LV Scanning electron microscope (SEM) was used to inspect deteriorated concrete microstructure. Concrete microstructure images were acquired at a magnification of x100 using Secondary Electron Imaging, which results from secondary electrons that could produce near surface topographies. Cement, aggregates and micro cracks could be easily distinguished by their colors and shapes in a backscattered electron (BSE) image at magnification of x100 (Figure 2.2).

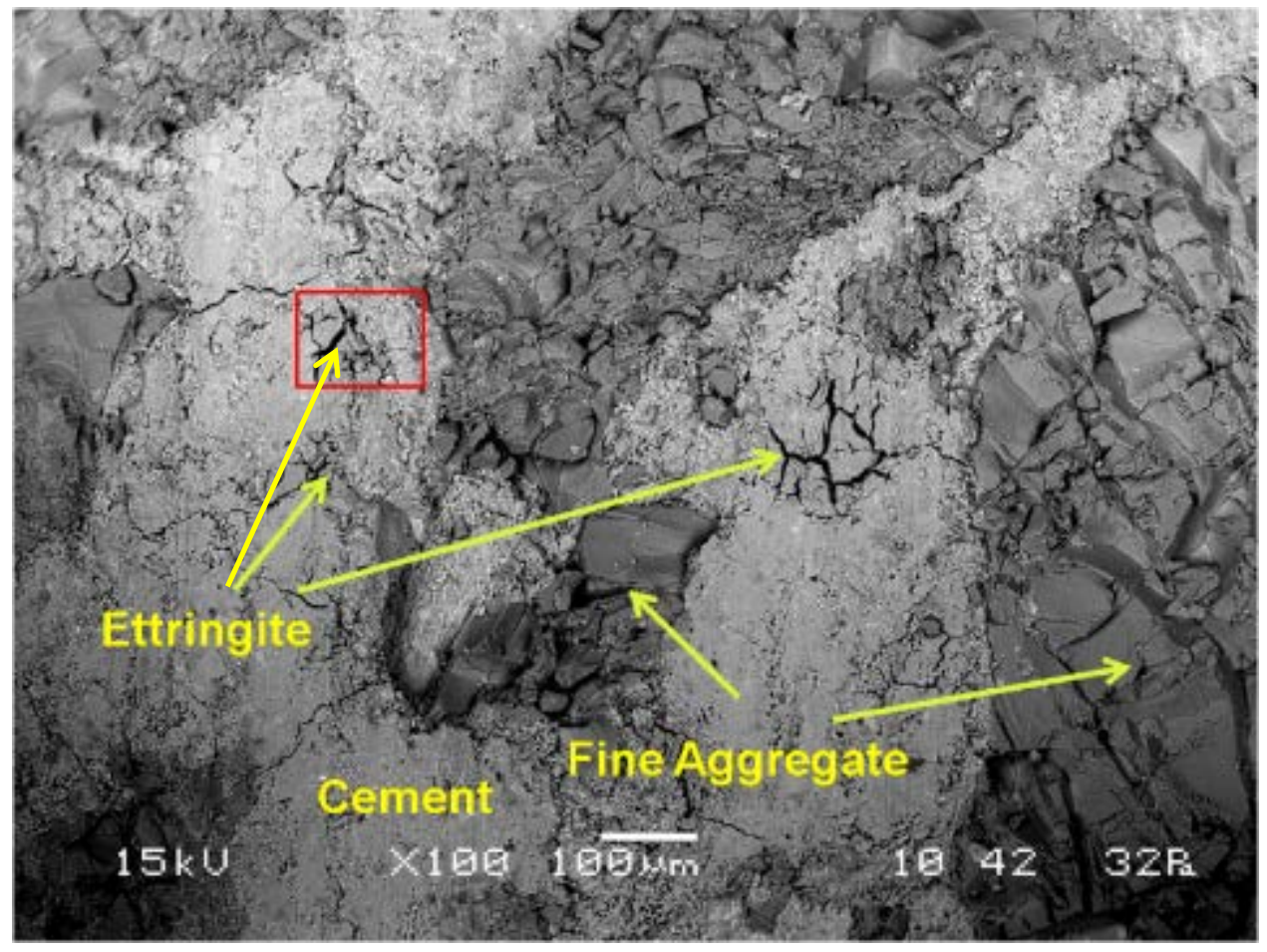

FIGURE 2.2. Typical backscattered electron image. 


\subsubsection{X-Ray Microanalysis}

$\mathrm{X}$-radiation is produced when specimen is bombarded by high-energy electrons. With the help of an energy-dispersive detector with wavelength detector, energydispersive X-ray spectroscopy (EDS) is displayed as the number of counts at each energy intervals. The positions of the peak positions are characteristic of certain elements. Mass concentration quantitative analysis can be determined using this technology with sufficient accuracy.

As stated in previous section, particles at flocculent shaped cracks are examined using EDS analysis method and found to be ettringite particles with sufficient proof. EDS images clearly showed the significant difference of sulfur atom between formed ettringite particles and nearby cement. The sulfate ion $\left(\mathrm{SO}_{4}{ }^{2-}\right)$ consists of a central sulfur atom (S) surrounded by four equivalent oxygen atoms (O), in which sulfur atom percentage is $20 \%$. Hydraulic cement consists of four main components, which are Belite $\left(\mathrm{CaO} \cdot \mathrm{SiO}_{2}\right)$, Alite $\left(\mathrm{CaO} \cdot \mathrm{SiO}_{2}\right)$, Celite $\left(\mathrm{CaO} \cdot \mathrm{Al}_{2} \mathrm{O}_{3}\right)$ and Brownmillerite $\left(\mathrm{CaO} \cdot \mathrm{Al}_{2} \mathrm{O}_{3} \cdot \mathrm{Fe}_{2} \mathrm{O}_{3}\right)$. Theoretically, non-contaminated cement particles should contain no sulfur atoms. Reaction between sulfate ions and cement particles results of Ettringite $\left((\mathrm{CaO})_{6}\left(\mathrm{Al}_{2} \mathrm{O}_{3}\right)\left(\mathrm{SO}_{3}\right)_{3} \cdot 32 \mathrm{H}_{2} \mathrm{O}\right)$ and Gypsum $\left(\mathrm{CaSO}_{4} \cdot 2 \mathrm{H}_{2} \mathrm{O}\right)$ depends on aluminate content as wells as $\mathrm{pH}$ level.

EDS spectrum of ettringite and nearby cement paste show a great difference (Figure 2.3). It could be observed that the aluminum and sulfur contents in the area with ettringite were higher when comparing to the area containing only cement paste. The spectrum results were then mapped on the sliced core SEM image (Figure 24) which illustrates EDS mapping 100 times magnification. At this magnification, it is easy to distinguish ettringite, cement, and aggregates by color. The EDS mapping was also 
compared to the SEM images to validate the ettringite's faveolate formation. The EDS spectrum or more specifically the percentage of sulfur atom was also used to identify the level of sulfate attack in the concrete by analyzing the amount at different depths of the cored specimens.

As discussed earlier, the percentage of sulfur atoms was used to identify sulfate penetration level. However, sulfur was not evenly distributed within cement (Figure 2.4). Thus, to obtain accurate results and avoid the influence of aggregate, two SEM images were taken for each slice in this study. For each SEM image, 5 separated measurements were taken to ensure only hydraulic cement was covered in the measured area. The average value was taken for these 10 measurements to reduce artificial error. The average values of sulfur content at different depths were then plotted for evaluation of the sulfate penetration. 

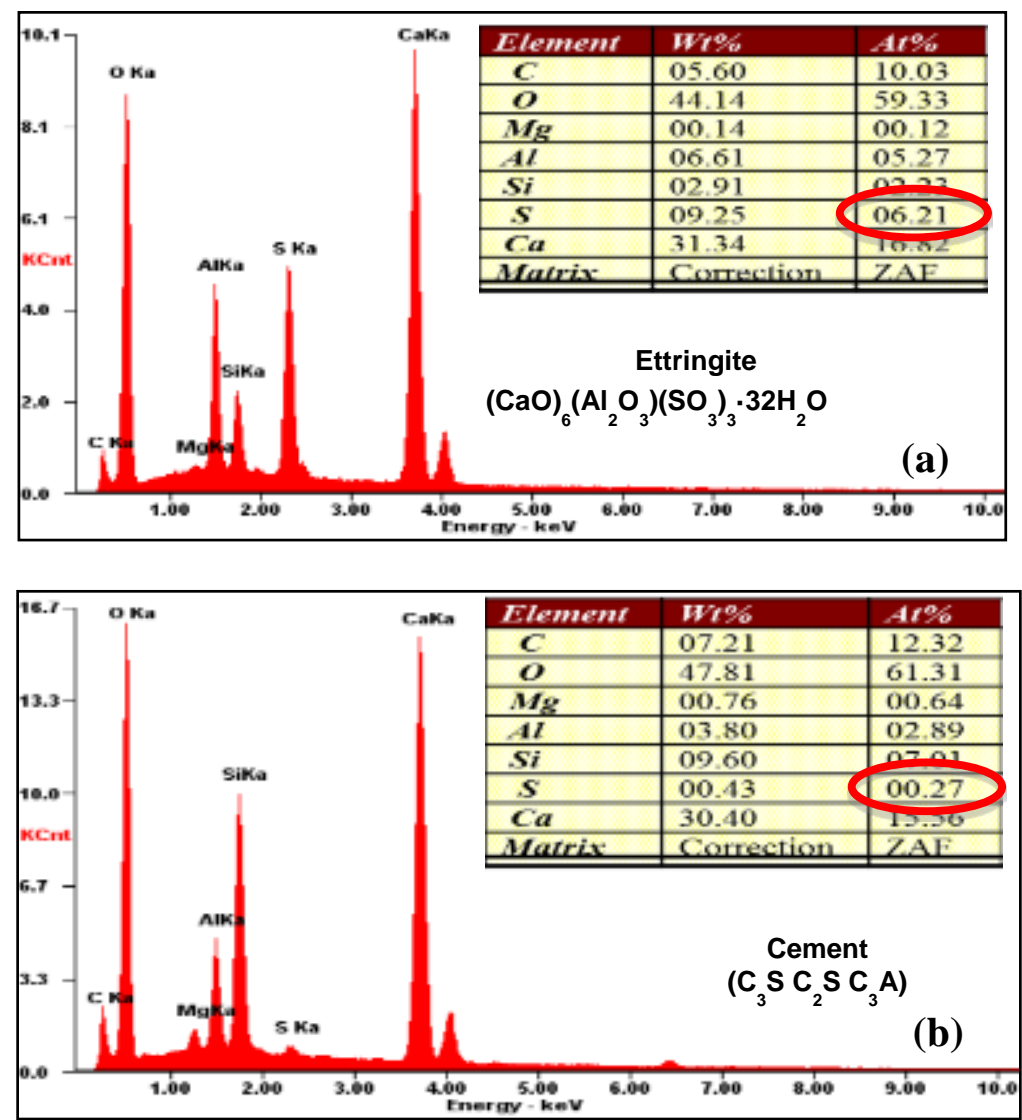

FIGURE 2.3. EDS spectrum of (a) ettringite and (b) nearby cement paste. 


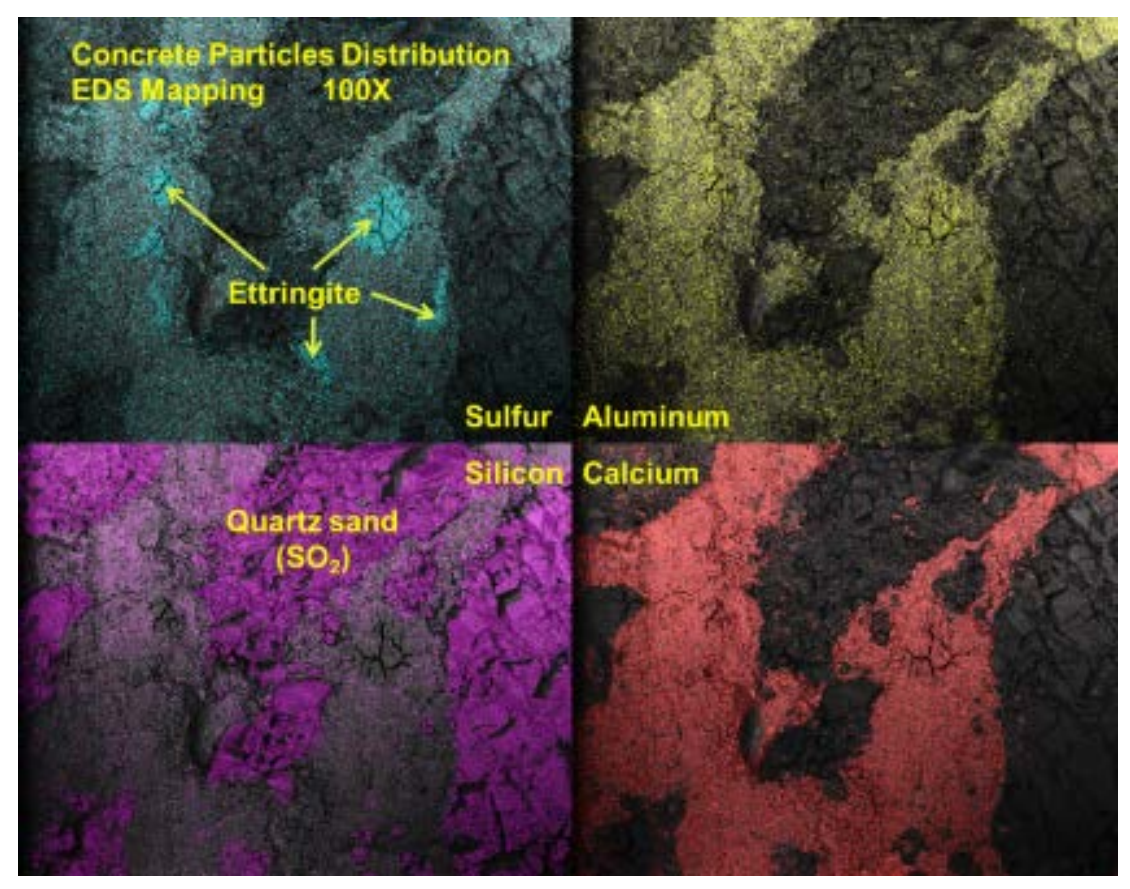

FIGURE 2.4. EDS mapping of ettringite particles within concrete.

\subsection{Results and Discussion}

\subsubsection{Visual Observations}

Among seven (7) inspected bridges, two (2) were found steel corrosion within concrete piles. No deterministic correlation has been found between surface scaling and steel corrosion.

For those bridges that appeared to have the most extensive scaling, which are bridge \#290045 (built in 1977, min. pH 4.23, sulfate 0-130 ppm) and bridge \#780088 (built in 1982, min. $\mathrm{pH}$ 6.3, sulfate 8-220 ppm), acid is likely to be the most critical factor that cause concrete deterioration. The surface condition of these two bridges appeared to be in bad shape (Figure 2.5). In such environmental condition, concrete cover have played an effectively role in protecting steel rebar. 10 inspection points have been drilled 
and checked for these two bridges and transported to laboratory for microstructure analysis. It is shown that even with severe scaling on concrete surface, no obvious cracks nor internal structure damages is observed (Figure 2.5). In structural design aspect, concrete that acting as protective layer is not considered to have contribution to bearing capacity. It means that in the condition like these two bridges, as long as internal structure and steel rebar remains protected, concrete foundation should still have sufficient functions. However, based on FDOT’s Florida Bridge Information, these two bridges were given health index of 45.38 and 53.05 out of 100, respectively. Without concrete core samples inspection, surface scaling conditions could be misleading.

Internal corrosion was found at two (2) bridges, which are bridge \#720476 (built in 1984, min. pH 6.4, sulfate 800-860 ppm) and bridge \#740033 (built in 1992, min. pH 6.3, sulfate 280-750 ppm). The point of corrosion was found at the end of concrete core samples (Figure 2.6). Concrete internal images (Figure 2.6) present the revealed steel sections. As mentioned above that even steel corrosion is found on these two bridges, their surface scaling is not comparable to bridge \#290045 and \#780088. Concrete surface mainly remains integrity (Figure 2.7). Although there is indeed some cement and aggregate scaled off, original surface could still be seen from the images. Bridge \#720476 is rated 84.76 and bridge \#740033 80.34 for health index. Corrosion bleeding has initiated extensive cracking around steel rebar. It is believed from concrete core samples that these two bridges will last much shorter than the previous two bridges. 

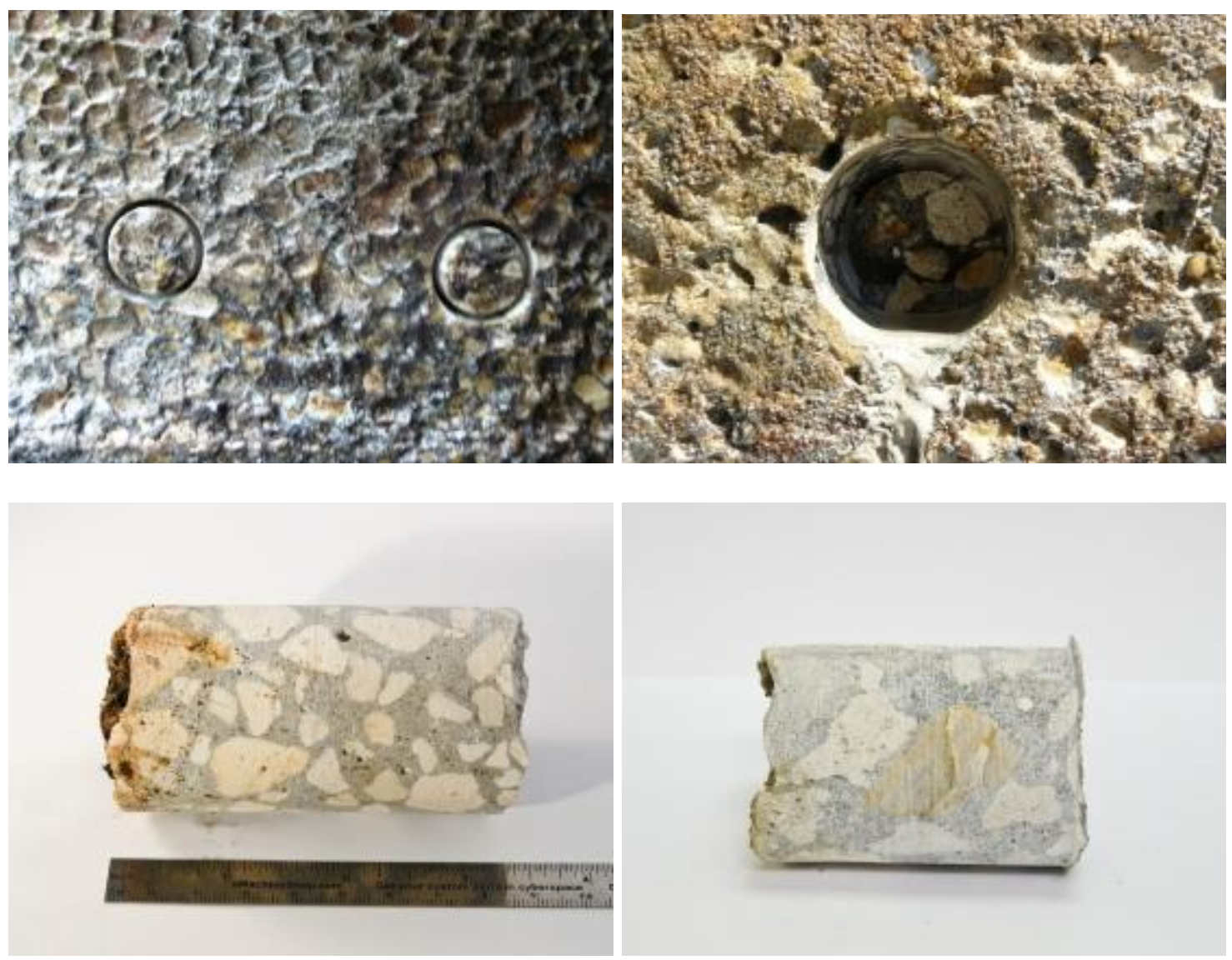

FIGURE 2.5. surface scaling and concrete core samples conditions of (a and c) Bridge \#290045 and (b and d) Bridge \#780088. 

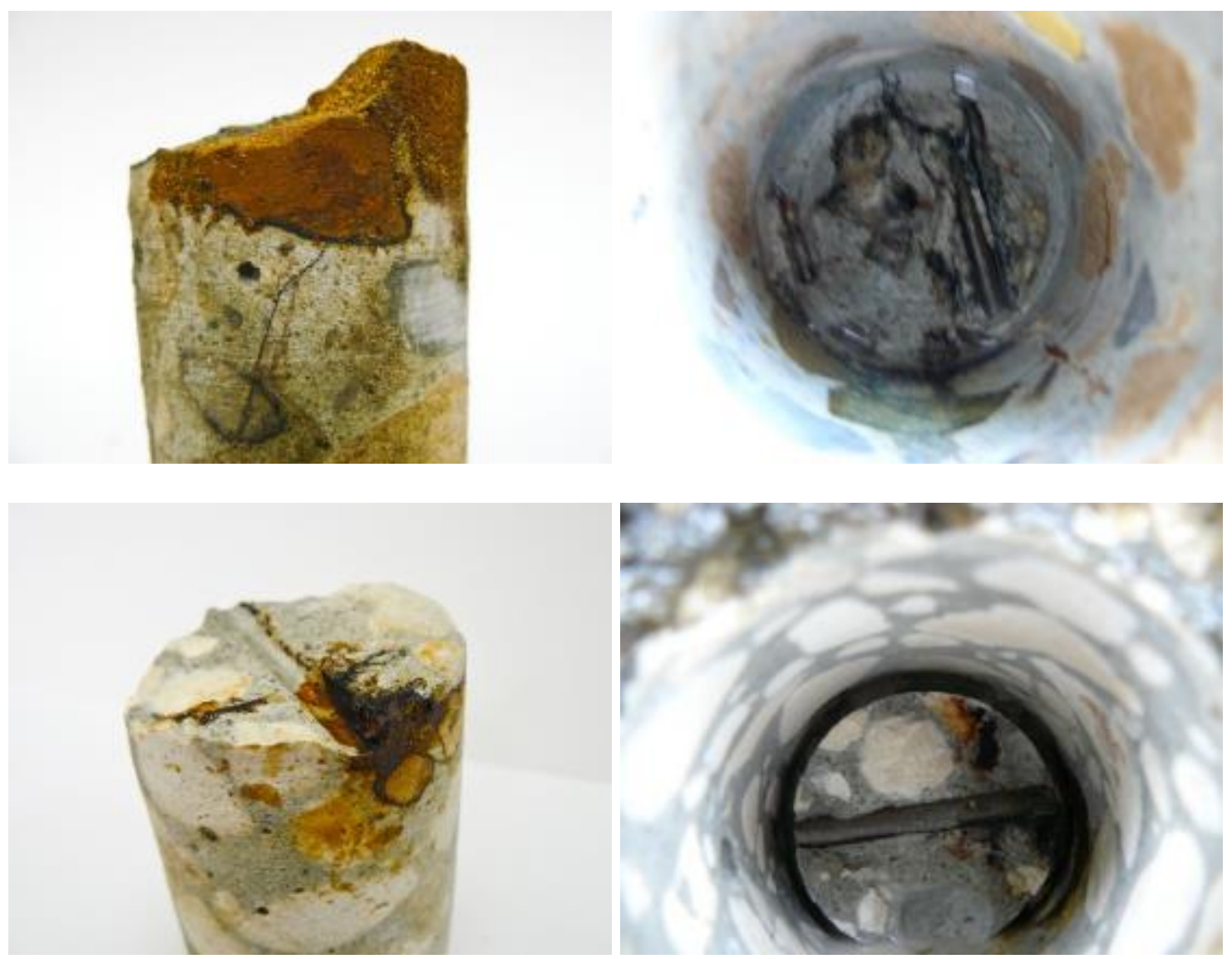

FIGURE 2.6. Steel corrosion revealed from (a) Bridge \#720476 and (b) Bridge \#740033. 

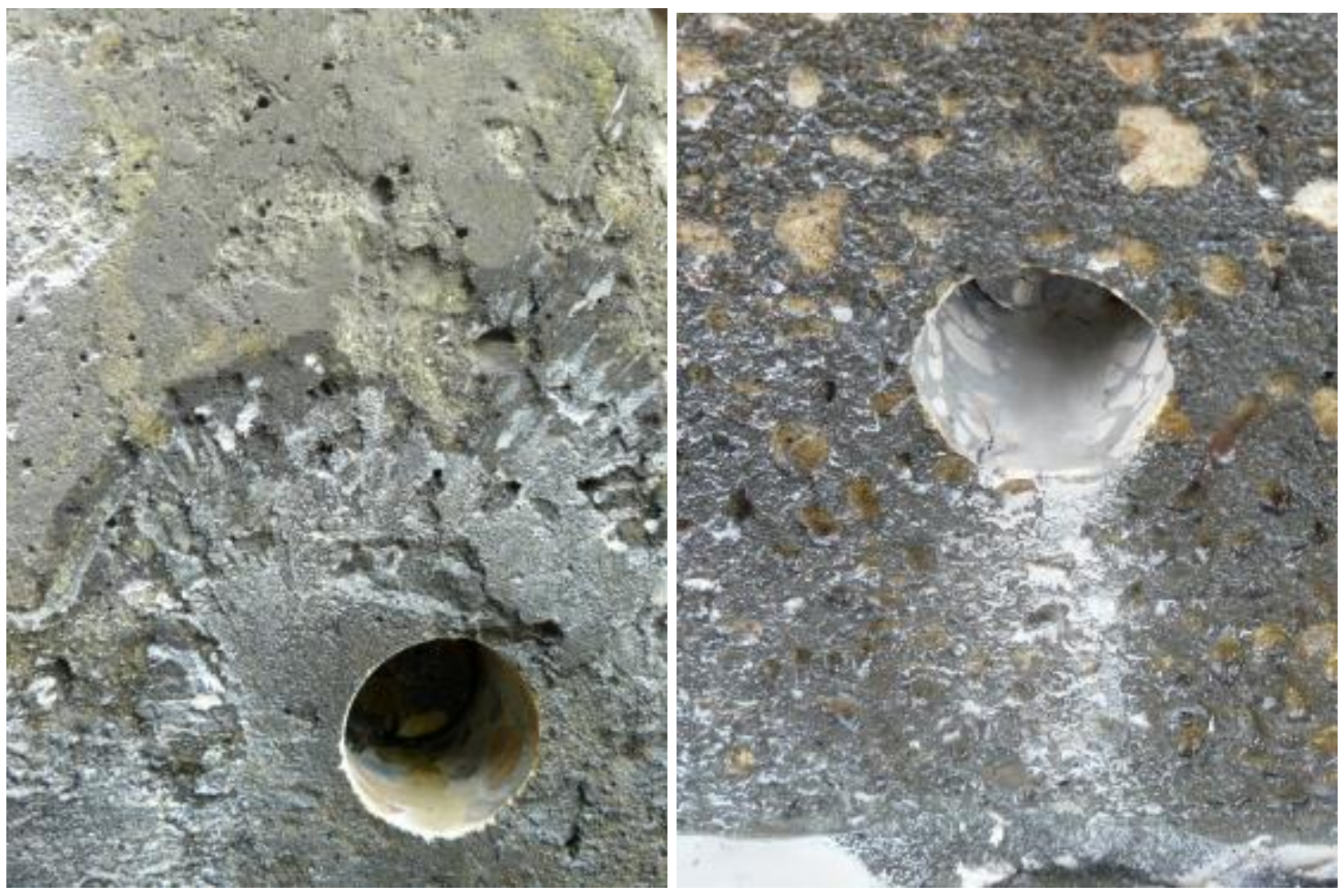

FIGURE 2.7. Concrete core samples condition of Bridge \#290045 (a) and \#780088 (b).

\subsubsection{X-Ray Microanalysis}

$\mathrm{X}$-Ray diffusivity spectrum is acquired and sulfur atom percentage is calculated using the procedure described previously. The amount of sulfate penetrated into concrete cover in unit of atom percentage is illustrated (Figures 2.8 and 2.9). Average values with standard deviation are shown in figures.

It can be seen that for 3 bridges, \#290045, \#580017, and \#780088 (Figure 2.8), sulfur penetration amount decreases as depth increases. This is expected as these samples were less likely affect by sulfate attack but rather by acid attack. It is confirmed that the surface scaling, although looks severe, would not necessarily lead to inner corrosion nor structural failure. 
For those bridges that mentioned above, all locate in low $\mathrm{pH}$ environment. The highest recorded sulfate content is 220 ppm. It can be considered as acid attack only. In such condition (pH less than 7, sulfate content less than $220 \mathrm{ppm}$ ), no significant sulfate attack nor critical damage was found using X-Ray microanalysis at the depth of 3-inch.

The rest of inspected bridges (\#490030, \#720476, \#170067, and \#740033)are different from the other bridges (Figure 2.9). Sulfate content is found not necessarily decreasing in this situation. Including bridges that were found rusting, all four bridges locate in relatively low $\mathrm{pH}$ (min. $\mathrm{pH}, 5.4$ to 6.4) and high sulfate content (sulfate content range, 280 to 1417 ppm) environments. Regardless bridge condition and field inspection results, according to FDOT’s Environmental Classification, this $\mathrm{pH}$ level and sulfate content range can be only classified as moderately aggressive environments. However, 50\% of inspected bridges were found rusting and internal sulfate content is shown as much as $10 \%$ to $70 \%$ higher than the other bridges at the depth of 3 inch from surface.

Comparing with visual observation results, it can be seen that for bridge locates in such environments, surface condition is not quite representative of concrete deterioration condition. It is found out from X-Ray microanalysis that it is possible for sulfate to penetrate through cracks to accumulate inside concrete and may result of extensive internal cracks. 

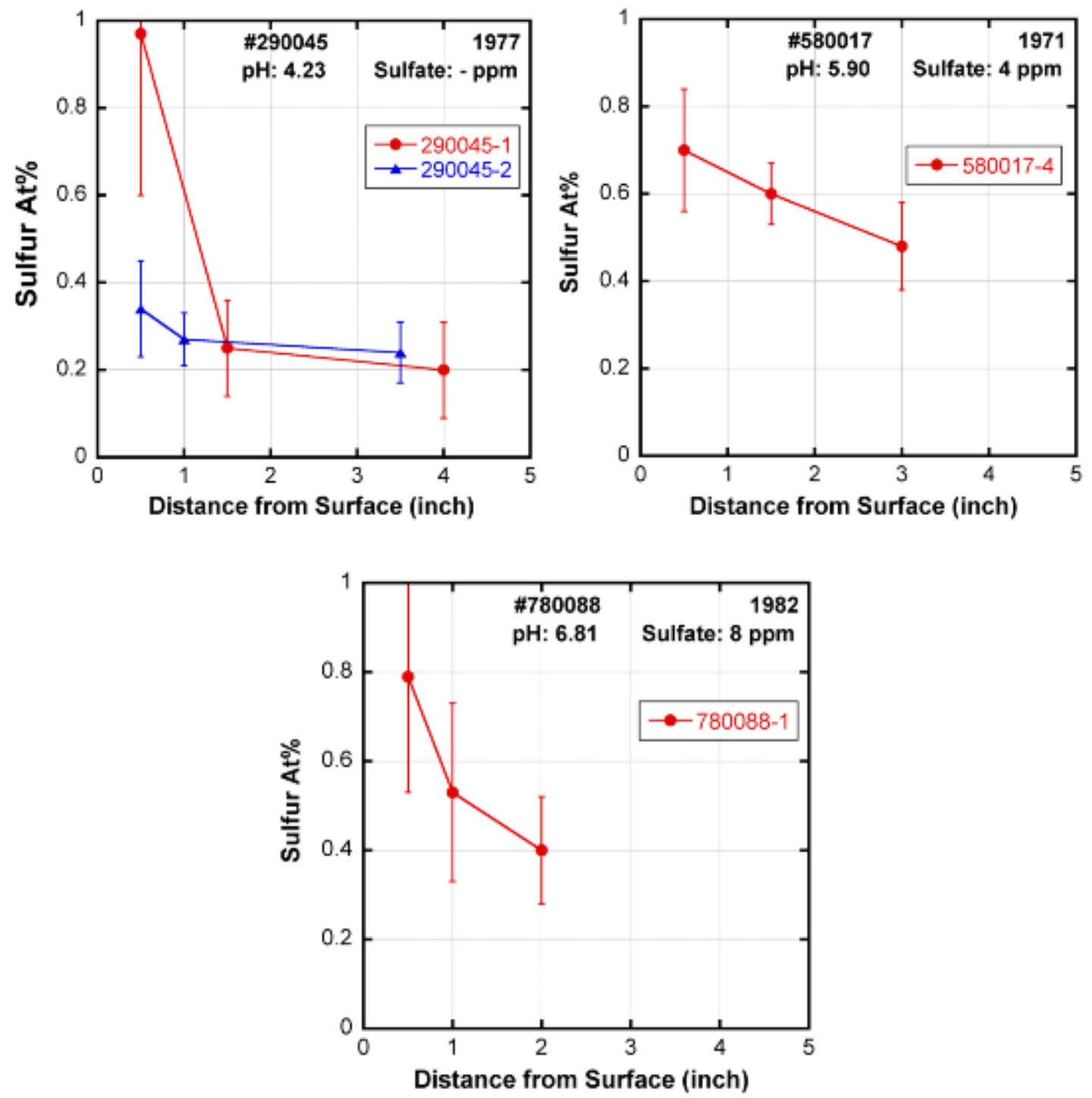

FIGURE 2.8. Sulfate distribution within concrete of (a) Bridge \#290045, (b) Bridge \#580017, and (c) Bridge \#780088. 

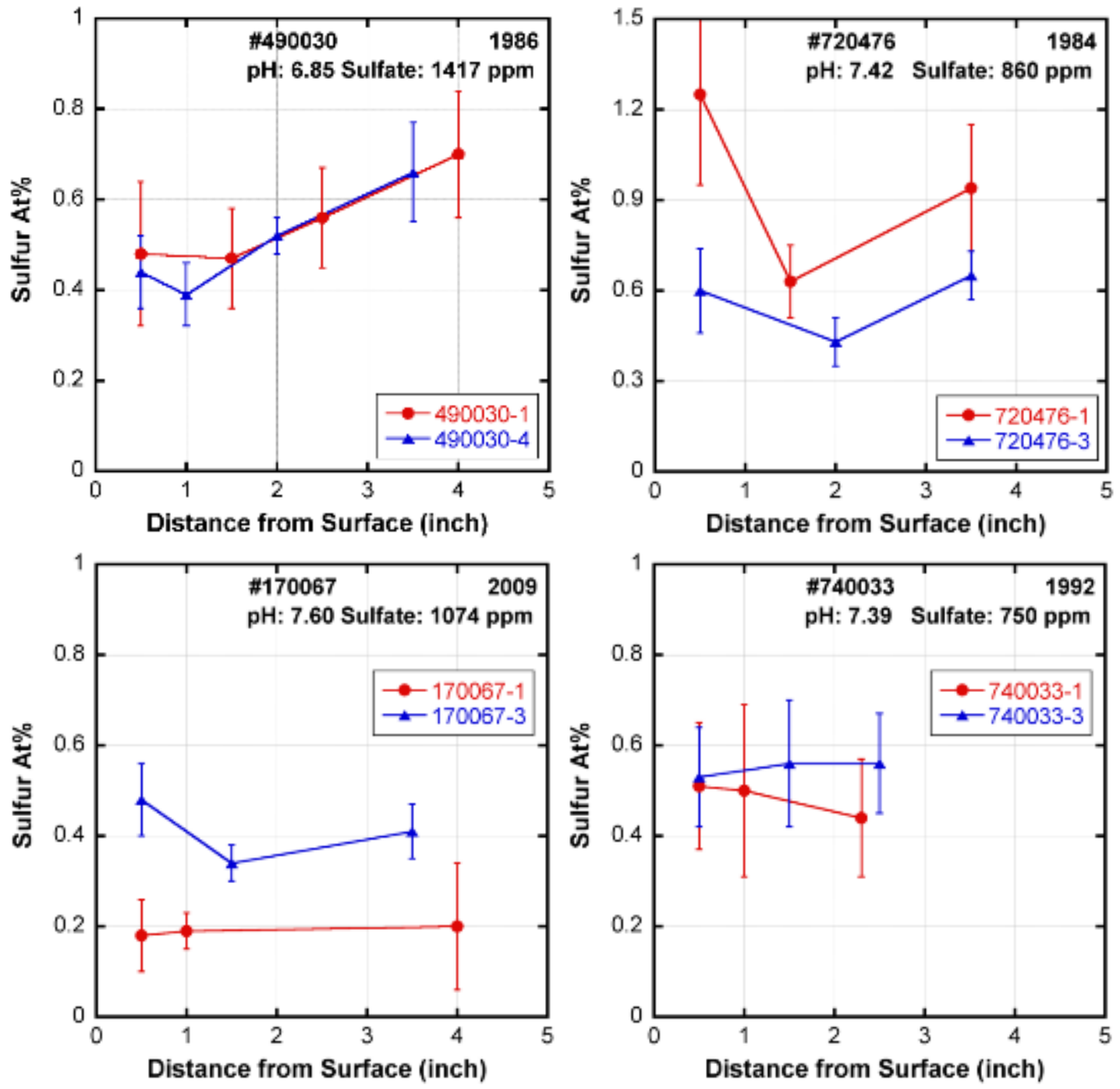

FIGURE 2.9. Sulfate distribution within concrete of (a) Bridge \#490030, (b) Bridge \#720476, (c) Bridge \#170067, and (d) Bridge \#740033.

\subsubsection{SEM Image Analysis}

Microstructure images developed from SEM at magnification of x100 have a resolution of $1280 \times 960$, for which 1 pixel stands for $1 \mu \mathrm{m}$. SEM images from four representative bridges of two types of environments that discussed above are summarized at the end of this section. For each bridge, SEM images from 3 different depths to surface 
were taken. Maximum crack width was measured using image processing software and noted in the chart.

Cracks are found to be developed and connected through aggregate interface and sulfate attack production. It is shown in those images that for bridges locate in $\mathrm{pH}$ attack only environment, concrete internal cracks are much less and tinier than bridges in $\mathrm{pH}$ and sulfate combined environment. Also it can be seen that for first type of bridges (bridge \#290045 and \#780088), concrete cracks are mostly developing near surface. In more inside positions, cracks are rare and even hardly to be seen (Figure 2.10). For the second type of bridges (bridge \#490030 and \#720476), surprisingly, internal cracks are severely developed at even depth of 3.5 inch, which already exceed the depth of concrete cover (Figure 2.11).

It is found that the existence of sulfate and crack development is reciprocal causation to each other. The sulfate content of each layer, regardless of year built, environmental sulfate concentration, concrete type, and so on, positively correlated with crack width. The relation between them is summarized and illustrated (Figure 2.12).

It is known that sulfate accumulation will result of more expansive product, therefore result of expansion and cracks. It is the foundation philosophy of most of sulfate attack experimental method. However, if the development of cracks will result of further sulfate penetration is still not clear. From the results of this study, the relation between internal sulfate content and concrete internal crack width is roughly drawn.

Concrete internal crack width is limited to certain size due to the restriction of surrounding materials. It is less possible that internal crack will develop unrestrictedly. Meanwhile, sulfate content unlikely range by 100 times different. Therefore, logarithm 
curve fitting is tried on these data. Logarithm sulfur atom percentage versus liner crack width is found to be the best curve fitting.

The relation of sulfate content and concrete internal crack width is calculated as

$$
\mathrm{W}_{\mathrm{c}}=5.16+6.44 \log \left(\mathrm{C}_{\mathrm{S}}\right) \mathrm{R}=0.74
$$

Where, Wc stands for concrete internal crack width in unit of $\mu \mathrm{m}$; Cs stands for sulfate contents in unit of atom percentage (\%).

Due to the difference concrete performance in acid only environment (sulfate concentration is less than $150 \mathrm{ppm}, \mathrm{pH}$ less than 7.0) and acid/sulfate combined environment (sulfate concentration is more than $150 \mathrm{ppm}$, $\mathrm{pH}$ less than 7.0), it is found that curve fitting two conditions separately is more accurately.

For bridges locate in comparatively low sulfate environment (sulfate concentration is less than $150 \mathrm{ppm}$ )

$$
\mathrm{W}_{\mathrm{c}}=2.94+2.57 \log \left(\mathrm{C}_{\mathrm{S}}\right) R=0.83
$$

For bridges locate in comparatively high sulfate environment (sulfate concentration is less than $150 \mathrm{ppm}$ )

$$
\mathrm{W}_{\mathrm{c}}=6.62+9.82 \log \left(\mathrm{C}_{\mathrm{S}}\right) R=0.91
$$




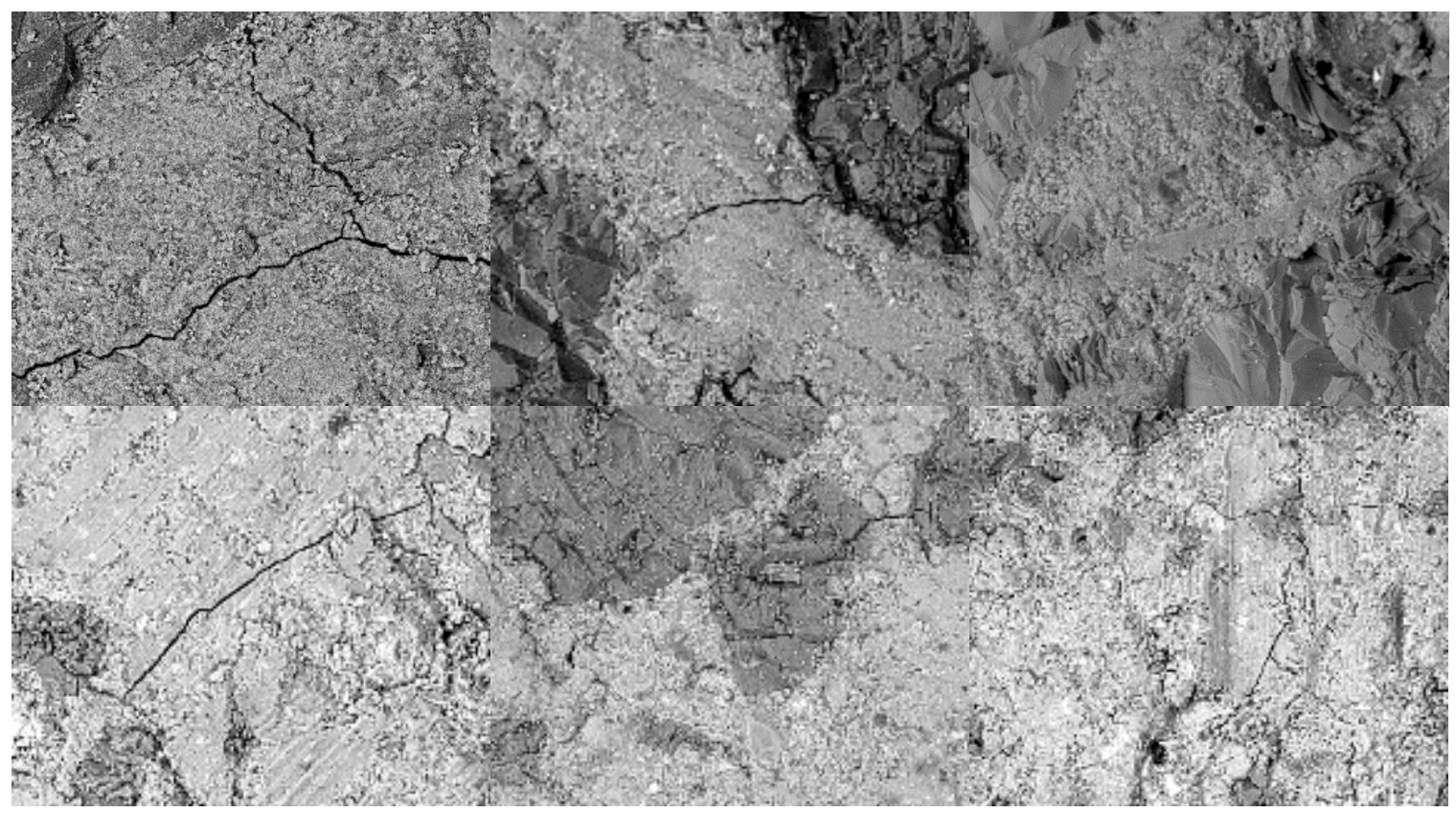

FIGURE 2.10. Internal cracks SEM images of bridge \# 290045 (a, b, c) and bridge \# 780088 (d, e, f).

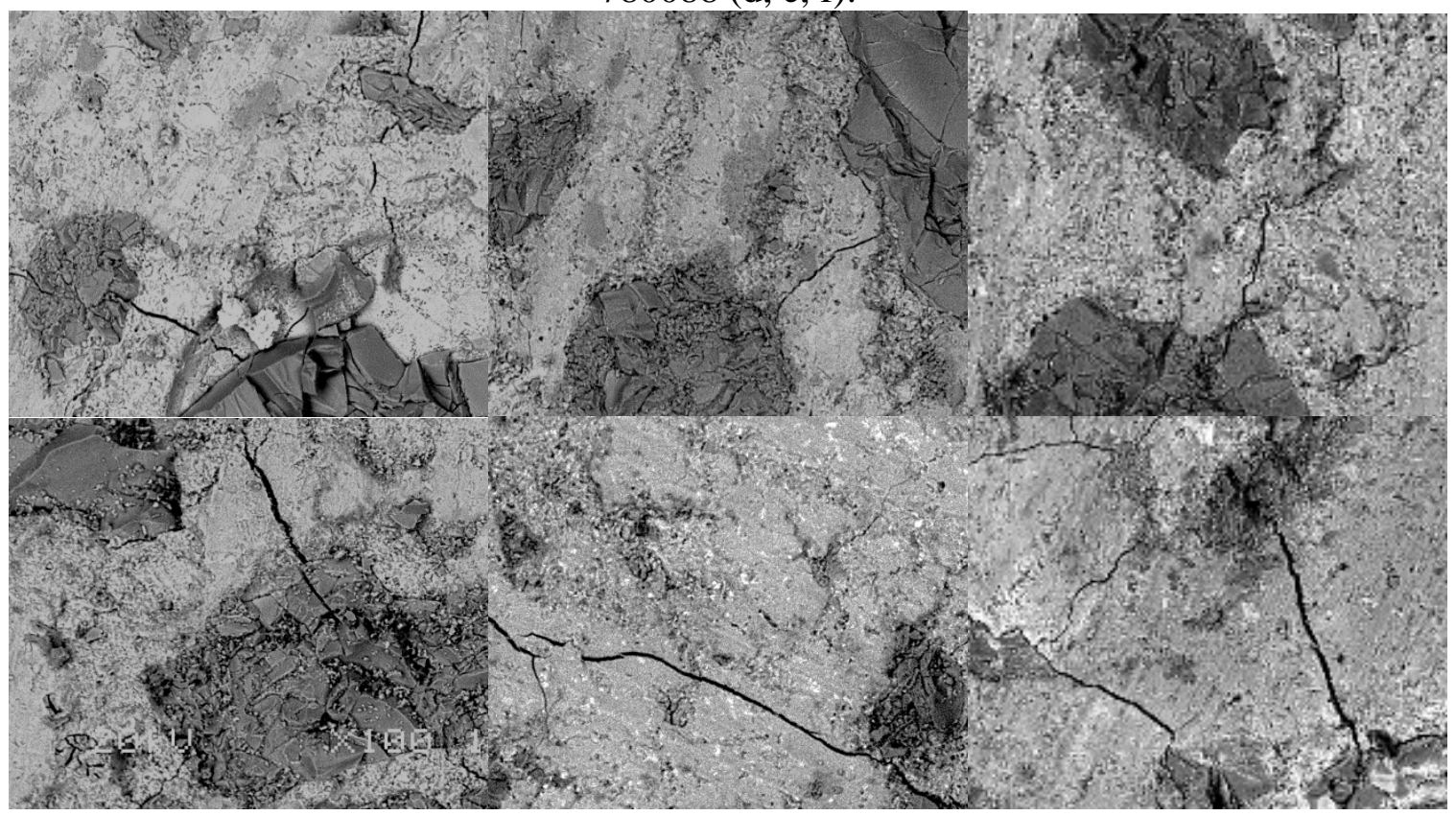

FIGURE 2.11. Internal cracks SEM images of bridge \# 490030 (a, b, c) and bridge \# 720476 (d, e, f). 


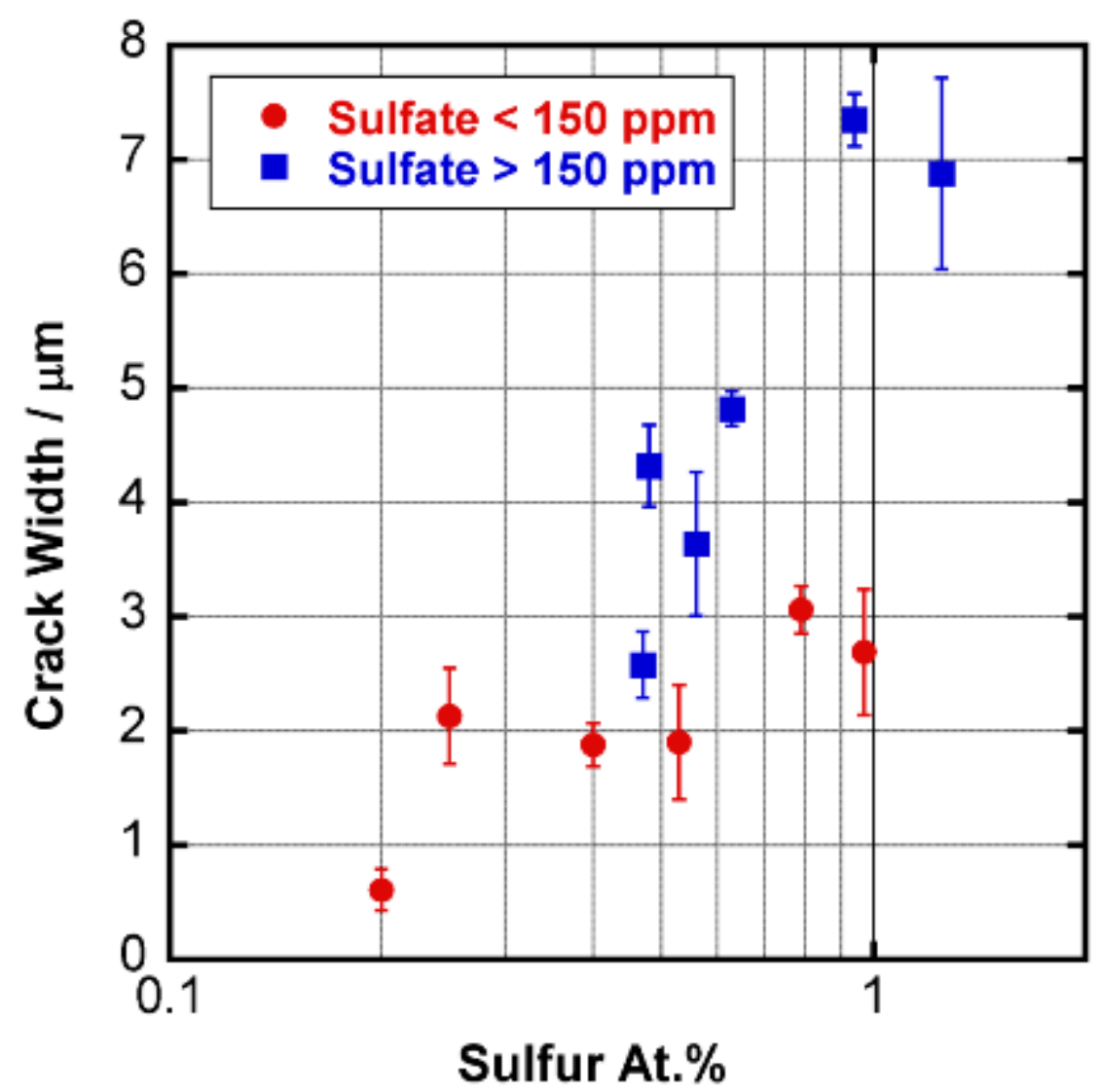

FIGURE 2.12. Relation of crack width versus sulfur atom percentage.

\subsection{Conclusions}

Scanning Electron Microscopic technology is applied for in-situ concrete bridge piles inspection, as well as energy-dispersive X-ray spectroscopy. It is found that the application of this technology enhances our ability to characterize cement and concrete microstructure. It helps evaluating concrete bridge piles durability capacity, sulfateinduced concrete deterioration. Quantitative evaluation can be acquired by simplified method with sufficient accuracy. 
The combined acid and sulfate attack will result of extensive internal cracks, even in environments with as low as $150 \mathrm{ppm}$ sulfate content. 50\% bridges under such condition were found steel corrosion during field inspection. This phenomenon has drawn special attention to researcher and further experiential study of concrete deterioration is conducted and will be published in a separate paper.

Concrete crack width is found to be positive related with inner sulfur contents. It is also revealed that the formation of ettringite is one of the main reasons of internal cracks formation. From SEM images, cracks are found to be connected at ettringite particles, along cement/aggregate interface.

Connected microcrack may cause secondary penetration of external sulfate ions, which could explain that some of inspected bridges suffer extensive internal high sulfate content, while outside parts have relatively lower sulfate content. This will jeopardize the concept that concrete serves as protection cover for steel rebar in extreme aggressive environments.

\subsection{Acknowledgment}

This research was funded by the Research Center of the Florida Department of Transportation (FDOT) under the direction of Dr. Darryll Dockstader. The authors are grateful to our Project Manager, Mr. Ivan Lasa, of the FDOT State Materials Office, for his guidance and support throughout the project. A special thanks to Mr. Richard Nalli III, also of the FDOT State Materials Office, for his help with the field work and coring of specimens. 


\subsection{References}

1. Allahverdi, Ali, and František Škvára. "Acidic Corrosion Of Hydrated Cement Based Materials." Ceramics-Silikáty 44, no. 4 (2000): 152-160.

2. American Concrete Institute 318 Building Code Requirements for Structural Concrete

3. American Society of Civil Engineers (2009) “2009 Report Card for America’s Infrastructure” ASCE, Reston, VA, p. 168

4. ASTM Standard C150 (2011) "Standard Specification for Portland Cement," ASTM International, West Conshohocken, PA, DOI: 10.1520/C0150_C0150M-11, www.astm.org.

5. Brown, P.W. and Taylor, H.F.W. (1999) "The role of ettringite in external sulfate attack”, in J. Marchand and J. Skalny (eds) Materials Science of Concrete Special Volume: Sulfate Attack Mechanisms, The American Ceramic Society, Westerville, OH, pp. 73-98.

\section{6. $\quad$ FDOT’s Structures Design Guidelines (2014)}

7. Federal Highway Administration (FHWA) (2010) "FHWA Bridge Programs NBI Data”, URL: http://www.fhwa.dot.gov/bridge/nbi.htm

8. Florida Department of Transportation (FDOT) (2010) "Standard Specifications for Road and Bridge Construction,” FDOT, Tallahassee, FL, p. 996

9. Florida Department of Transportation (FDOT) (2011a) "FDOT Structures Manual,” FDOT, Tallahassee, FL.

10. Florida Department of Transportation (FDOT) (2011b) “Bridge Environment Data” FDOT, State Materials Office, Gainesville, FL, p. 108

11. Gollop, R.S. and Taylor, H.F.W. (1992-1996) "Microstructural and microanalytical studies of sulfate attack I. Ordinary cement paste. II. Sulfate resisting Portland cement: Ferrite composition and hydration chemistry. III. Sulfate-resisting Portland cement: Reactions with sodium and magnesium sulfate solutions. IV. Reactions of a slag cement paste with sodium and magnesium sulfate solutions. V. Comparison of different slag blends", Cement and Concrete Research 22: 1027-1038; 24: 1347-1358; 25: 1581-1590; 26: 1013-1028; 26: 1029-1044.

12. Hill, J., E. A. Byars, J. H. Sharp, C. J. Lynsdale, J. C. Cripps, and Q. Zhou. "An experimental study of combined acid and sulfate attack of concrete." Cement and Concrete Composites 25, no. 8 (2003): 997-1003. 
13. Krus, M. Moisture Transport and Storage Coefficients of Porous Mineral Building Materials. Theoretical Principles and New Test Methods. IRB-Verlag Stuttgart (1996), S. 1-172. ISBN 3-8167-4535-0.

14. Mehta, P.K. (1983) "Mechanism of sulfate attack on portland cement concrete Another look,” Cement and Concrete Research, Vol. 13, No. 3, pp. 401 - 406.

15. Mehta, P.K. (1991) Concrete in Marine Environment, Elsevier Applied Science, London.

16. Mehta, P.K. (1992) "Sulfate attack on concrete - a critical review" Material Science of Concrete, American Ceramic Society, Westerville, OH, pp. 105-130.

17. Mehta, P.K. and Haynes, H. (1975) “Durability of concrete in seawater”, Journal of the American Society of Civil Engineers Structural Division 101(ST8): 1679-1686.

18. Nemati, Kamran M. "Fracture analysis of concrete using scanning electron microscopy." Scanning 19, no. 6 (1997): 426-430.

19. Sersale, R., Cioffi, R., de Vito, B., Frigione, G. and Zenone, F. (1997) "Sulphate attack on carbonated and uncarbonated Portland and blended cements", Proceedings of the 10th International Congress of the Chemistry of Cement, Gothenburg, paper 4iv17

20. Skalny, J. and Pierce, J. (1999) "Sulfate attack: an overview”, Materials Science of Concrete Special Volume: Sulfate Attack Mechanisms, The American Ceramic Society, Westerville, OH, pp. 49-63.

21. Skalny, J., Marchand, J. and Odler, I. (2002) Sulfate Attack on Concrete, Spon Press, London, UK.

22. Stutzman, Paul E. "Scanning electron microscopy in concrete petrography."Materials Science of Concrete Special Volume: Calcium Hydroxide in Concrete(2001): 59-72.

23. Suksawang, Nakin, and Shuo Zhang. "Performance of High Performance Concrete (HPC) in Low pH and Sulfate Environments." (2013).

24. USBR Concrete Manual, 6th Edition, 1956.

25. Yilmaz, A.B., Yazici, B. and Erbil, M. (1997) "The effects of sulphate ion on concrete and reinforced concrete," Cement and Concrete Research, Volume 27, Issue 8, pp 1271-1279.

26. Zhang, Minghua, Jiankang Chen, Yunfeng Lv, Dongjie Wang, and Jian Ye. "Study on the expansion of concrete under attack of sulfate and sulfate-chloride ions." Construction and Building Materials 39 (2013): 26-32. 


\section{CHAPTER III}

IMPACT OF POZZOLANIC MATERIALS FOR CONCRETE EXPOSED TO SULFATE AND ACIDIC ENVIRONMENTS 


\title{
CHAPTER III
}

\section{IMPACT OF POZZOLANIC MATERIALS FOR CONCRETE EXPOSED TO SULFATE AND ACIDIC ENVIRONMENTS}

\author{
Shuo Zhang ${ }^{1}$, Nakin Suksawang ${ }^{2}$ \\ ${ }^{1}$ Dept. of Civil \& Environ. Engineering, Florida International University, Miami, Florida \\ 33174, Tel: (305)298-1112, Fax: (305)348-2802, E-mail: szhan002@fiu.edu. \\ ${ }^{2}$ Dept. of Civil Engineering, Florida Institution of Technology, Melbourne, Florida \\ 32901, Tel: (321)674-7504, Fax: (321) 674-7565, E-mail: nsuksawang@fit.edu.
}

\subsection{Abstract}

This paper presents the results of an experimental investigation carried out to evaluate sulfate resistance properties of concrete mixtures in which fly ash, slag, metakaolin and silica fume were used to partially replace cement. A total of 15 mixtures with different mix designs were prepared. Accelerated sulfate resistance test and modulus of rupture test were carried out. The degree of sulfate attack was evaluated using expansion tests and loss of strength. Compression test results indicate that even under the same sulfate concentration, magnesium sulfate is more aggressive than sodium sulfate. Moreover, regardless the type of sulfate, the addition of pozzolanic materials significantly

\footnotetext{
${ }^{1}$ Graduate Student, Dept. of Civil \& Environ. Engineering, Florida International University, Miami, Florida 33174, Tel: (305)298-1112, Fax: (305)348-2802, E-mail: szhan002@fiu.edu.

${ }^{2}$ Assistant Professor, Dept. of Civil Engineering, Florida Institution of Technology, Melbourne, Florida 32901, Tel: (321)674-7504, Fax: (321) 674-7565, E-mail: nsuksawang@fit.edu.
} 
increased the resistance to sulfate attack. Among all tested pozzolanic materials, silica fume and slag cement exhibit the highest sulfate resistance.

KEY WORDS: Concrete; external sulfate attack; acid attack; accelerated test; expansion

\subsection{Introduction}

Sulfate attack is a highly complex phenomenon and in some cases not completely understood. All sulfate attack mechanisms are treated as physicochemical processes that lead to certain physicochemical consequences, such as changes in porosity and permeability, volumetric stability, compressive and flexural strengths, modulus of elasticity, and hardness. All these physicochemical consequences ultimately will result in loss of durability and shortening of service life.

The general governing phenomena for the transfer of sulfate through concrete is modeled by means of conservation-type equations involving diffusion, convection, chemical reaction, and sorption. Pommersheim et al. assume that the process is controlled by reaction rather than diffusion, based on an empirical linear equation that links the depth of deterioration at a given time to the C3A content and the concentration of sulfate in the original solution. Samson et al. used ion diffusion model to explain sulfate transport in concrete. Ferraris et al. state that penetration of the sulfate ions into the specimen, either by absorption or by diffusion depending on the saturation level of the specimen.

Currently, ASTM provides two accelerated test method in order to evaluate concrete sulfate resistance, namely ASTM C452 and ASTM C1012. Even these methods 
being given, many researches have expressed concerns and critics regarding different aspects. The critics mostly focus on not being representative of field condition, specimen sizes and geometry, not considering acid condition, and process being too protract etc. To address these concerns, the accelerated test method developed by Ferraris et al. (2006) was adopted in this study. In 2000, Monteiro et al. proposed a well-designed system that can condition the experiment condition at certain sulfate content and $\mathrm{pH}$ level. However, by only exposing to the same concentration provided by the ASTM C1012, the experiment process is still too protracted to apply. Ferraris et al. (2006) modified this system by using increased sulfate concentration and reduced specimens' size. The sulfate concentration proposed by Ferraris et al. (2006) is 50,000 ppm. Two types of sulfate solution were used in this study: 1) sodium sulfate and 2) magnesium sulfate. The effect of acid, unfortunately, was not studied by them.

\subsection{Laboratory Studies}

\subsubsection{Cement binders and concrete mixes}

Concrete mixes were prepared using Type II Portland cement mixed with cementitious materials, such as fly ash, slag, silica fume, and metakaolin. Totally 15 different mixes were evaluated for their performance in acid and sulfate environments. These mixtures were based on concrete exposed to moderately to extremely aggressive environment. Class IV concrete, which is typically used for the substructure, was used to develop the mixture proportions. As such, the maximum water-to-cementitious materials (w/cm) ratio was limited to 0.41 for mixtures containing fly ash or slag cement and 0.35 for mixture containing silica fume or metakaolin. It should also be noted that the fly ash 
used in this study was Class F as it is more readily available in Florida. Type II Portland Cement was also used for all mixture to conform to FDOT specification no. 346. The pozzolans and slag cement were used to replace cement by weight and their replacement percentages were based on FDOT limitations. These mixes are summarized in Table 3-1.

Table 3-1 Cement binders mixes, w/cm ratio, and concrete mixes

\begin{tabular}{|c|c|c|c|c|c|c|c|c|}
\hline \multicolumn{4}{|c|}{ CEMENT BINDERS } & \multicolumn{5}{|c|}{ CONCRETE SPECIMENS (LB/YD $\left.{ }^{3}\right)$} \\
\hline 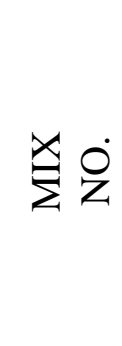 & 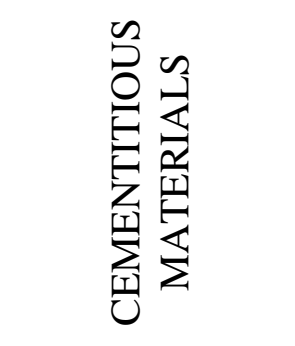 & 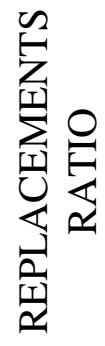 & $\sum_{3}$ & 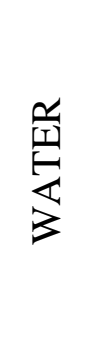 & 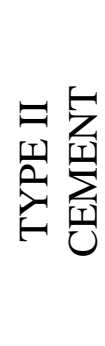 & 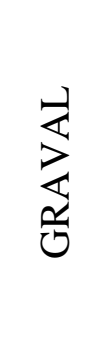 & $\underset{\omega}{\sum_{\infty}}$ & 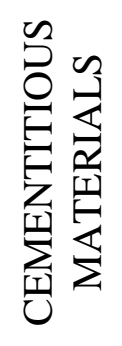 \\
\hline FA-1 & FLY ASH & $10 \%$ & 0.41 & 340 & 746 & 1744 & 978 & 83 \\
\hline $\begin{array}{c}\text { FA- } \\
2^{*}\end{array}$ & FLY ASH & $18 \%$ & 0.41 & 340 & 680 & 1744 & 961 & 149 \\
\hline FA-3 & FLY ASH & $25 \%$ & 0.41 & & & & & \\
\hline $\begin{array}{c}\text { FA- } \\
4^{*}\end{array}$ & FLY ASH & $35 \%$ & 0.41 & 340 & 539 & 1744 & 923 & 290 \\
\hline $\begin{array}{l}\text { FA- } \\
5^{* *}\end{array}$ & FLY ASH & $50 \%$ & 0.41 & 340 & 415 & 1744 & 890 & 415 \\
\hline S-1 & SLAG & $30 \%$ & 0.41 & 340 & 580 & 1744 & 934 & 249 \\
\hline S-2 & SLAG & $50 \%$ & 0.41 & 340 & 415 & 1744 & 890 & 415 \\
\hline S-3 & SLAG & $60 \%$ & 0.41 & & & & & \\
\hline S-4 & SLAG & $70 \%$ & 0.41 & 340 & 249 & 1744 & 845 & 580 \\
\hline SF-1 & SILICA FUME & $5 \%$ & 0.35 & & & & & \\
\hline SF-2 & SILICA FUME & $7 \%$ & 0.35 & & & & & \\
\hline SF-3 & SILICA FUME & $9 \%$ & 0.35 & & & & & \\
\hline M-1 & METAKAOLIN & $6 \%$ & 0.35 & & & & & \\
\hline M-2 & METAKAOLIN & $8 \%$ & 0.35 & & & & & \\
\hline M-3 & METAKAOLIN & $12 \%$ & 0.35 & & & & & \\
\hline
\end{tabular}

Notes:

* Mixes that were not tested in expansion test;

** Concrete strength at 28 days did not reach minimum strength (5,000 psi.). 


\subsubsection{Specimens preparation and exposure}

All specimens were cured for 14 days prior to submerge into acid and sulfate solutions. Four curing methods were studied and presented in this paper, named moist curing, steam curing, dry curing and compound curing.

Specimens were all moist cured for 1 day after casting. For moist curing method, specimens were placed in a controlled chamber at $75 \pm 5^{\circ} \mathrm{F}$ and $80 \% \mathrm{RH}$ after 1 day of casting for 13 more days. For no curing specimens, no special treatment has been applied after demoulded expect being exposed to A/C controlled room (about $70^{\circ} \mathrm{F}$ and $30 \% \mathrm{RH}$ ). Curing compound has been applied to specimens, which is so called compound curing. They were applied with a layer of curing compound before exposed to room temperature and 30\% RH for 13 days after demoulding.

\subsubsection{Environmental control}

Monteiro’s environmental control setup has been adopted in this research and optimized by expanding to two specimen tanks with one control tank. Solution is premixed and stored in reservoir before added into specimen tanks to ensure the stability. Solution's $\mathrm{pH}$ level is monitored using in-line $\mathrm{pH}$ sensor and adjusted using automatic metering pump. Sulfate content is set up as 5\% to conform ASTM C1012 "Standard Test Method for Length Change of Hydraulic-Cement Mortars Exposed to a Sulfate Solution” and as well as other sulfate attack researches. During experiment, sulfate content was test and adjusted once a month. In order to achieve accelerated test results, sulfate content is increased to times higher than actual sulfate content in the field providing excessive sulfate attack in laboratory. Same principle was applied to acid attack. $\mathrm{pH}$ level is set to 
3.5 in order to have the same level of excessive accumulation as sulfate in such accelerated test. Figure 3.1 shows the setup of the environmental control system.

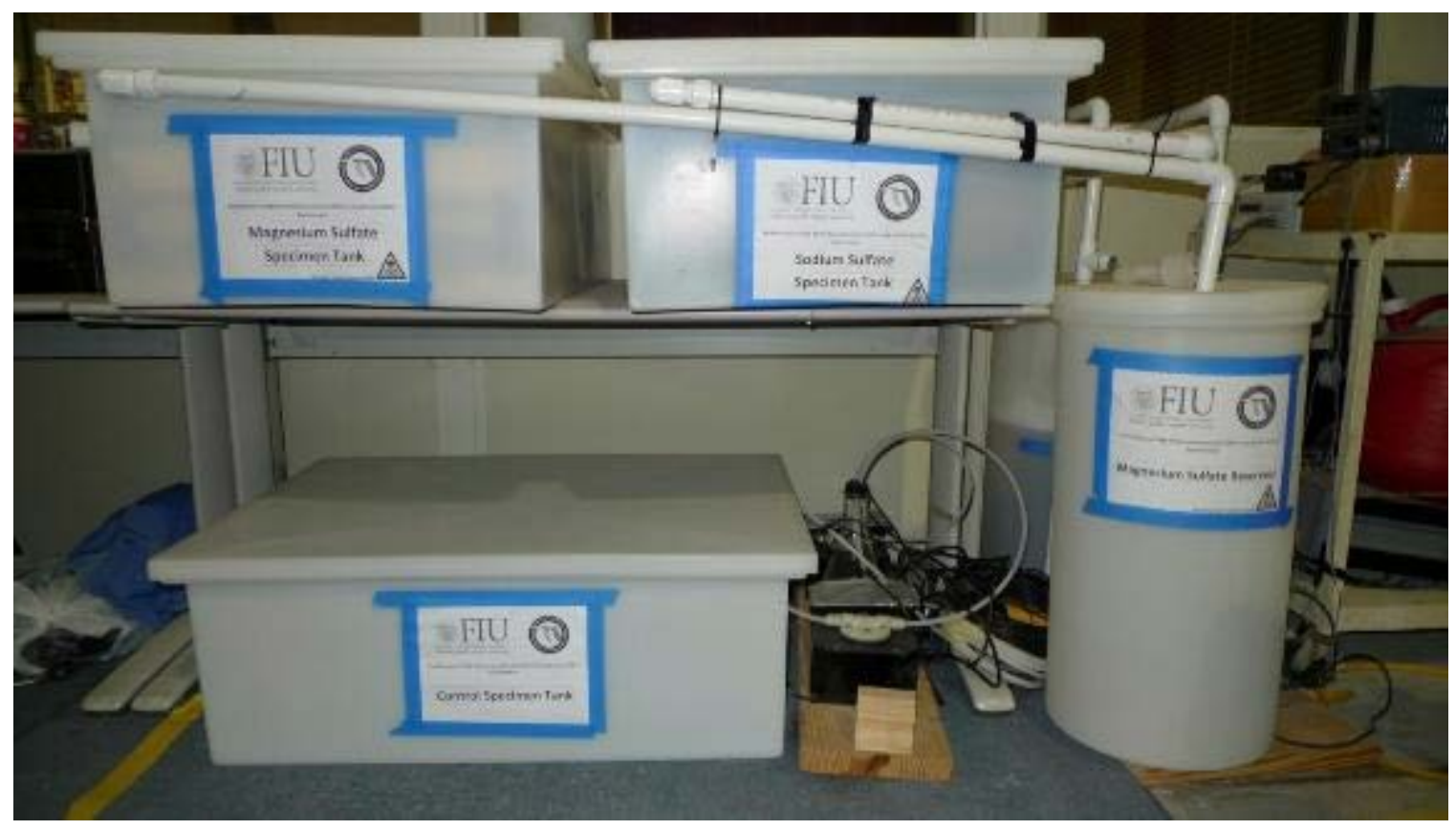

FIGURE 3.1. Laboratory environmental control system.

\subsection{Accelerated Sulfate Resistance Test}

The expansion test is adopted from the test method proposed by Ferraris (2006) to study sulfate attack in HPC. The test is similar to the ASTM C1012 test but using smaller specimens. The dimensions of the specimen used in this study were $0.5 \times 0.5 \times 2.0$-inch prisms with embedded stainless steel studs at both ends. A length comparator conforming to the requirements of ASTM C 490 was used to measure the expansion. The stand of the comparator was modified to accommodate measurements of the 2.0 in. prisms. After demoulding, the specimens were cured using different curing methods described above. During specimens' 14-day of curing period, threaded studs were screwed into the end pins, which were embedded in the specimens. To ensure that the stud remained stationary 
during the expansion experiment, small amounts of epoxy were used to fasten the studs to the pins. Additionally, small amounts of epoxy were also applied 1/4 inch along the top sides of the specimen to minimize sulfate penetration from the ends. Water should not contact the specimen or the epoxy during its 24-hour curing process. The specimens were then returned to the applicable curing method until the specimens reached an age of 14 days before exposing to the acid and sulfate solution. A reference bar made of the same type of stainless steel as the studs was used to determine the comparator reading in accordance with ASTM C490. The reference bar was also submerged in the experiment solution. The comparator readings were made daily for the first two weeks and then weekly thereafter. Figure 3.2 presents a typical specimen during expansion test.

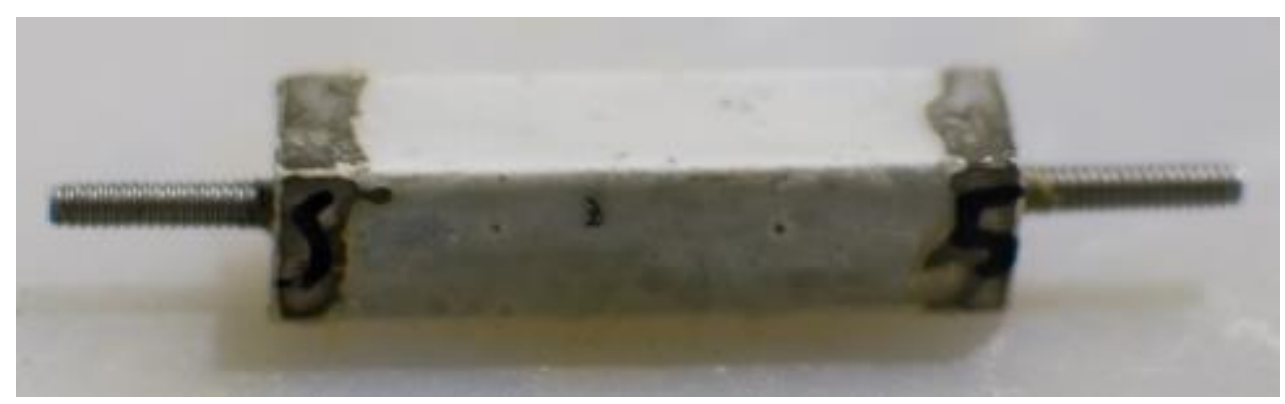

FIGURE 3.2. A typical specimen for accelerated expansion test.

\subsection{Modulus of Rupture Test}

The strength degradation of concrete exposed to low $\mathrm{pH}$ and sulfate environment was evaluated by testing the modulus of rupture. Concrete modulus of rupture was determined through a 3-point bending test. Smaller specimens with dimension of $1 \times 1 \times 4$ inch were used to accelerate the deterioration. The fabrication of test specimens followed the same procedure used for the expansion test. The beam was tested at 3-inch-apart 
using triangular shaped steel supports. Steel rod was used at the load point. The effect of curing method was evaluated using the modulus of rupture test.

\subsection{Results and Discussion}

Sodium sulfate and magnesium sulfate as two major forms of sulfate with different deterioration mechanism are used in the accelerated expansion test. The impact of these two types of sulfate is presented in FIGURE 3.3. Specimens containing $10 \%$ fly ash was exposed to sodium sulfate and magnesium sulfate solutions with the same sulfate ion concentration and $\mathrm{pH}$ level. As it is shown in FIGURE 3.3, specimens subjected to magnesium sulfate attack were clearly suffered from crumbling and softening of the paste near the surface much more than the ones emerged in sodium sulfate solution. Acid at such $\mathrm{pH}$ level also played a significant role by comparing to the ones that only enduring sulfate attack only. Sulfate attack can result of expansion, surface softening, and crumbling. Damages and erosions start from the edges and corners of specimens. In terms of expansion, there is no significant difference between sodium sulfate and magnesium sulfate. It is unveiled here in this experiment that expansion as the result of sulfate attack is depend on sulfate ion concentration. The type of cations, no matter sodium or magnesium, does not have significant effect to the expansion of the specimen. However, the difference of cations does have effect in terms of softening and scaling. At the same level of $\mathrm{pH}$ and sulfate concentration, magnesium sulfate results of much severe damage to specimens' surface. Acid in such condition could result of much accelerated degradation process. 

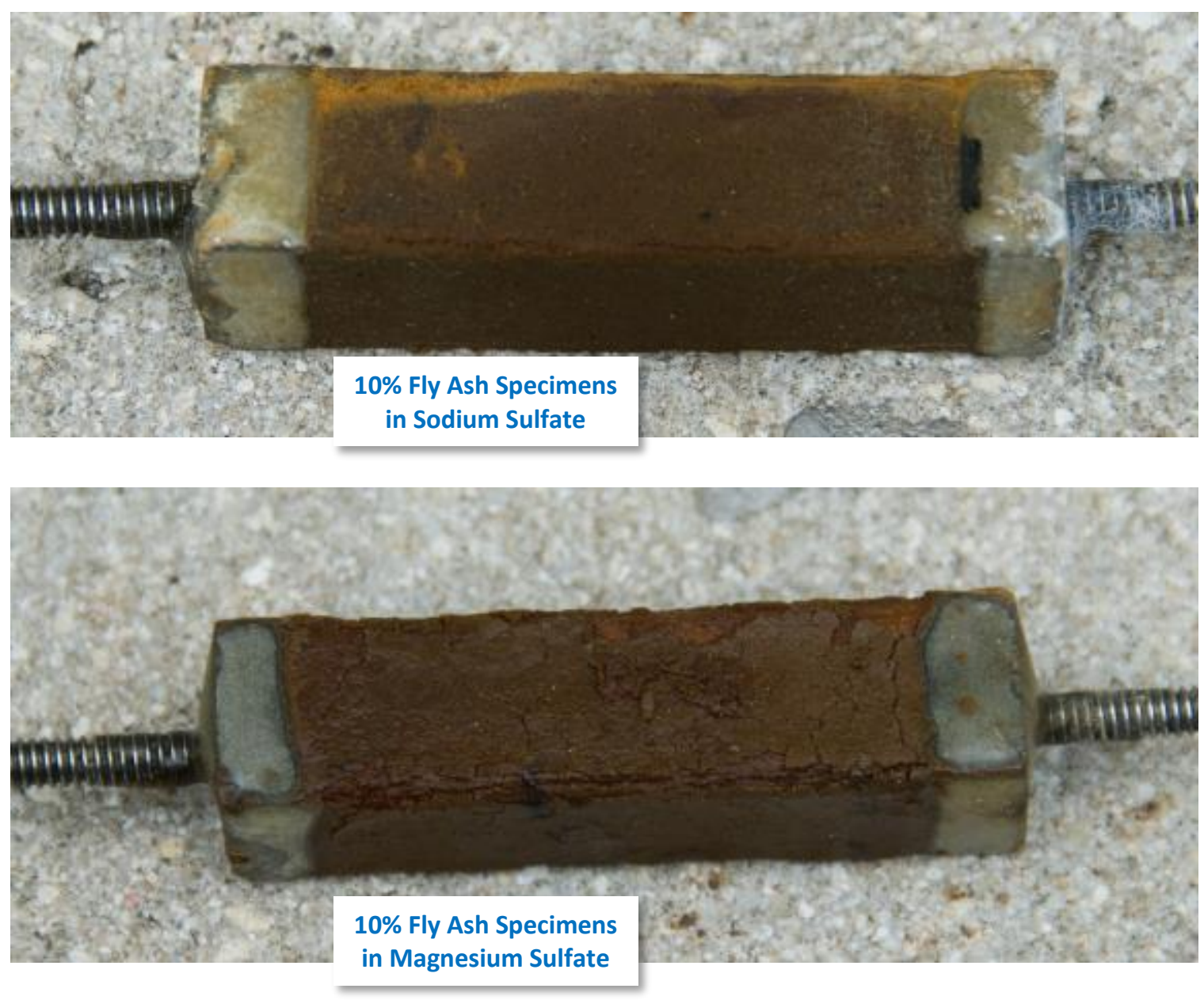

FIGURE 3.3. Fly ash specimens after 1 week of submerging under sodium and magnesium sulfate.

The introduction of cementitious materials significantly decreases sulfate attack process, as it is shown in FIGURE 3.4. After 2 weeks of submerging, specimens made of Portland cement with 0.41 water cement ratio have reached the expansion of $0.4 \%$ in both sodium sulfate and magnesium sulfate solution, which is 4-20 times more than specimens with cementitious materials. Among fly ash, slag, silica fume and metakaolin, slag cement has the best performance while fly ash performs the worst. Silica fume specimens performed as well as slag cement. But taken water cement ratio into consideration, slag 
cement specimens had the same performance as silica fume specimens even with higher water cement ratio. Metakaolin specimens were tested only in sodium sulfate. The water cement ratio of metakaolin and silica fume specimens was the same. However, the expansion of this specimen is much higher than silica fume and slag specimens. It is derived in this test that it is most effective to blend slag into concrete to increase its sulfate attack resistance. Even under the combination attack of acid and sulfate, slag cement still shows significantly exceptional performance compare to other cementitious materials.

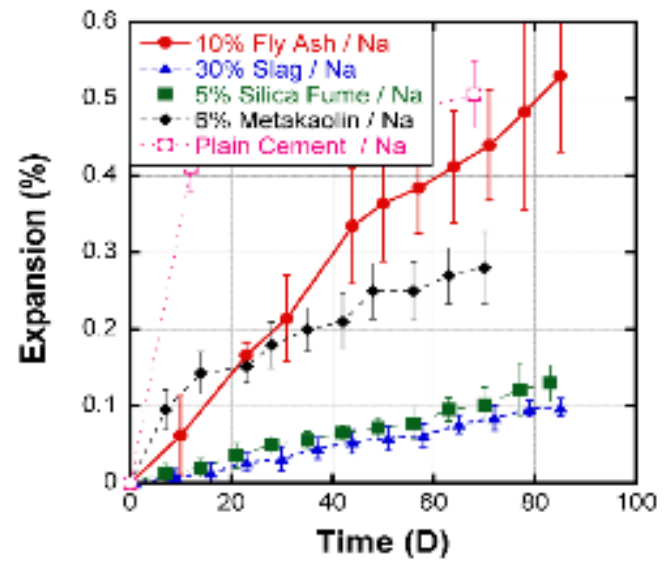

Moist Curing Concrete under Sodium Sulfate Attack with Min. Supplementary Cementitious Materials

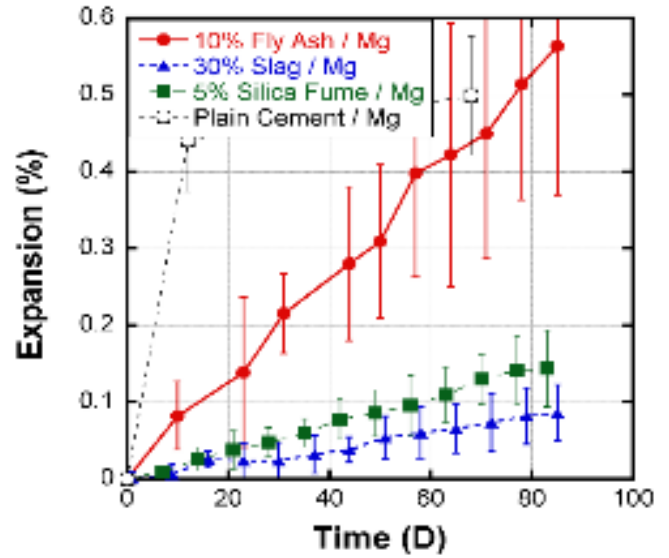

Moist Curing Concrete under Magnesium Sulfate Attack with Min. Supplementary Cementitious Materials

FIGURE 3.4. Specimens with different cementitious materials under sodium and magnesium attack.

In addition, the effect of curing method was evaluated in this study. Three different curing methods were evaluated using the expansion test. Figure 3.5 presents the specimens after 6 weeks of exposure to sodium sulfate solution. Severe degradation was noted on all specimens. Specifically, surface scaling was much severe on dry curing 
specimens and wet curing specimens. There seems to be little difference between these two curing methods in terms of surface degradation. Curing compound provided exceptional protection to the specimens. Scaling was only noted at the corners of the specimens. It is conducted that even when drying curing method could result of microcracks on surface, in terms of surface scaling, the difference between drying and moist curing method is not significant. Meanwhile, curing compound could not only provide early age curing protection but also protection against acid and sulfate attack from environment.
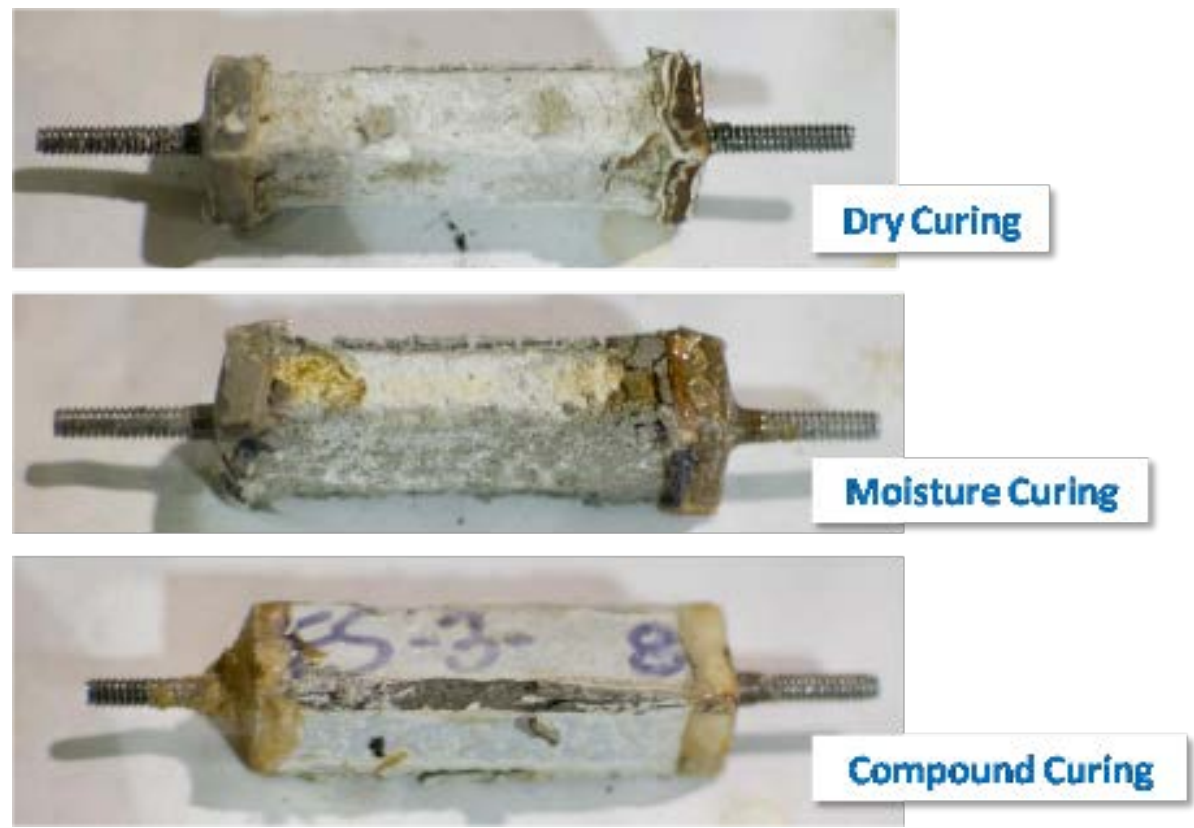

FIGURE 3.5. Fly ash cement paste with dry curing, moist curing and compound curing after 6 weeks of submerging in sodium sulfate solution.

Figure 3.6 shows the expansion results of blended cement specimens with $10 \%$ and $25 \%$ fly ash during 80 days of exposure to sodium sulfate and magnesium sulfate solution. 
For specimens blended with $10 \%$ fly ash, the expansion achieved $0.4 \%$ to $0.6 \%$ in sodium sulfate solution depends on different curing methods at the end. It can be seen that although curing compound provided an exceptional surface protection from scaling, it couldn't stop sulfate penetration that created expansion. In magnesium sulfate solution, specimens that were cured in moist curing method and compound curing method expanded to as much as $0.5 \%$ at the end of the test, which is the same as specimens in sodium sulfate solution. It is once again proved that no matter magnesium or sodium cation there is, specimens' expansion is totally depended on sulfate and acid concentration. For dry cured specimens, the extensive expansion may because of the extreme damages and surface softening to specimens due to magnesium sulfate attack. As discussed previously, magnesium sulfate may results of more extensive softening and micro structural destruction. It is the most reasonable speculation of this phenomenon. It is the same for specimens that blended with $25 \%$ fly ash. Due to the weaker strength, these specimens are more easily to be penetrated and therefore cause of losing strength and extensive expansion. Leave these specimens aside, the expansion result of $25 \%$ fly ash specimen has reached about $0.5 \%$ after 80 days of exposure to magnesium sulfate solution. Specimens in sodium sulfate has the expansion of $0.5 \%$ to $0.7 \%$ depends on curing methods. It is also conducted from this test that lower specimen strength could also be another factor that results of extensive expansion. 

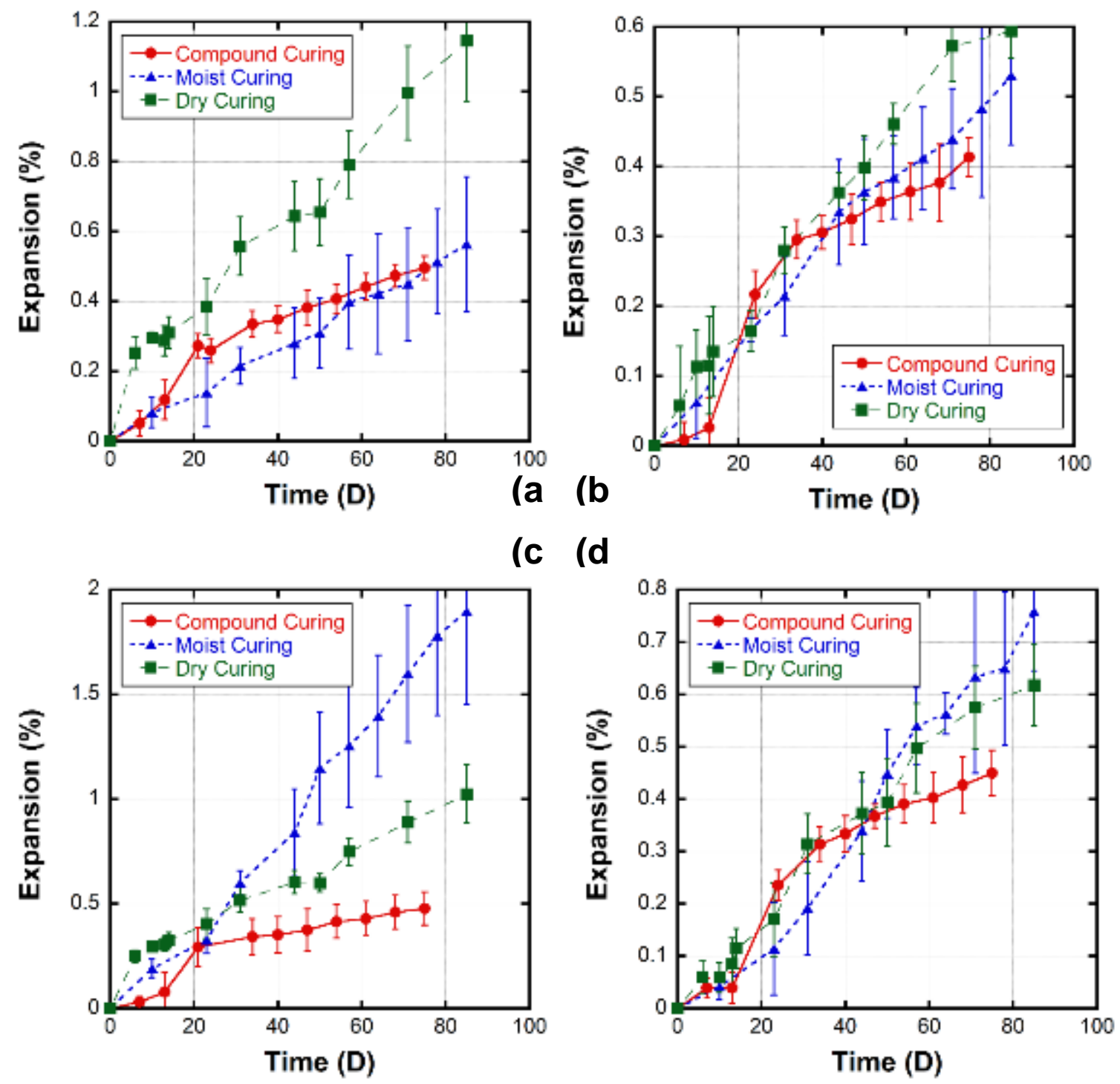

a. $10 \%$ Fly Ash concrete in magnesium sulfate

b. $10 \%$ Fly Ash concrete in sodium sulfate

c. $25 \%$ Fly Ash concrete in magnesium sulfate

d. $25 \%$ Fly Ash concrete in sodium sulfate

FIGURE 3.6. Comparison of expansion of various fly ash specimens under different curing conditions.

Cement specimens blended with $25 \%$ fly ash was used to in the testing of the modulus of rupture. 3 curing methods have been tested. Figure 3.7 illustrates the modulus 
of rupture test results after 8 weeks of exposure to sodium sulfate solution. Specimens have gone through the combination attack of acid and sulfate attack. Specimens were applied of 3-point bending and tensile strength was derived from maximum load and specimens' dimensions. Moist curing specimens show the highest tensile strength, then compound curing, and at last dry curing specimens with the lowest tensile strength. Compare to original specimen tensile strength, moist curing specimens' tensile strength reduced by about $22 \%$, compound curing specimens' tensile strength reduced by about $36 \%$, and dry curing specimens' tensile strength reduced by about $61 \%$. Both moist curing and compound curing methods can successfully provide early age protection for cement specimens and reduce the generation of microcrack on the surface. But although cement was covered by curing compound, moist could still leak out through the compound cover. Dry curing samples have the highest strength reduction. It is because that surface drying will result of extensive amount of cracks. And strength degradation may result from crack extending and cement tensile strength degradation. 


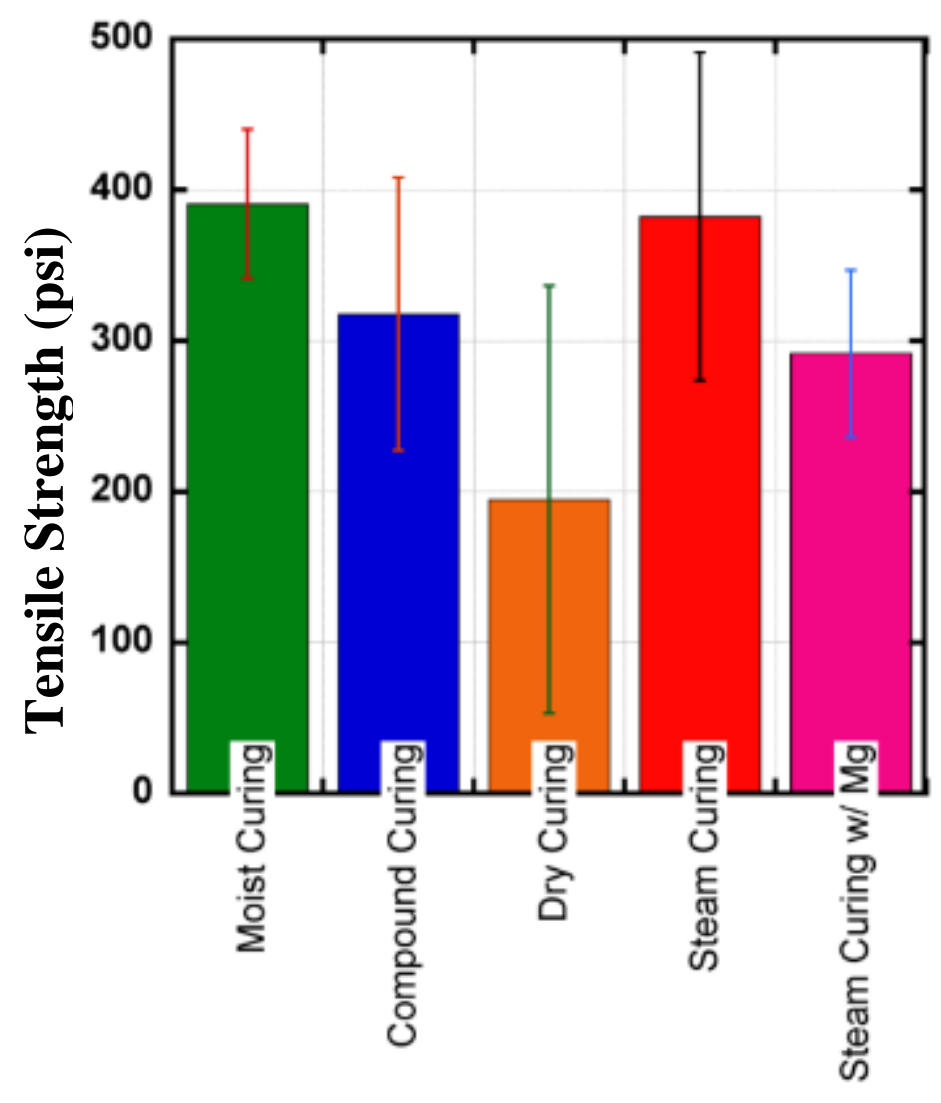

FIGURE 3.7. Comparison between different curing conditions (under sodium sulfate attack if not noted).

\subsection{Conclusion}

Laboratory experimental tests were performed to determine the deterioration induced by the sodium and magnesium sulfate on the fly ash, slag, metakaolin, and silica fume concretes and the following conclusion are reached:

The specimen subjected to magnesium sulfate attack clearly suffered more from crumbling and softening of the paste near the surface.

Overall, pozzolanic materials significantly improved the durability performance of concrete structure in sulfate and acidic Environments. Among the HPC mixtures, the 
mixtures containing slag cement and silica fume performed the best, while mixture containing fly ash performed the worst.

In addition, different curing methods were studied in this study. Overall, the compound curing had the best surface condition. There seems to be very little difference in the surface condition between dry curing and moist curing. For the samples exposed to magnesium sulfate, dry curing clearly performed the worst with the highest expansion. The difference between the performance of dry curing and other curing method was less pronounced for samples exposed to sodium sulfate. Overall, both moist curing and curing compound performed well and comparable to each other.

\subsection{References}

1. Akoz, F., Turker, F., Koral, S. and Yuzer, N. (1999) "Effects of raised temperature of sulfate solutions on the sulfate resistance of mortar with and without silica fume”, Cement and Concrete Research 29: 533-537.

2. Al-Akhras, N. M. (2006), "Durability of Metakaolin Concrete to Sulfate Attack," Cement and Concrete Research, V. 36, Issue 9, pp. 1727-1734.

3. Al-Tayyib, A. J. and Shamim K. M. (1991), "Effect of Sulfate Ions on the Corrosion of Rebars Embedded in Concrete," Cement and Concrete Composites, V. 13, Issue 2, pp. 123-127.

4. American Concrete Institute Committee 318 (ACI 318) (2011), Building Code Requirements for Structural Concrete and Commentary, Farmington Hill, MI, p. 503

5. ASTM Standard C150 (2012), "Standard Specification for Portland Cement," ASTM International, West Conshohocken, PA, DOI: 10.1520/C0150_C0150M-11, wWw.astm.org.

6. ASTM Standard C452 (2012), "Standard Test Method for Potential Expansion of Portland-Cement Mortars Exposed to Sulfate," ASTM International, West Conshohocken, PA, DOI: 10.1520/C0452_C0452M-10, www.astm.org. 
7. ASTM Standard C1012 (2012), "Standard Test Method for Length Change of Hydraulic-Cement Mortars Exposed to a Sulfate Solution," ASTM International, West Conshohocken, PA, DOI: 10.1520/C1012_C1012M-10, www.astm.org.

8. $\quad$ ASTM Standard C1556-04 (2012), "Standard Test Method for Determining the Apparent Chloride Diffusion Coefficient of Cementitious Mixtures by Bulk Diffusion," ASTM International, West Conshohocken, PA, DOI: 10.1520/C1556-04, www.astm.org.

9. $\quad$ Biricik, H. Akoz, F., Turker, F. and Berktay, I. (2000) "Resistance to magnesium sulfate and sodium sulfate attack of mortars containing wheat straw ash", Cement and Concrete Research 30: 1189-1197.

10. Bonen, D. and Cohen, M. D. (1992), "Magnesium Sulfate Attack on Portland Cement Paste. I. Microstructural Analysis. II. Chemical and Mineralogical Analysis,” Cement and Concrete Research 22, pp. 169-180 and 707-718.

11. Brown, P. W. and Taylor, H. F. W. (1999), "The Role of Ettringite in External Sulfate Attack,” J. Marchand and J. Skalny (eds) Materials Science of Concrete Special Volume: Sulfate Attack Mechanisms, The American Ceramic Society, Westerville, OH, pp. 73-98.

12. Courard, L., Darimont, A., Schouterden, M., Ferauche, F., Willem, X., and Degeimbre, R. (2003), "Durability of mortars modified with metakaolin," Cem. Concr. Res., V. 33, pp. 1473-1479.

13. Cohen, M. D. and Bentur, A. (1988), "Durability of Portland Cement-Silica Fume Pastes in Magnesium Sulfate and Sodium Sulfate Solutions,” ACI Material Journal, pp. $148-157$.

14. Djuric, M., Ranogajec, R., Omorjan, R., and Niletic, S. (1996), "Sulfate Corrosion of Portland Cement - Pure and Blended with 30\% of Fly Ash," Cement and Concrete Research, Vol. 26, pp. 1295-1300.

15. Ferraris, C. F., Stutzman, P. E. and Snyder, K. A. (2006), "Sulfate Resistance of Concrete: A New Approach,” PCA R\&D Serial No. 2486, p. 93.

16. Giergiczny Z. (1997), "Sulphate Resistance of Cements with Mineral Admixtures," Proceedings of the 10th International Congress on the Chemistry of Cement, Gothenburg.

17. Gollop, R. S. and Taylor, H. F. W., "Microstructural and Microanalytical Studies of Sulfate Attack I. Ordinary Cement Paste. II. Sulfate Resisting Portland Cement: Ferrite Composition and Hydration Chemistry. III. Sulfate-resisting Portland Cement: Reactions with Sodium and Magnesium Sulfate Solutions. IV. Reactions of a Slag Cement Paste with Sodium and Magnesium Sulfate Solutions. V. Comparison of Different Slag Blends,” Cement and Concrete Research, Vol. 22, 1992, pp. 1027-1038; Vol. 24, 1993, pp. 1347- 
1358; Vol. 25, 1994, pp. 1581-1590; Vol. 26, 1995, pp. 1013-1028; Vol. 26, 1996, pp. 1029-1044.

18. Guneyisi, E., Gesoglu, M., Mermerdas, K. (2010), "Strength Deterioration of Plain and Metakaolin Concretes in Aggressive Sulfate Environments," J. of Materials in Civil Engineeing, Vol. 22, No. 4, pp. $403-407$.

19. Hooton, R. D. (1993), "Influence of Silica Fume Replacement of Cement on Physical Properties and Resistance to Sulfate Attack, Freezing and Thawing, and AlkaliSilica Reactivity,” ACI Materials Journal, Vo. 90, No. 2, pp. 143-151.

20. Hooton, R. D. (2011), “A Review of Different Forms of Sulfate Attack” a presentation to the Department of Energy, URL: http://srnl.doe.gov/grout_present/2b_02_Hooton.pdf

21. Irassar, D.F. and Ans-Batic, O. (1989) "Effect of low calcium fly ash on sulfate resistance of Portland cement”, Cement and Concrete Research 19: 194-202.

22. Johnston, R. H. and Bush, P. W. (1988), "Summary of the Hydrology of the Floridan Aquifer System in Florida and in Parts of Georgia, South Carolina, and Alabama," USGS Professional Paper 1403-A.

23. Khatib, J. M., and Wild, S. (1998), "Sulphate Resistance of Metakaolin Mortar,” Cem. Concr. Res., Vol. 28, pp. 83-92.

24. Krizan, D. and Zivanovic, B. (1997), "Resistance of Fly Ash Cement Mortars to Sulphate Attack," Proceedings of the 10th International Congress on Cement Chemistry, Gothenburg, paper 4iv020.

25. Mangat, P.S. and Khatib, J.M. (1992) "Influence of initial curing on sulphate resistance of blended cement concrete”, Cement and Concrete Research 22: 1089-1100.

26. Mangat, P.S. and Khatib, J.M. (1995) "Influence of fly ash, silica fume and slag on sulfate resistance of concrete”, ACI Materials Journal 92: 542-552.

27. Mehta, P. K. (1983), "Mechanism of Sulfate Attack on Portland Cement Concrete — Another Look," Cement and Concrete Research, Vol. 13, No. 3, pp. 401-406.

28. Mehta, P. K. (1991), "Concrete in Marine Environment," Elsevier Applied Science, London.

29. Mehta, P. K. (1992), "Sulfate Attack on Concrete - a Critical Review," Material Science of Concrete, American Ceramic Society, Westerville, OH, pp. 105-130.

30. Mehta, P. K. and Haynes, H. (1975), "Durability of Concrete in Seawater," Journal of the American Society of Civil Engineers Structural Division 101(ST8), pp. 1679-1686. 
31. Miletic, S.R. and Ilic, M.R. (1997) "Effect of ammonium sulphate corrosion on the strength of concrete", Proceedings of the 10th International Congress on the Chem $\neg$ istry of Cement, Gothenburg, paper 4iv023.

32. Monteiro, P. J. M., Roesler, J., Kurtis, K. E., and Harvey, J. (2000), “Accelerated Test for Measuring Sulfate Resistance of Hydraulic Cements for Caltrans LLPRS Program,” FHWA/CA/OR-2000/03, p. 46.

33. PCA (2013) URL: http://www.cement.org/tech/cct_dur_acid.asp

34. Sersale, R., Cioffi, R., de Vito, B., Frigione, G. and Zenone, F. (1997), "Sulphate Attack on Carbonated and Uncarbonated Portland and Blended Cements," Proceedings of the 10th International Congress of the Chemistry of Cement, Gothenburg, paper 4iv17.

35. Skalny, J., Marchand, J. and Odler, I. (2002), Sulfate Attack on Concrete, Spon Press, London, UK.

36. Skalny, J. and Locher, F.W. (1999), "Curing Practices and Delayed Ettringite Forma $\neg$ tion: the European Experience,” Cem. Concr. Aggr., Vol. 21, ASTM.

37. Skalny, J. and Pierce, J. (1999), “Sulfate Attack: an Overview," Materials Science of Concrete Special Volume: Sulfate Attack Mechanisms, The American Ceramic Society, Westerville, OH, pp. 49-63.

38. Sersale, R., Cioffi, R., de Vito, B., Frigione, G. and Zenone, F. (1997) "Sulphate attack on carbonated and uncarbonated Portland and blended cements", Proceedings of the 10th International Congress of the Chemistry of Cement, Gothenburg, paper 4iv17.

39. Soroushian P. and Alhozami A. (1992) "Correlation between fly ash effects on permeability and sulfate resistance of concrete", Proceedings of the 9th International Congress on the Chemistry of Cement, New Delhi, 5: 196-202.

40. Talero, R. (2005), "Performance of Metakaolin and Portland Cements in Ettringite Formation as Determined by ASTM C 452-68: Kinetic and Morphological Differences,” Cem. Concr. Res., Vol. 35, 2005, pp. 1269-1284.

41. Tuutti, K. (1982), Corrosion of Steel in Concrete, Swedish Cement and Concrete

42. Research institute (CBI) Research Report Fo 4:82.

43. USBR Concrete Manual, 6th Edition, 1956.

44. Xiao, J., Deng, D., Yuan, Q., Pan, W., and Chen, F. (2006), "Improvement Effect of Silica Fume on the Cement Paste in Sulfate Attack," Journal of Southwest Petroleum Institute, Vol. 28, Issue 3, pp. 103-105. 
45. Yilmaz, A. B., Yazici, B. and Erbil, M. (1997), "The Effects of Sulphate Ion on Concrete and Reinforced Concrete,” Cement and Concrete Research, Vol. 27, Issue 8, 1997, pp. 1271-1279. 


\section{CHAPTER IV}

SULFATE MITIGATION AND ATTACK MODELING IN BLENDED CEMENT-

BASED MATERIALS 


\section{CHAPTER IV}

\section{SULFATE MITIGATION AND ATTACK MODELING IN BLENDED CEMENT- BASED MATERIALS}

Shuo Zhang ${ }^{1}$, Nakin Suksawang ${ }^{2}$

${ }^{1}$ Dept. of Civil \& Environ. Engineering, Florida International University, Miami, Florida 33174, Tel: (305)298-1112, Fax: (305)348-2802, E-mail: szhan002@fiu.edu.

2 Dept. of Civil Engineering, Florida Institution of Technology, Melbourne, Florida 32901, Tel: (321)674-7504, Fax: (321) 674-7565, E-mail: nsuksawang@fit.edu.

\subsection{Abstract}

In this study, the absorption based model was established using Richards Equation and it's validated with other scholars' data and experimental data. From these computations, it was concluded that under acid condition, sulfate penetration could be described using absorption based model. Very few studies however tried to distinguish the saturation condition to the calculation of concrete sulfate resistance. In the present study, durability concerns have been focused on the modeling of external sulfate attack. A literature review has exposed the different aspects trying to explain the mechanisms underlying this complex phenomenon. A model has been developed based on a finite element method by implying absorption-reaction equation. After extrapolation of the short-term to the long term case, it was possible to validate the outputs of the model by comparing it to experimental results.

KEY WORDS: Concrete; absorption; sulfate attack 


\subsection{Introduction}

Sorption-based model is used in this research. This model is based on the assumption that concrete is porous material and both liquid water and water vapour can penetrate into the pores and permeate through them. Sulfate migrates within concrete along with liquid water through cracks and into pores, yet not migrates with water vapour. Sulfate will react with concrete particles and reaction products can result of expansion and cracks within concrete. To better understand the migration of sulfate, water transport in concrete must be understood and simulated using Finite Element Method (FEM). Concrete service life will be calculated using threshold suggested in Chapter 2. FEM model will firstly be validated with other references and concrete degradation simulation will be processed using concrete properties tested in Chapter 3 and the result will be compared with in-situ bridge piles to verify the model's accuracy.

\subsection{Literature Review}

To link the concrete characteristics such as formation factor and sorptivity coefficient to the degradation of concrete, several models of sulfate stack have been derived by researchers using approaches mainly based on two kinds of models. These models adopt different theories for use in modeling sulfate mitigation in concrete.

\subsubsection{Diffusion based service prediction models}

Mobasher-Tixier Model is based on the assumption that the degradation by the sulfate is the estimation of sulfate concentration profile into the specimen. This depends 
on the diffusion of sulfate into the specimen, depends on the geometry of the specimen, and on the sulfate concentration in the solution surrounding the specimen.

The combination of the diffusion and the reaction with the cement paste allows the model to calculate the profile of the sulfate concentration versus depth in specimens of various geometries and its evolution with time.

Concrete degradation is then evaluated by calculating the expansion of the specimen resulting from the reaction. The model uses the modulus of elasticity of the material, its capillary porosity, and the calculated sulfate penetration and reaction distribution in the specimen to calculate the overall expansion and deterioration.

\subsubsection{Sorptivity based service prediction models}

NIST CONCLIFE was developed to address the deterioration of sulfate attack and freeze-thaw of bridge decks and pavement. It was assumed that the sulfate solution could ingress the concrete by sorption. It assumes that sulfates enter concrete only by sorption and not by diffusion. The concrete specimen is dry or only partially saturated.

The service life model for sulfate attack in CONCLIFE is developed based on the model developed by Atkinson and Hearne. It calculates spalling depth based on the information of environment and concrete properties. The basic equation is:

$$
\mathrm{X}_{\text {spall }}=\left(2 \alpha \gamma_{\mathrm{f}}(1-v)\right) /\left(\mathrm{E}\left(\beta \mathrm{C}_{\mathrm{E}}\right)^{2}\right)
$$

Where $C_{E}=$ concentration of reacted sulfate as ettringite $\left(\mathrm{mol} / \mathrm{m}^{3}\right)$

$$
\begin{aligned}
& E=\text { Young's modulus }(\mathrm{GPa}) \\
& \mathrm{X}_{\text {spall }}=\text { spalling depth }(\mathrm{m}) \\
& \alpha=\text { roughness factor for fracture path } \\
& \beta=\text { linear strain caused by one mole of sulfate reacted }\left(\mathrm{m}^{3} / \mathrm{mol}\right)
\end{aligned}
$$




$$
\begin{aligned}
& \gamma_{\mathrm{f}}=\text { fracture surface energy of concrete }(\mathrm{N} / \mathrm{m}) \\
& \sigma=\text { surface tension }(\mathrm{N} / \mathrm{m}) \\
& \nu=\text { Poisson's ratio }
\end{aligned}
$$

The basic assumption of this model is that deleterious expansion and cracking are due to the formation of ettringite within the concrete. For a sorptivity-based model, the buildup of ettringite is considered to be due to external sulfate ions penetrating into the concrete along with sorbed external solution.

\subsection{Theories and Considerations}

\subsubsection{Unsaturated liquid migration within concrete}

Water is absorbed into the interior of concrete by capillary forces arising from the contact of the pores of the concrete with the water phase. This unsaturated flow (u) is described locally by the extended Darcy’s Equation

$$
\mathrm{u}=\mathrm{K}(\theta) \mathrm{F}
$$

where $\mathrm{F}$ is the capillary force and

$\theta$ is the ratio of liquid volume to bulk volume (volume fraction saturation). If we expressed this equation using capillary potential $\Psi$, so that

$$
\mathrm{u}=-\mathrm{K}(\theta) \nabla \Psi
$$

Here, $\Psi$ (dimension [L]), defined to be coherent with the pressure potential $\mathrm{P}$, is the capillary potential/unit weight of liquid.

Combining Equ. 4.3 with the continuity equation leads to the fundamental equation of unsaturated flow, the Richards equation 


$$
\frac{\partial \theta}{\partial \mathrm{t}}=\nabla \mathrm{K}(\theta) \nabla \Psi
$$

Clearly two material properties must be known in order for flow rates to be calculated. These are $K(\theta)$ and $\Psi(\theta)$. It is often more convenient to write Eq. 4.4 in terms of $\theta$ rather than $\Psi$. If we define a quantity $\mathrm{D}=\mathrm{K}(\mathrm{d} \Psi / \mathrm{d} \theta)$ then Eq. 4.4 becomes

$$
\frac{\partial \theta}{\partial \mathrm{t}}=\nabla \mathrm{D} \nabla \theta
$$

where $\mathrm{D}$ is the capillary diffusivity, with dimensions $\left[\mathrm{L}^{2} \mathrm{~T}^{-1}\right]$. $\mathrm{D}$ depends both on the material and on the fluid: it describes the tendency of the material to transmit the fluid in question by capillarity. Most commonly, the fluid is water and D is then called the hydraulic diffusivity.

It is the Richards equation that provides the basis for our description of unsaturated flow in porous materials. Unsaturated flow processes can be represented by solution to Richards equation subject to appropriate boundary conditions.

\subsubsection{Dependence of gravity}

In many cases in building materials, the strong capillary forces and the short distances over which migration occurs mean that we can neglect the effects of gravity on unsaturated flow. If the heights involved are much less than the variation in hydraulic potentials, then the assumption is justified. However, due to weak suction and especially for sections close to saturation and for large height of water transport, especially when long-term analysis involved in this research, effects of gravity cannot be neglected.

For this case, the fundamental equation of unsaturated flow Eq. 4.2 will include the effects of gravity by replacing the hydraulic potential $\Psi$ by a total potential $\Phi=\Psi+\mathrm{z}$ 
which thus depends on elevation. Here $\mathrm{z}$ is the vertical coordinate (positive upwards). It follows that the diffusivity formulation of unsaturated flow is

$$
\frac{\partial \theta}{\partial \mathrm{t}}=\nabla(\mathrm{D} \nabla \theta)+\frac{\mathrm{dK}}{\mathrm{d} \theta} \frac{\partial \theta}{\partial \mathrm{z}}
$$

Therefore, for problems involving gravity effects we need to know D and K, rather than just $\mathrm{D}$ alone.

\subsubsection{Dependence of material properties}

We already know the governing equation for solving simplest unsaturated liquid migration, and solving liquid migration problem with the consideration of gravity. It is still not feasible if we don't know the properties of concrete.

D, hydraulic diffusivity, is controlling material properties. It is commonly represented by the equation

$$
\mathrm{D}\left(\theta_{\mathrm{r}}\right)=\mathrm{D}_{0} \exp \left(\mathrm{B} \theta_{\mathrm{r}}\right)
$$

Where $\mathrm{D}_{0}$, B are constant

The wetting diffusivity may also be represented by a power-law form:

$$
\mathrm{D}(\theta)=\mathrm{D}_{0} \theta^{\mathrm{n}}
$$

Where $\mathrm{n}$ is a constant. There is also evidence available suggests that the exponential model fits wetting profile data slightly better than the power law. 
Table 4-1 Hydraulic diffusivities of concrete represented by Eq. 4.8

\begin{tabular}{|l|l|l|}
\hline \multirow{2}{*}{ Material } & Diffusivity & \\
\cline { 2 - 3 } & $D_{0} \mathrm{~m}^{2} \mathrm{~s}^{-1}$ & B \\
\hline Concrete, w/c 0.62 & $1.5 \times 10^{-10}$ & 6.2 \\
\hline Concrete, w/c 0.55 & $3.7 \times 10^{-11}$ & 7.2 \\
\hline Concrete, w/c 0.40 & $1.3 \times 10^{-11}$ & 7.4 \\
\hline
\end{tabular}

It is possible to "convert" these two forms of expression in both ways. For given two materials stated in Table 4-2, both exponential expression and power-law expression are drawn in Fig 4.1. It is found out that for water content larger than 0.6, both expression give similar hydraulic diffusivity. However, for water content less than 0.6 , power-law expression is more conservative in calculating diffusivity, which can cause water distribution different at the "tail”. We will be discussing this phenomenon in Stage I.

Table 4-2 Difference diffusion expression for same materials

\begin{tabular}{|l|l|l|l|l|}
\hline \multirow{2}{*}{ Material } & \multicolumn{2}{|c|}{$\begin{array}{c}\mathrm{D}\left(\theta_{\mathrm{r}}\right)=\mathrm{D}_{0} \exp \left(\mathrm{B} \theta_{\mathrm{r}}\right) \\
\text { Exponential Expression }\end{array}$} & \multicolumn{2}{c|}{$\begin{array}{c}\mathrm{D}(\theta)=\mathrm{D}_{0} \theta^{\mathrm{n}} \\
\text { Power-law Expression }\end{array}$} \\
\cline { 2 - 5 } & $\mathrm{D}_{0}$ & $\mathrm{~B}$ & $\mathrm{D}_{0}$ & $\mathrm{n}$ \\
\hline Concrete, w/c 0.40 & $\begin{array}{l}1.3 \\
\mathrm{~m}^{2} \mathrm{~s}^{-1}\end{array}$ & 7.4 & $\begin{array}{l}2.13 \times 10^{-8} \\
\mathrm{~m}^{2} \mathrm{~s}^{-1}\end{array}$ & 6.5 \\
\hline Wire-cut clay brick ceramic & $\begin{array}{l}0.13 \\
\mathrm{~mm}^{2} \mathrm{~min}^{-1}\end{array}$ & 6.28 & $\begin{array}{l}69.39 \\
\mathrm{~mm}^{2} \mathrm{~min}^{-1}\end{array}$ & 5 \\
\hline
\end{tabular}



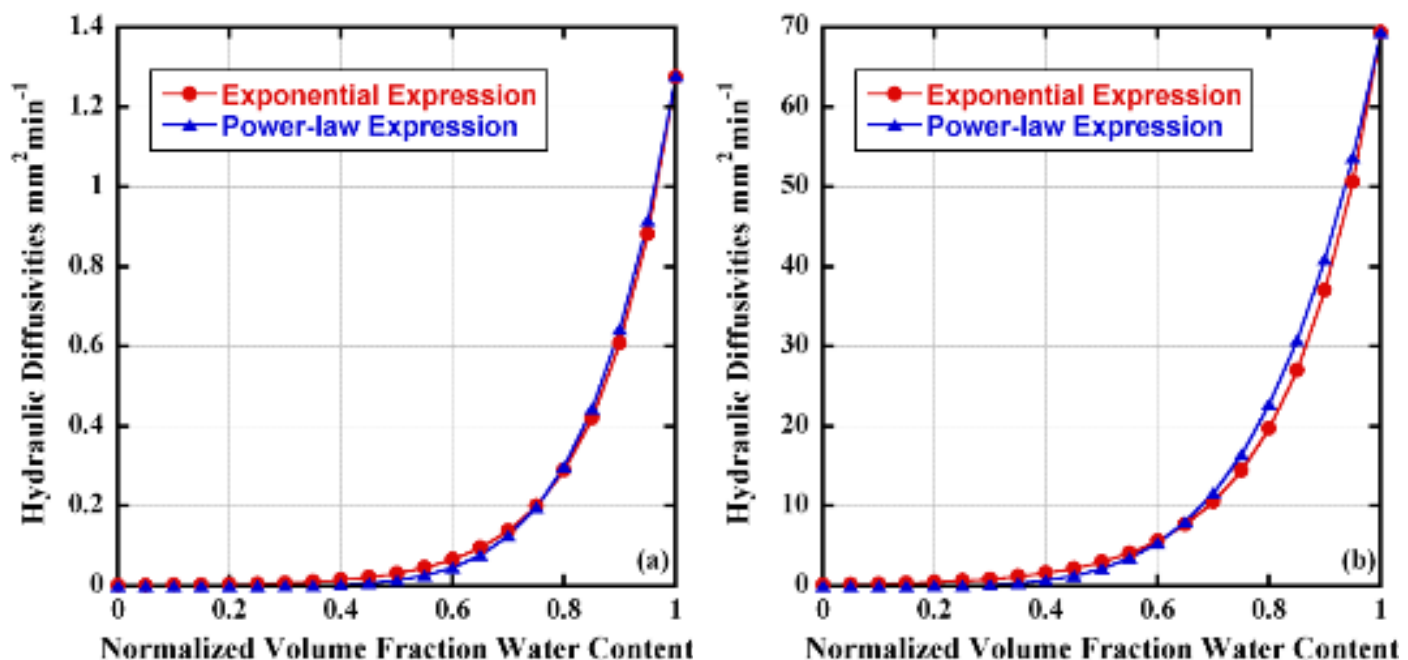

FIGURE 4.1. Hydraulic diffusivity of concrete (left) and ceramic (right) using exponential expression and power-law expression

$\mathrm{K}$, generalized or unsaturated permeability but is conventionally described as liquid conductivity.

Direct measurement of the unsaturated hydraulic conductivity is experimentally difficult and not suitable for concrete. Indirect estimates of unsaturated conductivity may be obtained from measurements of the diffusivity and hydraulic potential.

The most widely used model of $\mathrm{K}(\theta)$ is the Mualem equation. Used with van Genuchten hydraulic potential function, Mualem equation leads to the following function for $K(\theta)$

$$
\mathrm{K}\left(\theta_{\mathrm{r}}\right)=\mathrm{K}_{\mathrm{s}} \theta_{\mathrm{r}}^{\mathrm{l}}\left[1-\left(1-\theta_{\mathrm{r}}^{\frac{1}{\mathrm{~m}}}\right)^{\mathrm{m}}\right]^{2}
$$

Where $\mathrm{m}$ is the van Genuchten parameter and $\mathrm{l}$ is a constant equal to about 0.5 . It is often used to represent the hydraulic conductivity of concrete. 
Here we have some examples of the permeability of cement-based materials in Table 4-3. The permeability depends on free water content, water/cement ratios, curing and drying conditions.

Table 4-3 Permeability of cement-based materials

\begin{tabular}{|c|c|c|}
\hline Material & Fluid & $\begin{array}{l}\text { Permeability } \\
\mathrm{K}_{\mathrm{s}} / \mathrm{ms}^{-1}\end{array}$ \\
\hline Hardened cement paste w/c $0.5^{\mathrm{a}}$ & Water & $3.8 \times 10^{-13}$ \\
\hline Hardened cement paste w/c $0.8^{\mathrm{a}}$ & Water & $4.6 \times 10^{-11}$ \\
\hline Cement-sand mortars $^{\mathrm{b}}$ & Water & $4.6 \times 10^{-11}$ \\
\hline High strength concrete, moist cured $^{c}$ & Water & $7.7 \times 10^{-13}$ \\
\hline High strength concrete, air cured ${ }^{\mathrm{c}}$ & Water & $1.9 \times 10^{-11}$ \\
\hline
\end{tabular}

Notes:

a Fully hydrated cement paste

b 1:3 cement:sand mortar

c Portland cement concrete w/c 0.45

\subsubsection{Dependence of environmental conditions}

For environmental conditions, we are talking about temperature, humidity, air speed, and sulfate concentration. In this research, the role of acid is not discussed. By defining target $\mathrm{pH}$ level 5.0, we assume that concrete performance calculated in this research suitable for any bridges facing $\mathrm{pH}$ level of 5.0 or milder conditions.

In the water sorption process, temperature, humidity, and air speed merely play any role. Concrete properties have the most crucial role in water transport within concrete. Sulfate concentration is very important in calculating sulfate concentration in concrete.

Temperature, humidity and air speed are only considered when water evaporation is considered in the model. Evaporation, also called drying, means the transfer of water from the pores of concrete to the surrounding air. The process generally includes: 
unsaturated flow of liquid within concrete; vapour flow within concrete; the liquidvapour phase change; convective-diffusive transfer of vapour from the surface of concrete to the surroundings.

Drying process occurs in at least two distinct stages, called the constant drying rate period (Stage I) and the falling drying rate period (Stage II). For first stage, Selih recommends in his paper that for concrete, $0.18 \mathrm{~kg} / \mathrm{day} / \mathrm{m}^{2}$ could be used and for the second stage, $0.02 \mathrm{~kg} / \mathrm{day} / \mathrm{m}^{2}$.

Environmental condition mostly affects the process of stage I drying. Increasing humidity will result of evaporation slowing down. The faster air speed is, the faster evaporation is. And for temperature, the higher temperature will increase the speed of evaporation.

Hall et al. explained this phenomenon in his paper and the effects of humidity and air speed is shown in Figure 4.2.
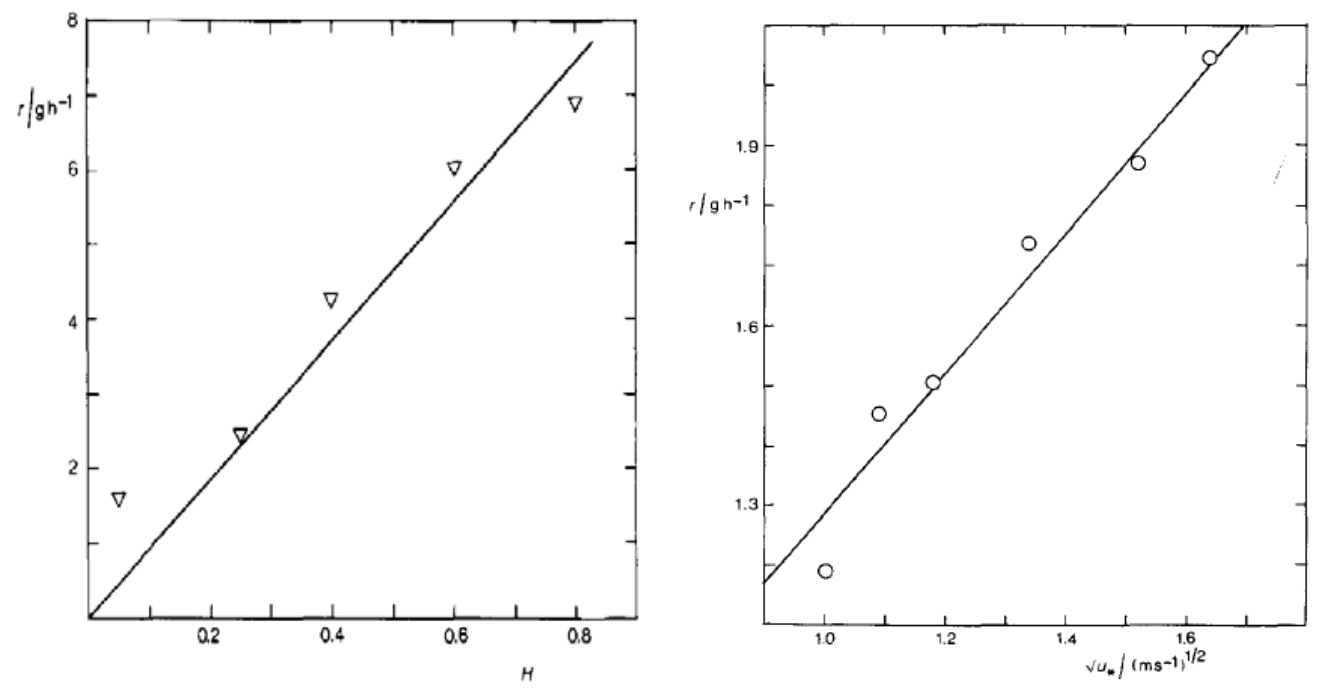

FIGURE 4.2. Variation of water evaporation rate $\left(\mathrm{g} \mathrm{h}^{-1}\right)$ with humidity (Left, humidity factor $\mathrm{H}=1-(\%$ R.H./100) and air speed (Right) 
There is now considerable evidence that the stage I drying in a wide range of porous materials is equal to the evaporation rate of a free water surface under the same conditions. Stage I drying only happens in a first few hours when concrete is exposed from water from long time emerge.

The drying rate eventually ceases to be constant and begins to decrease. This change marks the beginning of stage II drying. Hall suggests that in stage I, the evaporation rate is controlled by vapour phase diffusion above the surface. However, in stage II, the rate is limited by unsaturated flow within concrete.

Therefore, to conclude, environmental condition will barely influence the sorption process. In desorption, or evaporation, drying, process, environmental condition dominate the rate in stage I drying, which only happens in the first few hours. After stage I drying, unsaturated flow within concrete once again limits the evaporation rate. In this research, the effects of environmental condition are limited and will be barely considered.

\subsubsection{Dependence of time}

The penetration of water into a concrete surface with uniform initial water content may be described by Eq. 4.4. Take one-dimensional horizontal flow of liquid, the unsaturated flow may be described mathematically by

$$
\frac{\partial \theta}{\partial \mathrm{t}}=\frac{\partial}{\partial \mathrm{x}}\left(\mathrm{D} \frac{\partial \theta}{\partial \mathrm{x}}\right)
$$

To obtain Eq. 4.10 in the form of an ordinary differential equation, we introduce Bolzmann variable

$$
\emptyset=\mathrm{xt}^{-1 / 2}
$$

Using this equation and Eq. 4.10 may be written 


$$
-\frac{1}{2} \emptyset \frac{\mathrm{d} \theta}{\mathrm{d} \emptyset}=\frac{\mathrm{d}}{\mathrm{d} \emptyset}\left(\mathrm{D} \frac{\mathrm{d} \theta}{\mathrm{d} \emptyset}\right)
$$

Then if we use power-law diffusivity equation Eq. 4.8 and Eq. 4.12 yields an extremely simple to use analytical expression by

$$
2 \mathrm{D}_{0}\left(1-\theta^{\mathrm{n}}\right) / \mathrm{n}=\mathrm{s} \emptyset+\frac{\mathrm{A}}{2} \emptyset^{2}
$$

with

$$
s^{2}=D_{0} \frac{3+2 n}{(1+n)(2+n)}
$$

and

$$
A=2-\frac{(1+n) s^{2}}{D_{0}}
$$

With given concrete properties $\mathrm{D}_{0}$ and $\mathrm{n}$, we are able to solve the water content distribution versus $\phi$. And if we need to know the distribution for a certain time, just plug in the time into Eq. 4.11.

Take concrete in Table 4-2 for example. With power-law expression, $\mathrm{D}_{0}=$ $2.13 \times 10^{-8} \mathrm{~m}^{2} \mathrm{~s}^{-1}$ and $\mathrm{n}=6.5$. Then the water distribution problem will be solved as shown in Figure 5.3. 

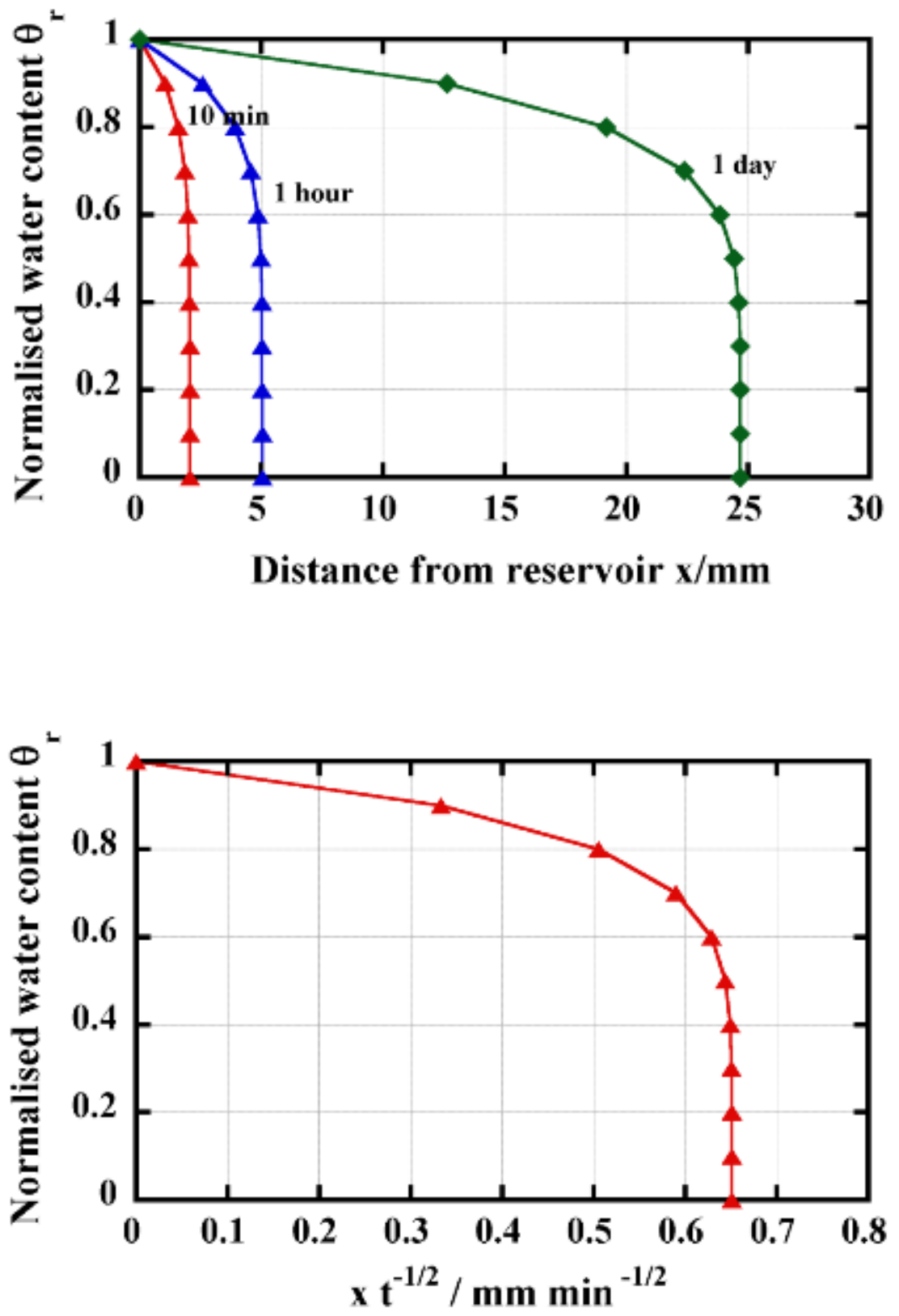

FIGURE 4.3. Water content profiles calculated by Eq. 4.12 and using power-law diffusivity for concrete $\mathrm{w} / \mathrm{c}=0.40$

In FEM calculation, instead of using Bolzmann variable, time-dependent method will be used. 


\subsubsection{Sulfate chemical reaction}

The reaction of sulfate with concrete results of the formation of ettringite from an aluminate phase and the potential expansions associated with that. Three compounds may react with ingressing sulfates according to one of the following reactions:

$$
\begin{gathered}
\mathrm{C}_{4} \mathrm{AH}_{13}+3 \mathrm{C} \overline{\mathrm{S}} \mathrm{H}_{2}+14 \mathrm{H} \rightarrow \mathrm{C}_{6} \mathrm{AS}_{3} \mathrm{H}_{32}+\mathrm{CH} \\
\mathrm{C}_{4} \mathrm{AS} \mathrm{S}_{12}+2 \mathrm{C} \overline{\mathrm{S}} \mathrm{H}_{2}+16 \mathrm{H} \rightarrow \mathrm{C}_{6} \mathrm{AS}_{3} \mathrm{H}_{32} \\
\mathrm{C}_{3} \mathrm{~A}+3 \mathrm{C} \overline{\mathrm{S}} \mathrm{H}_{2}+26 \mathrm{H} \rightarrow \mathrm{C}_{6} \mathrm{~A}_{3} \overline{\mathrm{H}}_{32}
\end{gathered}
$$

These reactions are lumped in a global sulfate phase-aluminate phase reaction (Tixier and Mobasher 2003) and represented as $P_{i}+a_{i} \bar{S} \rightarrow C-6 A \bar{S}_{3} H_{32}$ where $P_{i}$ represents the weighted average proportion of the aluminate phase taking part in the reaction, and $a_{i}$ represents the stoichiometric sulfate required for the reaction. Similar to the model by Clifton et al. (1994), the expansion is predicted from the molar volumes of the different components of the cement paste and its microstructural parameters (Clifton and Pommersheim 1994). The crystallization pressure of the products of the reaction results in a bulk expansion of the solid.

In this research, to simplify, accumulated sulfate and reaction products are measured with XRD and evaluated in terms of atom weight percentage. The expansion results created by crystallization pressure from expandable reaction products or sulfate accumulation are lump summed as the function of sulfate weight percentage generalized using in-situ concrete experimental data.

In the reaction of cement particles and sulfate, $\mathrm{P}_{\mathrm{i}}$ is considered to be unlimited compare to sulfate. Therefore, reaction rate is only depends on the content of sulfate. In 
this research, we use $\mathrm{mol} / \mathrm{L}$ as the unit of evaluating sulfate content, no matter in water or penetrated into concrete.

Here we have another assumption. We assume the sulfate content in water stays constant no matter in or out of concrete, since the water body serves as an almost unlimited sulfate reserve. We also ignore the effect of temperature. Therefore, the reaction rate will be only related with sulfate content in surrounding water body.

B. Mobasher et al. states in his paper that the differential equation for the penetration of sulfates and the reaction is represented as a first order diffusion reaction equation and represented as the following:

$$
\frac{\partial \mathrm{u}(\mathrm{x}, \mathrm{t})}{\partial \mathrm{t}}=\mathrm{D} \frac{\partial^{2} \mathrm{u}(\mathrm{x}, \mathrm{t})}{\partial \mathrm{x}^{2}}-\mathrm{ku}(\mathrm{x}, \mathrm{t}) \mathrm{c}(\mathrm{x}, \mathrm{t})
$$

where $c(x, t)$ stands for the amount of cement particles in the reaction. $u$ is the adjusted surrounding sulfate content.

Comparatively, Mobasher's equation evaluate sulfate penetration simply using Fick's second law, while in this research, sulfate are considered penetrating into concrete with water and calculated using Finite Element Modeling. The advantage of Mobasher's equation is that it simplifies sulfate reaction function using linear expression. This function is adopted in this research.

Considering $\mathrm{c}(\mathrm{x}, \mathrm{t})$ is not the limitation, the reaction rate can be calculated using function:

$$
\frac{\partial \mathrm{C}(\mathrm{x}, \mathrm{t})}{\partial \mathrm{t}}=\mathrm{ku}(\mathrm{x}, \mathrm{t})
$$


where $\mathrm{C}[\mathrm{wt} . \%]$ is the sulfate reaction products content in concrete. $\mathrm{u}$ is the adjusted surrounding sulfate content [ppm]. $\mathrm{k}$ is the reaction parameter calculated from experiments. $t$ is time in unit of second.

When water penetrating into concrete, for unit volume, adjusted surrounding sulfate content is calculated using following equation:

$$
u(x, t)=\theta_{r}(x, t) \times f \times U
$$

where $\theta_{\mathrm{r}}$ is reduced water content. $\mathrm{f}$ is volume fraction porosity. $\mathrm{U}$ is surrounding sulfate content.

Here is how we calculate reaction parameter. From experiment, fly ash cement with $25 \%$ fly ash is immerged into sulfate solution for 52 weeks. Figure 4.4 shows the Scanning Electron Microscope image at 100 times magnification. The sulfur atom weight percentage of the marked area in Figure 4.4 is tested using X-ray diffraction analysis shown in Figure 4.5. The result shows that sulfate atom weight percentage on the surface is 3.46 .

Because the test point is near the surface, $\mathrm{u}=\mathrm{f} \times \mathrm{U}=6,750 \mathrm{ppm}$, assuming $\mathrm{f}=$ 0.135. Then we get $\mathrm{k}=9.86 \times 10^{-6}$.

To use this function, $\mathrm{C}$, $\mathrm{u}$ and $\mathrm{t}$ must keep the same unit as mentioned previously. Therefore, combine Eq. 4.17 and Eq. 4.18, we get sulfate reaction product [weight percentage] at certain point and time:

$$
C(x, t)=\int_{0}^{t} k \times \theta_{r}(x, T) \times f \times U d T
$$




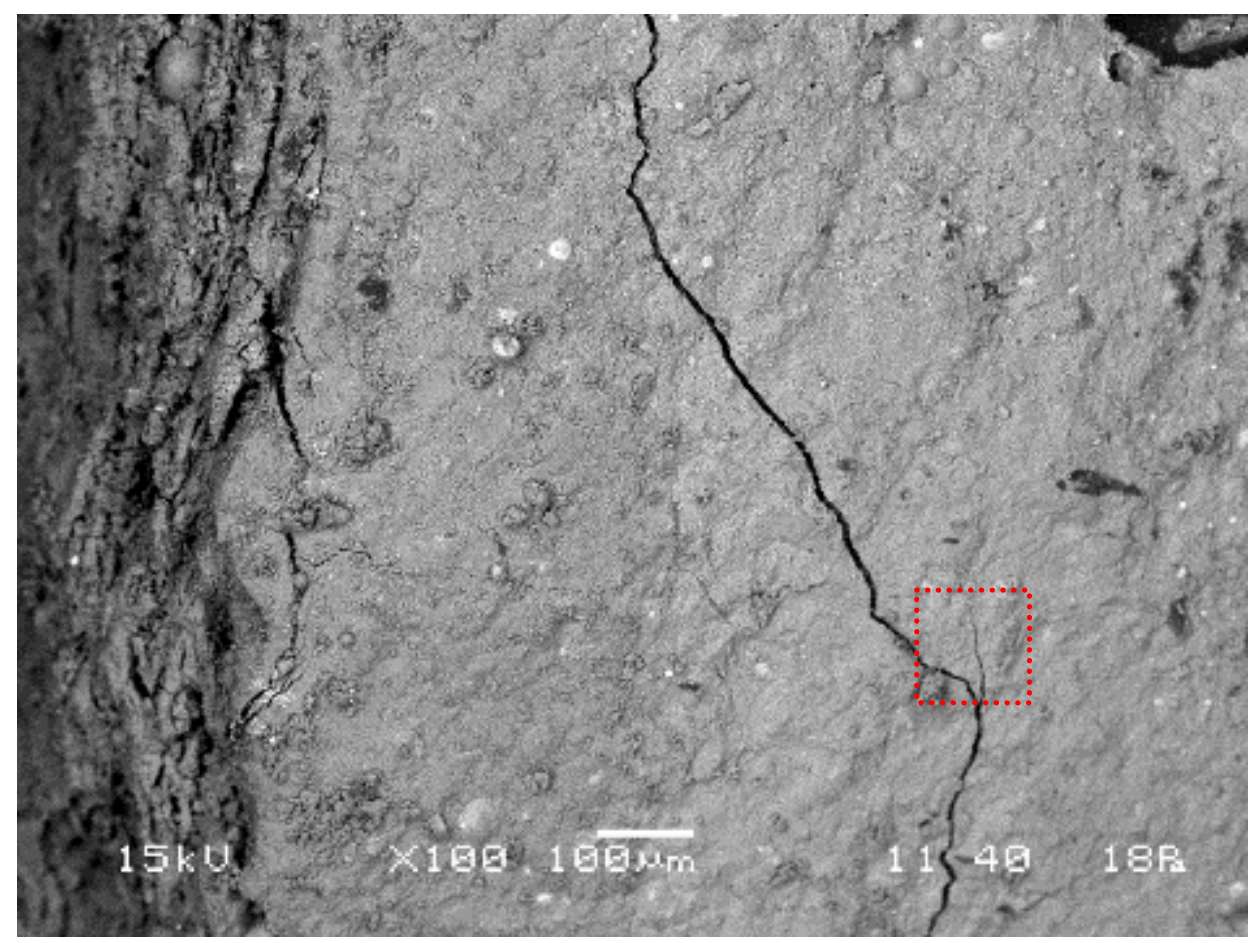

FIGURE 4.4. Scanning Electron Microscope image of the surface of fly ash cement (25\% fly ash) after 4 weeks immerged into 50,000 ppm sulfate solution.

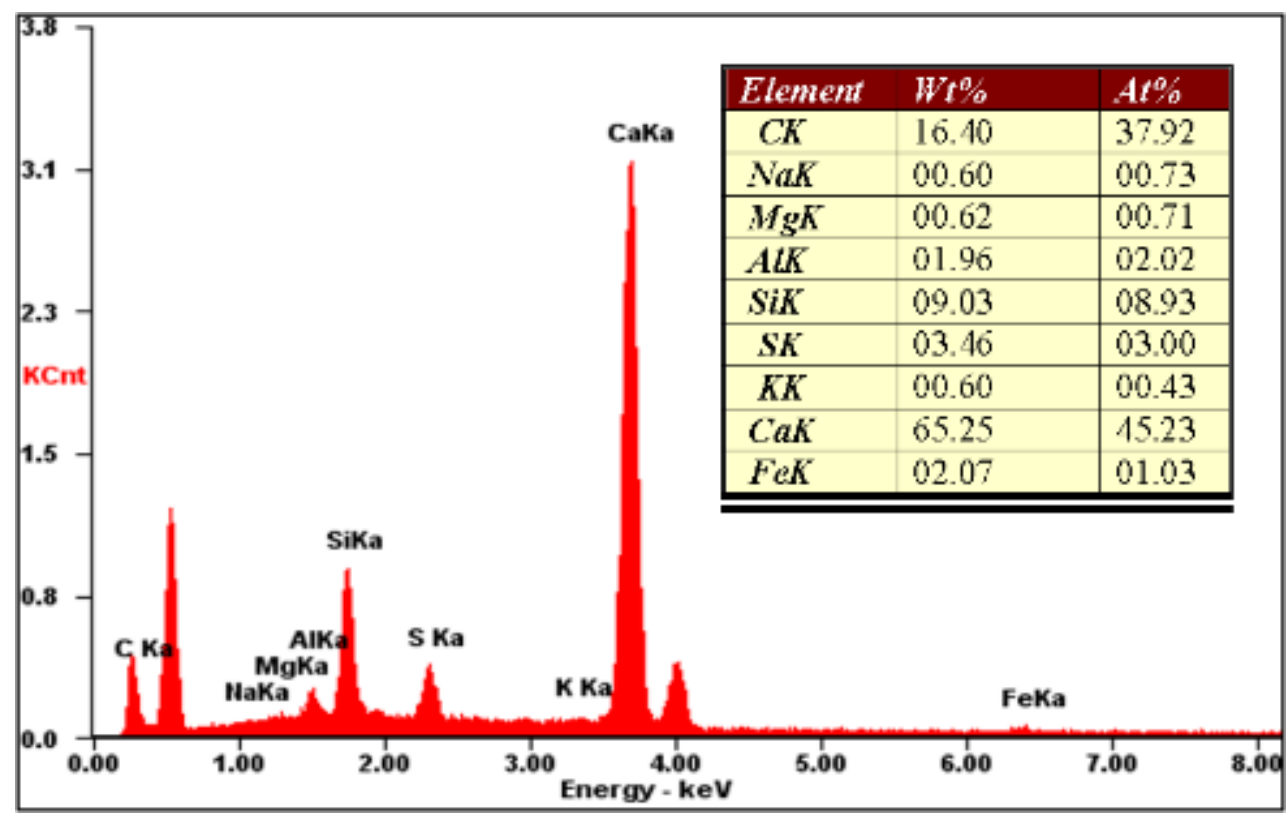

FIGURE 4.5. X-ray diffraction analysis of the surface of fly ash cement (25\% fly ash) after 4 weeks immerged into 50,000 ppm sulfate solution 


\subsubsection{Evaporation and accumulation}

The process of desorption by evaporation is not simply a reversal of the capillary absorption process. There is no liquid/vapour phase change in simple absorption, but evaporation inescapably involves such a phase change.

As stated previously, there are two phases of drying, so-called stage I drying and stage II drying. Stage I drying, if we state clearly, happens when water content on the surface is not equal to 0 . For concrete above water level, there is no surrounding water as it is for concrete under water level. As part of boundary conditions, water content is restricted to 0 in this research.

Stage II drying, which happens when water content on surface equal to 0 , is driven by water vapour diffusivity force. The surrounding air serves as "free vapour reservoir" with constant vapour concentration, temperature, air pressure as assumed in this research. Water vapour concentration is related with Relative Humidity (RH) and air conditions (temperature, air pressure). Within concrete, because water content is not 1 , the rest of the pores are filled with water vapour due to the appearance of liquid water. This condition is so called $\mathrm{RH}=1$. Therefore, there will be a concentration difference between the air inside concrete and outside if $\mathrm{RH}_{\mathrm{ext}}<1$.

According to Fick's first law, the water vapour concentration changes within concrete can be calculated as:

$$
\frac{\partial \mathrm{c}_{\mathrm{v}}(\mathrm{x}, \mathrm{t})}{\partial t}=-\mathrm{D}_{\mathrm{v}} \frac{\mathrm{H}}{\mathrm{x}}
$$

where $c_{v}$ is water vapour concentration $\left[\mathrm{g} / \mathrm{m}^{3}\right] . \mathrm{D}_{\mathrm{v}}$ stands for vapour diffusivity parameter. $\mathrm{H}=(1-\mathrm{RH} / 100)$ is a humidity factor 
Because for the same location, water appearance with water vapour. Transferred water vapour can be supplemented almost immediately by evaporated liquid water. Therefore, the water content changes at the same location will be calculated as:

$$
\partial \theta_{\mathrm{r}}(\mathrm{x}, \mathrm{t}) \times \mathrm{dV} \times \rho=\left[1-\theta_{\mathrm{r}}(\mathrm{x}, \mathrm{t})\right] \times \mathrm{dV} \times \partial \mathrm{c}_{\mathrm{v}}(\mathrm{x}, \mathrm{t}) \times \mathrm{M}
$$

The mass change of liquid water on the left side equals to the mass change of vapour water on the right side at the same location with porous volume dV. $\rho$ is the density of liquid water $997 \mathrm{~kg} / \mathrm{m}^{3}$ at $25^{\circ} \mathrm{C}$ and $\mathrm{M}$ is the molar mass of liquid water $18.0 \times$ $10^{-3} \mathrm{~kg} / \mathrm{mol}$. We simplify Eq. 4.21 and get:

$$
\frac{\partial \theta_{\mathrm{r}}(\mathrm{x}, \mathrm{t})}{\partial t}=\frac{1-\theta_{\mathrm{r}}(\mathrm{x}, \mathrm{t})}{\mathrm{A}} \times \frac{\partial \mathrm{c}_{\mathrm{v}}(\mathrm{x}, \mathrm{t})}{\partial t}
$$

where $A=\rho / M=5.54 \times 10^{4} \mathrm{~mol} / \mathrm{m}^{3}$ at $25{ }^{\circ} \mathrm{C}$. It's a constant for given temperature.

Therefore, given Eq. 4.22 and Eq. 4.20, we have the change of water content at any location due to water evaporation:

$$
\frac{\partial \theta_{\mathrm{r}}(\mathrm{x}, \mathrm{t})}{\partial t}=\frac{1-\theta_{\mathrm{r}}(\mathrm{x}, \mathrm{t})}{\mathrm{A}} \times-\mathrm{D}_{\mathrm{v}} \frac{\mathrm{H}}{\mathrm{x}}
$$

As we already know, water transport within concrete can be driven by absorption force, which can be calculated by Richards Equation as Eq. 4.4. Water as carrier of sulfate ions, migrates from surrounding reservoir to concrete without any liquid/vapour change. Therefore, sulfate concentration does not change as water driven by absorption force. However, when there is liquid/vapour change happens as demonstrated previously, sulfate concentration of this location increases due to solution loss. It is called sulfate accumulation. 
The sulfate concentration at certain time of any location before evaporation happens is

$$
\mathrm{c}_{\mathrm{s}}=\frac{\mathrm{n}}{\mathrm{dVp} \theta_{\mathrm{r}}}
$$

where, $\mathrm{Cs}_{\mathrm{s}}$ is sulfate concentration at this location and time with unit $\left[\mathrm{mol} / \mathrm{m}^{3}\right] . \mathrm{n}$ is number of moles of sulfate ions. $\mathrm{dV}$ stands for the volume of this location. $\mathrm{p}$ is the porosity of concrete. $\theta_{\mathrm{r}}$ is reduced water content at this location.

After a very short time $\Delta \mathrm{t}$, the concentration of this location will be

$$
\mathrm{c}_{\mathrm{s}}+\Delta \mathrm{c}_{\mathrm{s}}=\frac{\mathrm{n}}{\mathrm{dVp}\left(\theta_{\mathrm{r}}+\Delta \theta_{\mathrm{r}}\right)}
$$

Therefore, $\Delta \mathrm{c}_{\mathrm{s}}$ is calculated using Eq. 4.24 and Eq. 4.25

$$
\Delta c_{s}=\frac{n}{d V p\left(\theta_{r}+\Delta \theta_{r}\right)}-\frac{n}{d V p \theta_{r}}
$$

We simplify Eq. 4.24 and get

$$
\Delta \mathrm{c}_{\mathrm{s}}=\frac{-\Delta \theta_{\mathrm{r}} \mathrm{c}_{\mathrm{s}}}{\left(\theta_{\mathrm{r}}+\Delta \theta_{\mathrm{r}}\right)}
$$

When $\Delta \mathrm{c}_{\mathrm{s}}$ is close to $0,\left(\theta_{\mathrm{r}}+\Delta \theta_{\mathrm{r}}\right)$ gets close to $\theta_{\mathrm{r}}$ and $\Delta \theta_{\mathrm{r}}$ is $\mathrm{d} \theta_{\mathrm{r}}$. We get

$$
\mathrm{dc}_{\mathrm{s}}=-\frac{\mathrm{c}_{\mathrm{s}}}{\theta_{r}} d \theta_{r}
$$

Therefore, combining Eq. 4.26 and Eq. 4.23, we have the sulfate accumulated concentration change at any location and time:

$$
\frac{\partial c_{\mathrm{s}}(\mathrm{x}, \mathrm{t})}{\partial t}=\frac{\mathrm{c}_{\mathrm{S}}(\mathrm{x}, \mathrm{t})}{A} \times \frac{1-\theta_{\mathrm{r}}(\mathrm{x}, \mathrm{t})}{\theta_{r}(x, t)} \times \mathrm{D}_{\mathrm{v}} \frac{\mathrm{H}}{\mathrm{x}}
$$

Therefore, for any location and time, we are able to calculate the sulfate concentration as

$$
\mathrm{c}_{\mathrm{S}}(\mathrm{x}, \mathrm{t})=\mathrm{C}+\int_{0}^{\mathrm{t}} \frac{\mathrm{c}_{\mathrm{S}}(\mathrm{x}, \mathrm{T})}{A} \times \frac{1-\theta_{\mathrm{r}}(\mathrm{x}, \mathrm{T})}{\theta_{r}(x, T)} \times \mathrm{D}_{\mathrm{v}} \frac{\mathrm{H}}{\mathrm{x}} \mathrm{dT}
$$




\subsection{Finite Element Analysis}

\subsubsection{Governing equations}

With the theoretical and empirical considerations stated previously, we now present the governing equations of this FEM model. Two-dimensional problem will be adequate for practical problem. For a two-dimensional problem in an x-y plane, which is the focus of the current study, the governing equation is

$$
\frac{\partial \theta}{\partial \mathrm{t}}=\frac{\partial\left[\mathrm{D}(\theta) \frac{\partial \theta}{\partial \mathrm{x}}\right]}{\partial \mathrm{x}}+\frac{\partial\left[\mathrm{D}(\theta) \frac{\partial \theta}{\partial \mathrm{y}}\right]}{\partial \mathrm{y}}
$$

If the effect of gravity is considered, Eq. 4.29 will be modified to

$$
\frac{\partial \theta}{\partial \mathrm{t}}=\frac{\partial\left[\mathrm{D}(\theta) \frac{\partial \theta}{\partial \mathrm{x}}\right]}{\partial \mathrm{x}}+\frac{\partial\left[\mathrm{D}(\theta) \frac{\partial \theta}{\partial \mathrm{y}}\right]}{\partial \mathrm{y}}+\frac{\mathrm{dK}}{\mathrm{d} \theta} \frac{\partial \theta}{\partial \mathrm{y}}
$$

where y is positive in upward direction.

\subsubsection{Boundary conditions}

The FEM model will be designed to solve water penetration into concrete through the surface under water, of which the water content stays constant as 1 , and for concrete above water level, water content stays constant as 0 . If we set water level is at $x=0$, then, the boundary condition is as follows.

For $\mathrm{x}=0$ and $\mathrm{y}<0, \theta=1$ (under water level)

For $\mathrm{x}=0$ and $\mathrm{y}>0, \theta=0$ (above water level)

For $\mathrm{x}>0$ and $\mathrm{t}=0, \theta=0$ (initial condition)

For $\mathrm{y} \rightarrow:, \theta=0$ (up bound limitation)

\subsubsection{Model geometry and meshes}

The water penetration process is simulated in the two-dimensional FE model using commercially available software, COMSOL Multiphysics®. The dimension of the FE model is illustrated in Figure 4.6. Water is only considered to be penetrating from 
outside. Therefore, only a section of concrete pile is simulated. For boundary y $=-1000$ $\mathrm{mm}$, no water flow is considered since it's emerged and away from water level. For boundary $\mathrm{y}=2000 \mathrm{~mm}$, no water flow is considered as well, since it's far away from water level.

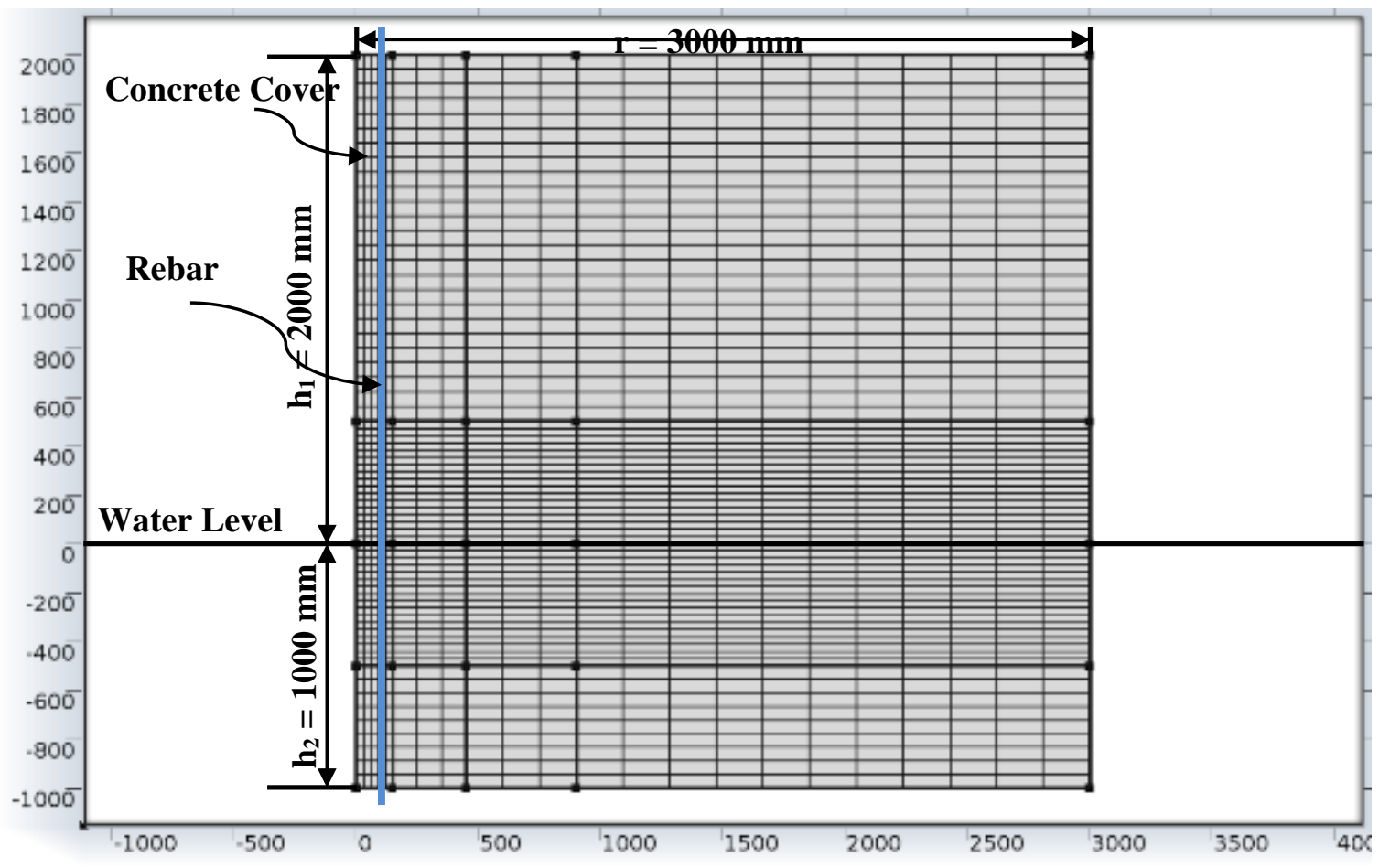

FIGURE 4.6. The FE model used in this study: specimen size, discretization scheme and boundary conditions

The entire domain is discretized using 4-node quadrilateral elements, with the highest mesh density in the contact position with water. Progressively coarser mesh is used as we move away from the contact resulting in 1946 elements in the model.

\subsubsection{Model validation}

The fully time-dependent one-dimensional case is very important, since it provides the foundation for understanding many practical phenomena and is also the 
basis of many experimental methods and test procedures. It is necessary to verify the calculation before the application to two-dimensional model.

One-dimensional FE model is used to verify time-dependent calculation by applying Eq. 4.11 and the result is compared with analytical expression in Eq. 4.13.

Governing equation that used for one-dimensional FE model is

$$
\frac{\partial \theta}{\partial \mathrm{t}}=\frac{\partial\left[\mathrm{D}(\theta) \frac{\partial \theta}{\partial \mathrm{x}}\right]}{\partial \mathrm{x}}
$$

and the boundary conditions are

$$
\begin{gathered}
\text { For } \mathrm{x}=0, \theta=1 \\
\text { For } \mathrm{x}>0 \text { and } t=0, \theta=0
\end{gathered}
$$

Two different diffusivity functions are used in this FE model, power-law diffusivity function and exponential diffusivity function. Concrete properties in Table 4-2 are used in this model.

The calculation results are shown in Figure 4.9. It is found out that both FE models fit well with analytical solution that used power-law diffusivity function. But for short term solution, FE model with exponential diffusivity function is better than using power-law diffusivity function with less tail noise and smother water content profile. 

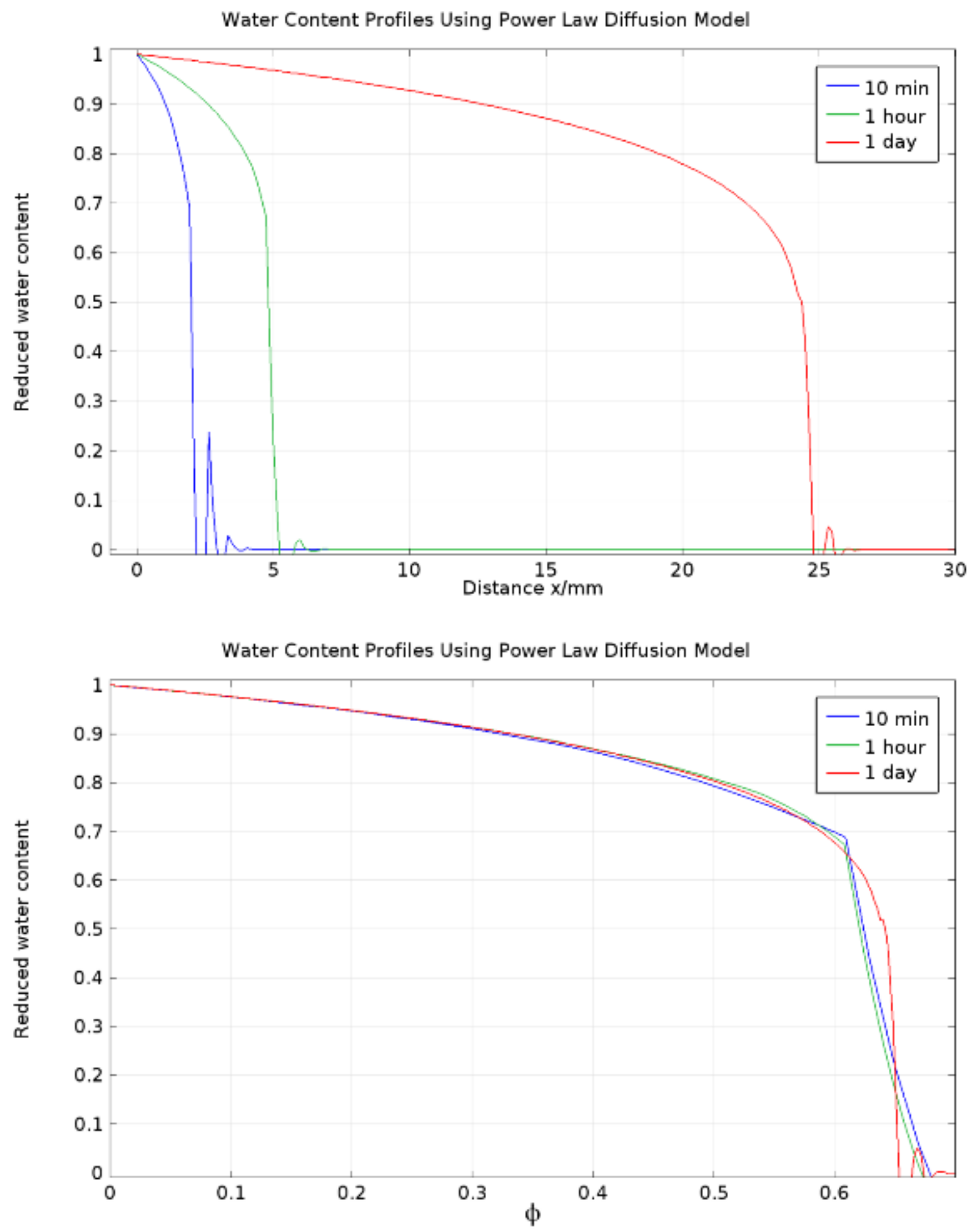

FIGURE 4.7. Water content profiles using power-law diffusivity function at a series of elapsed times t for water absorption into concrete having the diffusivity function $\mathrm{D} / \mathrm{m}^{2} \mathrm{~s}^{-1}$

$$
=2.13 \times 10^{-8} \theta_{\mathrm{r}}^{6.5}
$$



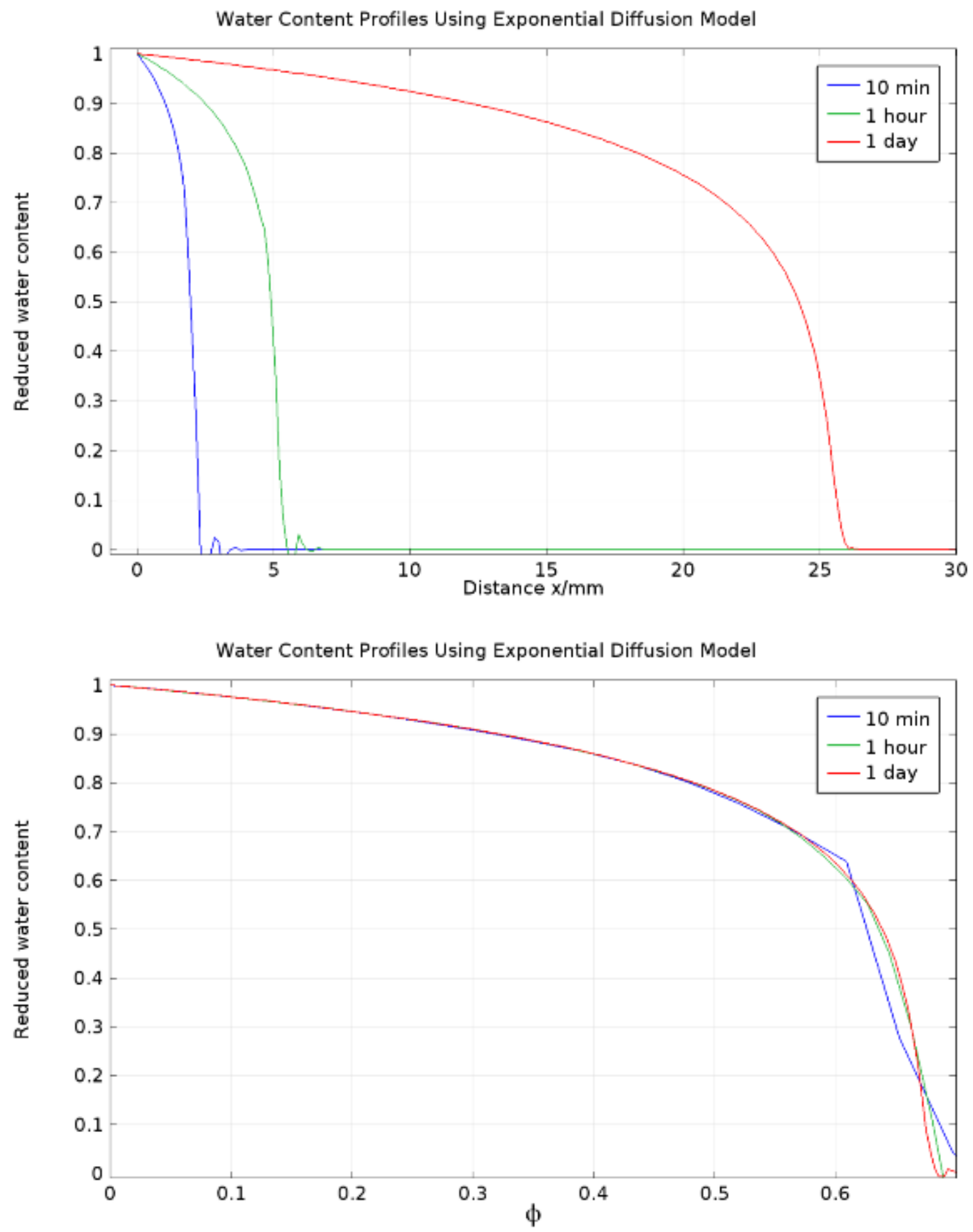

FIGURE 4.8. Water content profiles using exponential diffusivity function at a series of elapsed times $t$ for water absorption into concrete having the diffusivity function $\mathrm{D} / \mathrm{m}^{2} \mathrm{~s}^{-1}$ $=1.3 \times 10^{-11} \exp \left(7.4 \theta_{\mathrm{r}}\right)$ 

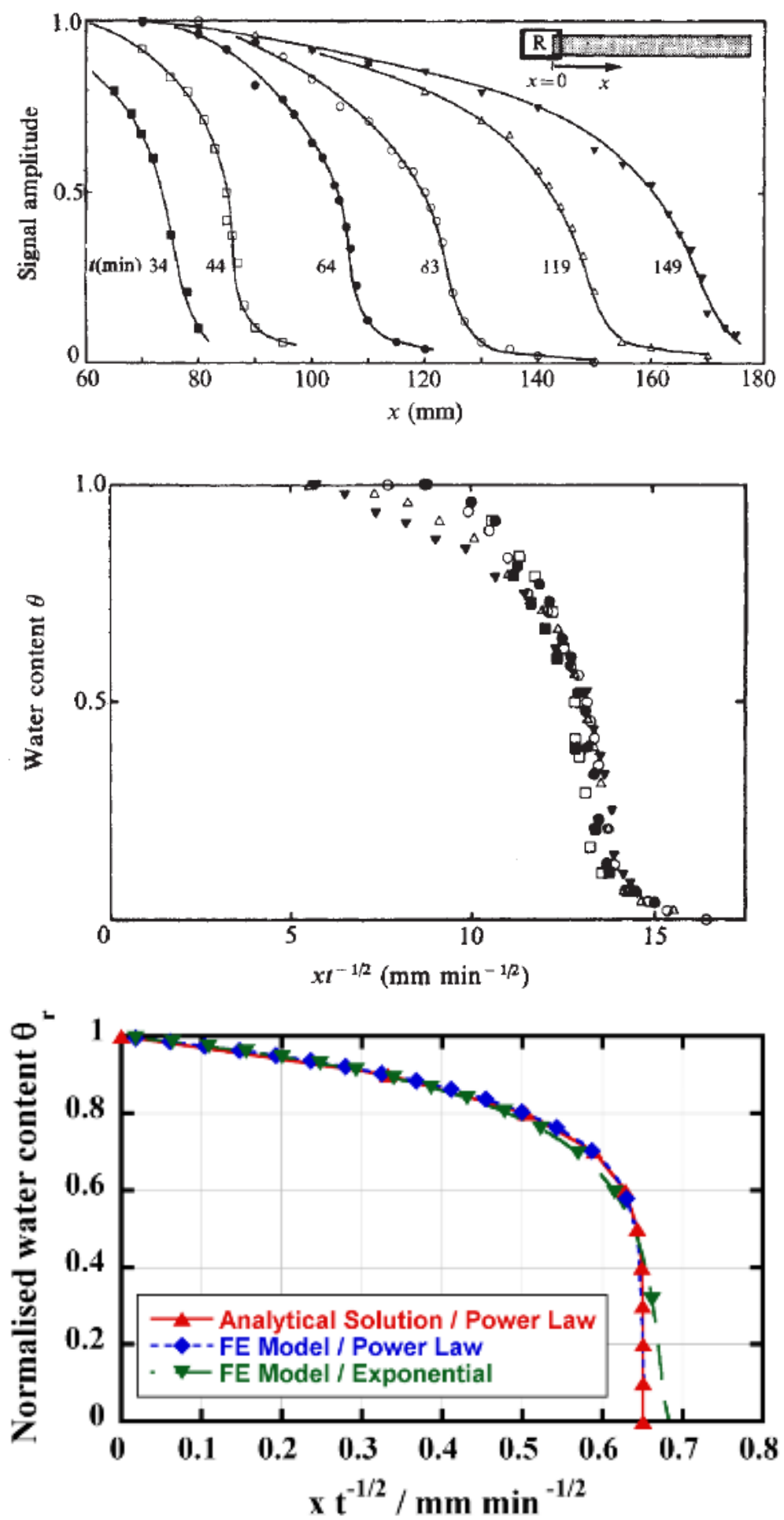

FIGURE 4.9. Water content profiles obtained by NMR during capillary absorption of water by a plaster bar (a, b) and water content profiles calculated by FE models and power-law diffusivity analytical solution of concrete 
Gummerson et al. have done experiment using nuclear magnetic resonance (NMR) to obtain water content profile of a plaster bar (Figure 4.9). Philip has developed an accurate quasi-analytical iterative method of solving the non-linear diffusion equation. Parlange gave another approximate method which provided adequate results without iteration. More recently, Parlange and his collaborators have found a better solution by generalize a method originally used by Heaslet and Alksne to solve the restricted case of non-linear diffusion in a material with a power-law diffusivity.

In Figure 4.10a, the calculated water content profiles are shown for onedimensional absorption using the extended Heaslet-Alksne method. In this example, the profile exhibits the characteristic steep gradients in the vicinity of the wetting front, and advances as $\mathrm{t}^{1 / 2}$ maintaining constant shape, as the Boltzmann transformation requires. In Figure 4.10b, a compare of the calculated distribution $\phi(\mathrm{x})$ using the extended HeasletAlksne method with the accurate iterative method of Philip is shown. The curves are almost indistinguishable.

In Figure 4.10, we calculate water content profiles by FE model using the exact same material properties for one-dimensional absorption problem. FE model provides almost identical curve as extended Heaslet-Alksne method and Philip method.

In Figure 4.11, it is clearly seen that using FE model with exponential diffusivity function provides more accurate water content profile, especially in the wetting front. Besides, FE model with exponential diffusivity function appears to be more stable and gives much less "noise" at the "tail". Therefore, for the rest of this research, exponential diffusivity function is used, if not noted. 

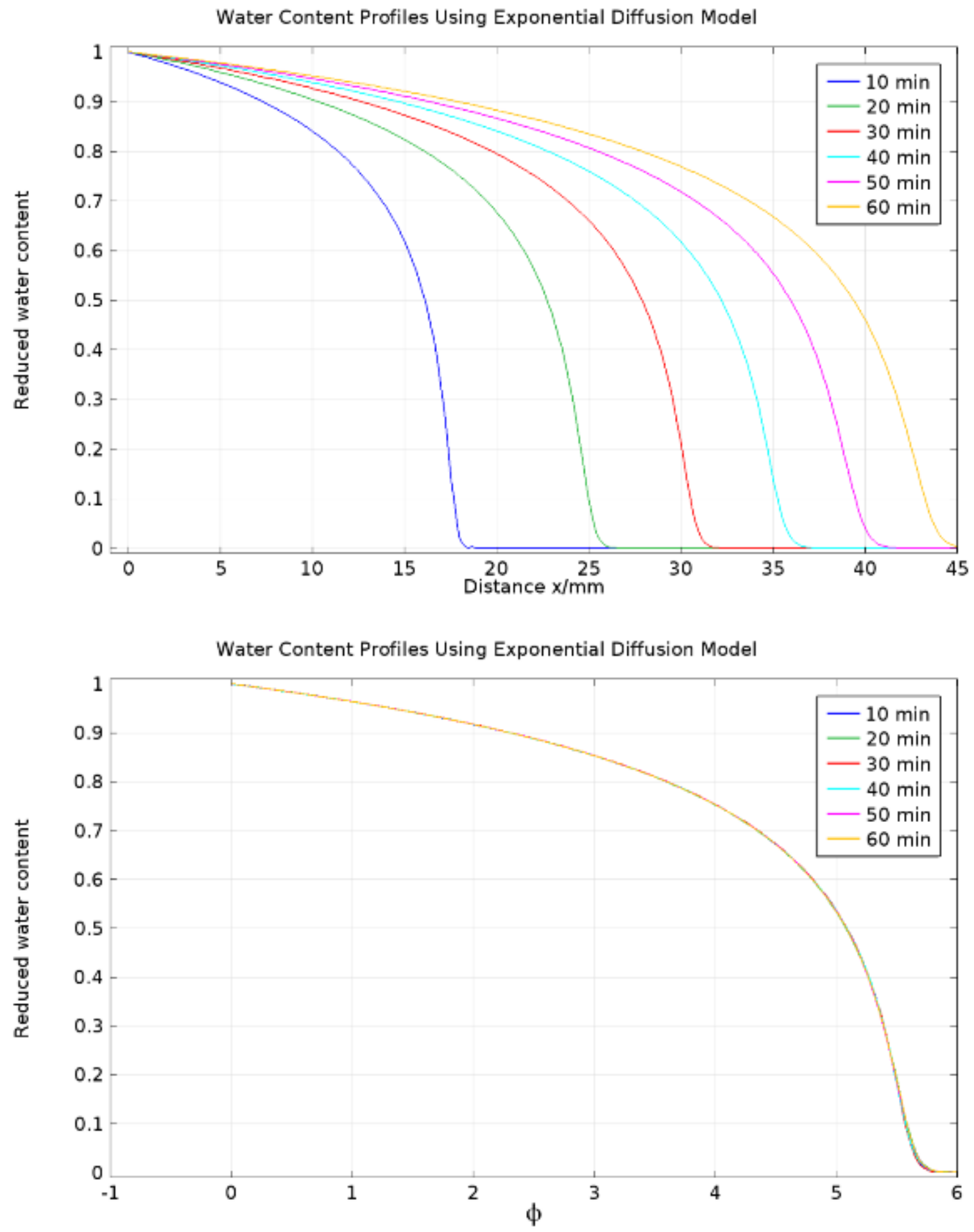

FIGURE 4.10. Water content profiles using exponential diffusion model at different time. 

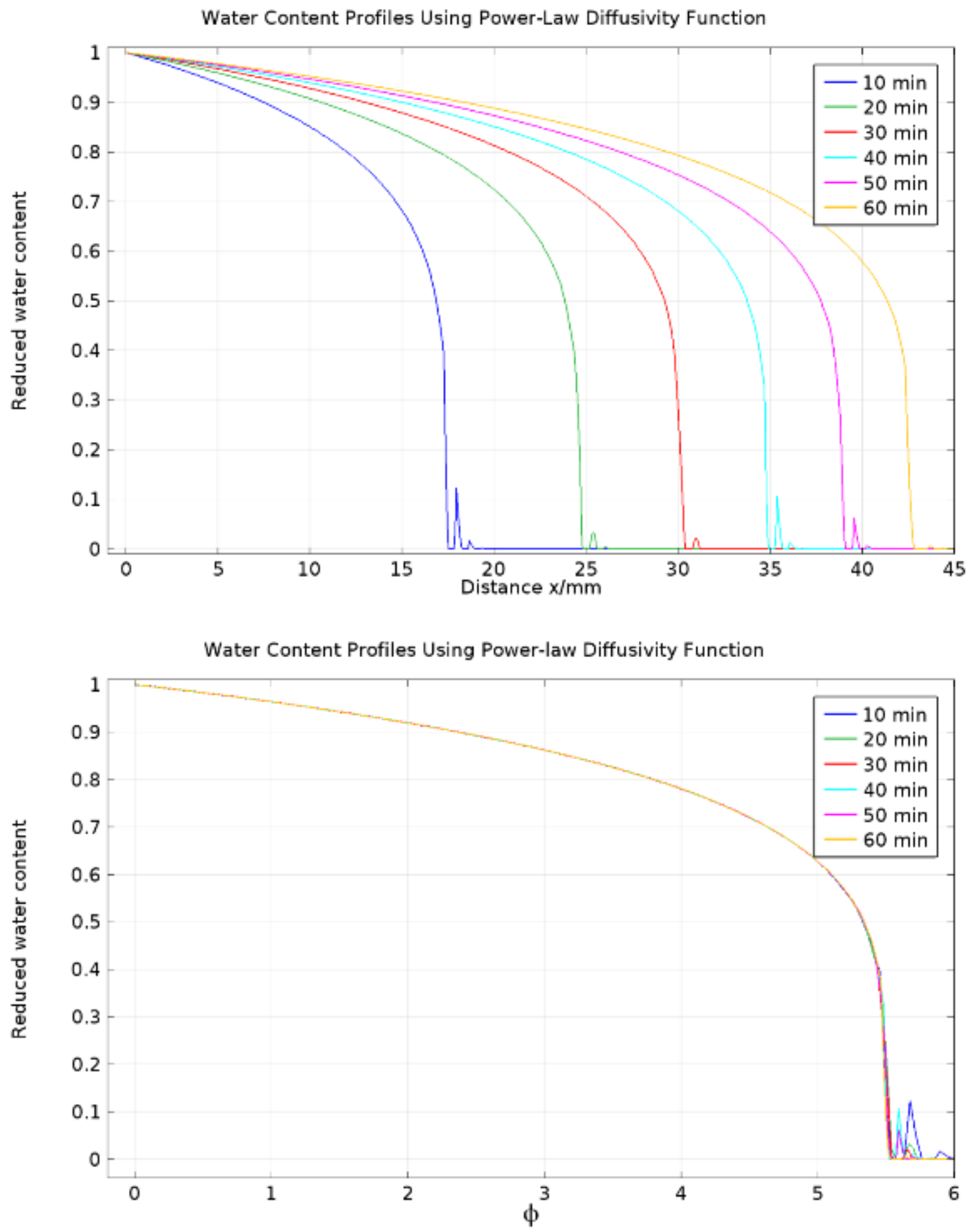

FIGURE 4.11 Water content profiles using power-law diffusion model at different time. 


\subsection{Sulfate Mitigation Model}

\subsubsection{Stage I unsaturated liquid migration under minimum water level}

For concrete piles emerged into water deeply away from water level, the water flow can be treat as unsaturated liquid flow from external to internal without migrating upward or downward. Therefore, a one-dimensional migration simulation is completed for this stage.

Simulation has been done to a 36 inch $(0.91 \mathrm{~m})$ square concrete pile. Concrete properties from Table 4-2 have been adopted in this simulation. Exponential diffusivity function is used for this simulation, in which $\mathrm{D}_{0}=1.3 \times 10^{-11} \mathrm{~m}^{2} \mathrm{~s}^{-1}, \mathrm{~B}=7.4$.

One-dimensional FE model is established applying governing equation:

$$
\frac{\partial \theta}{\partial \mathrm{t}}=\frac{\partial\left[\mathrm{D}(\theta) \frac{\partial \theta}{\partial \mathrm{x}}\right]}{\partial \mathrm{x}}
$$

And boundary conditions are

$$
\begin{aligned}
& \text { For } \mathrm{x}=0 \text { or } \mathrm{x}=0.91, \theta=1 \\
& \text { For } \mathrm{x}>0 \text { and } t=0, \theta=0
\end{aligned}
$$

Saturated condition is applied on both side of the model, since water is penetrating from both sides of concrete piles.

Figure 4.12 shows the calculated water content profiles up to 2 years. For less than 3 months, the wetting front has reached the depth of rebar. For only less than 1.5 years, the whole concrete pile will be filled with water. Figure 4.13 shows the water content at the depth of rebar and in the middle of concrete. To conclude, for this kind of concrete, at the first 1.5 years of calculation, water profiles within concrete need to be 
considered. However, for long-term simulation, concrete that kept emerged in water can be considered as fully saturated.

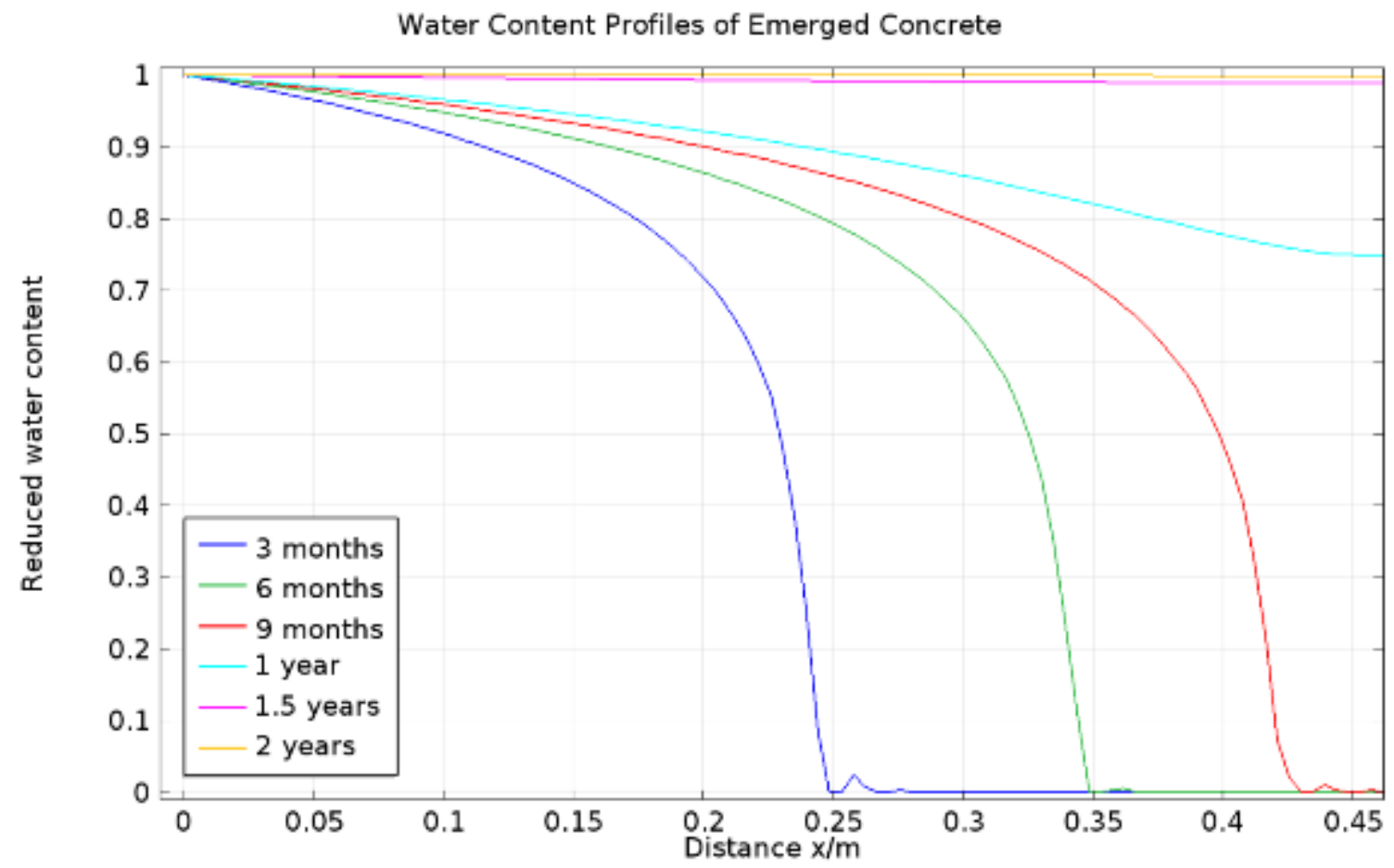

FIGURE 4.12. Water content profiles of emerged concrete under both side penetrations. Concrete $\mathrm{w} / \mathrm{c}=0.4$. Calculation use exponential diffusivity function, $\mathrm{D}_{0}=1.3 \times 10^{-11}$ $\mathrm{m}^{2} \mathrm{~s}^{-1}, \mathrm{~B}=7.4$ 


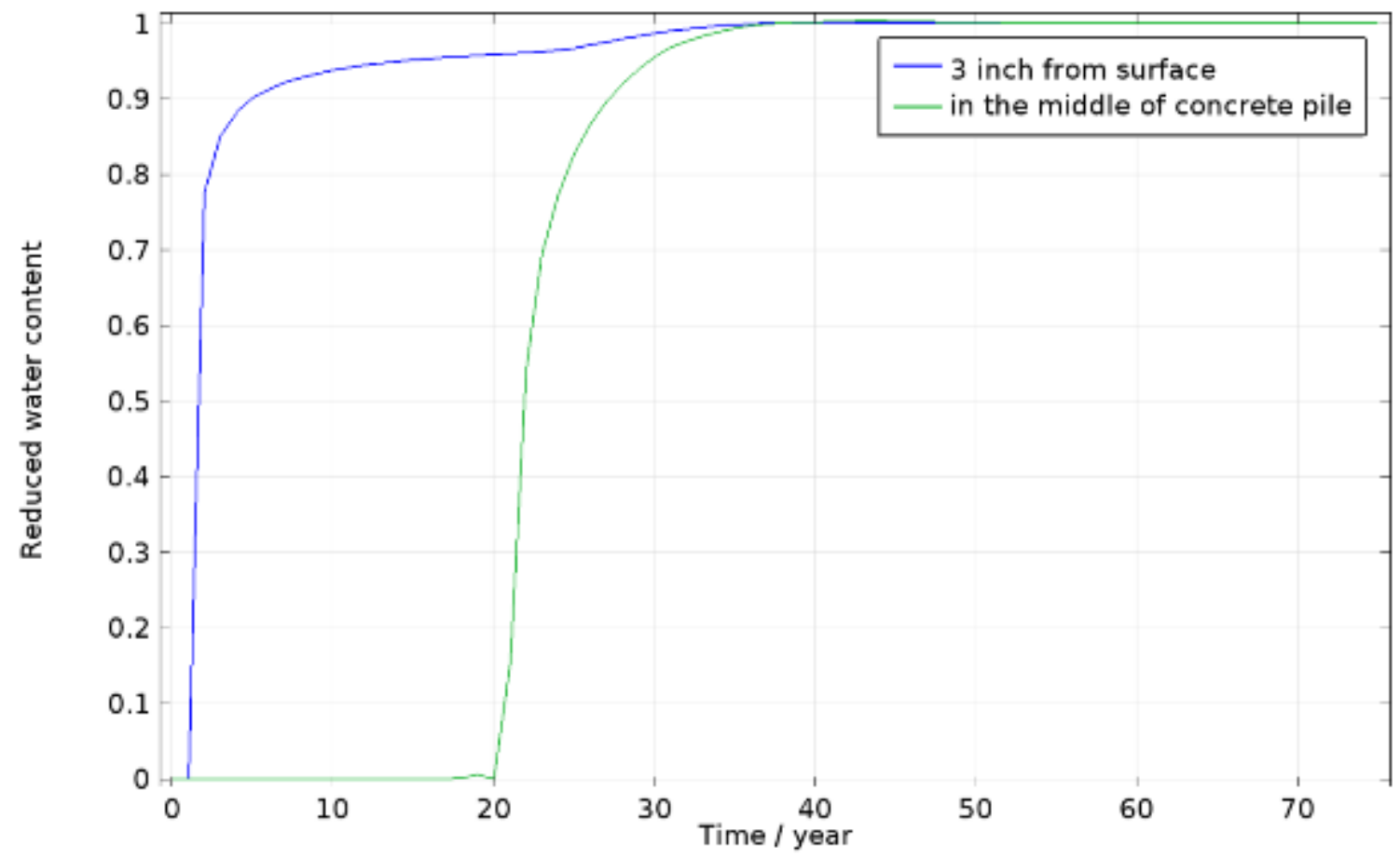

FIGURE 4.13. Water content at the depth of steel rebar and in the middle of concrete pile.

We assume surrounding water body has sulfate content $\mathrm{U}=1500 \mathrm{ppm}$. The $\mathrm{pH}$ level is lower than 6.5 satisfying low $\mathrm{pH}$ condition. Concrete porosity is assumed to be 0.135. Based on water content profile and Eq. 4.19, sulfate reaction products content in terms of sulfur weight percentage at different depth and time are illustrated in Figure 4.14. The sulfur weight percentage at 3-inch depth at the end of 2 years period is about 0.2 . 


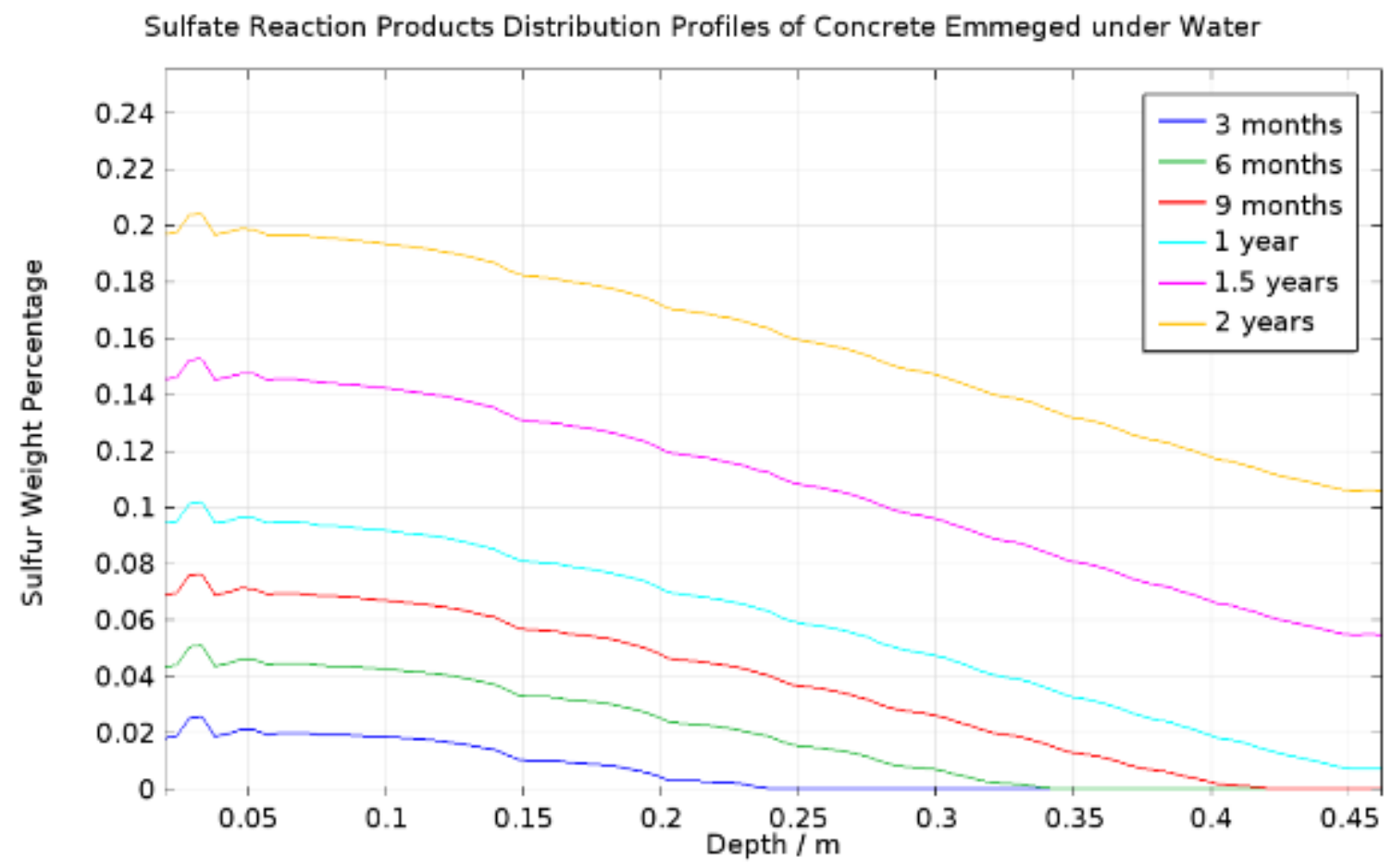

FIGURE 4.14. Sulfate reaction products content in form of sulfur weight percentage distribution at different period

\subsubsection{Stage II short term unsaturated liquid migration of bulk concrete}

The research at this stage mainly focuses on the short-term water penetration at water level. The effect of gravity is not considered in this problem, due to the short distance capillary absorption.

A two-dimensional FE model is used in this stage of study. As illustrated in Figure 4.15, the entire domain is discretized using 4-node quadrilateral elements, with the highest mesh density in the contact position with water. Progressively coarser mesh is used as we move away from the contact resulting in 1898 elements in the model. 


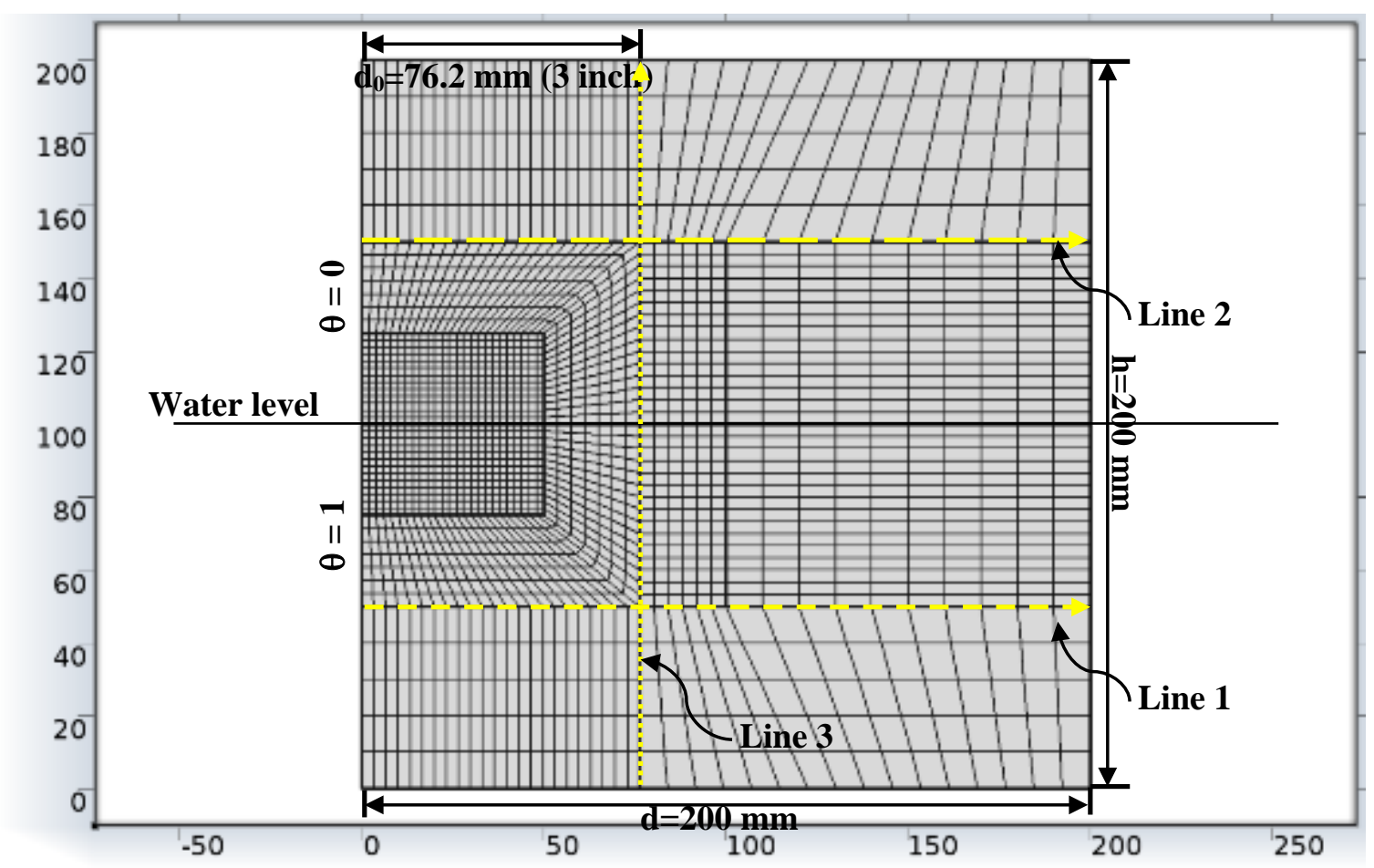

FIGURE 4.15. The FE model used in this study: specimen size, discretization scheme and boundary conditions

3 lines are preset for analysis, which is $50 \mathrm{~mm}$ under water level, $50 \mathrm{~mm}$ above water level, and at the distance of 3 inch to concrete surface. A total of 28 days (4 weeks) analysis has been done to this problem to simulate the short-term water transport at the very beginning of pile installation. The same material properties are used as in stage I.

Figure 4.16 to Figure 4.19 shows the results of water content profiles of the whole domain at 1 week to 4 weeks. It can be seen that water penetrates into concrete and spreading not only horizontally but also vertically. The wetting front could reach over $100 \mathrm{~mm}$ depth in only 3 weeks. In total of 4 weeks test period, the wetting front has reached as high as $60 \mathrm{~mm}$ above water level. Vertical water transit is proved to be nonneglected. For concrete under water level, the highest water content is at the surface and 
gradually decreases with depth. However, for concrete above water level, the highest water content is not at surface but at certain distance away from surface.

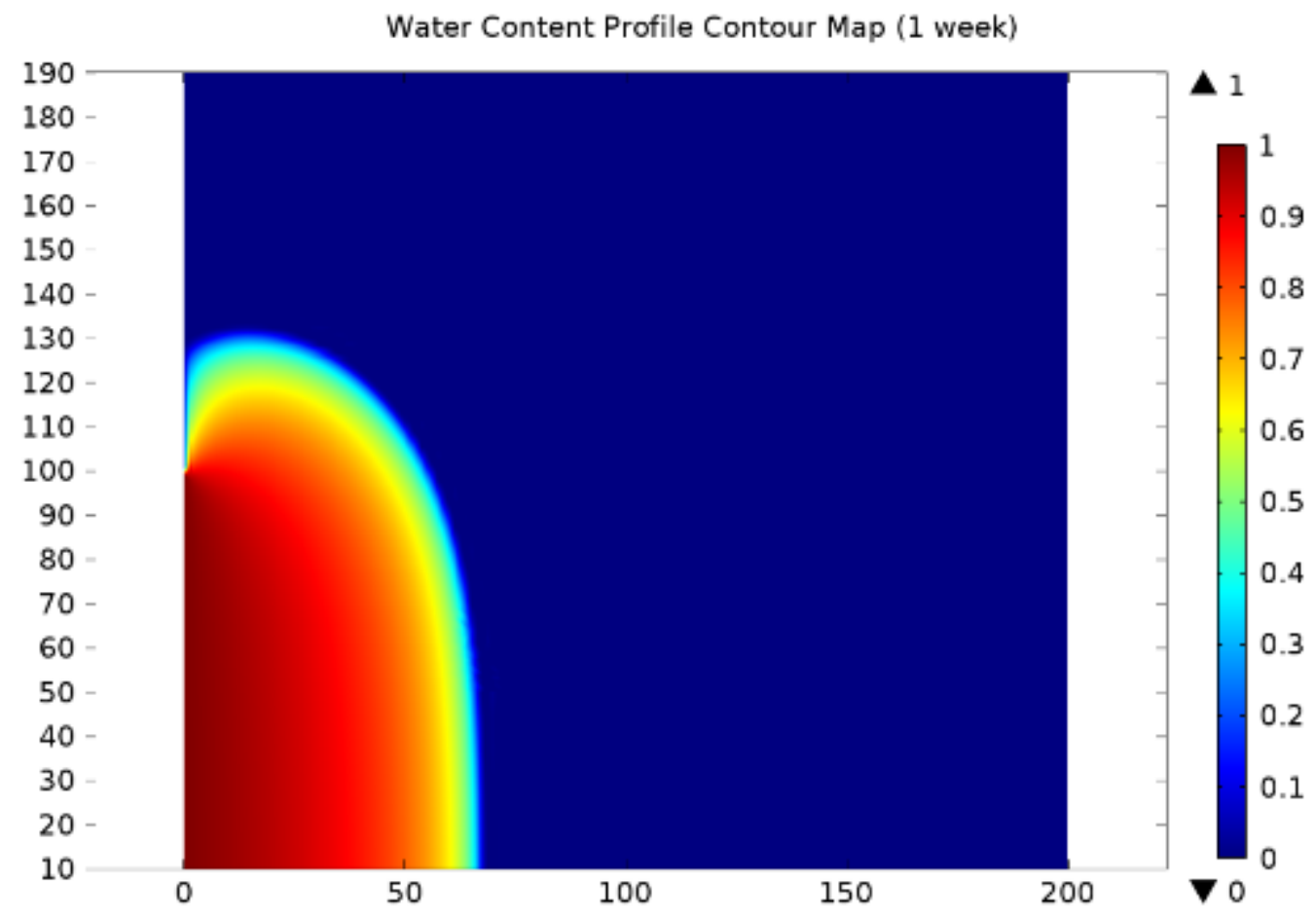

FIGURE 4.16. Water content profiles contour map of concrete half immerged in water for 1 week. 
Water Content Profile Contour Map (2 weeks)

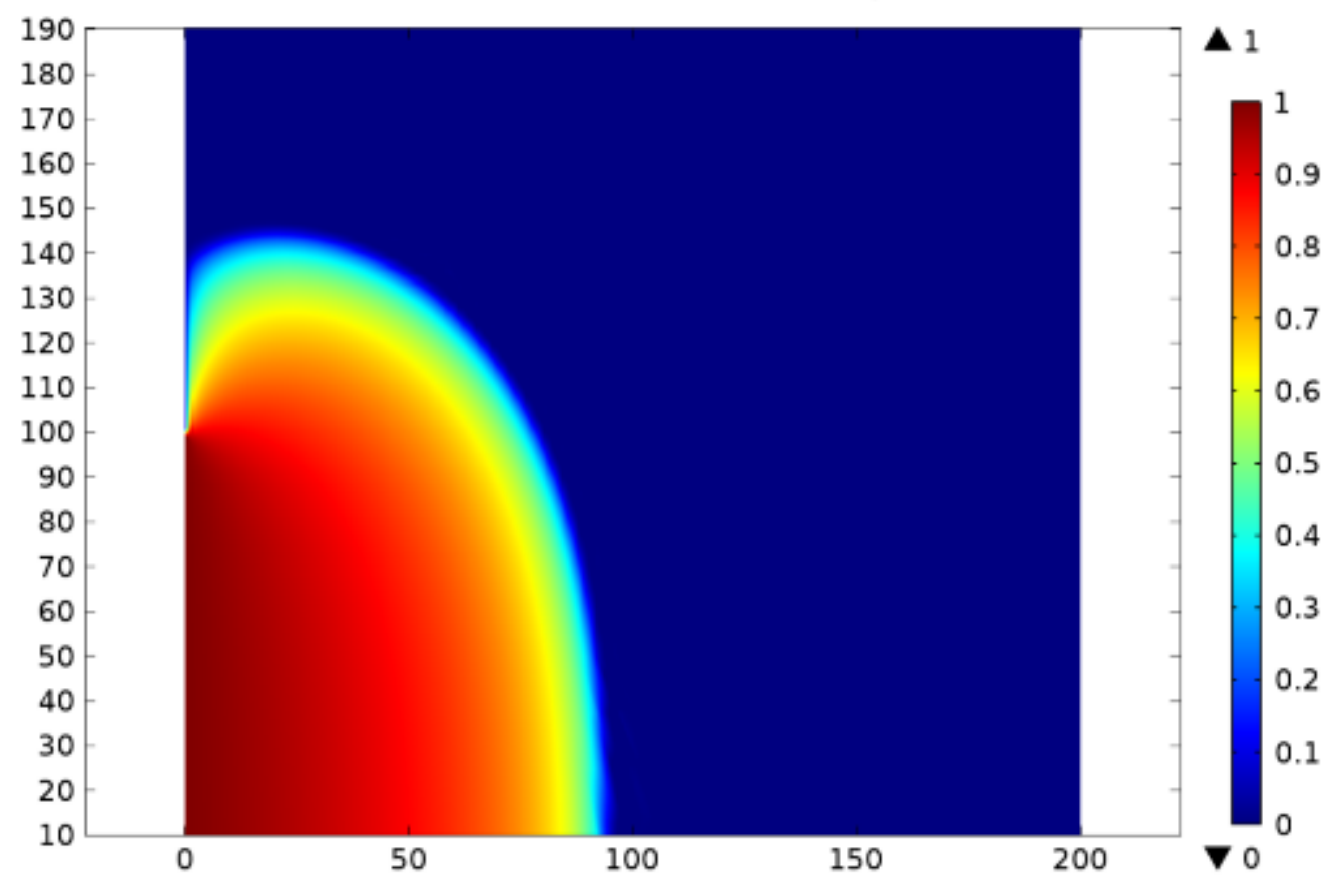

FIGURE 4.17. Water content profiles contour map of concrete half immerged in water for 2 weeks.

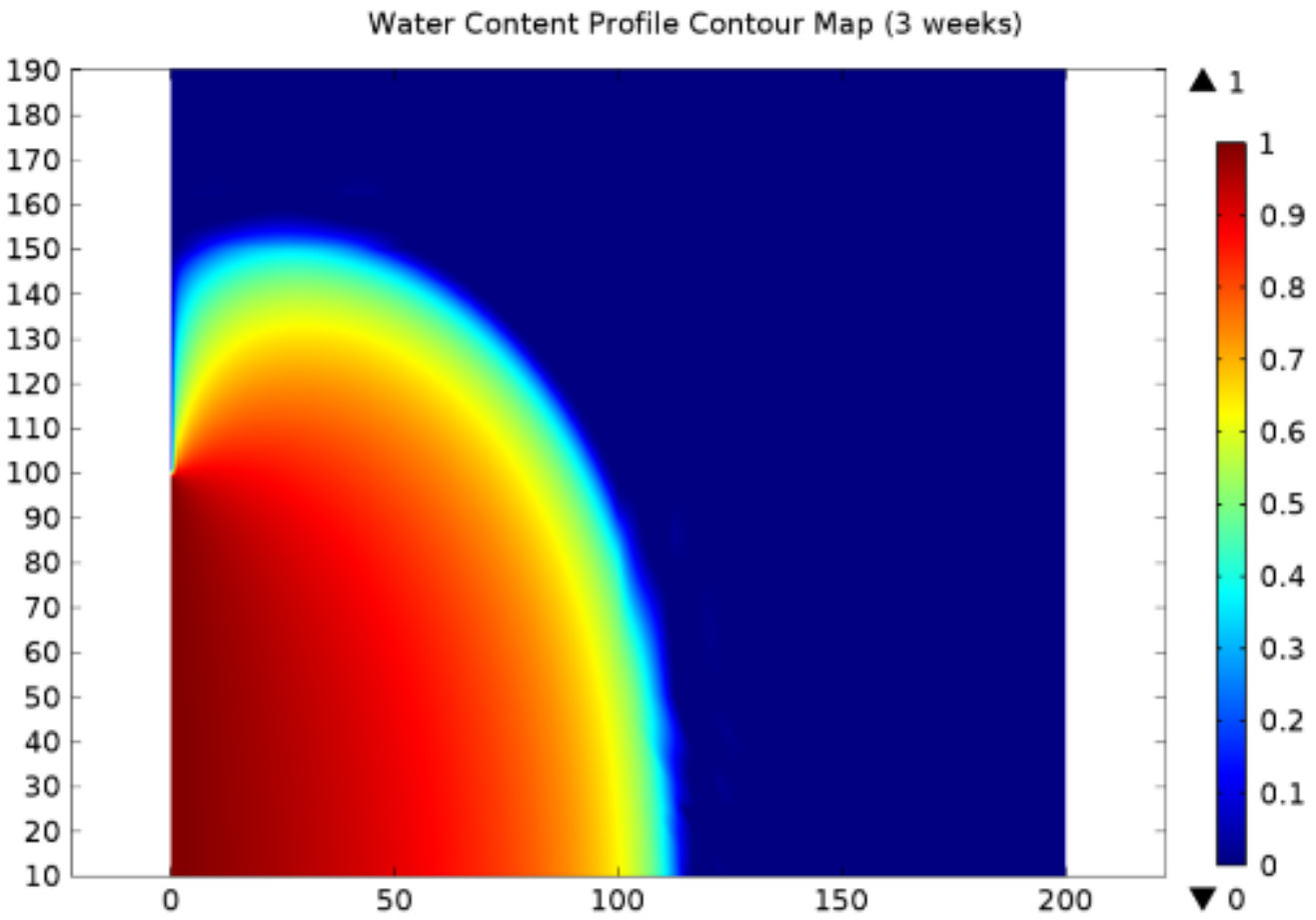

FIGURE 4.18. Water content profiles contour map of concrete half immerged in water for 3 weeks. 


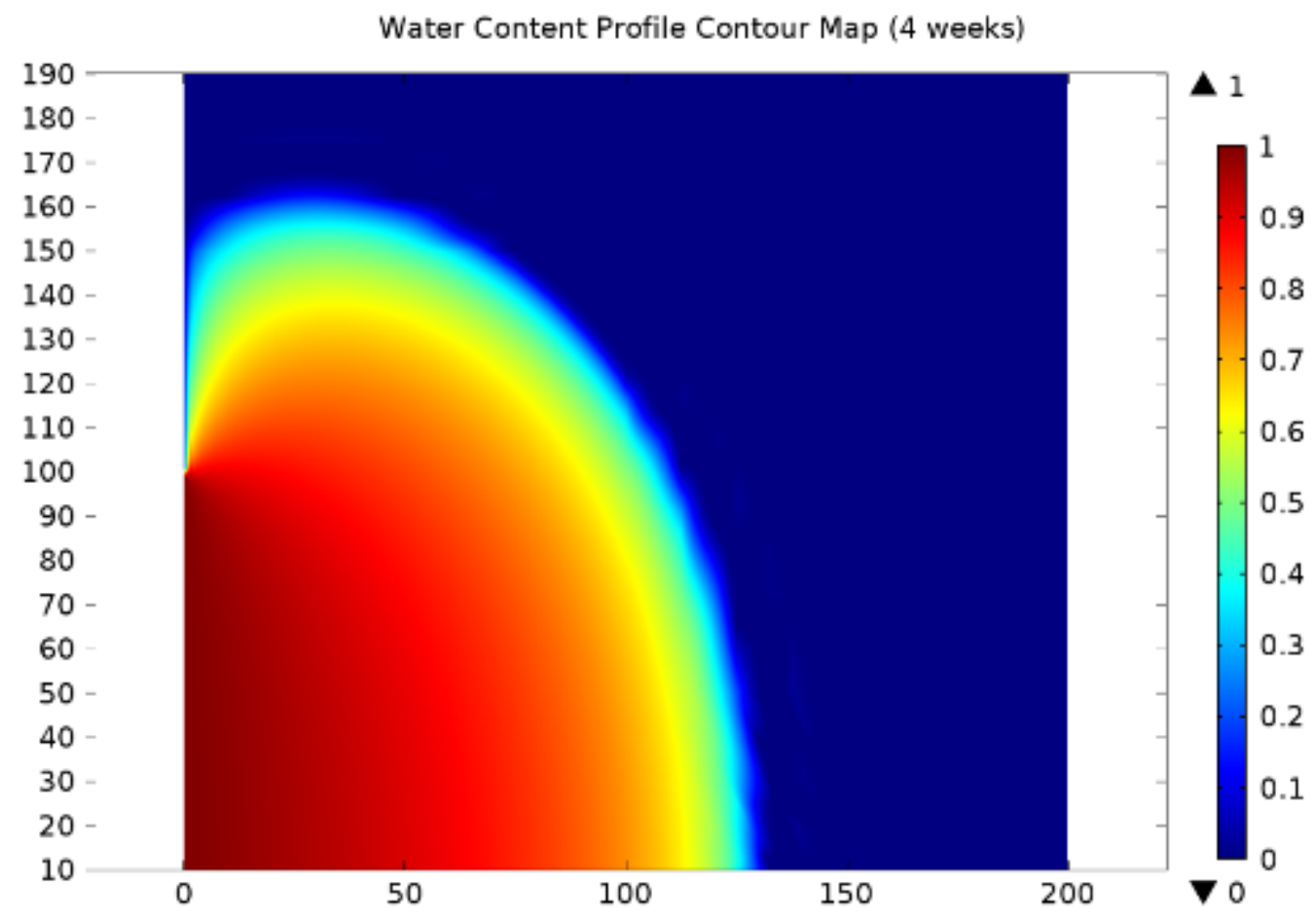

FIGURE 4.19. Water content profiles contour map of concrete half immerged in water for 4 weeks.

Water content profiles calculated at the 3 preset lines are illustrated in Figure 4.20 and Figure 4.21. For concrete at $50 \mathrm{~mm}$ above water level, pores are half filled with water at 4 weeks period. The highest water content appears to be at around 20 to $40 \mathrm{~mm}$ depth from surface depends on time. Wetting front reaches 3-inch distance after 1 week. Water content increases tremendously after reach wetting front. The increase slows down at 4 weeks after reach about 0.85 water content. But vertically, wetting front keeps climb up along 3-inch-depth line. 


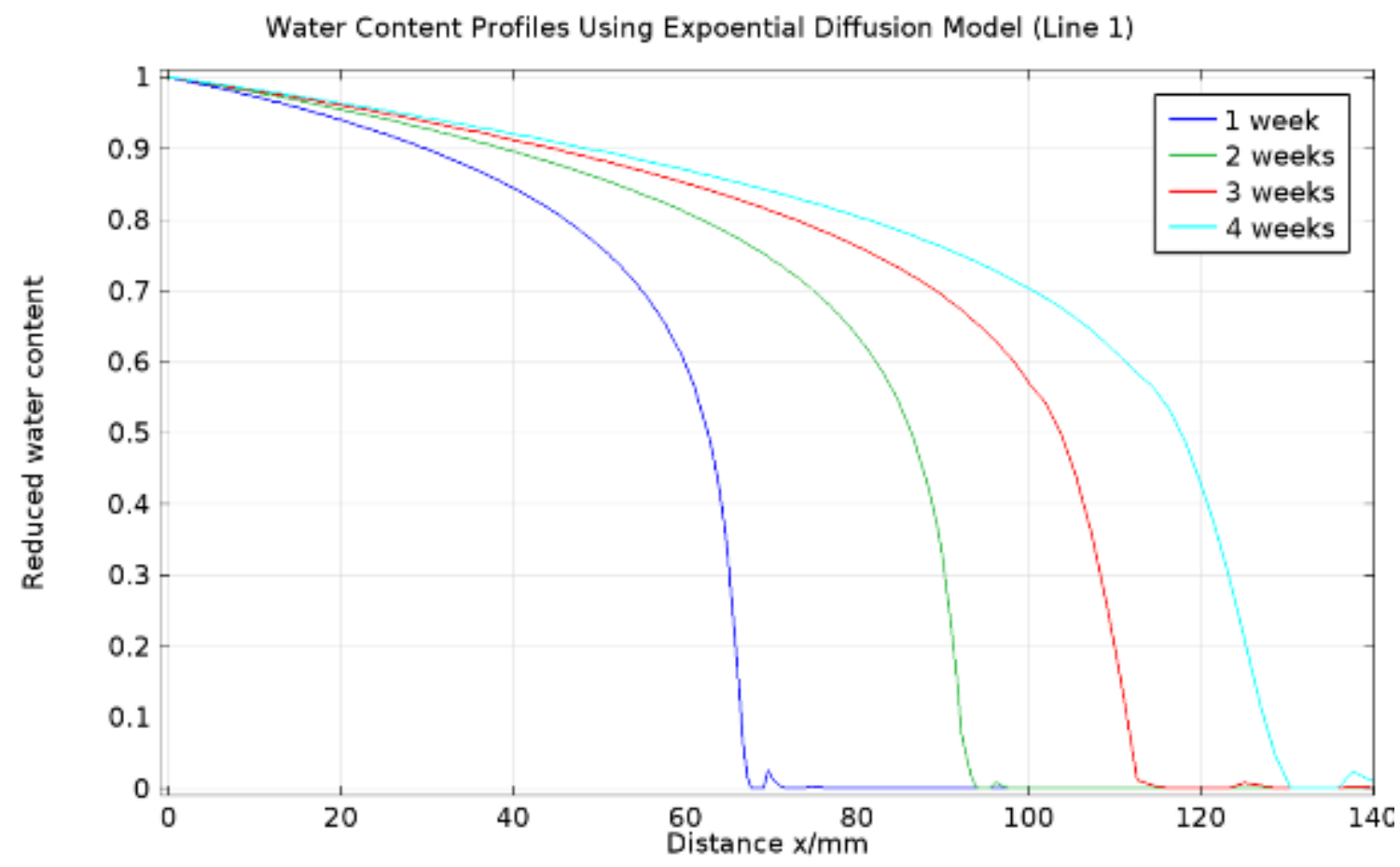

FIGURE 4.20. Water content profiles of concrete half immerged in water for a series of time. Measurements are taken at $50 \mathrm{~mm}$ under water level.

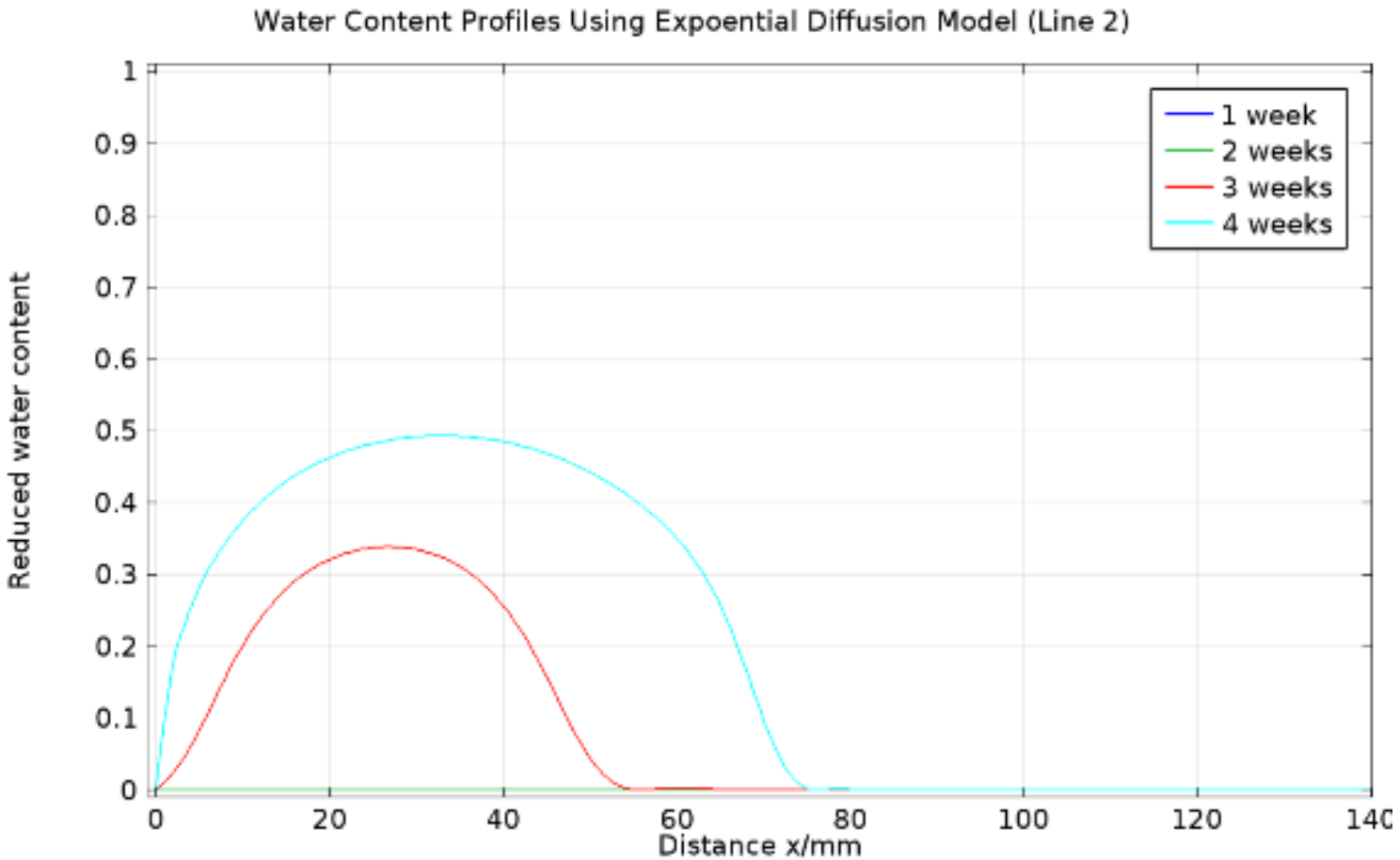

FIGURE 4.21. Water content profiles of concrete half immerged in water for a series of time. Measurements are taken at $50 \mathrm{~mm}$ above water level. 


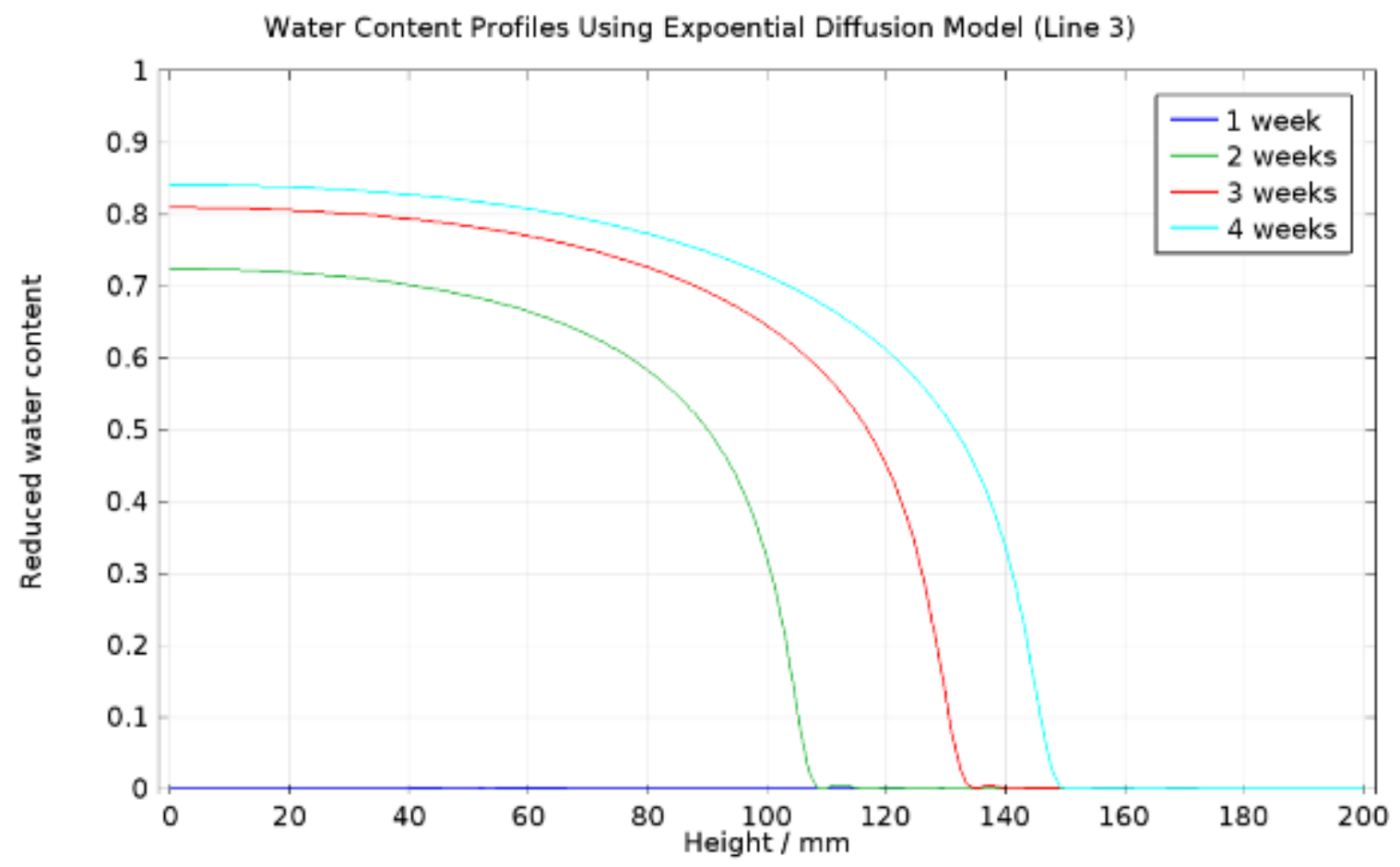

FIGURE 4.22. Water content profiles of concrete half immerged in water for a series of time. Measurements are taken at 3 inch depth from surface. Water level is at $100 \mathrm{~mm}$ height.

We assume the same condition as we did for stage I. Sulfate reaction products distribution is calculated and shown in Figure 4.23 and Figure 4.24. The maximum sulfur weight percentage of concrete at the end of 4 weeks period is 0.008 close to surface. At the depth of rebar, which is at 3 inch depth from the surface, sulfur weight percentage reaches 0.004 at the end of 4 weeks. For short term reaction, there is more sulfate reaction products produced below water level than above. 


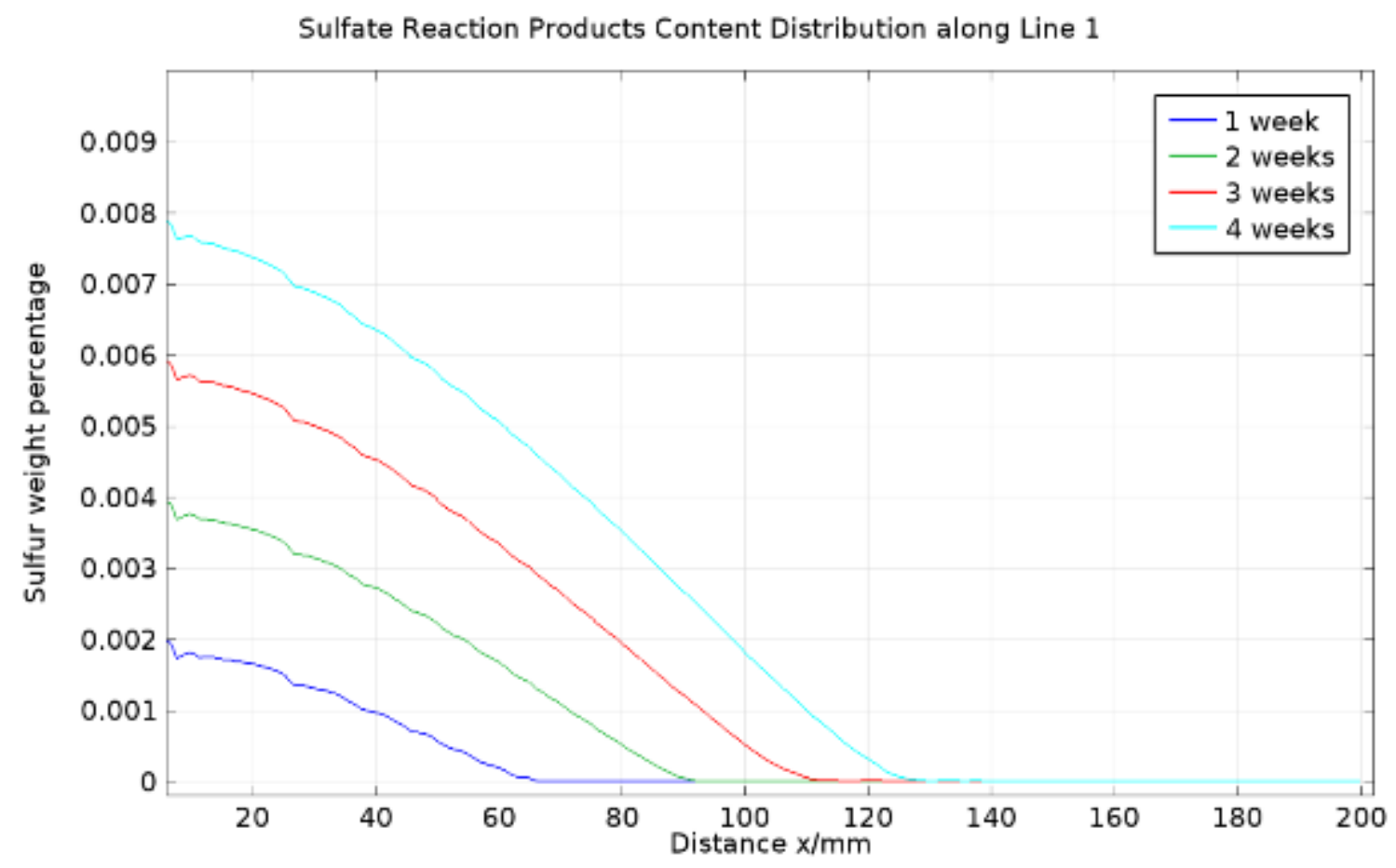

FIGURE 4.23. Sulfate reaction products distribution of concrete half immerged in water for a series of time at 3-inch below water level.

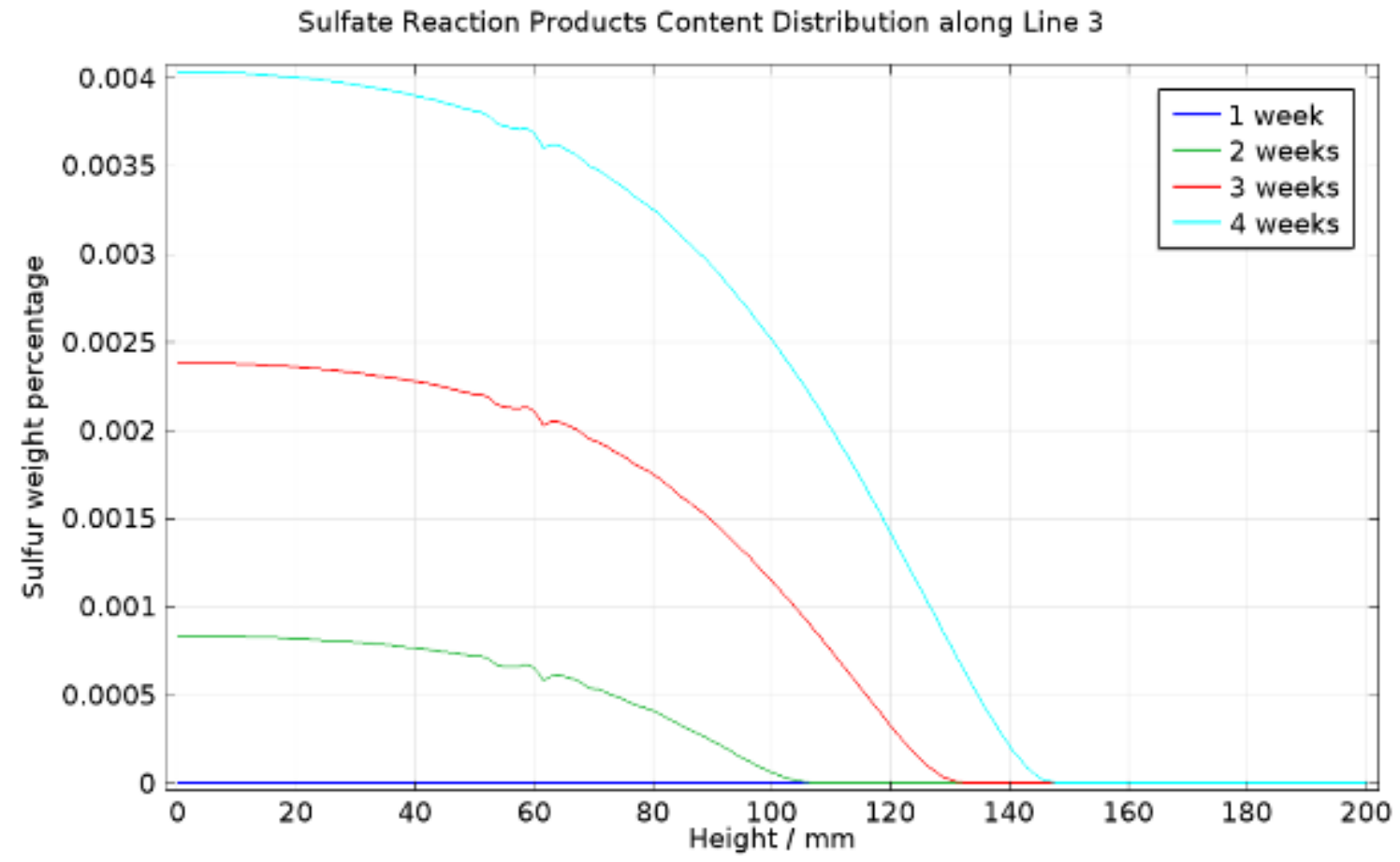

FIGURE 4.24. Sulfate reaction products distribution of concrete half immerged in water for a series of time at 3-inch depth from surface. Water level is at $100 \mathrm{~mm}$ height. 


\subsubsection{Stage III long term unsaturated liquid migration of bulk concrete}

For long term liquid migration, effect of gravity must be taken into consideration. Therefore, the governing equation of the model in Stage III is:

$$
\frac{\partial \theta}{\partial \mathrm{t}}=\nabla(D \nabla \theta)+\frac{\mathrm{dK}}{\mathrm{d} \theta} \frac{\partial \theta}{\partial \mathrm{z}}
$$

The same concrete properties as the last two stages are used and conductivity of moist cured high strength concrete from Table 4-3 is used in this Stage.

A two-dimensional FE model is used in this stage of study. As illustrated in Figure 4.25. the entire domain is discretized using 4-node quadrilateral elements, with the highest mesh density in the contact position with water. Progressively coarser mesh is used as we move away from the contact resulting in 1626 elements in the model.

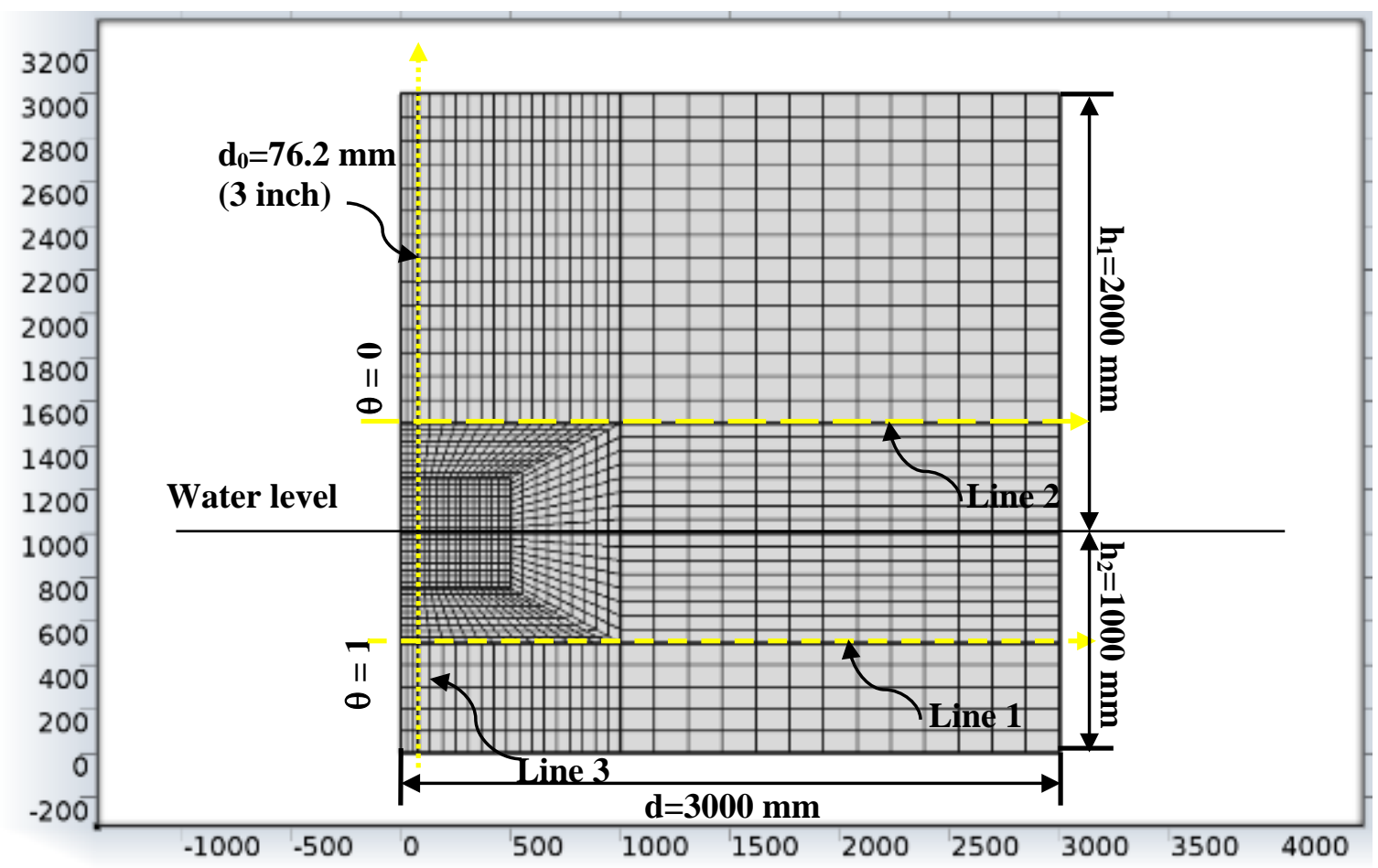

FIGURE 4.25. The FE model used in this study: specimen size, discretization scheme and boundary conditions 
Although we mostly concentrate on the penetration from one side of boundaries, saturated water boundary conditions have been still applied on both side of the model to ensure saturated condition at the center when long-term analysis is taken into consideration. Width of concrete is set up to ensure enough migration distance. There is not much different in terms of near-surface water content conditions for concrete with different widths.

75 years analysis has been done to this model. Environmental conditions are as same as Stage II, which is $1500 \mathrm{ppm}$ sulfate concentration with $\mathrm{pH}$ under 6.5.

The water content profiles contour map of the domain is illustrated in Figure 4.26 through Figure 4.29. Results show that water has tremendous vertical migration even when gravity effect is taken into consideration. Water is absorbed into concrete and transport through concrete under capillary pressure. At the end of 50 years surrounding by such environmental condition, water migration wetting front has reached as high as $1800 \mathrm{~mm}$ above water level. 
Water Content Profiles Contour Map (10 years)

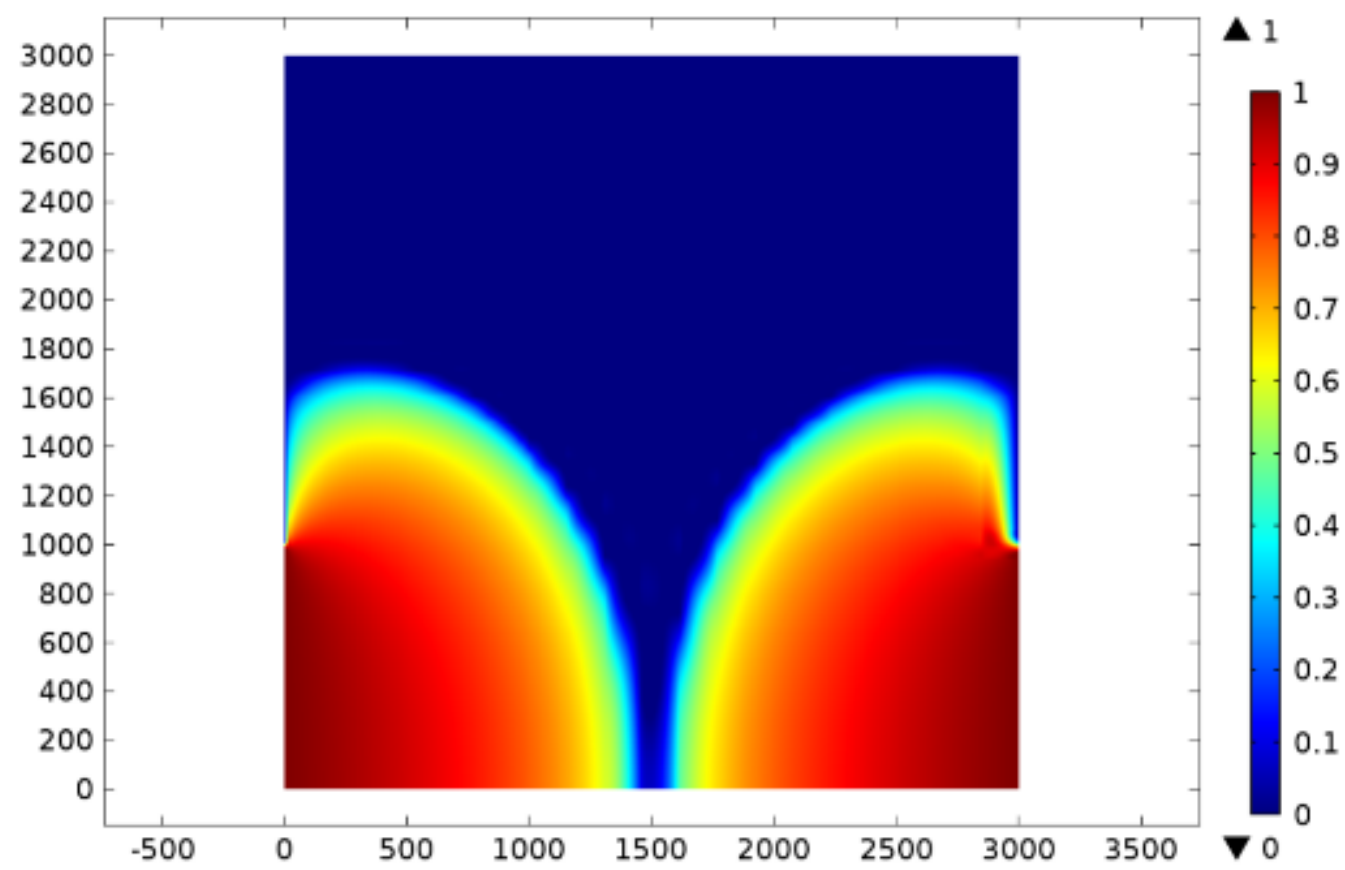

FIGURE 4.26. The water content profiles contour map of research domain at the end of 10 years. Analysis concentrates on the left side of domain.

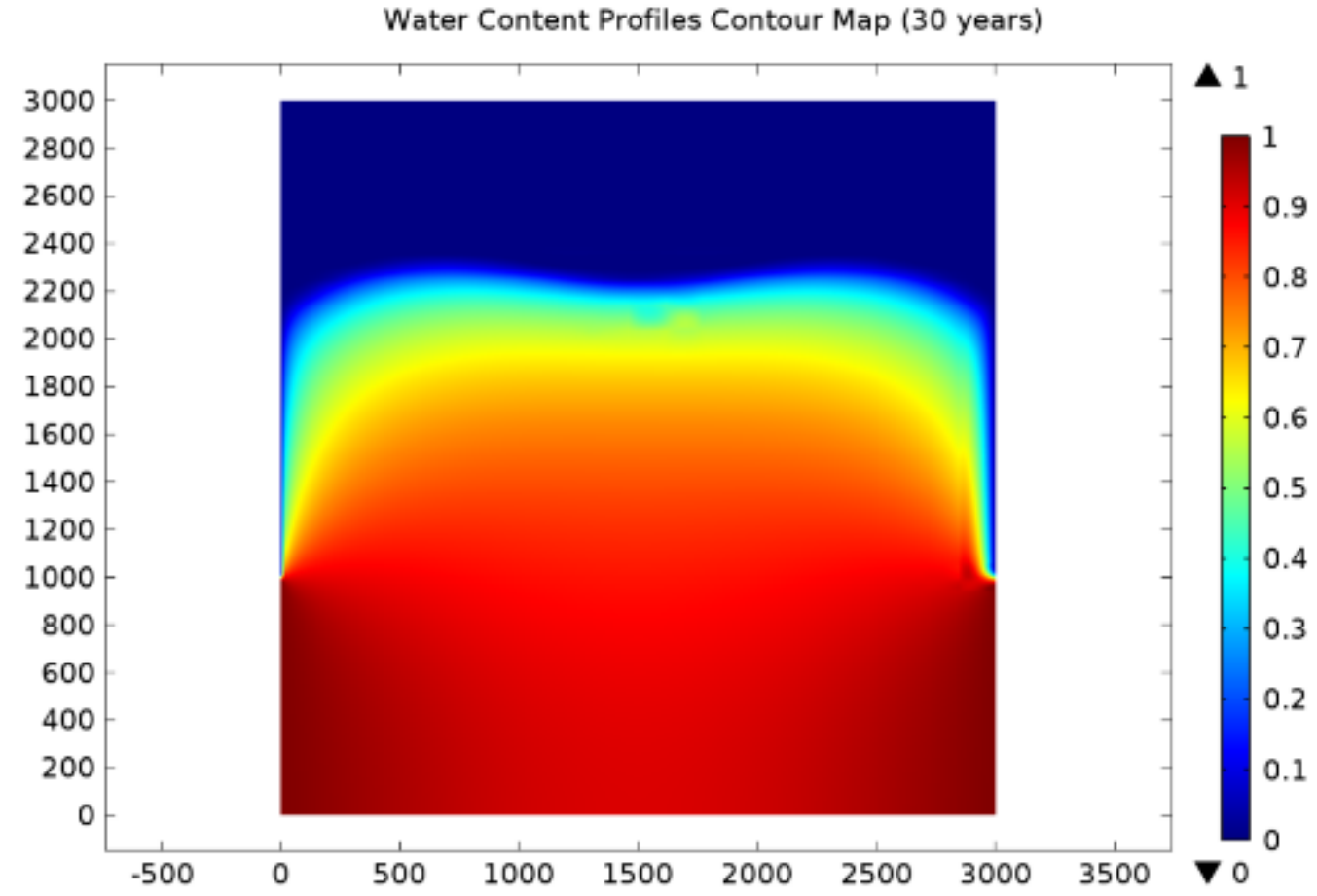

FIGURE 4.27. The water content profiles contour map of research domain at the end of 30 years. 
Water Content Profiles Contour Map (50 years)

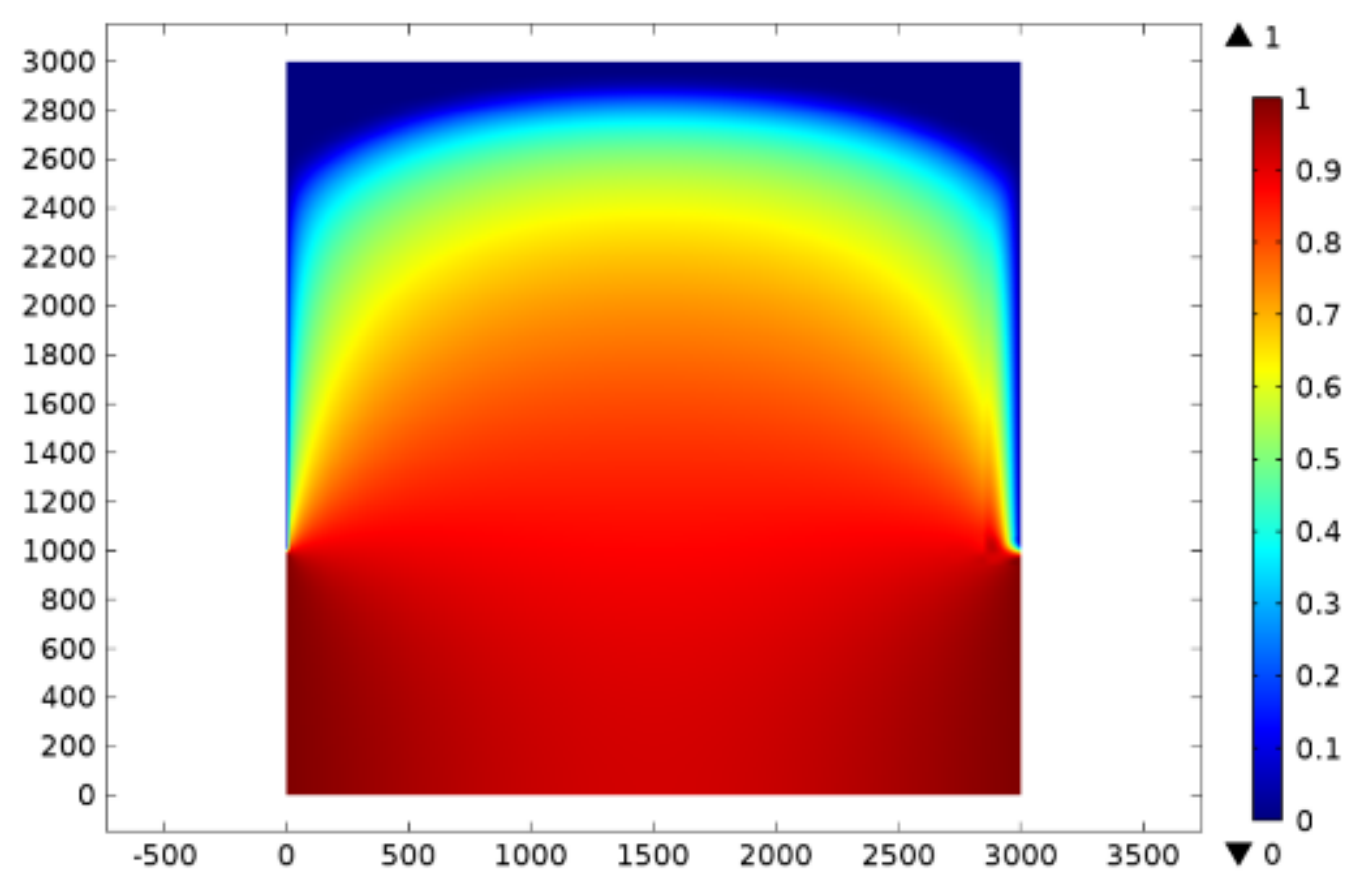

FIGURE 4.28. The water content profiles contour map of research domain at the end of 30 years.

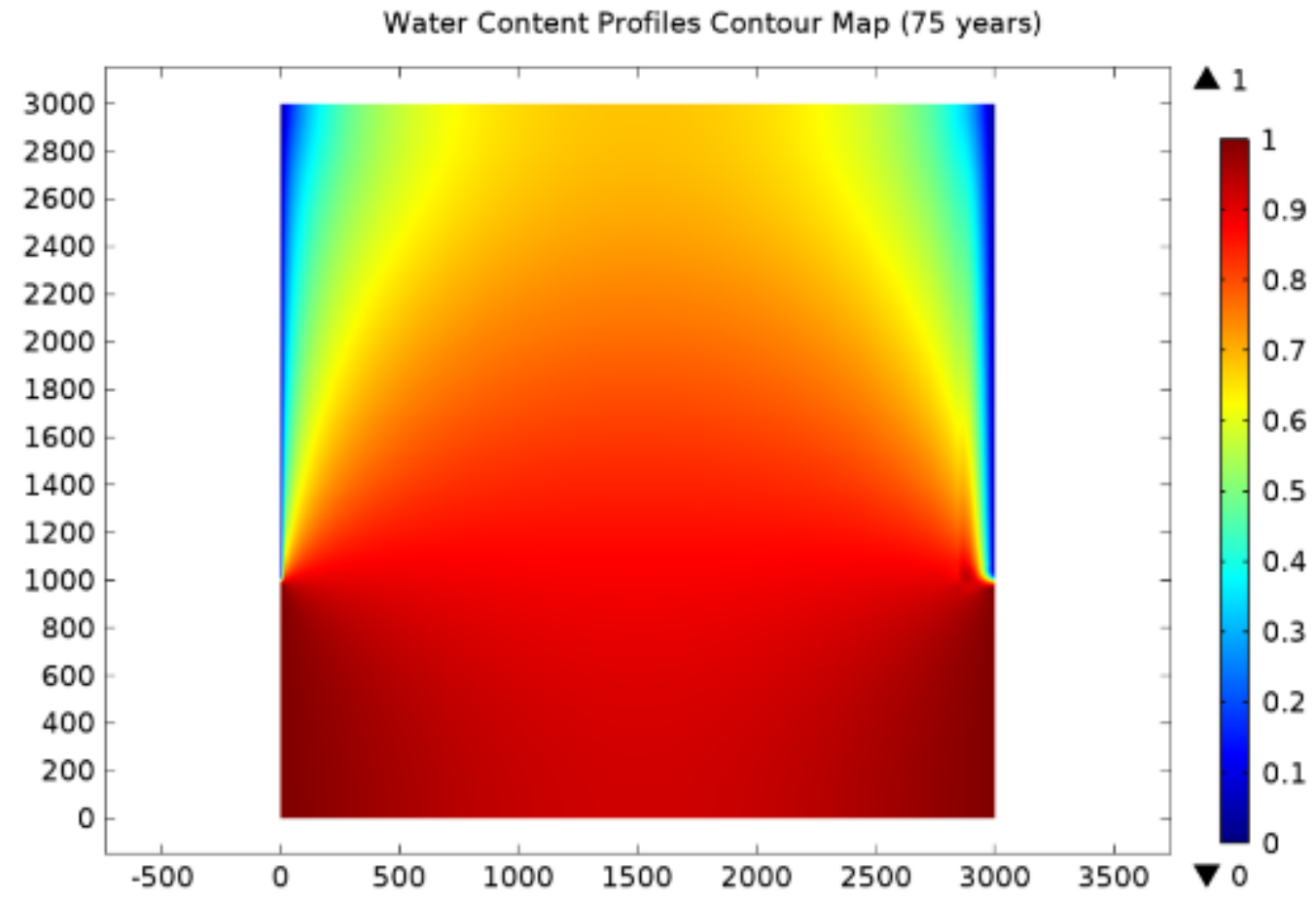

FIGURE 4.29. The water content profiles contour map of research domain at the end of 30 years. 
Line 1 is $500 \mathrm{~mm}$ under water level. The water content profile is illustrated in Figure 4.26 for 10 years, 30 years, 50 years, and 75 years. Water penetrates into concrete as deep as $1400 \mathrm{~mm}$ at the end of 10 years, if it's possible. During water penetration, sulfate begins reaction and results of reaction productions more close to surface and gradually reduced while move inside. For concrete above water level. Sulfate content is limited on the surface and increases while move inside. This result matches the findings of in-service concrete bridge piles.

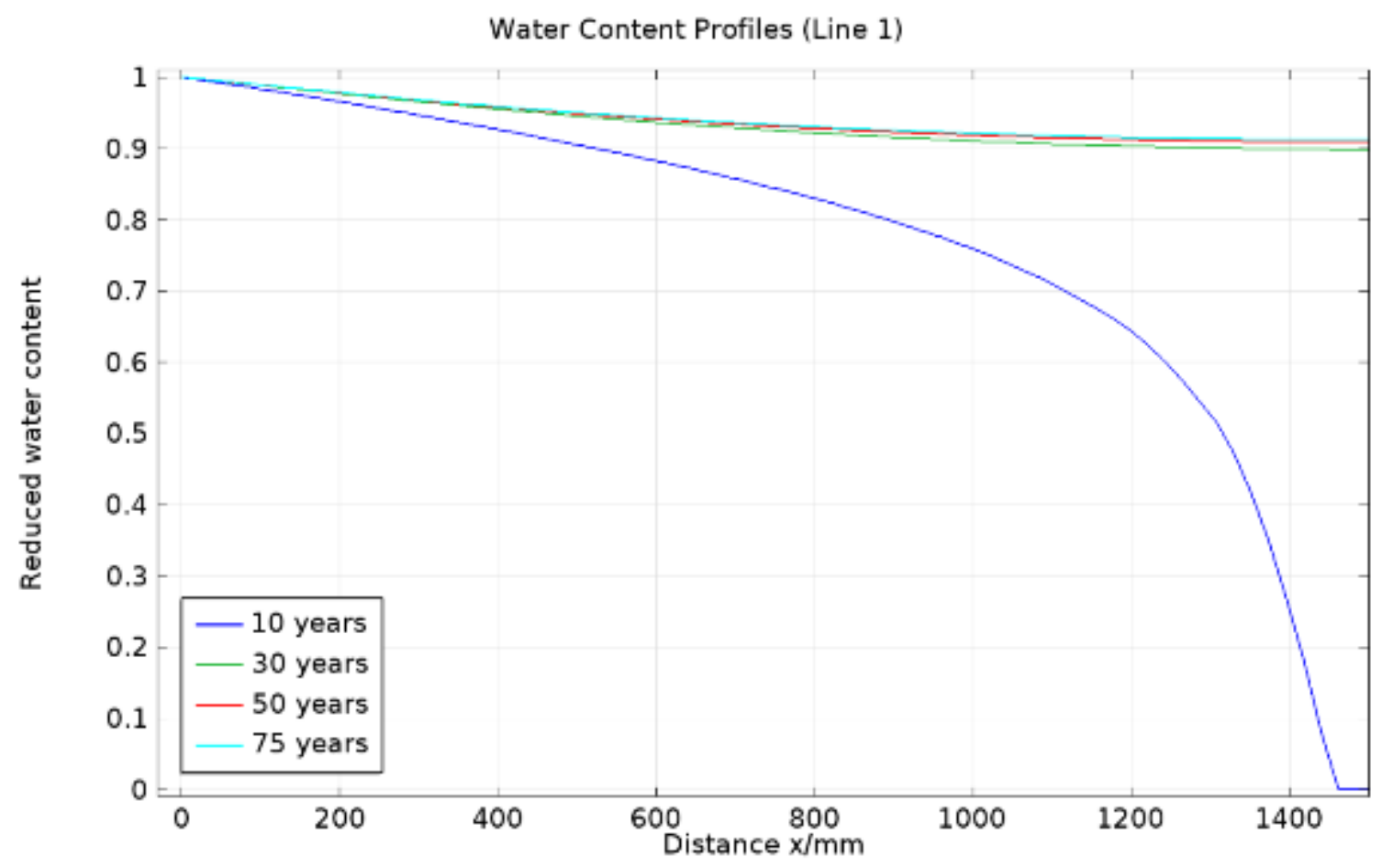

FIGURE 4.30. Reduced water content profiles along line 1,500 mm under water level at different time period 


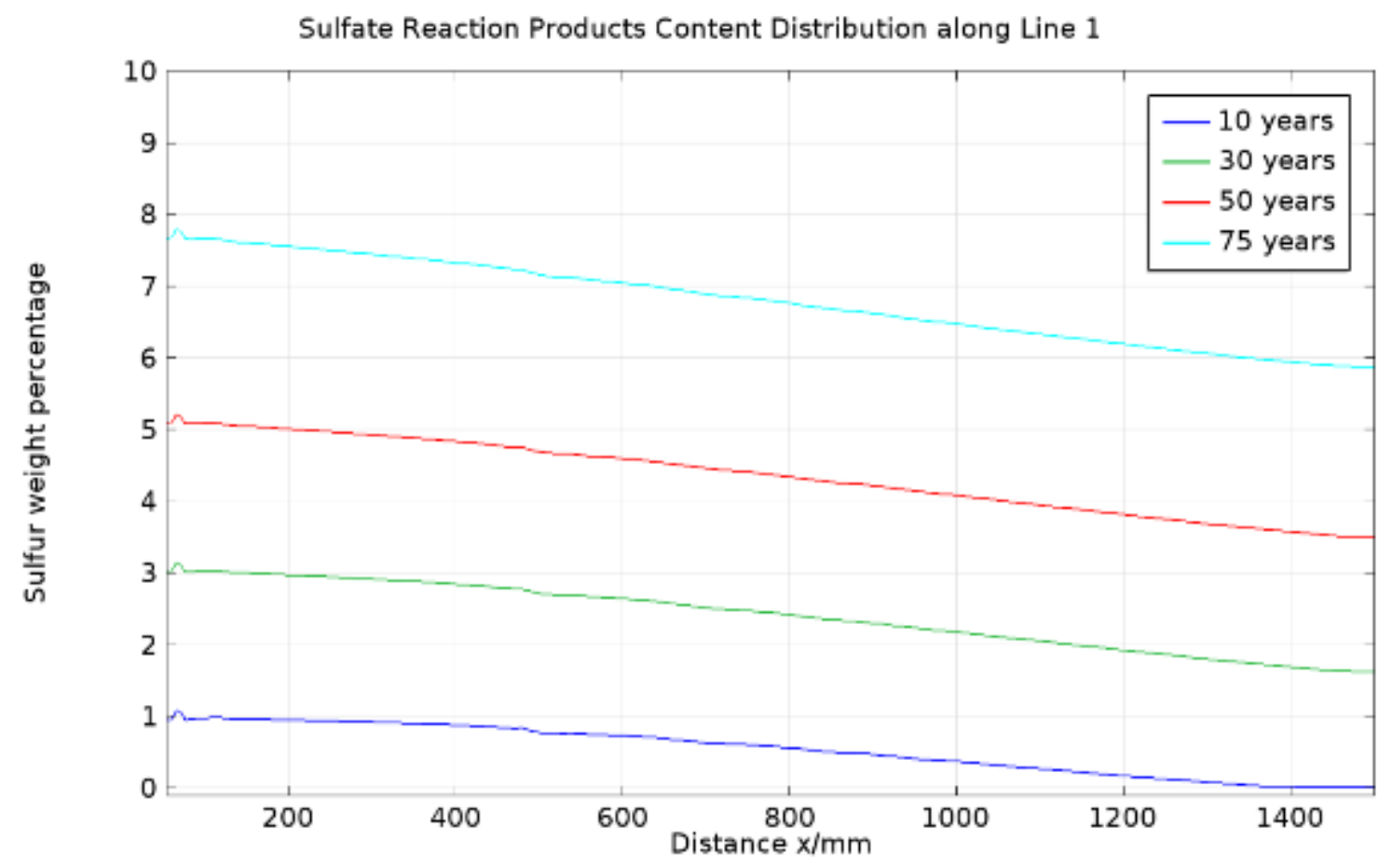

FIGURE 4.31. Sulfur weight percentage along line 1,500 $\mathrm{mm}$ under water level at different time period.

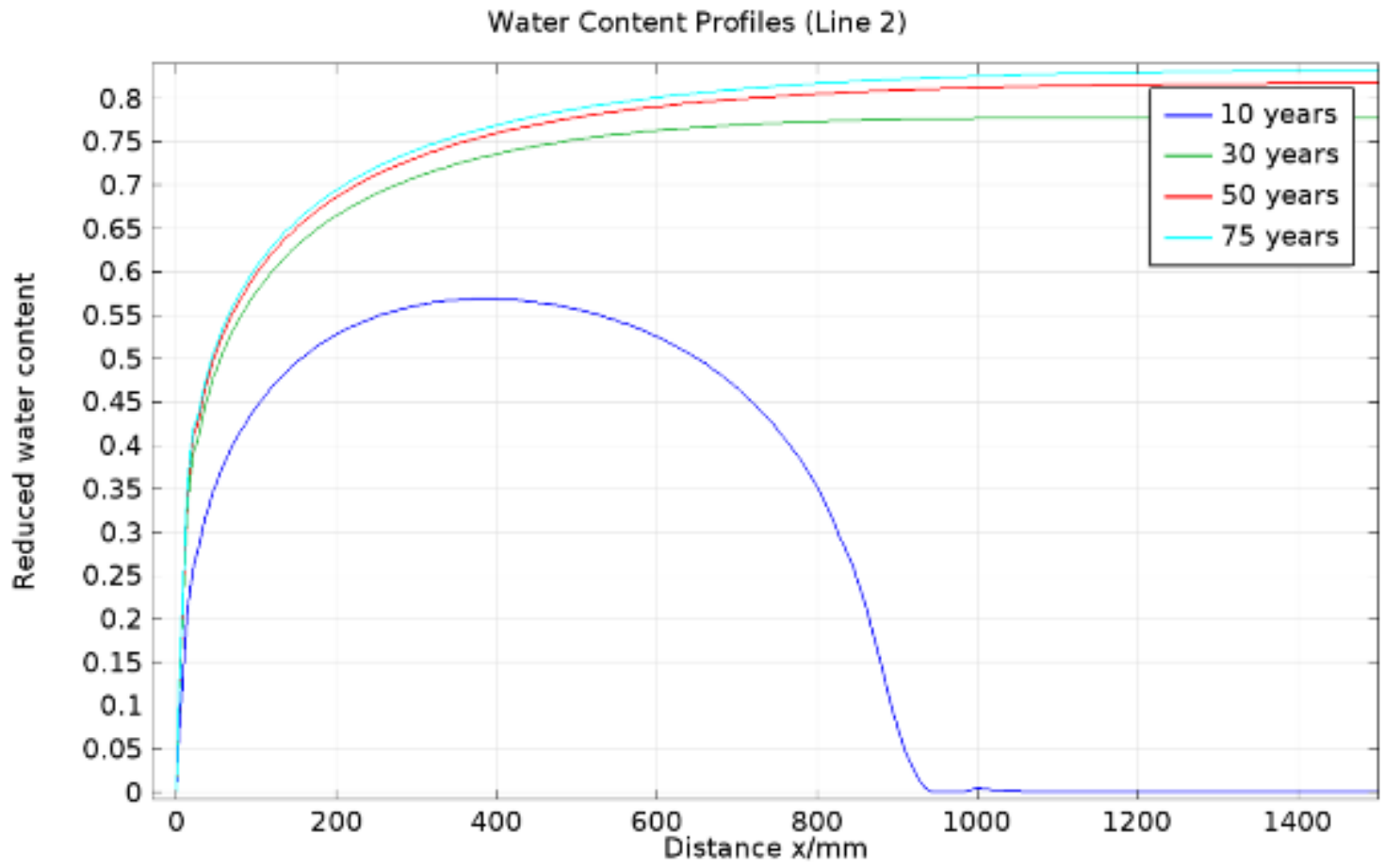

FIGURE 4.32. Reduced water content along line 1,500 mm above water level at different time period. 
Sulfate Reaction Products Content Distribution along Line 2

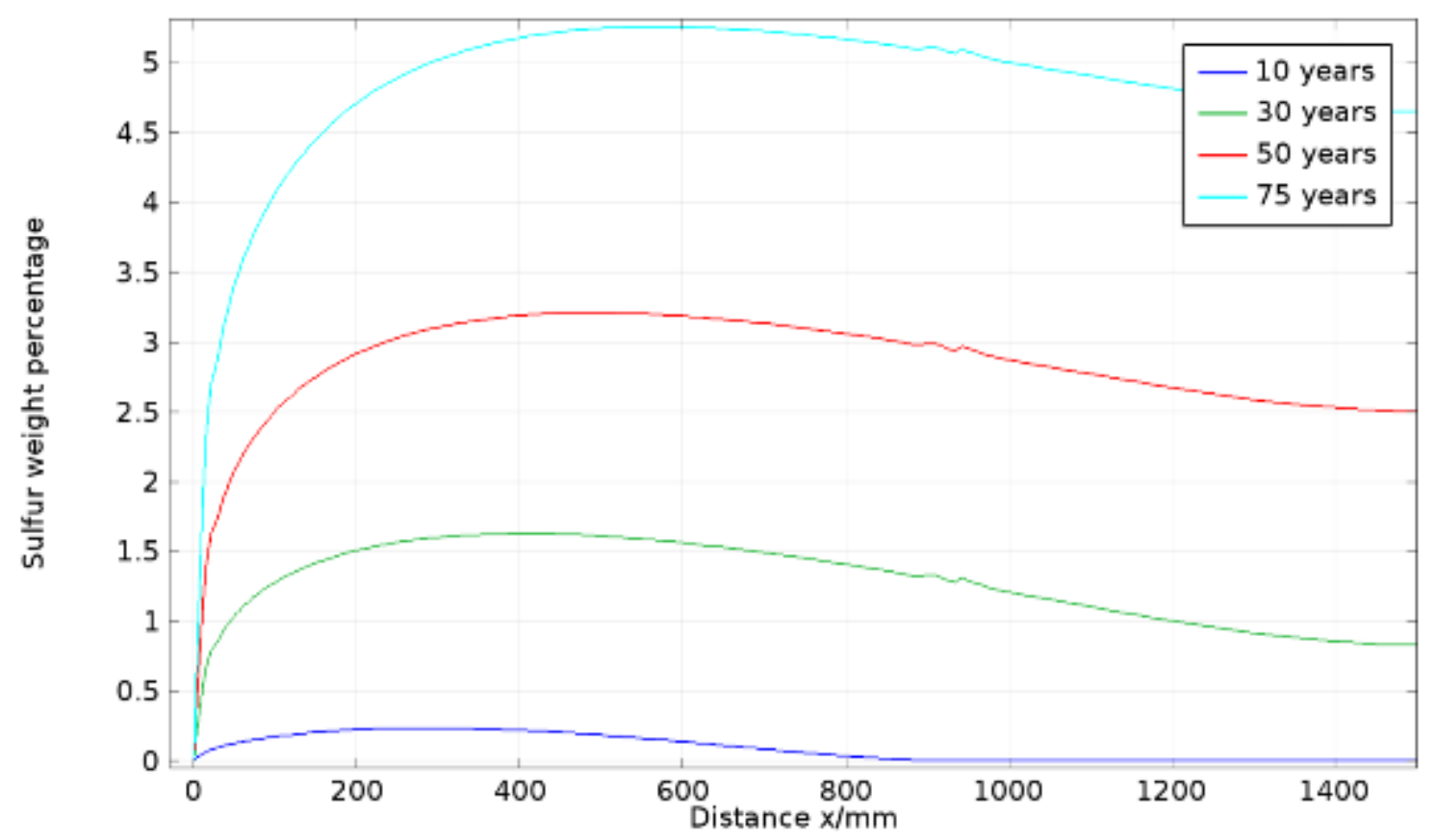

FIGURE 4.33. Sulfur weight percentage along line $1,500 \mathrm{~mm}$ above water level at different time period.

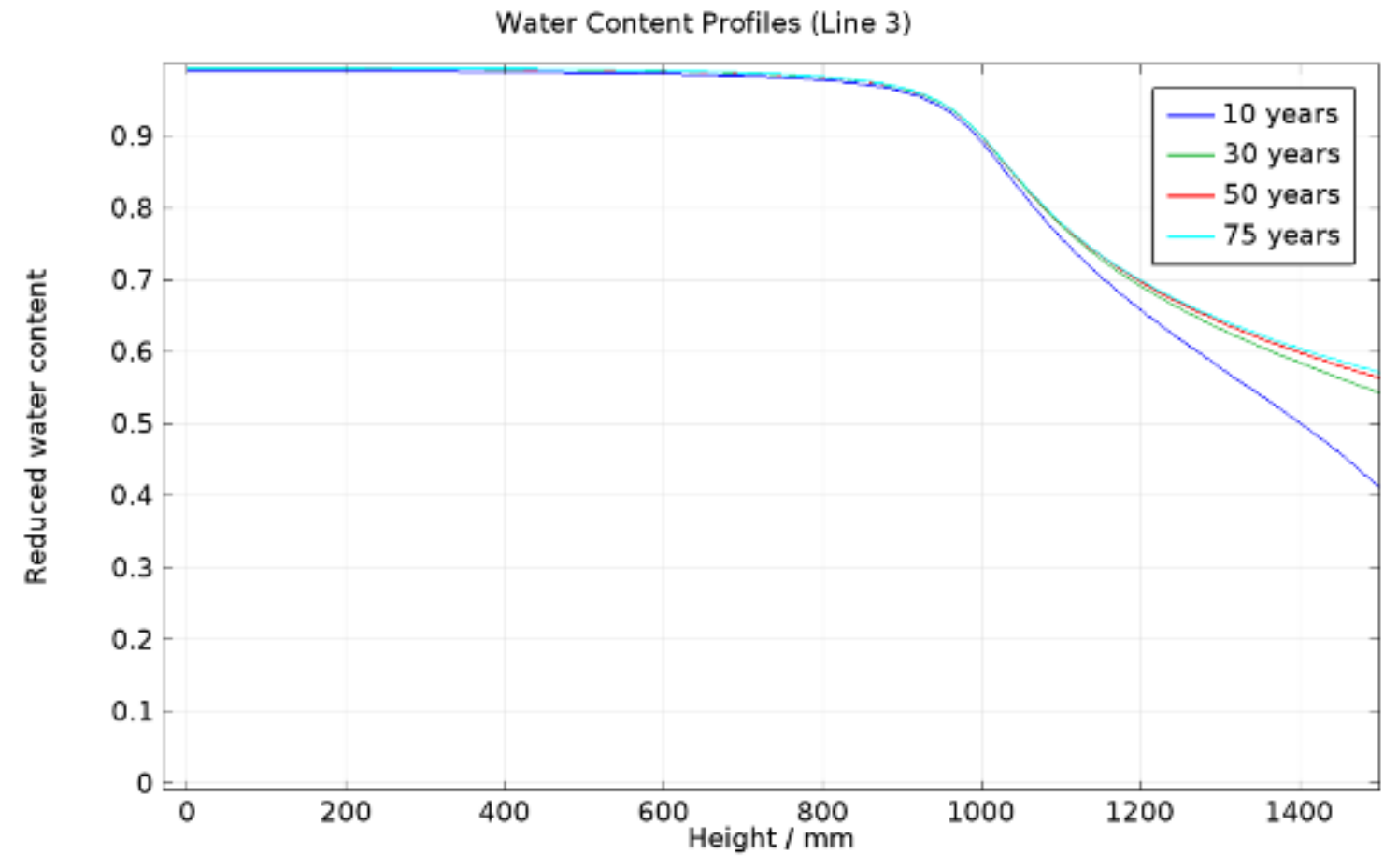

FIGURE 4.34. Reduced water content along line 3.3 inch depth from the surface at different time period. 


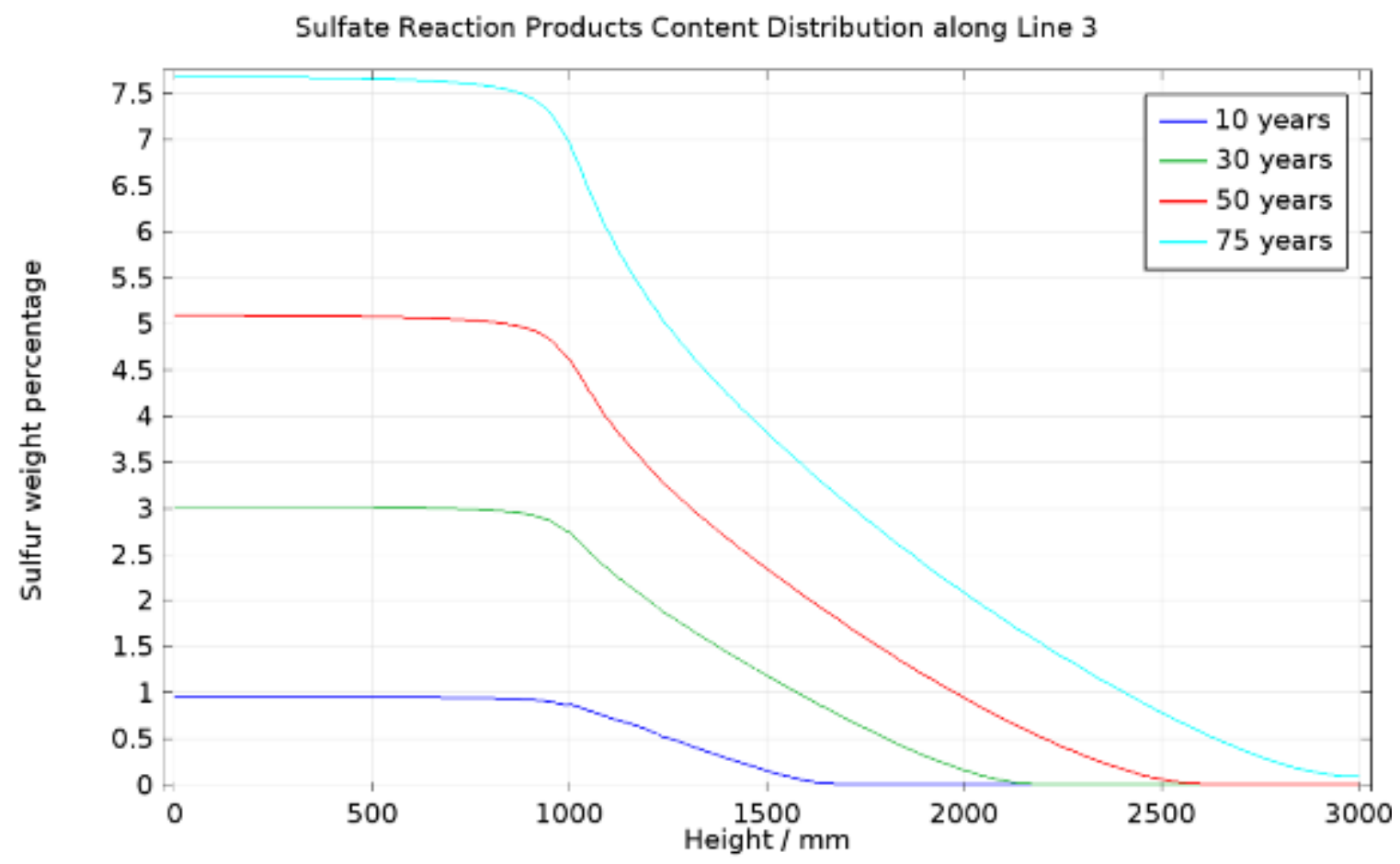

FIGURE 4.35. Sulfur weight percentage along line 3.3 inch depth from the surface at different time period.

\subsection{Comparative Study with In-Service Concrete Piles}

To simulate concrete bridge pile \# 490030, sulfate concentration is set to be 1417 ppm. The rest of parameters remain the same. FE model width is set to be 36 inches and give us about 2523 elements to calculate. Figure 4.36 shows the picture of concrete pile of bridge \#490030. 


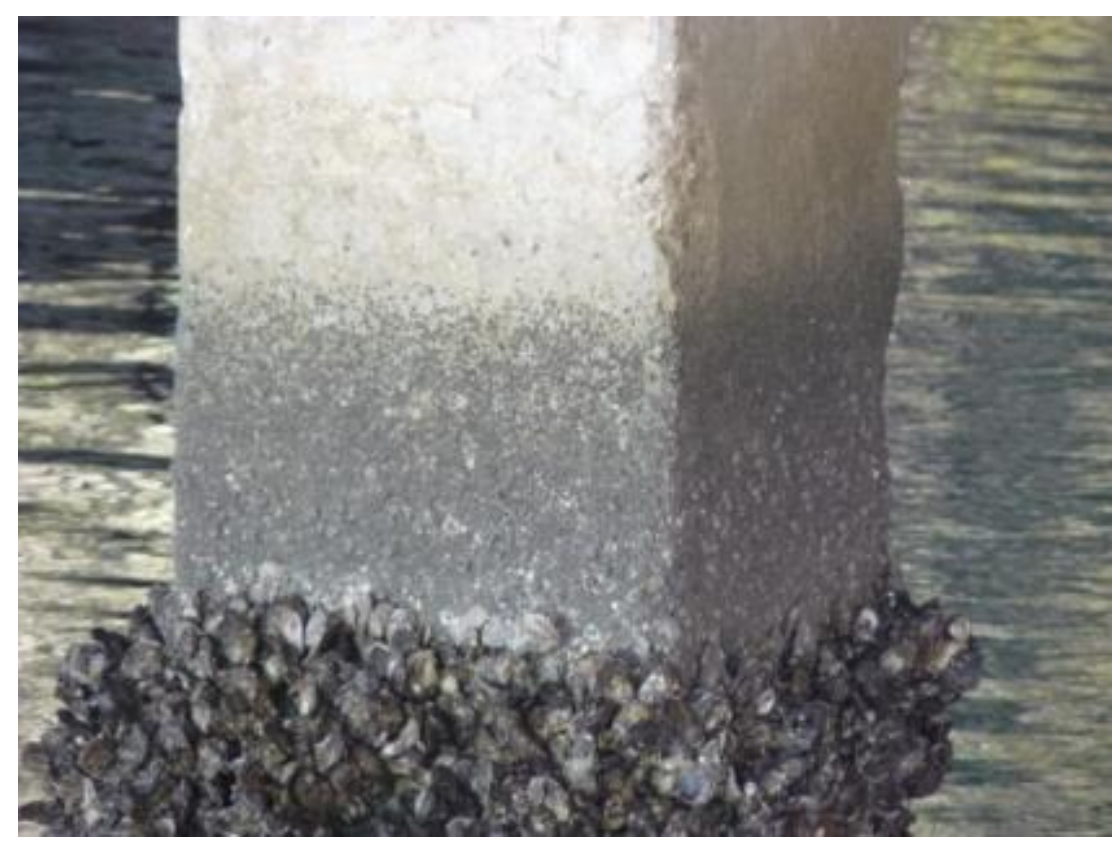

FIGURE 4.36. Bridge \#490030 on-site picture

Core samples are taken about 0.5 meter above water level. Concrete at the same level at core samples is taken for analysis in FE model. The calculation results are shown in Figure 4.37 at different time period from 10 years to 75 years. Figure 4.38 shows the findings of field inspection with compare of Finite Element Model. The results show that the results of FE model match field inspection results pretty well.

Because the water level movement is not taken into consideration in FE model, the sulfate concentration calculated near surface is not as conservative as inside concrete. 


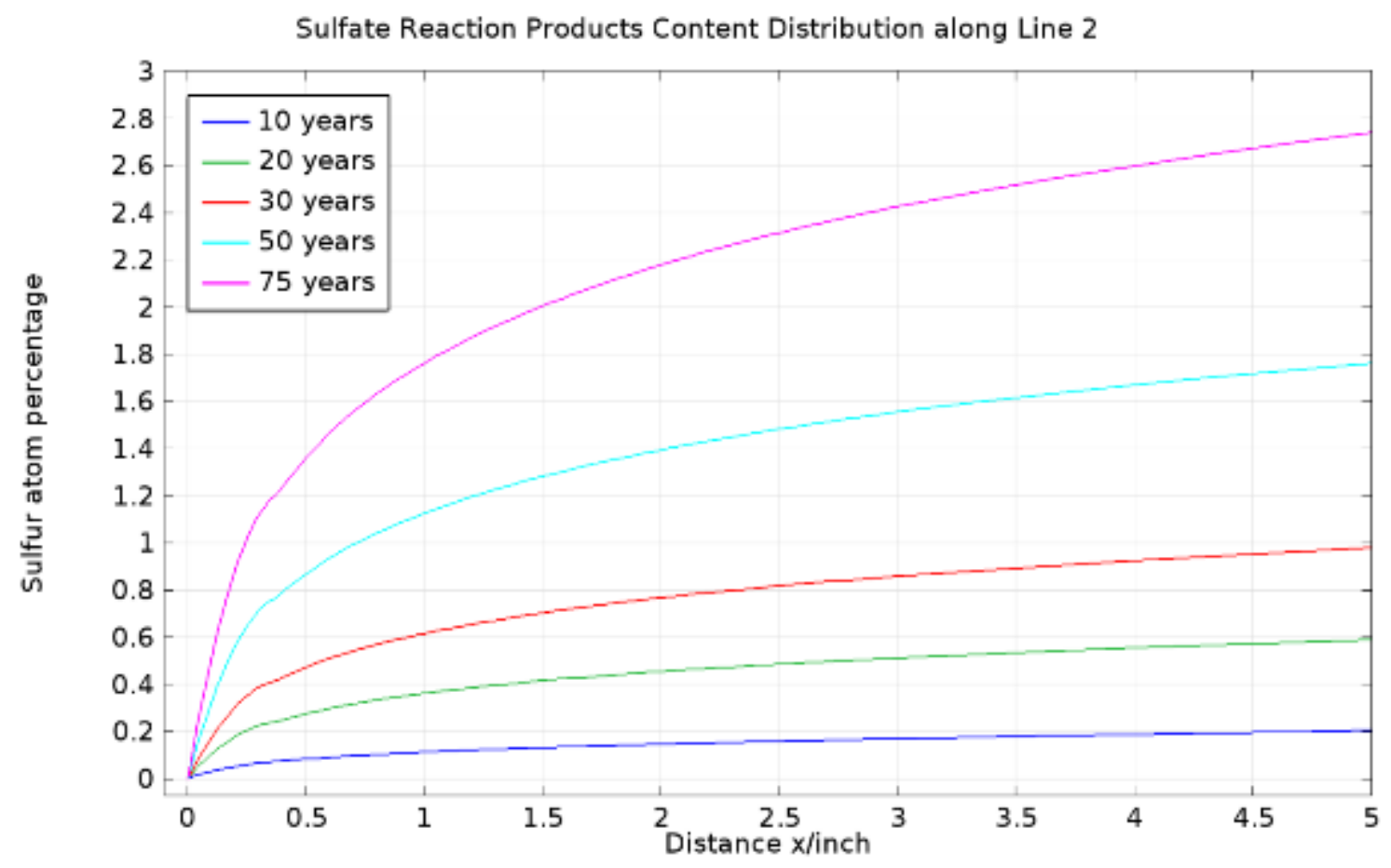

FIGURE 4.37. Sulfur atom percentage along line $2.500 \mathrm{~mm}$ above water level at different time period. Results come from Finite Element Model.

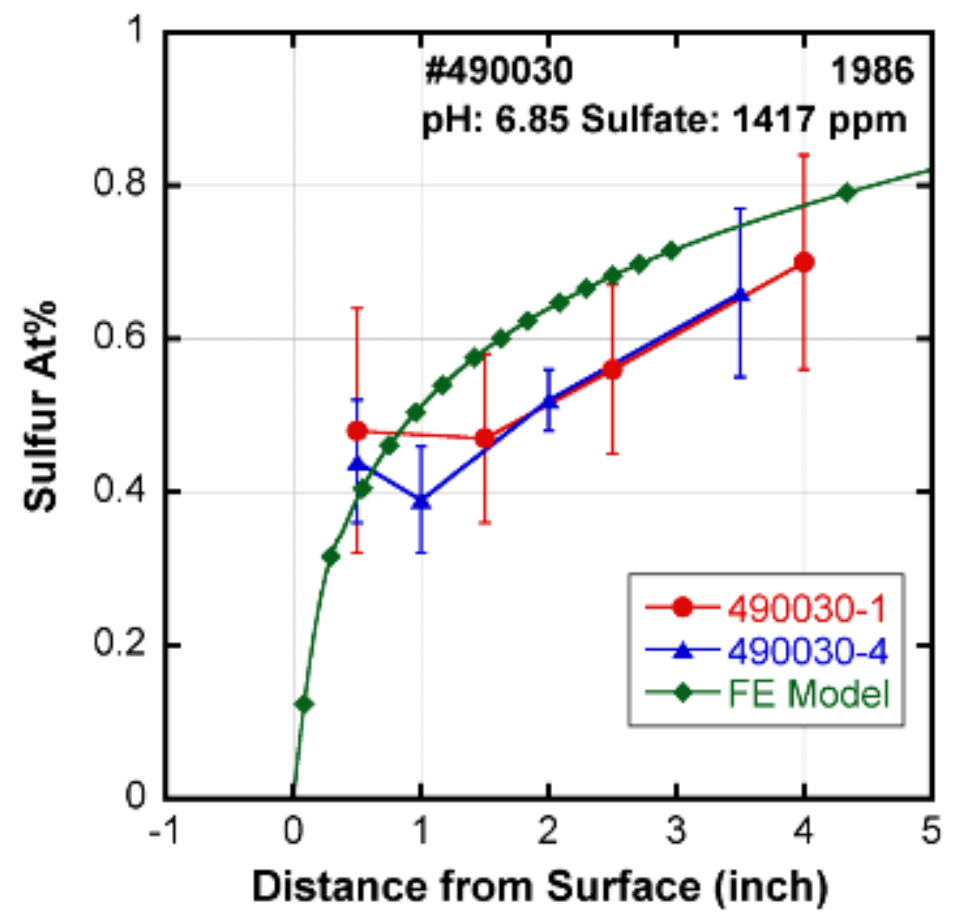

FIGURE 4.38. Compare on sulfur atom percentage between on-site exploration and FE model to a 27-year old bridge at $500 \mathrm{~mm}$ above water level. 


\subsection{Application Scopes and Limitations}

The FE model is based on several important assumptions and simplicities, which are:

1. Concrete pores are considered as connected pores that water can transport through due to the acid attack.

2. Cement particles and surrounding sulfate ions reaction reactants are considered to be unlimited.

3. Calcium is considered to be restricted within concrete instead of leaching out under acid attack.

4. Sulfate accumulation due to Stage I drying is not considered because there is no water level change considered in FE model.

5. Concrete bulk weight change is neglected in FE model.

The Finite Element Model built in this research is based on sorptivity sulfate transport mechanism. It simplifies the sulfate penetration and reaction process as two basic steps:

1. Water penetrating as carrier of sulfate ions;

2. Sulfate reaction happens locally without consideration of ion diffusion.

Sulfate reaction rate is based on accelerated test in low $\mathrm{pH}$ and high sulfate environment. Therefore, it is necessary to verify targeted environmental condition before applying this FE model. Because the transport of sulfate is carried by water migration into and through concrete pores, water content becomes a very important aspect in the calculation of sulfate reaction products concentration. Water level movement is not covered in this model. Thus, a long-term and more stable environmental condition is the best applicable scope of this FE model. 


\subsection{Conclusion}

A literature review has been firstly conducted to discuss different theories to explain the mechanism underlying sulfate attack. Thereafter, sulfate reaction model using is established using Richards equation based water penetration model and linear reaction rate. By applying boundary conditions and governing equation, sulfate reaction process is easily modeled using commercially available software, COMSOL Multiphysics ${ }^{\circledR}$. Multiple conditions and factors are discussed in this model, such as gravity, temperature, sulfate concentration, and so on. FE model is approached by taking 3 steps as sulfate attack to concrete under water level, short term penetration and long term penetration. Model is validated with literatures and finally with in-service field bridge samples. The result concludes that the sorption-reaction model successfully addresses the mechanism of sulfate attack.

\subsection{References}

1. Al-Akhras, N. M. (2006), Durability of Metakaolin Concrete to Sulfate Attack, Cement and Concrete Research, V. 36, Issue 9, 1727-1734.

2. Atkinson, A., Haxby, A., \& Hearne, J. A. (1988). The chemistry and expansion of limestone-Portland cement mortars exposed to sulphate containing solutions. United Kingdom Nirex, Ltd., Harwell (UK).

3. Baroghel-Bouny, V. (2007). Water vapour sorption experiments on hardened cementitious materials: Part I: Essential tool for analysis of hygral behaviour and its relation to pore structure. Cement and Concrete Research, 37(3), 414-437.

4. Baroghel-Bouny, V., Mainguy, M., \& Coussy, O. (1999, October). Isothermal drying process in weakly permeable cementitious materials- assessment of water permeability. In International Conference on Ion and Mass Transport in Cement-Based Materials (pp. 59-80).

5. Bear, J. (1996). Modeling transport phenomena in porous media. InEnvironmental Studies (pp. 27-63). Springer New York. 
6. Bear, J., \& Bachmat, Y. (1990). Introduction to modeling of transport phenomena in porous media (Vol. 4). Springer.

7. Bentz, D.; Ehlen, M.; Ferraris, C., and Garboczi, E. (2001), Sorptivity-Based Service Life Predictions for Concrete Pavements, Proc. of 7th International Conference on Concrete Pavements, Orlando, Florida, USA, sponsored by Int. Soc. for Concrete Pavements, Vol. 1, 181-193.

8. Brown, P. W. and Taylor, H. F. W. (1999), The Role of Ettringite in External Sulfate Attack, J. Marchand and J. Skalny (eds) Materials Science of Concrete Special Volume: Sulfate Attack Mechanisms, The American Ceramic Society, Westerville, OH, 73-98.

9. Buckingham, E. (1907). Studies on the movement of soil moisture.

10. Clifton, J. F. (1991). Predicting the remaining service life of concrete (No. NISTIR--4712). National Inst. of Standards and Technology (NML), Gaithersburg, MD (United States). Center for Atomic, Molecular and Optical Physics.

11. Espenson, J. H. (1995). Chemical kinetics and reaction mechanisms (pp. 156-160). New York: McGraw-Hill.

12. Ferraris, C. F., Stutzman, P. E. and Snyder, K. A. (2006), Sulfate Resistance of Concrete: A New Approach, PCA R\&D Serial No. 2486, 93.

13. Frohnsdorf, G. (1998), Modeling Service Life and Life-Cycle Cost of SteelReinforced Concrete, NIST/ACI/ASTM Workshop, Gaithersburg, MD, November 9-10.

14. Gollop, R. S. and Taylor, H. F. W., Microstructural and Microanalytical Studies of Sulfate Attack I. Ordinary Cement Paste. II. Sulfate Resisting Portland Cement: Ferrite Composition and Hydration Chemistry. III. Sulfate-resisting Portland Cement: Reactions with Sodium and Magnesium Sulfate Solutions. IV. Reactions of a Slag Cement Paste with Sodium and Magnesium Sulfate Solutions. V. Comparison of Different Slag Blends, Cement and Concrete Research, Vol. 22, 1992, pp. 1027-1038; Vol. 24, 1993, 13471358; Vol. 25, 1994, pp. 1581-1590; Vol. 26, 1995, pp. 1013-1028; Vol. 26, 1996, pp. 1029-1044.

15. Gollop, R. S., \& Taylor, H. F. W. (1996). Microstructural and microanalytical studies of sulfate attack. V. Comparison of different slag blends. Cement and Concrete Research, 26(7), 1029-1044.

16. Gollop, R. S., \& Taylor, H. F. W. (1996). Microstructural and microanalytical studies of sulfate attack. IV. Reactions of a slag cement paste with sodium and magnesium sulfate solutions. Cement and Concrete Research, 26(7), 1013-1028. 
17. Green, K. M., Hoff, W. D., Carter, M. A., Wilson, M. A., \& Hyatt, J. P. (1999). A high pressure permeameter for the measurement of liquid conductivity of porous construction materials. Review of scientific instruments, 70(8), 3397-3401.

18. Gummerson, R. J., Hall, C., Hoff, W. D., Hawkes, R., Holland, G. N., \& Moore, W. S. (1979). Unsaturated water flow within porous materials observed by NMR imaging.

19. Hall, C., \& Hoff, W. D. (2011). Water transport in brick, stone and concrete. CRC Press.

20. Hall, C., Hoff, W. D., \& Skeldon, M. (1983). The sorptivity of brick: dependence on the initial water content. Journal of Physics D: Applied Physics, 16(10), 1875.

21. Heaslet, M. A., \& Alksne, A. (1961). Diffusion from a fixed surface with a concentration-dependent coefficient. Journal of the Society for Industrial \& Applied Mathematics, 9(4), 584-596.

22. Hooton, R. D. (2000). High strength concrete as a by-product of design for low permeability. In International Conference on Concrete (pp. 1627-1637).

23. Jason, L., Pijaudier-Cabot, G., Ghavamian, S., \& Huerta, A. (2007). Hydraulic behaviour of a representative structural volume for containment buildings.Nuclear engineering and design, 237(12), 1259-1274.

24. Kumar, A. (2010). Water flow and transport of chloride in unsaturated concrete(Doctoral dissertation, College of Graduate Studies and Research in Partial Fulfillment of the Degree of Master of Science in the Department of Civil and Geological Engineering, University of Saskatchewan).

25. Kyritsis, K., Hall, C., Bentz, D. P., Meller, N., \& Wilson, M. A. (2009). Relationship Between Engineering Properties, Mineralogy, and Microstructure in Cement Based Hydroceramic Materials Cured at $200^{\circ}-350^{\circ}$ C. Journal of the American Ceramic Society, 92(3), 694-701.

26. Leech, C., Lockington, D., Hooton, R. D., Galloway, G., Cowin, G., \& Dux, P. (2008). Validation of Mualem's conductivity model and prediction of saturated permeability from sorptivity. ACI Materials Journal, 105(1).

27. Lockington, D., Parlange, J. Y., \& Dux, P. (1999). Sorptivity and the estimation of water penetration into unsaturated concrete. Materials and Structures, 32(5), 342-347.

28. Loosveldt, H., Lafhaj, Z., \& Skoczylas, F. (2002). Experimental study of gas and liquid permeability of a mortar. Cement and Concrete Research, 32(9), 1357-1363.

29. Mehta, P. K. (1983), Mechanism of Sulfate Attack on Portland Cement Concrete — Another Look, Cement and Concrete Research, Vol. 13, No. 3, 401-406. 
30. Mehta, P. K. and Haynes, H. (1975), Durability of Concrete in Seawater, Journal of the American Society of Civil Engineers Structural Division 101(ST8), 1679-1686.

31. Monlouis-Bonnaire, J. P., Verdier, J., \& Perrin, B. (2004). Prediction of the relative permeability to gas flow of cement-based materials. Cement and Concrete Research, 34(5), 737-744.

32. Mualem, Y. (1976). A new model for predicting the hydraulic conductivity of unsaturated porous media. Water resources research, 12(3), 513-522.

33. Navarro, V., Yustres, A., Cea, L., Candel, M., Juncosa, R., \& Delgado, J. (2006). Characterization of the water flow through concrete based on parameter estimation from infiltration tests. Cement and concrete research, 36(9), 1575-1582.

34. Parlance, M. B., Prasad, S. N., Parlange, J. Y., \& Römkens, M. J. M. (1992). Extension of the Heaslet-Alksne Technique to arbitrary soil water diffusivities.Water resources research, 28(10), 2793-2797.

35. Parlange, J. Y. (1972). Theory of Water Movement in Soils: 4. Two and Three Dimensional Steady Infiltration. Soil Science,113(2), 96-101.

36. Philip, J. (1955). Numerical solution of equations of the diffusion type with diffusivity concentration-dependent. Trans. Faraday Soc., 51, 885-892.

37. Philip, J. R. (1957). Numerical Solution of Equations of the Diffusion Type with Diffusivity Concentration? Dependent. II. Australian Journal of Physics, 10(1), 29-42.

38. Philip, J. R. (1957). The theory of infiltration: 1 . The infiltration equation and its solution. Soil science, 83(5), 345-358.

39. Philip, J. R. (1973). Flow in porous media. In Theoretical and applied mechanics (pp. 279-294). Springer Berlin Heidelberg.

40. Pommersheim, J. M., \& Clifton, J. R. (1991). Models of transport processes in concrete. Nuclear Regulatory Commission, Washington, DC (USA). Div. of Engineering.

41. Powers, T. C., \& Brownyard, T. L. (1946, November). Studies of the physical properties of hardened Portland cement paste. In ACI Journal Proceedings(Vol. 43, No. 9). ACI.

42. Richards, L. A. (2004). Capillary conduction of liquids through porous mediums.Journal of Applied Physics, 1(5), 318-333.

43. Savage, B. M., \& Janssen, D. J. (1997). Soil physics principles validated for use in predicting unsaturated moisture movement in portland cement concrete.ACI materials journal, 94(1). 
44. Skalny, J. and Pierce, J. (1999), Sulfate Attack: an Overview, Materials Science of Concrete Special Volume: Sulfate Attack Mechanisms, The American Ceramic Society, Westerville, $\mathrm{OH}, 49-63$.

45. Sposito, G. (1986). The "physics" of soil water physics. Water Resources Research, 22(9S), 83S-88S.

46. Sposito, G. (1990). Lie group invariance of the Richards equation. IN: Dynamics of Fluids in Hierarchical Porous Media. Academic Press, Inc., San Diego, California. 1990. p 327-347, 1 tab, 40 ref, append. NSF Grant.

47. Van Genuchten, M. T. (1980). A closed-form equation for predicting the hydraulic conductivity of unsaturated soils. Soil science society of America journal, 44(5), 892-898.

48. Van Genuchten, M. T., Leij, F. J., \& Yates, S. R. (1991). The RETC code for quantifying the hydraulic functions of unsaturated soils. 


\section{CHAPTER V}

\section{EMPIRICAL MODEL TO PREDICT CONCRETE CRACK DEVELOPMENT}

CAUSED BY SULFATE ATTACK 


\title{
CHAPTER V
}

\section{EMPIRICAL MODEL TO PREDICT CONCRETE CRACK DEVELOPMENT CAUSED BY SULFATE ATTACK}

\author{
Shuo Zhang ${ }^{1}$, Nakin Suksawang ${ }^{2}$
}

\footnotetext{
${ }^{1}$ Dept. of Civil \& Environ. Engineering, Florida International University, Miami, Florida 33174, Tel: (305)298-1112, Fax: (305)348-2802, E-mail: szhan002@fiu.edu.

${ }^{2}$ Dept. of Civil Engineering, Florida Institution of Technology, Melbourne, Florida 32901, Tel: (321)674-7504, Fax: (321) 674-7565, E-mail: nsuksawang@fit.edu.
}

\subsection{Abstract}

The empirical model to predict concrete crack is developed using field exploration data and laboratory data. In order to quantitatively analyze concrete deterioration level, an image processing program is designed using Matlab to process the Scanning Electron Microscope (SEM) images and obtain crack percentage (A crack $\left./ A_{\text {surface }}\right)$. Correlation analysis were implemented between related variable(s) and concrete deterioration. Environmental sulfate concentration and bridge age were found to be positively correlated, while environmental $\mathrm{pH}$ level was found to be negatively correlated. Linear/non-linear regression analysis were accomplished to conclude the relationships between variables. Besides environmental conditions, concrete property factor was also considered in the equation and was derived from laboratory accelerated expansion testing. The empirical equation was concluded and validated with field bridges testing data. It is concluded that the equation could provide sufficient accuracy in prediction of concrete crack development. Two examples were given to demonstrate the 
practical implementation of this equation in predicting new and existing concrete bridges' condition.

KEY WORDS: SEM, image processing, correlation analysis, regression analysis, crack, sulfate attack, service life.

\subsection{Introduction}

The research of sulfate attack in the past 25 years is mainly focus on evaluating the expansion effect that sulfate attack result of. The reaction between sulfate and hydrated cement particles results of ettringite, which causes significant expansion and then results of cracks and spalling. And recently, the Scanning Electron Microscope (SEM) has been more and more used to assess the sulfate attack process. However, there is merely no quantitative evaluation method for existing bridges.

Introducing pozzolanic materials, such as fly ash, slag, and silica fume could improve concrete workability, reduce concrete permeability and increase concrete durability. Multiple researches indicates that introducing these materials helps increasing concrete sulfate resistivity. But firstly, none of these researches have considered the influence of acid and secondly, there is no good connection between the accelerated test and practical application.

A good, easily applied model is needed that taking environmental conditions and concrete properties into consideration. The service life models available are mostly based on chloride diffusion model (4SIGHT, Life-365, and CIKS) and use chloride concentration as indicator. ConcLife uses permeability as indicator but only applied to concrete deck service life. 


\subsection{Image Processing}

The concrete specimen shown in Figure 5.1 was taken using SEM imaging by backscattered electrons. The two materials, aggregate and hydrated cement, can now be differentiated based on contrast. Elements of cement appear lighter than aggregate. Aggregate appear lighter than cement. A total of fifty nine (59) images were collected at magnification 100X during the research at different depths of tested field bridges.

In order to evaluate concrete deterioration level, crack percentage (Acrack/Asurface) was obtained from those SEM images using Matlab program. Figure 5.2 illustrated the proceeded image by increasing crack-cement/aggregate contrast and enhancing/preserving cracks’ details.

A few steps were proceeded to achieve this object. First of all, the image was loaded in Matlab and converted into gray scaled image. After that, anisotropic diffusion (Perona-Malik diffusion) was applied to the image to reduce image noise without removing significant parts, such as the edge of aggregates and cracks. Median filter was used to reduce single point noises. The cracks were thereafter enhanced using a specially designed Matlab program. The image processing progress is demonstrated in Figure 5.3. 


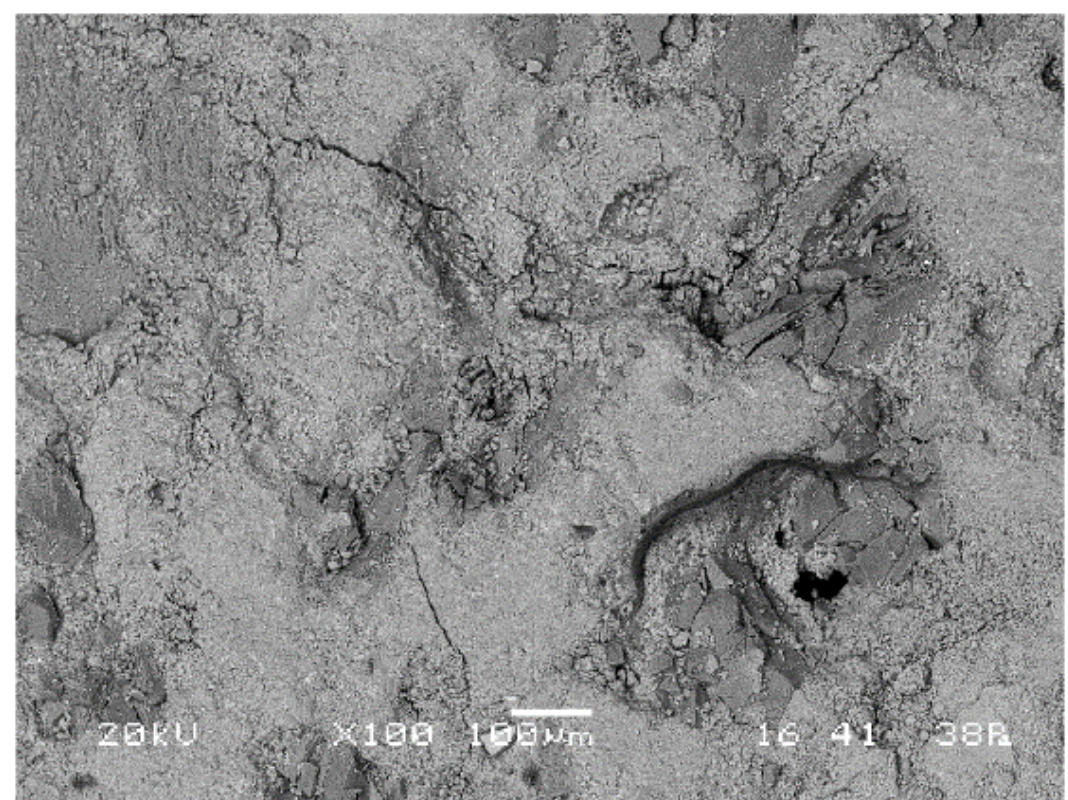

FIGURE 5.1. Original concrete SEM image.

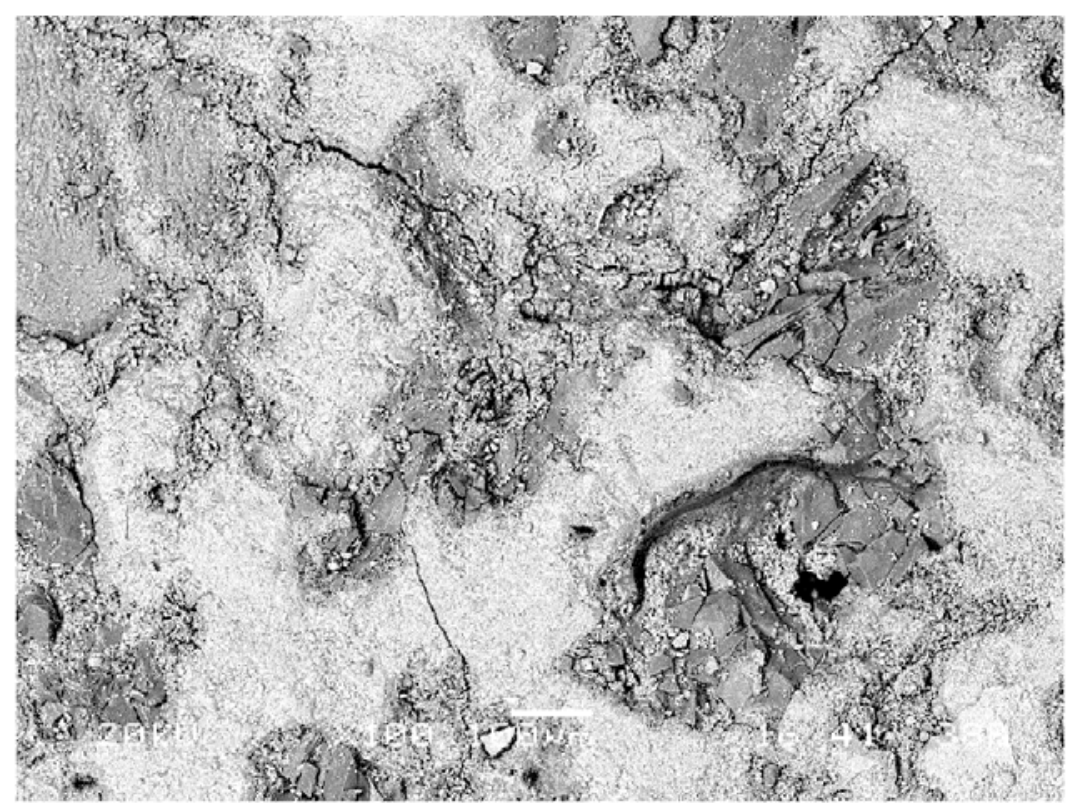

FIGURE 5.2. Crack enhenced concrete SEM image. 


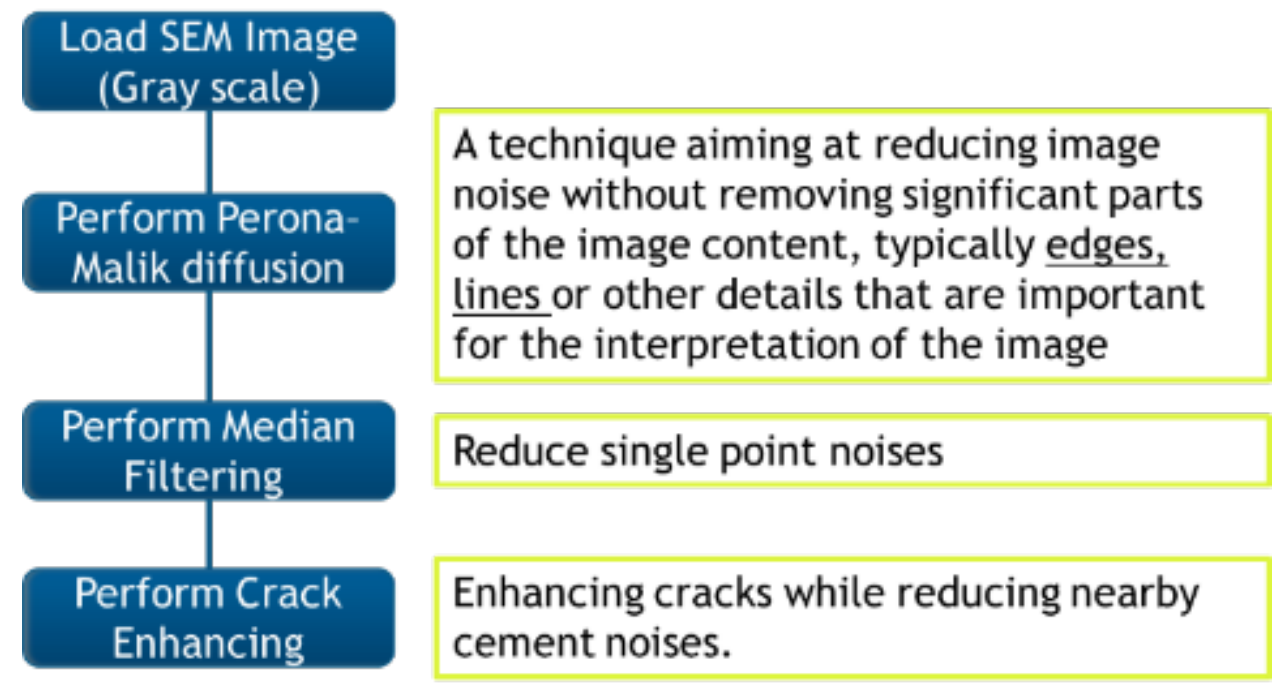

FIGURE 5.3. Image processing methodologies.

All image processing filters were applied using Matlab. Crack enhancing program was designed in this research to fulfill the purpose of locating micro-cracks and increasing contract between cracks and nearby aggregate/cement elements. The algorism is shown in Figure 5.4. Each original pixel (value 0 255) is firstly grouped with nearby pixels. If standard deviation of this group is above 50 , it is believed that there are cracks among this group of pixels. If not, this area is the elements of cement or aggregate. The value of the pixel is compared with median value of nearby pixels. If the pixel is darker than most nearby pixels, it is believed that this pixel belongs to micro-cracks. Crack is enhanced by decreasing its pixel value (darker).

Expansion induced cracks exist among cement elements and the interface between cement and aggregates. Therefore, it is necessary to eliminate the influence of aggregates. It is believed that the cracks are outliers of nearby elements. Before converting image to binary image, it is blurred to eliminate cracks using mean values without considering outliers. Figure 5.5 shows the algorism flowchart of the process. 
At the end, crack enhanced image is converted to binary format while eliminating the elements of aggregates. Cracks (value 0) and surrounding elements (value 1) are counted and crack percentage is reported at the end of the program.

The results is partially tabulated in Table 5-1 with related information of depth, sulfur contents, environmental sulfate concentration, $\mathrm{pH}$ and so on.

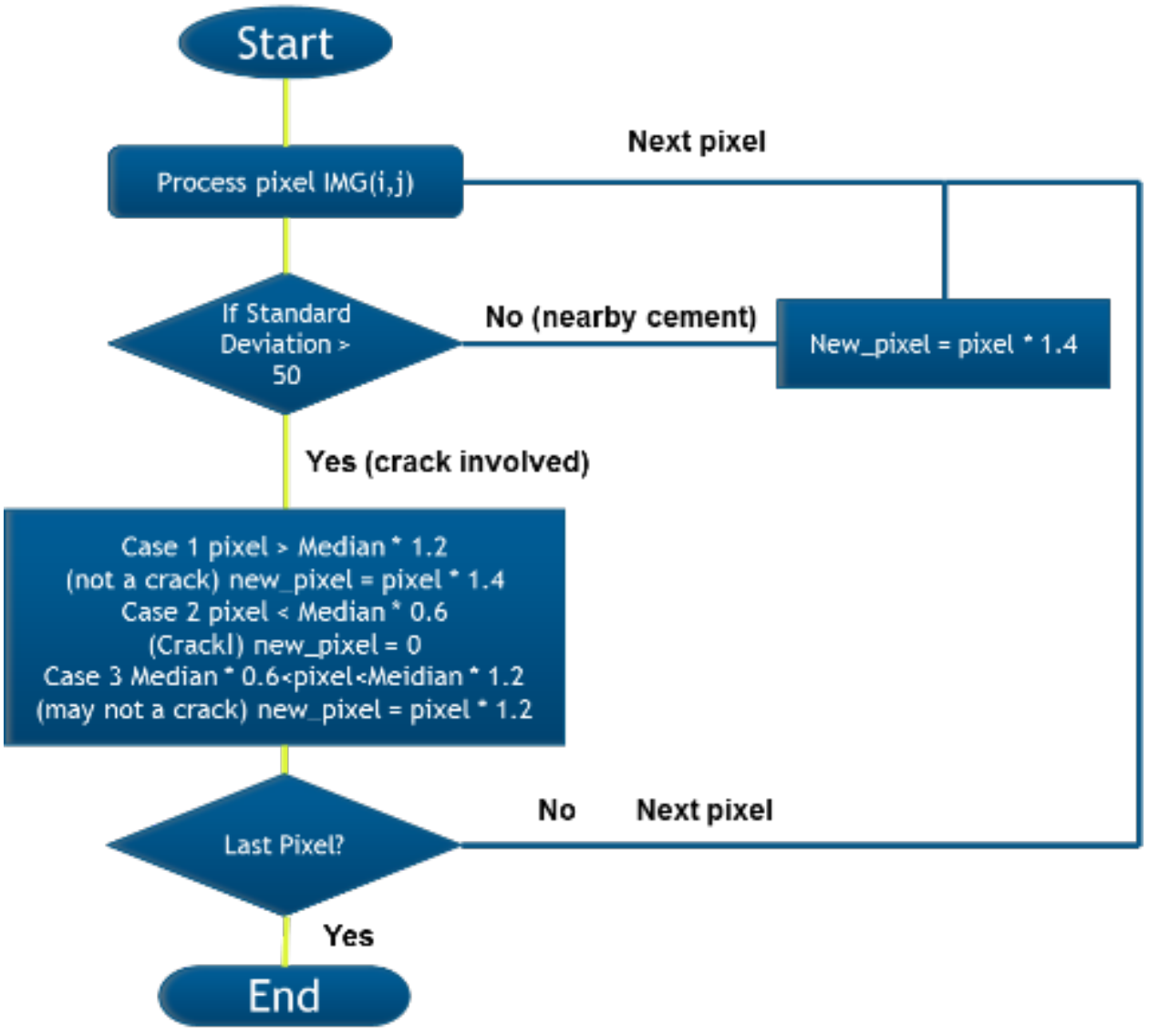

FIGURE 5.4. Crack enhancement program algorithm flowchart. 


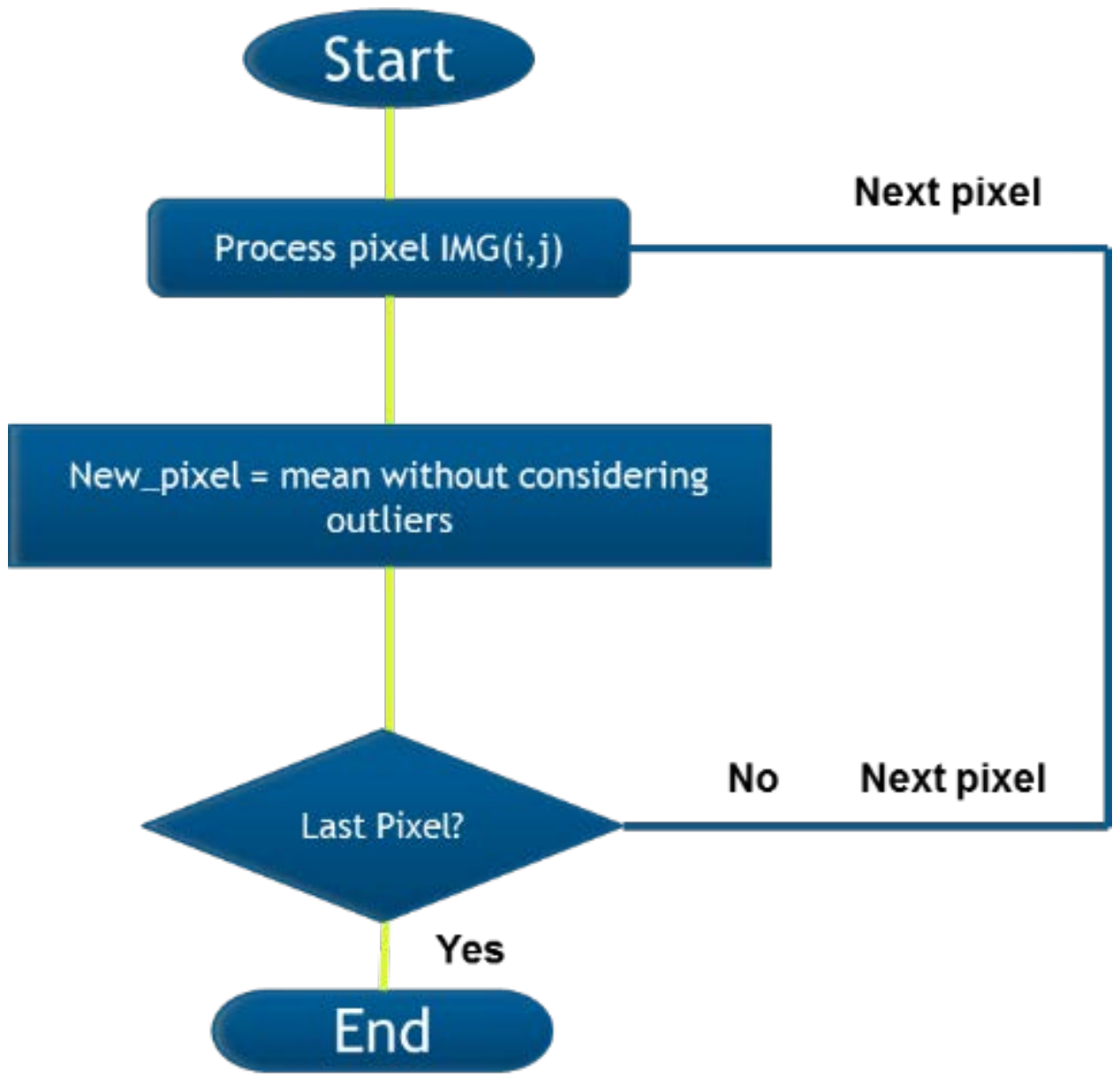

FIGURE 5.5. Aggregate identification program algorithm flowchart.

Table 5-1 Results of crack percentage.

\begin{tabular}{|c|c|c|c|c|c|c|c|}
\hline 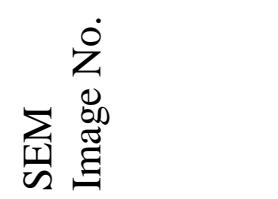 & $\begin{array}{l}\dot{0} \\
\dot{z} \\
\stackrel{0}{0} \\
\dot{0}\end{array}$ & 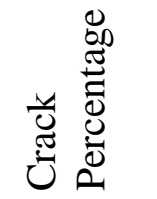 & 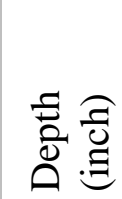 & 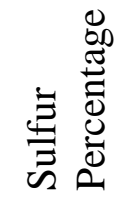 & 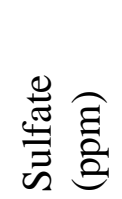 & 壱 & $\stackrel{80}{4}$ \\
\hline 780088-1-1-2 & 780088 & 0.91443 & 1 & 0.79 & 220 & 6.81 & 30 \\
\hline 780088-1-2-2 & 780088 & 2.0981 & 2 & 0.53 & 220 & 6.81 & 30 \\
\hline 170067-1-0.5-1 & 170067 & 1.1533 & 0.5 & 0.18 & 1074 & 5.4 & 3 \\
\hline 170067-1-1-1 & 170067 & 2.6306 & 1 & 0.19 & 1074 & 5.4 & 3 \\
\hline 170067-1-4-2 & 170067 & 1.705 & 4 & 0.2 & 1074 & 5.4 & 3 \\
\hline 720476-1-0.5-1 & 720476 & 6.8414 & 0.5 & 1.25 & 860 & 7.42 & 28 \\
\hline
\end{tabular}




\begin{tabular}{|l|l|l|l|l|l|l|l|}
\hline $720476-1-1.5-1$ & 720476 & 4.2804 & 1.5 & 0.63 & 860 & 7.42 & 28 \\
\hline $720476-3-3.5-1$ & 720476 & 3.1675 & 3.5 & 0.65 & 860 & 7.42 & 28 \\
\hline $740033-1-0.5-1$ & 740033 & 4.235 & 0.5 & 0.51 & 750 & 7.39 & 20 \\
\hline $740033-1-0.5-2$ & 740033 & 4.9818 & 0.5 & 0.51 & 750 & 7.39 & 20 \\
\hline $490030-1-1.5-2$ & 490090 & 3.2423 & 1.5 & 0.47 & 552 & 6.85 & 26 \\
\hline $490030-1-2.5-1$ & 490090 & 2.6495 & 2.5 & 0.56 & 552 & 6.85 & 26 \\
\hline $490030-1-2.5-2$ & 490090 & 3.1316 & 2.5 & 0.56 & 552 & 6.85 & 26 \\
\hline $490030-4-2-1$ & 490090 & 1.5082 & 2 & 0.52 & 552 & 6.85 & 26 \\
\hline $490030-4-2-2$ & 490090 & 2.0058 & 2 & 0.52 & 552 & 6.85 & 26 \\
\hline $290045-1-1.5-2$ & 290045 & 0.91602 & 1.5 & 0.25 & 10 & 4.23 & 35 \\
\hline $290045-1-4-1$ & 290045 & 0.5049 & 4 & 0.2 & 10 & 4.23 & 35 \\
\hline $290045-2-3.5-1$ & 290045 & 1.3866 & 3.5 & 0.24 & 10 & 4.23 & 35 \\
\hline $290045-2-3.5-2$ & 290045 & 1.3173 & 3.5 & 0.24 & 10 & 4.23 & 35 \\
\hline
\end{tabular}

\subsection{Correlation Analysis}

Concrete crack percentage is correlated with multiple variables, such as bridge age (time), sample depth, penetrated sulfur contents, environmental condition (sulfate concentration, $\mathrm{pH})$, concrete properties, and so on. Therefore, it can be expressed as a function of all possible variables as shown in Eq. 5.1. It is essential to perform a correlation analysis to find out the most critical variables that correlated with concrete deterioration.

$$
\rho_{\text {crack }}=f\left(t, d, \rho_{s}, p H, c_{s}, p_{c}, \ldots\right)
$$

where $\rho_{\text {crack: }}$ crack percentage

t: $\quad$ time

d: depth

$\rho_{s}: \quad$ penetrated sulfur contents

$\mathrm{pH}$ : environmental $\mathrm{pH}$ level 


\section{cs: environmental sulfate concentration \\ pc: $\quad$ concrete properties \\ $f()$ : function of all variables.}

Correlation analysis is performed to the following variables, which is sulfur percentage, environmental sulfate concentration, environmental $\mathrm{pH}$ level, bridge age, and sample depth. The results of these correlation analysis are plotted in Figure 5.6 through 5.10. The correlation coefficients between crack percentage and these variables are found to be $0.54,0.08,0.08,0.22$, and -0.37 , respectively.

The results shows a strong positive correlation between crack percentage and sulfur percentage regardless other variables. It is verified of the hypothesis that the microcracks shown in concrete SEM images are sulfate attack induced cracks. No direct correlation is found between crack percentage and environmental conditions. It is of the hypothesis that although external sulfate is the reason and sources of crack expansion, other variables play great role in the formation of cracks, which results of numerous noises in correlation analysis. Weak positive correlation is found between crack percentage and bridge age. Weak negative correlation is found between crack percentage and sample depth. 


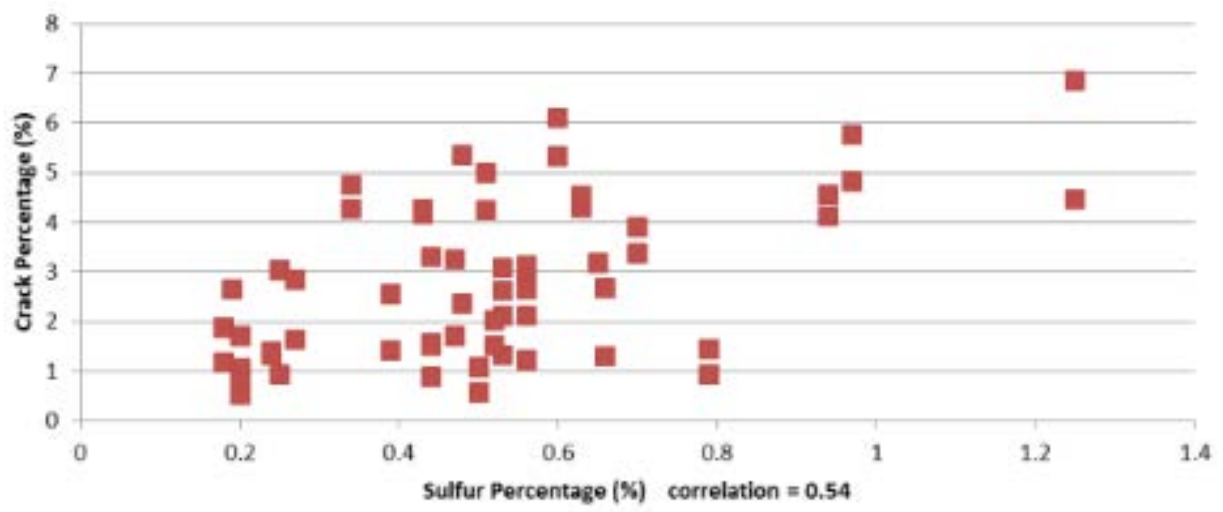

FIGURE 5.6. Correlation between crack percentage and sulfur percentage.

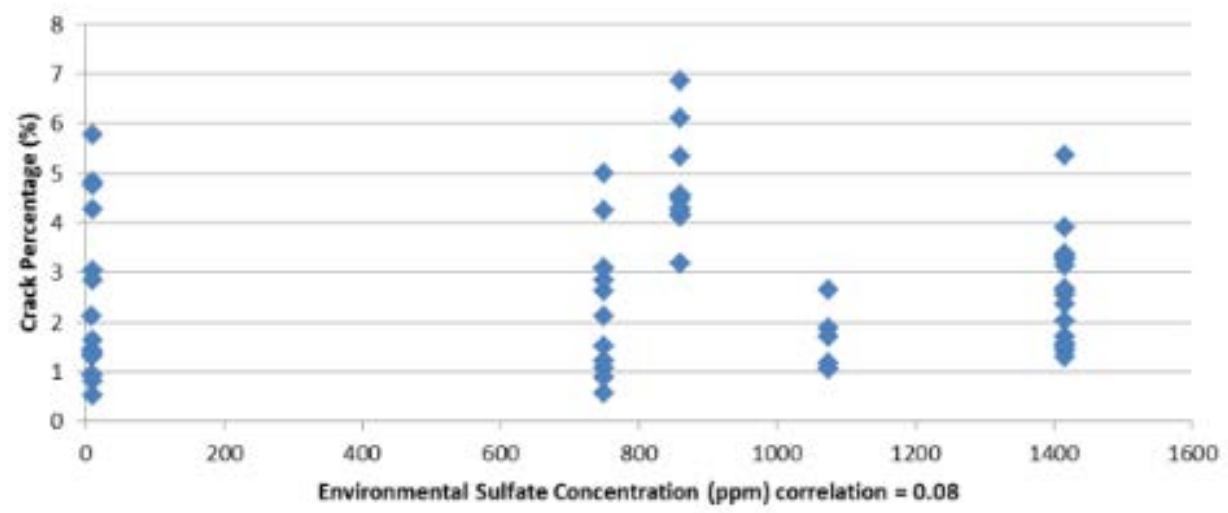

FIGURE 5.7. Correlation between crack percentage and environmental sulfate concentration.

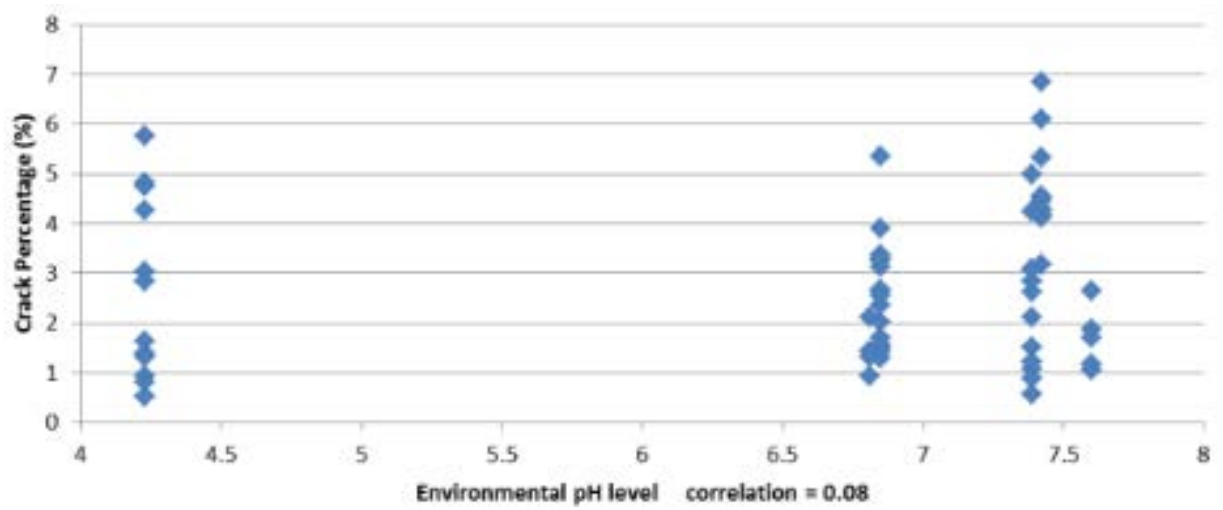

FIGURE 5.8. Correlation between crack percentage and environmental pH level. 


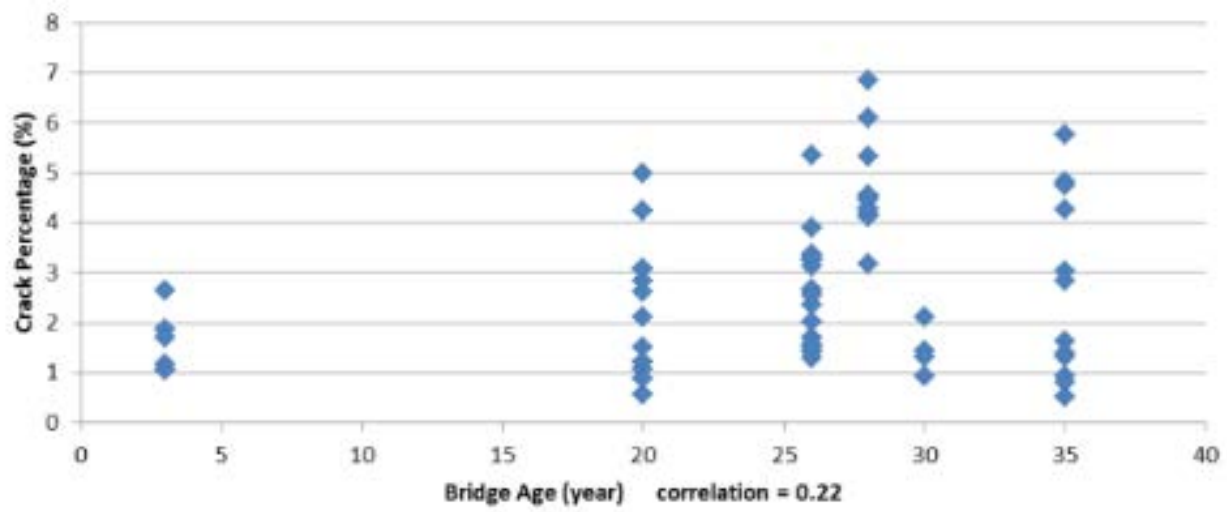

FIGURE 5.9. Correlation between crack percentage and bridge age.

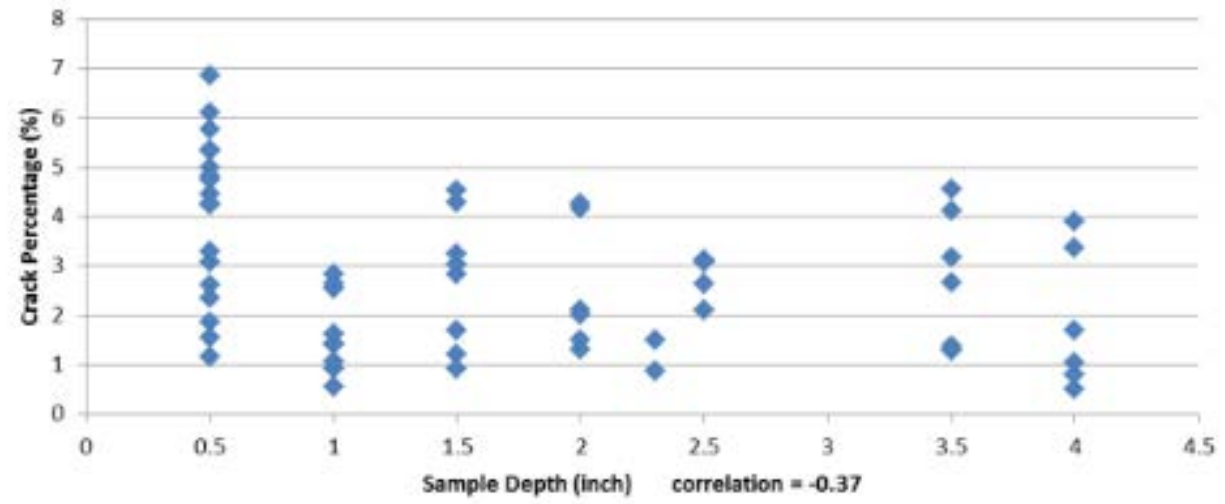

FIGURE 5.10. Correlation between crack percentage and sample depth.

Normalization is performed to eliminate the influence of environmental sulfate concentration. Crack percentage is divided by environmental sulfate concentration of each bridge to obtain the normalized value (Eq. 5.2).

$$
\rho_{\text {crack }}^{0}=\frac{\rho_{\text {crack }}}{c_{s}}
$$

where $\rho^{0}$ crack: normalized crack percentage

$\rho_{\text {crack: }}$ crack percentage

$c_{s}$ : environmental sulfate concentration 
Correlation analysis is performed and plotted in Figure 5.11 and 5.12. Strong negative correlation is found between normalized crack percentage and environmental $\mathrm{pH}$ with correlation coefficient of -0.75 . Strong positive correlation is found between normalized crack percentage and bridge age (time) with correlation coefficient of 0.51 .

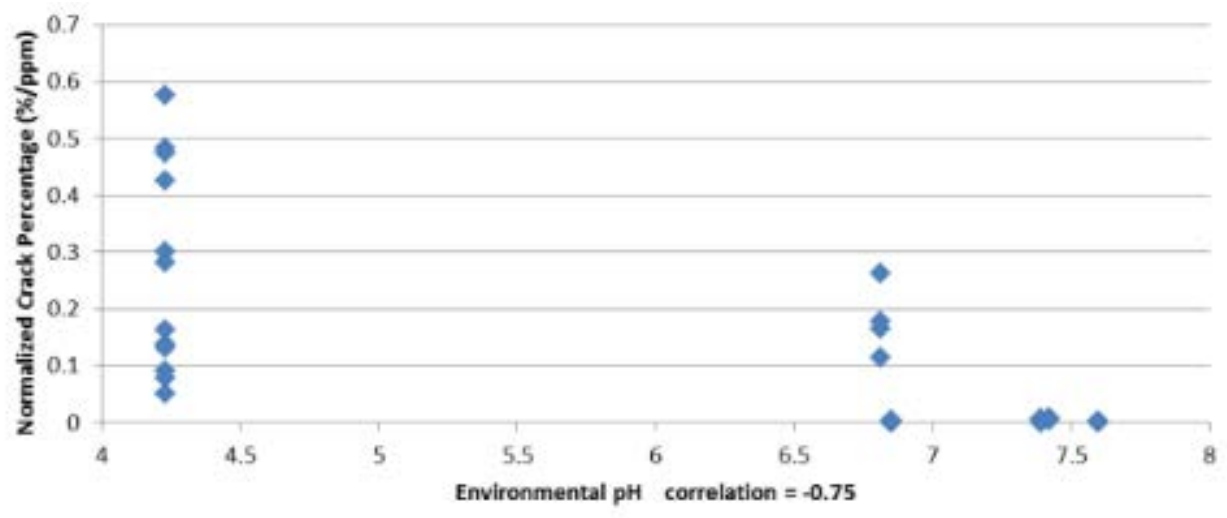

FIGURE 5.11. Correlation between normalized crack percentage and environmental pH.

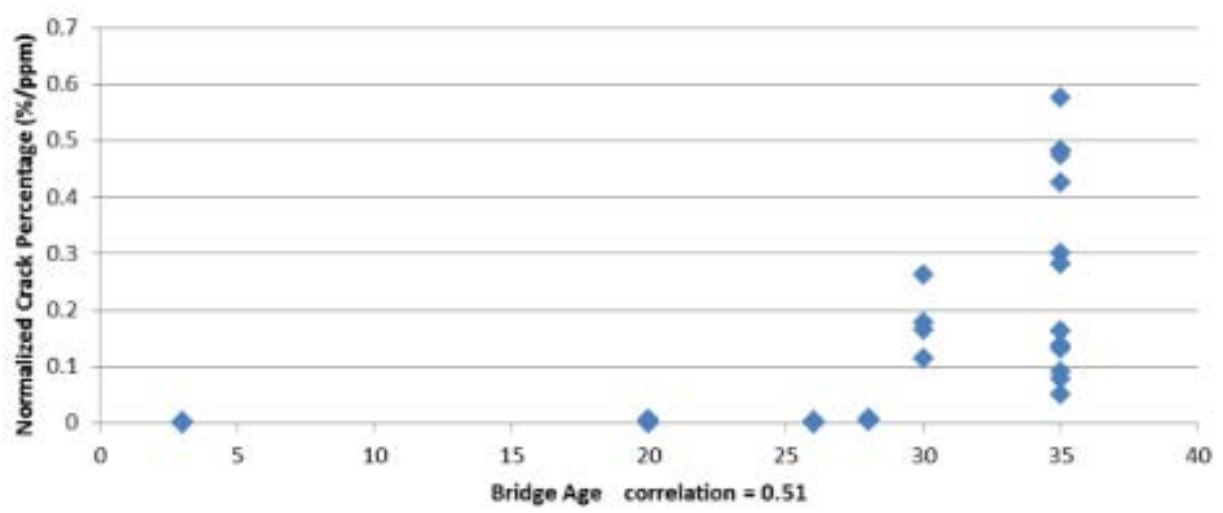

FIGURE 5.12. Correlation between normalized crack percentage and bridge age.

It is concluded from correlation analysis that the hypothesis expressed in Eq. 5.1 is verified. The variables, such as environmental conditions (sulfate concentration, $\mathrm{pH}$ ), 
time, depth and sulfur contents, have significant correlation with concrete deterioration (crack percentage).

\subsection{Regression Analysis}

Linear and non-linear regression analysis were performed to the variables. The results are plotted in Figure 5.13 through 5.16. The equations are shown in Eq. 5.3 through 5.6.

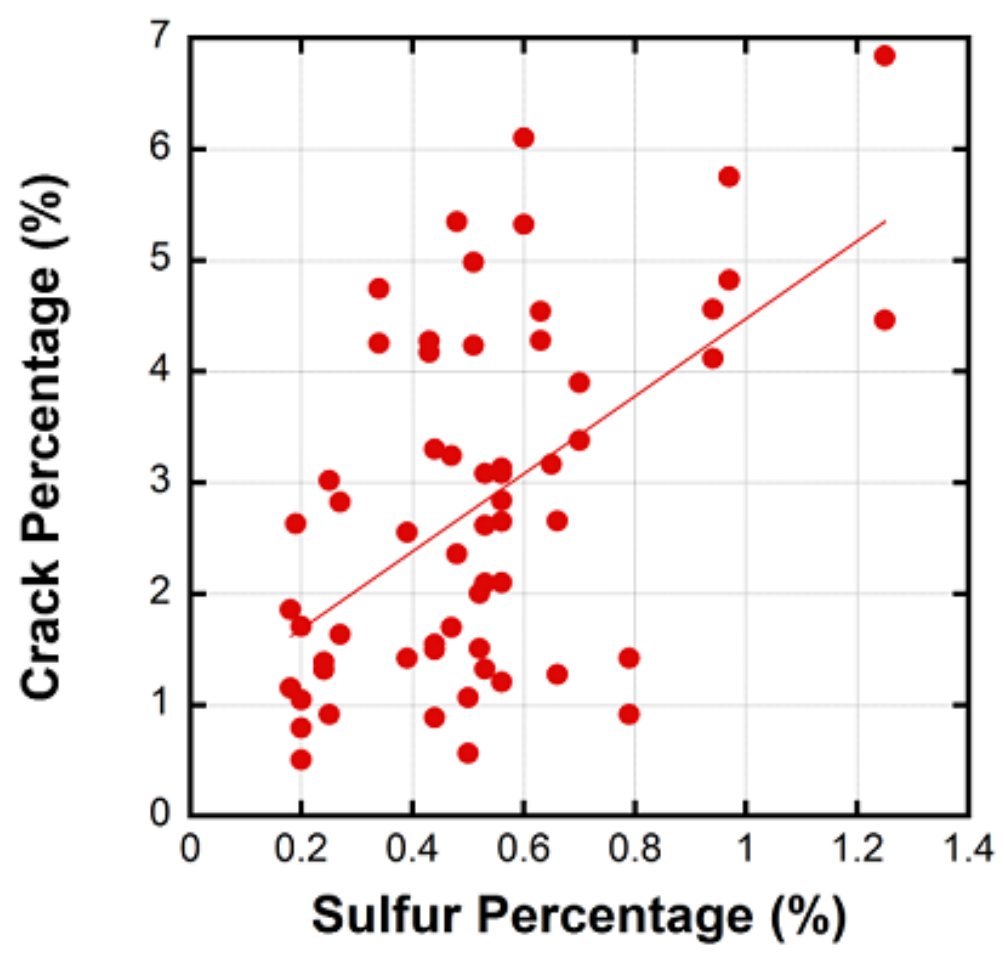

FIGURE 5.13. Regression analysis of the relation between sulfur percentage and crack percentage. 


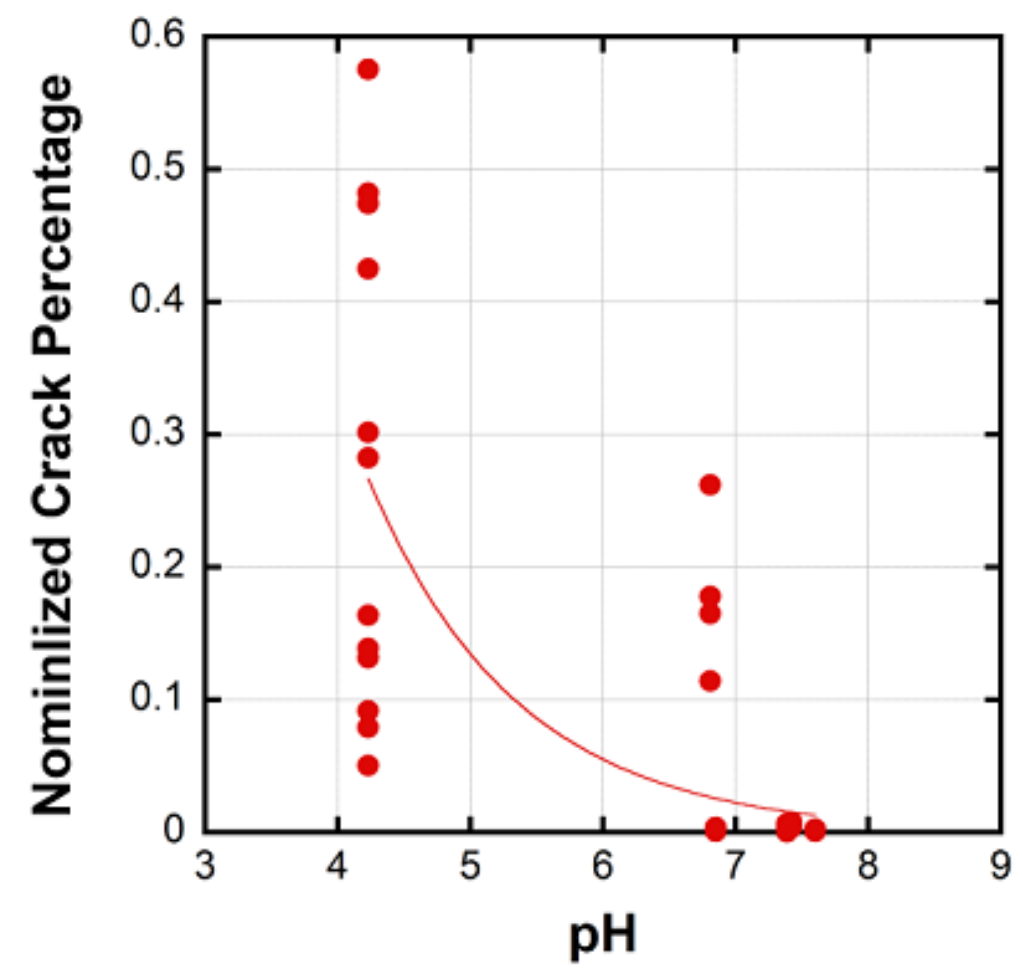

FIGURE 5.14. Regression analysis of the relation between environmental $\mathrm{pH}$ level and normalized crack percentage.

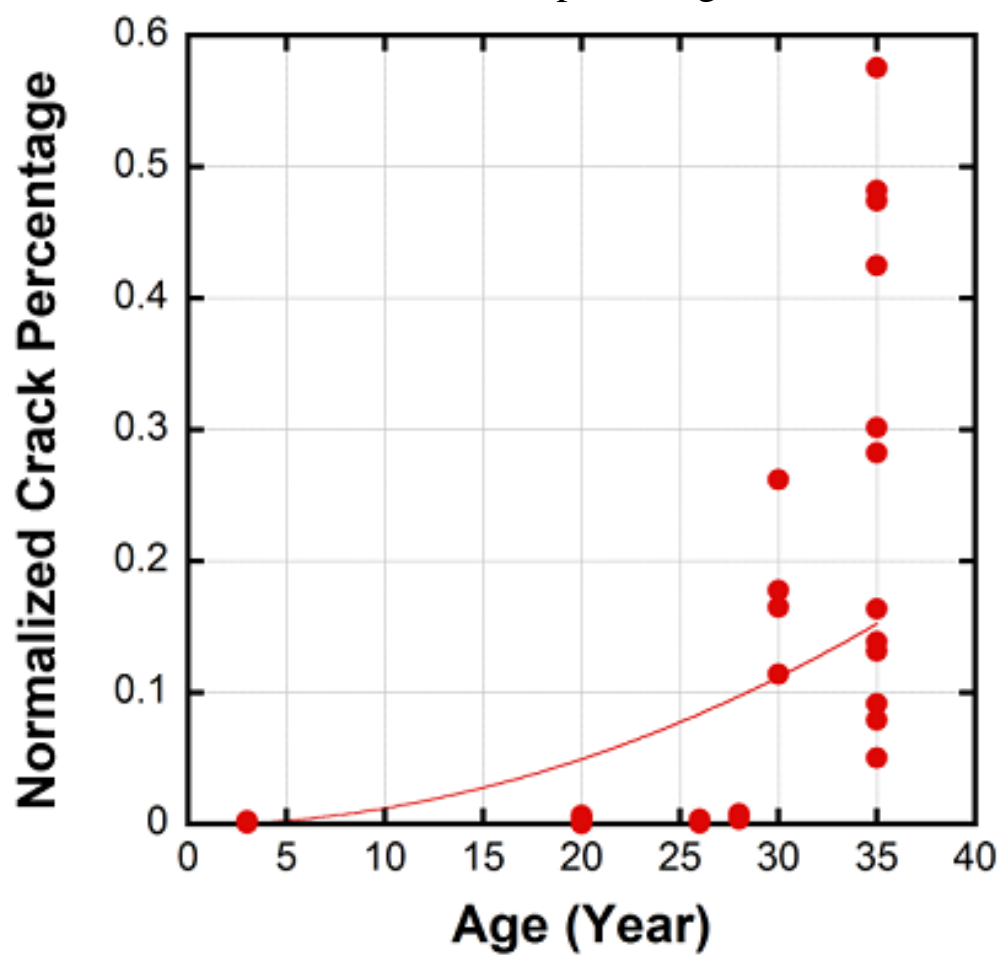

FIGURE 5.15. Regression analysis of the relation between bridge age and normalized crack percentage. 


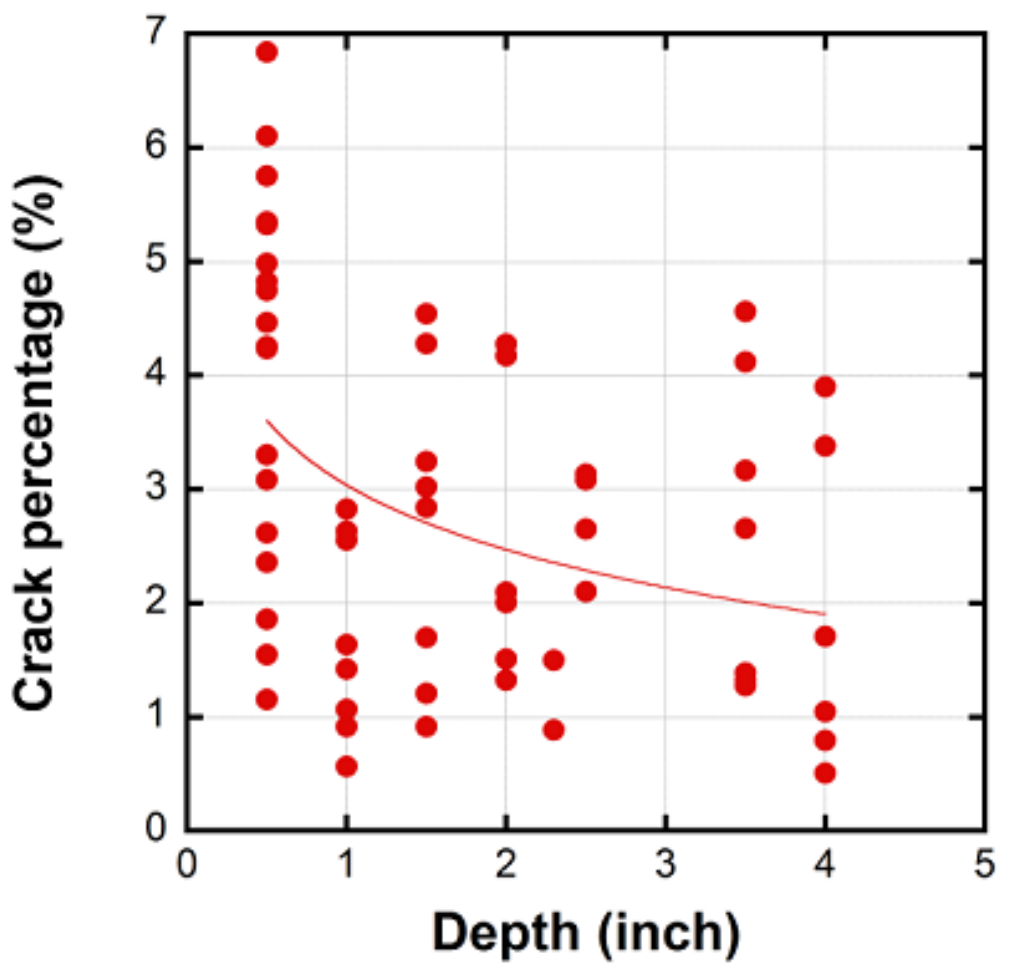

FIGURE 5.16. Correlation between crack percentage and sample depth. 


$$
\rho_{\text {crack }}=3.5 \rho_{s}+1.0
$$

Eq. 5.3

where

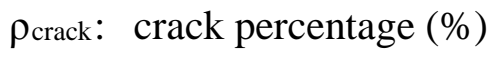

$\rho_{s}: \quad$ sulfur percentage (\%)

$$
\rho_{\text {crack }}^{0}=11.4 e^{-0.89 p H}
$$

Eq. 5.4

where $\rho^{0}$ crack: normalized crack percentage

$\mathrm{pH}: \quad$ environmental $\mathrm{pH}$ level

$$
\rho_{\text {crack }}^{0}=0.000125 t^{2}
$$

Eq. 5.5

where $\rho^{0}$ crack: normalized crack percentage

$\mathrm{t}: \quad$ time (year)

$$
\rho_{\text {crack }}=3-1.9 \log (d)
$$

Eq. 5.6

where $\rho_{\text {crack: }}$ crack percentage

d: depth (inch) 
It is of our best interest to predict concrete deterioration degree for given time and depth for given environmental conditions and concrete properties. Therefore, considering all variables, Eq. 5.4 through 5.6 are derived to the function of correlation factors and function of other variables as shown in Eq. 5.7 through 5.9, respectively.

$$
\begin{gathered}
\rho_{\text {crack }}=C_{p H} c_{s} h\left(t, d, p_{c}\right) \\
C_{p H}=11.4 e^{-0.89 p H}
\end{gathered}
$$

where $\rho_{\text {crack: }}$ crack percentage

$\mathrm{C}_{\mathrm{pH}}: \mathrm{pH}$ correlation factor

$\mathrm{c}_{\mathrm{s}}: \quad$ environmental sulfate concentration $(\mathrm{ppm})$

$\mathrm{pH}: \quad$ environmental $\mathrm{pH}$ level

$h()$ function of time, depth and concrete properties

$$
\begin{gathered}
\rho_{\text {crack }}=C_{t} c_{s} i\left(d, p H, p_{c}\right) \\
C_{t}=0.000125 t^{2}
\end{gathered}
$$

where $\rho_{\text {crack: }}$ crack percentage
$\mathrm{C}$ : $\quad$ time correlation factor
cs: environmental sulfate concentration (ppm)
t: $\quad$ time (year)
$\mathrm{i}()$ : function of depth, $\mathrm{pH}$ and concrete properties 


$$
\begin{gathered}
\rho_{\text {crack }}=C_{d} j\left(t, c_{s}, p H, p_{c}\right) \\
C_{d}=3-1.9 \log (d)
\end{gathered}
$$

where $\rho_{\text {crack: }}$ crack percentage

Cd: depth correlation factor

d: depth (inch)

$\mathrm{j}()$ : function of time, environmental sulfate concentration, $\mathrm{pH}$ and concrete properties

Combining Eq. 5.7 through 5.9, it is derived that crack percentage equals to the multiply of $\mathrm{pH}$ correlation factor, time correlation factor, depth correlation factor, sulfate concentration, and function of concrete properties as shown in Eq. 5.10.

$$
\begin{gathered}
\rho_{\text {crack }}=C_{p H} C_{t} C_{d} c_{s} k\left(p_{c}\right) \\
C_{p H}=11.4 e^{-0.89 p H} \\
C_{t}=0.000125 t^{2} \\
C_{d}=3-1.9 \log (d)
\end{gathered}
$$

where $\rho_{\text {crack: }}$ crack percentage

$\mathrm{C}_{\mathrm{pH}}: \quad \mathrm{pH}$ correlation factor

$\mathrm{C}_{\mathrm{t}}: \quad$ time correlation factor

Cd: depth correlation factor

$\mathrm{C}_{\mathrm{s}}$ : environmental sulfate concentration

$\mathrm{pH}: \quad$ environmental $\mathrm{pH}$ level 


$$
\begin{aligned}
& \text { t: } \quad \text { time (year) } \\
& \mathrm{d}: \quad \text { depth (inch) } \\
& \mathrm{k}(\text { ): function of concrete properties }
\end{aligned}
$$

Concrete properties play significant role in concrete external sulfate attack. Expansion is found to be linear related with time. As shown in Eq. 5.11, expansion rate is expressed as the multiply of concrete property factor and expansion rate of pure cement. It is to be noted that the expansion rate calculated based on laboratory experiments of this research is measured in sulfate concentration of 50,000 $\mathrm{ppm}$ and $\mathrm{pH}$ value of 3.48. Specimens are in dimension of $1 \times 1 \times 4 \mathrm{~cm}$. The results of the accelerated expansion test are plotted in Figure 5.17 through 5.22.

$$
\begin{aligned}
& \varepsilon_{\text {exp }}=E^{\prime} T \\
& E^{\prime}=C_{p c} E_{0}^{\prime}
\end{aligned}
$$

where $\varepsilon_{\exp }$ : expansion (\%)

E': expansion rate $(50000 \mathrm{ppm}, \mathrm{pH}: 3.48)$
$\mathrm{C}_{\mathrm{pc}}:$ concrete property factor
$\mathrm{E}^{\prime} 0$ : expansion rate (no pozzolanic materials

replacement)

$\mathrm{T}$ : time (day) 


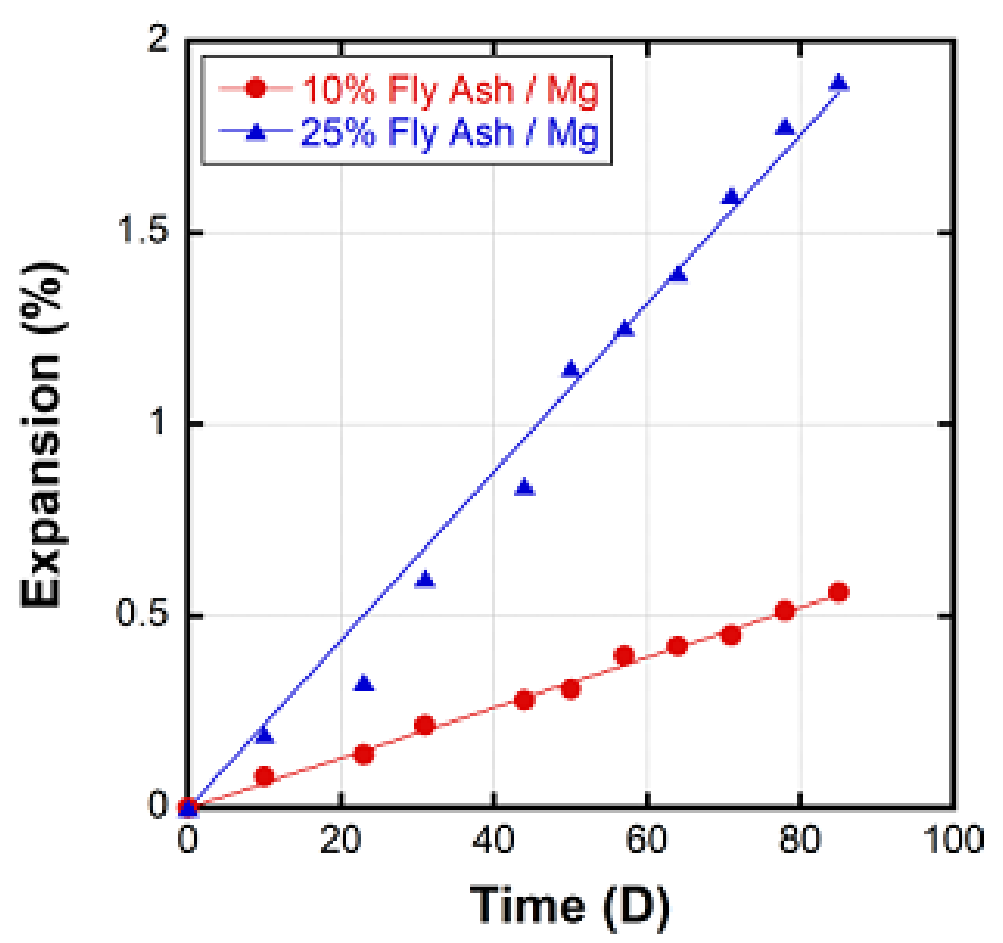

FIGURE 5.17. Expansion of specimens with fly ash 10\% and 25\% replacements of cement in magnesium $\left(\mathrm{Mg}^{+}\right)$sulfate solution.

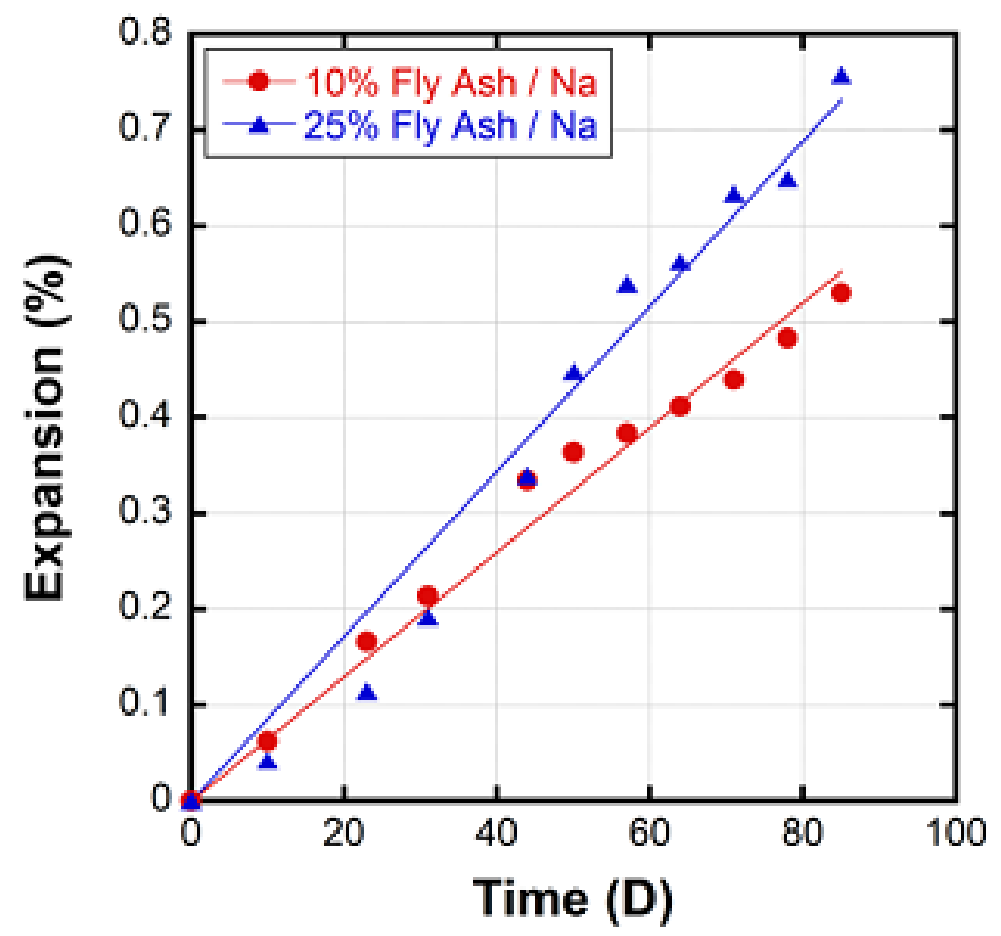

FIGURE 5.18. Expansion of specimens with fly ash 10\% and 25\% replacements of cement in sodium $\left(\mathrm{Na}^{+}\right)$sulfate solution. 


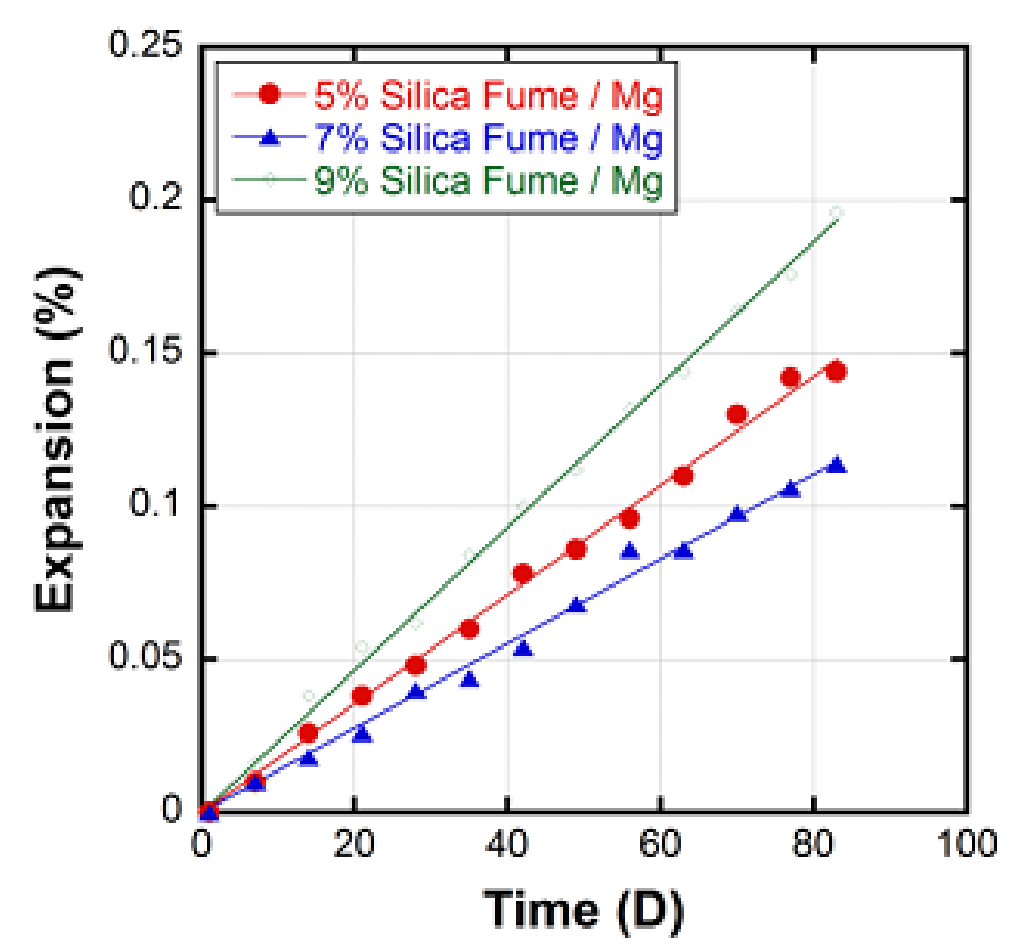

FIGURE 5.19. Expansion of specimens with silica fume 5\%, 7\% and 9\% replacements of cement in magnesium $\left(\mathrm{Mg}^{+}\right)$sulfate solution.

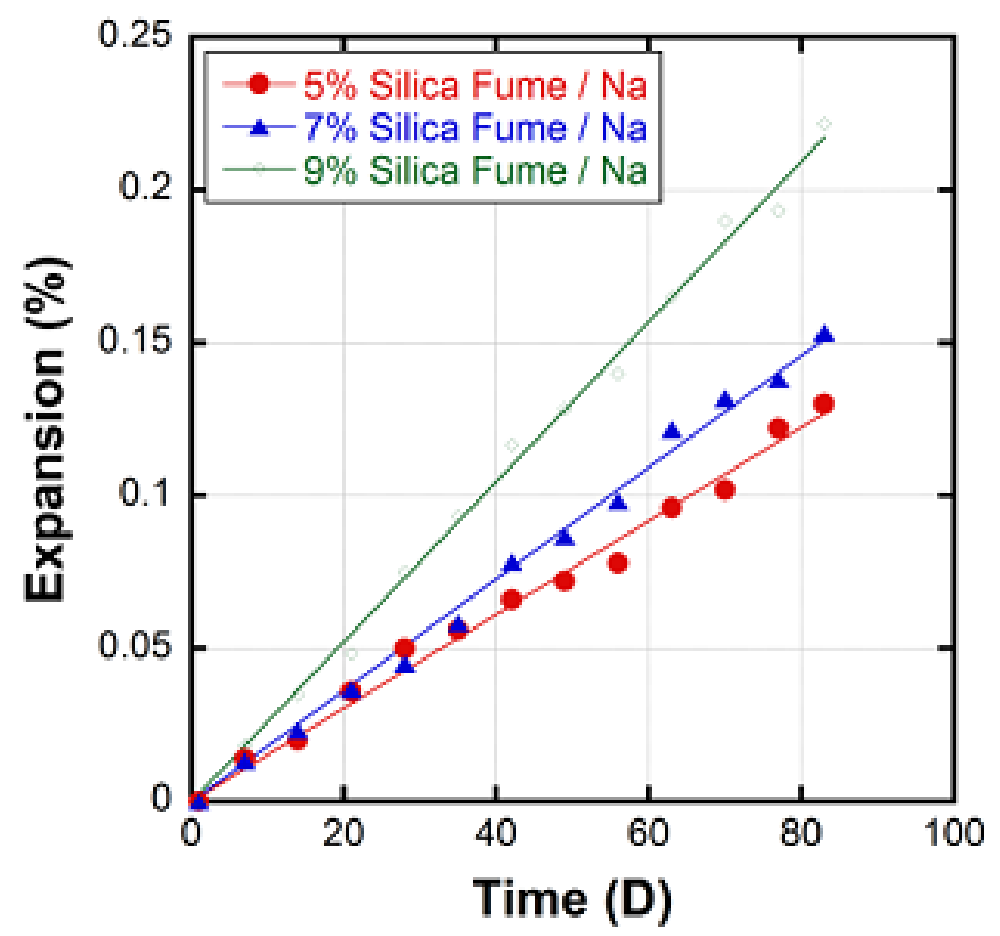

FIGURE 5.20. Expansion of specimens with silica fume 5\%, 7\% and 9\% replacements of cement in sodium $\left(\mathrm{Na}^{+}\right)$sulfate solution. 


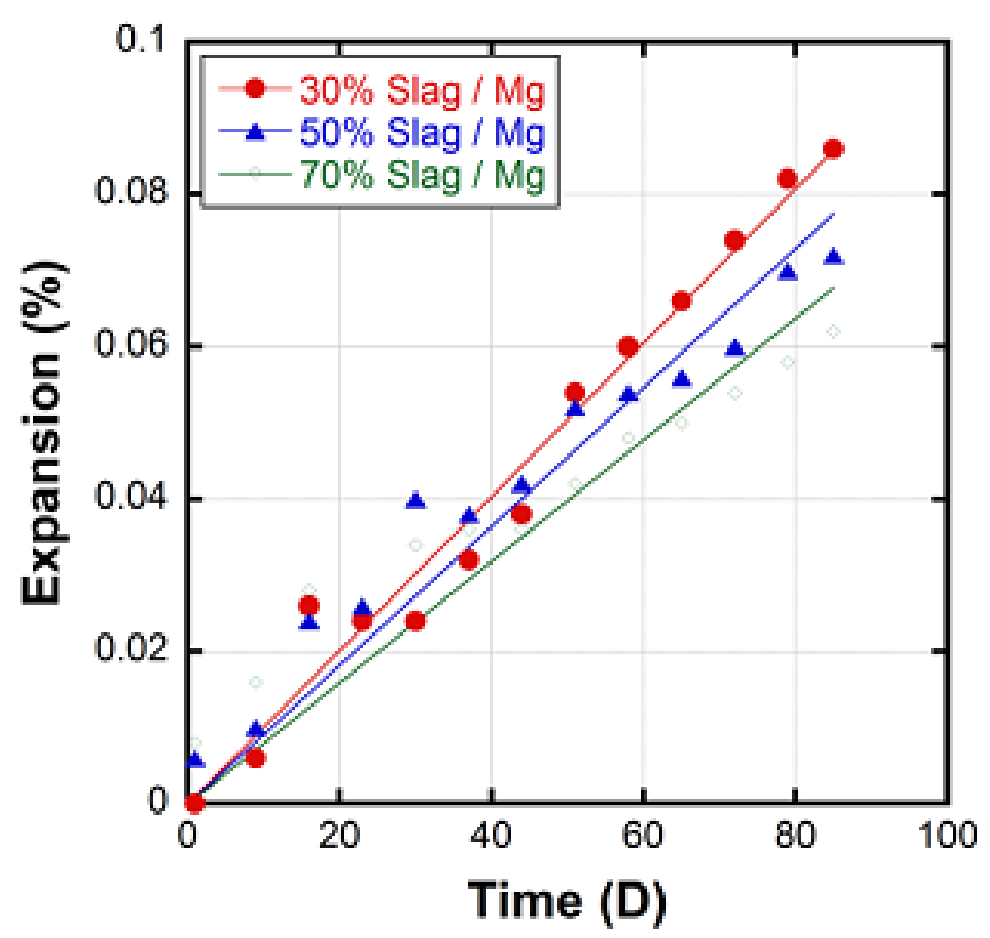

FIGURE 5.21. Expansion of specimens with slag 30\%, 50\% and 70\% replacements of cement in magnesium $\left(\mathrm{Mg}^{+}\right)$sulfate solution.

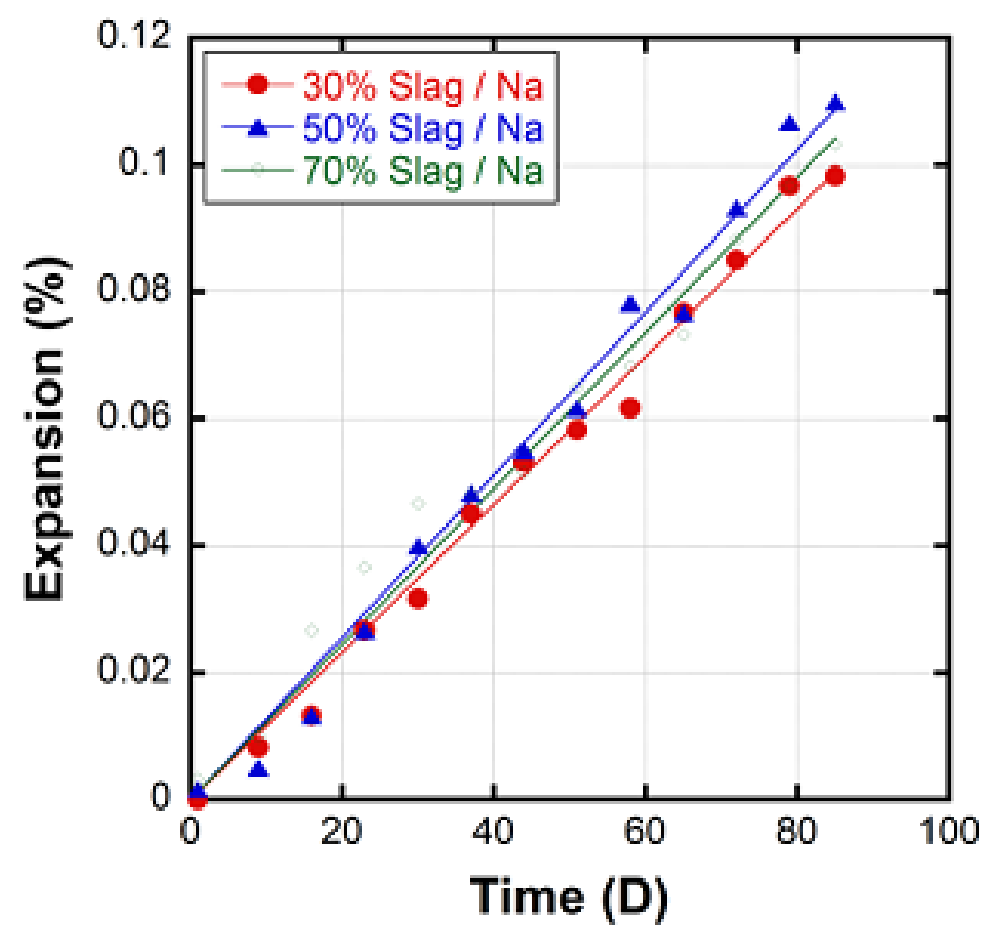

FIGURE 5.22. Expansion of specimens with slag 30\%, 50\% and 70\% replacements of cement in sodium $\left(\mathrm{Na}^{+}\right)$sulfate solution. 
Linear regression analysis was applied to obtain expansion rate of the specimens with different pozzolanic materials replacements in two types of sulfate solution. The results are plotted in Figure 5.23 through 5.25 as expansion rate vs. replacement. 2nd order polynomial regression analysis was performed to investigate the relationship between expansion rate and pozzolanic material replacements. To be conservative, the minimum value of the equation is limited by the smallest test value.

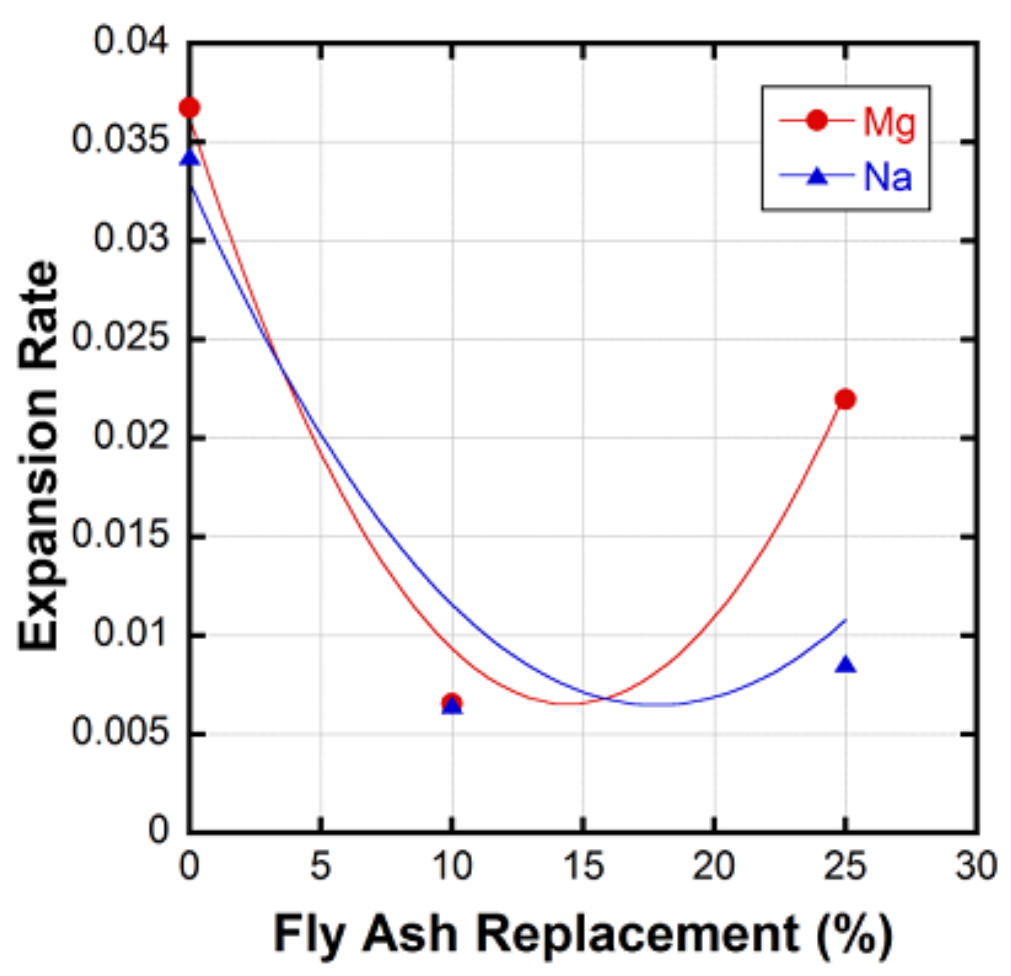

FIGURE 5.23. Expansion rate of specimens with fly ash replacements in sodium $\left(\mathrm{Na}^{+}\right)$ and magnesium $\left(\mathrm{Mg}^{+}\right)$sulfate solution. 


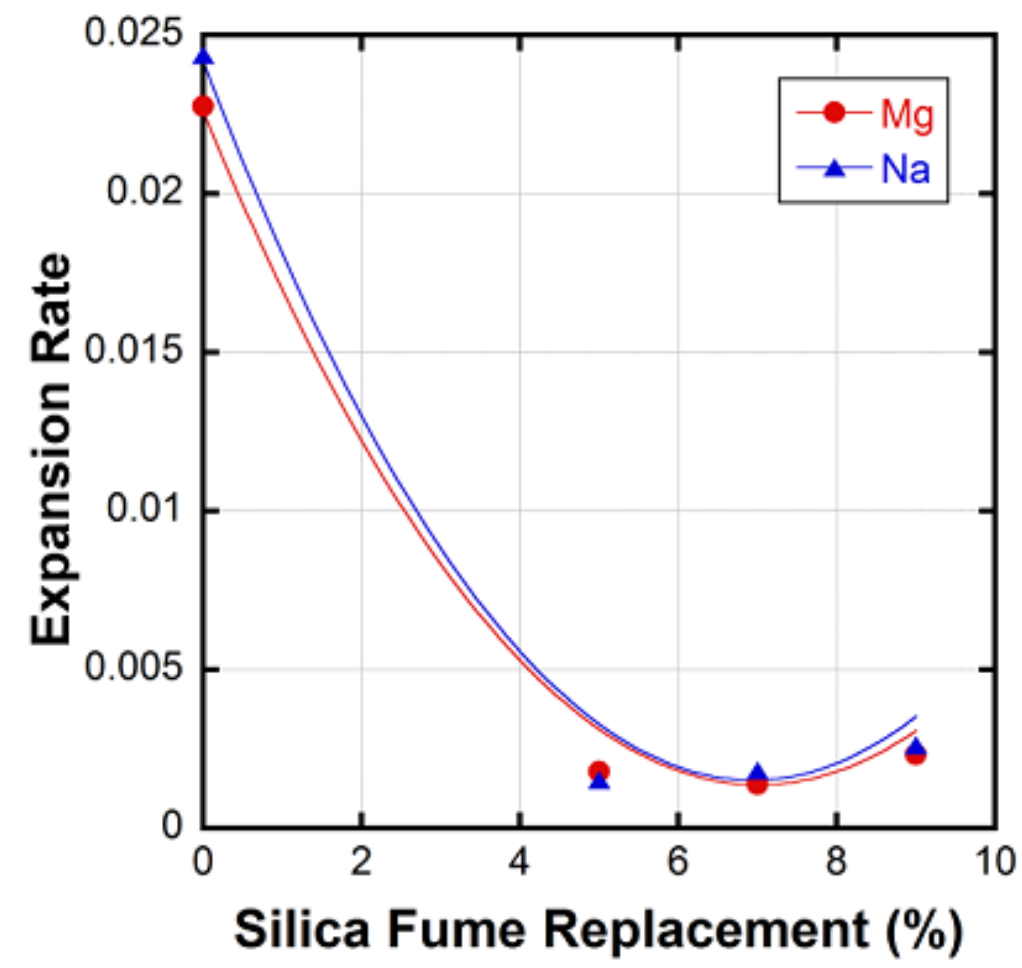

FIGURE 5.24. Expansion rate of specimens with silica fume replacements in sodium $\left(\mathrm{Na}^{+}\right)$and magnesium $\left(\mathrm{Mg}^{+}\right)$sulfate solution.

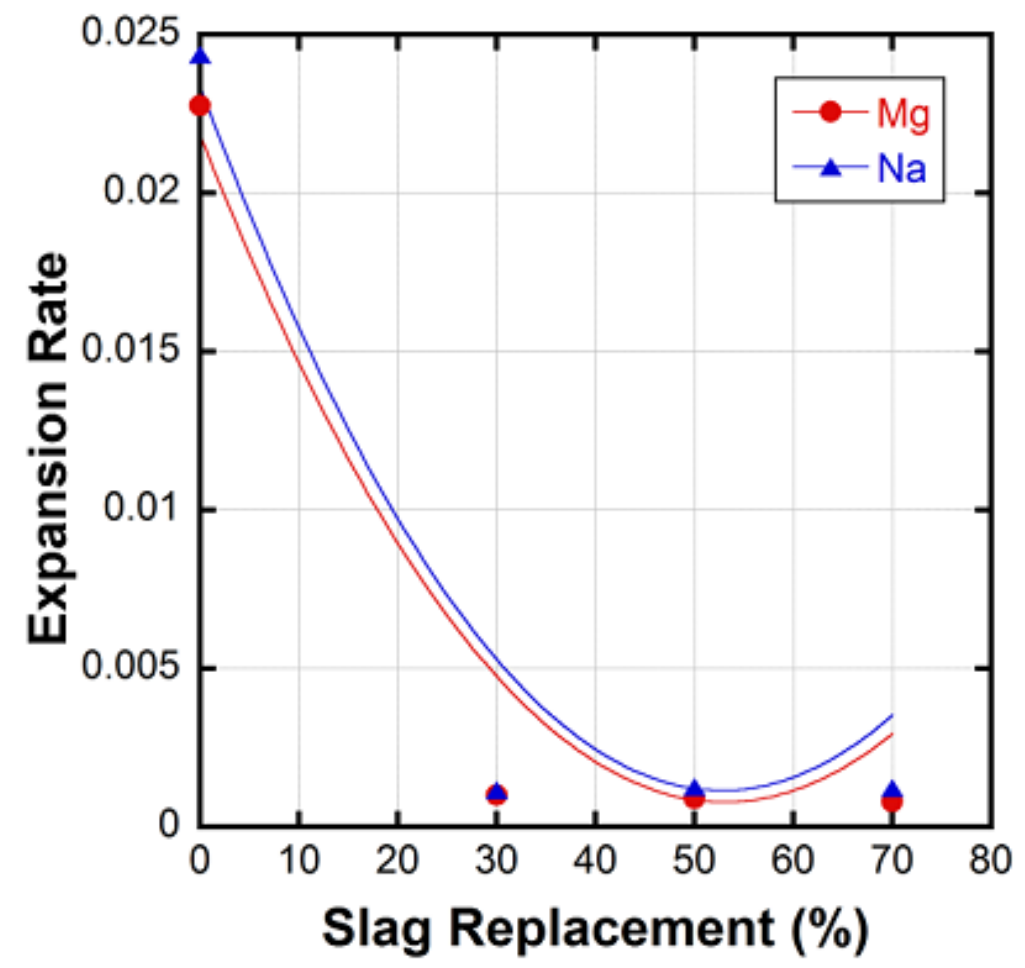

FIGURE 5.25. Expansion rate of specimens with slag replacements in sodium $\left(\mathrm{Na}^{+}\right)$and magnesium $\left(\mathrm{Mg}^{+}\right)$sulfate solution. 
Concrete property factor is expressed as a function of pozzolanic materials (fly ash, slag, and silica fume) replacement, the value of which will be 1 in case of pure cement. The equation is shown in Eq. 5.12. The results were calculated and tabulated in Table 5-2. It is to be noted that the constants shown in the table is limited of the environments of $50000 \mathrm{ppm}$ sulfate and $3.48 \mathrm{pH}$ value.

$$
C_{p c}=C_{1} \rho^{2}+C_{2} \rho+1
$$

where $\mathrm{C}_{1}, \mathrm{C}_{2}$ : constants

$$
\rho: \quad \text { pozzolanic materials replacements (\%) }
$$

Table 5-2 Expansion rate constants of pozzolanic materials in magnesium and sodium sulfate solutions (50000 ppm, pH: 3.48).

\begin{tabular}{llllll|} 
& C1 & C2 & E0' & Sulfate \\
\hline \multirow{2}{*}{ Fly Ash } & 0.003928 & -0.113432 & 0.03622 & $\mathrm{Mg}^{+}$ \\
& 0.002531 & -0.090159 & 0.03297 & $\mathrm{Na}+$ \\
Silica & 0.019094 & -0.267758 & 0.02258 & $\mathrm{Mg}+$ \\
Fume & 0.019481 & -0.270153 & 0.02416 & $\mathrm{Na}+$ \\
\multirow{2}{*}{ Slag } & 0.000343 & -0.036354 & 0.02182 & $\mathrm{Mg}^{+}$ \\
& 0.000342 & -0.036034 & 0.02336 & $\mathrm{Na}^{+}$ \\
\hline
\end{tabular}

The equation is converted to incorporate any given $\mathrm{pH}$ value and sulfate concentration as shown in Eq. 5.13. The constants are converted and tabulate in Table 3.

$$
\begin{gathered}
\varepsilon_{e x p}=\left(E_{0}^{\prime} \times \frac{11.4 e^{-0.89 p H}}{11.4 e^{-0.89 \times 3.480}}\right)(t \times 365)\left(c_{s} \times \frac{1}{50000}\right) C_{p c} \\
\varepsilon_{e x p}=\left(11.4 e^{-0.89 p H}\right) E_{0} t c_{s} C_{p c}
\end{gathered}
$$




$$
\begin{aligned}
& \text { where } \quad \varepsilon_{\text {exp }}: \quad \text { expansion (\%) } \\
& \begin{array}{ll}
\mathrm{E}_{0}: & \text { expansion rate } \\
\mathrm{C}_{\mathrm{pc}}: & \text { concrete property factor } \\
\mathrm{pH}: & \text { environmental pH level } \\
\mathrm{C}_{\mathrm{s}}: & \text { environmental sulfate concentration }(\mathrm{ppm}) \\
\mathrm{t}: & \text { time (year) }
\end{array}
\end{aligned}
$$

Table 5-3 Expansion rate constants of pozzolanic materials in magnesium and sodium sulfate solutions.

\begin{tabular}{l|ll|ll} 
& $\mathrm{C} 1$ & $\mathrm{C} 2$ & $\mathrm{E} 0$ & Sulfate \\
\hline \multirow{2}{*}{ Fly Ash } & 0.003928 & -0.113432 & $5.13 \mathrm{E}-04$ & $\mathrm{Mg}+$ \\
& 0.002531 & -0.090159 & $4.67 \mathrm{E}-04$ & $\mathrm{Na}+$ \\
Silica & 0.019094 & -0.267758 & $3.20 \mathrm{E}-04$ & $\mathrm{Mg}+$ \\
Fume & 0.019481 & -0.270153 & $3.42 \mathrm{E}-04$ & $\mathrm{Na}+$ \\
\multirow{2}{*}{ Slag } & 0.000343 & -0.036354 & $3.09 \mathrm{E}-04$ & $\mathrm{Mg}+$ \\
& 0.000342 & -0.036034 & $3.31 \mathrm{E}-04$ & $\mathrm{Na}+$
\end{tabular}

With all variables incorporated, it is concluded in Eq. 5.14 that crack percentage is a function of $\mathrm{pH}$, time, concrete property, depth, and sulfate concentration. The Eq. 5.15 through 19 shows the way to calculate corresponding correlation factors. The constants of Eq. 5.18 can be found in Table 5-3.

$$
\begin{gathered}
\rho_{\text {crack }}=C_{0} \varepsilon_{\text {exp }} \\
\rho_{\text {crack }}=C_{p H} C_{t} C_{0} C_{p c} C_{d} E_{0} c_{s} \\
C_{p H}=11.4 e^{-0.89 p H} \\
C_{t}=0.000125 t^{2}
\end{gathered}
$$

Eq. 5.16 


$$
\begin{gathered}
C_{0}=2437 \\
C_{p c}=C_{1} \rho^{2}+C_{2} \rho+1 \\
C_{d}=3-1.9 \log (d)
\end{gathered}
$$

Eq. 5.18

Eq. 5.19

where $\rho_{\text {crack: }}$ crack percentage (\%)

$\mathrm{C}_{\mathrm{pH}}: \quad \mathrm{pH}$ correlation factor
$\mathrm{C}_{\mathrm{t}}: \quad$ time correlation factor
$\mathrm{C}_{0}: \quad$ constant
$\mathrm{C}_{\mathrm{pc}}: \quad$ concrete property factor
$\mathrm{C}_{\mathrm{d}}: \quad$ depth correlation factor
$\mathrm{E}_{0}: \quad$ expansion rate
$\mathrm{C}_{\mathrm{s}}: \quad$ environmental sulfate concentration (ppm)
$\mathrm{pH}: \quad$ environmental pH level
$\mathrm{t}: \quad$ time (year)
$\rho: \quad$ pozzolanic materials replacement rate (\%)

\subsection{Model Validation}

The empirical equation shown in Eq. 5.14 is validated with tested field bridges. The results are plotted in Figure 5.26 as calculated vs. tested crack percentage. It provides a sufficiently accurate results in predicting crack percentage. 


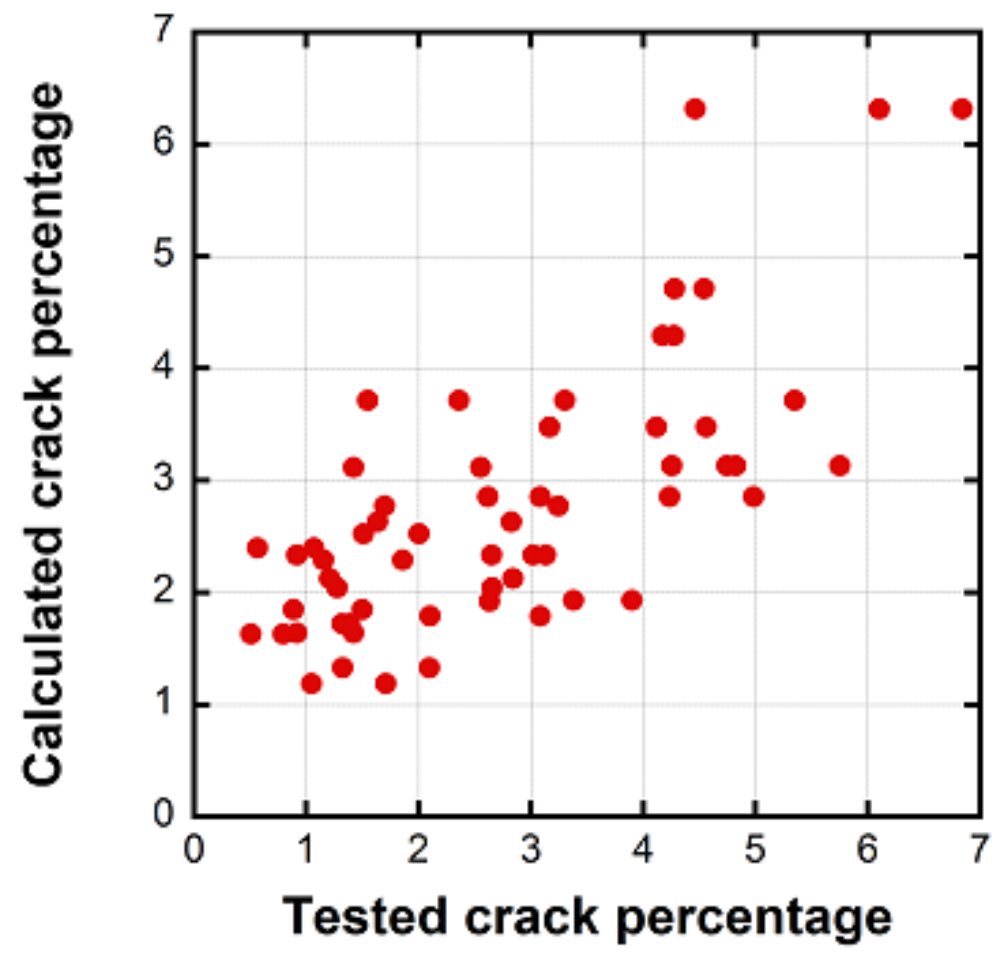

FIGURE 5.26. Correlation between the tested crack percentage and calculated crack percentage.

\subsection{Conclusion and Practical Implementation}

It is concluded from the research that crack percentage is found be highly related to concrete degradation level. Acid is found to have significantly effect in concrete sulfate attack. Increasing sulfate concentration would result of increasing concrete microcracks. Introducing pozzolanic materials could help reinforcing concrete sulfate resistivity for excessive amount. The empirical equation is compared and validated with field exploration data. Results show that the proposed equations compared well with field test results with a maximum deviation of $\pm 20 \%$. Two examples showing how to use the proposed equations are shown below.

Ex. 1 FDOT is planning to build a new bridge in a location with environmental sulfate $(\mathrm{Na}+)$ of 1200 ppm, pH value of 6.5. 24-inch driven piles will be used for this bridge. 
Two mix designs are considered: option 1. 10\% fly ash concrete; option 2. 50\% slag concrete. FDOT would like to use this model to calculate crack percentage at depth of rebar at the end of bridge service life.

The information of the proposed bridge is tabulated below:

\begin{tabular}{|l|l|l|l|l|l|l|l|}
\hline & \multicolumn{2}{|l|}{ Environment } & Concrete \\
\hline $\begin{array}{l}\text { Sulfate } \\
\text { type }\end{array}$ & $\begin{array}{l}\text { Concentratio } \\
\mathrm{n}(\mathrm{ppm})\end{array}$ & $\mathrm{pH}$ & $\begin{array}{l}\text { Pozzolani } \\
\text { c material }\end{array}$ & $\begin{array}{l}\text { Replaceme } \\
\mathrm{nt} \\
(\%)\end{array}$ & $\begin{array}{l}\text { Depth } \\
\text { (inch) }\end{array}$ & $\begin{array}{l}\text { Time } \\
\text { (year) }\end{array}$ \\
\hline Option 1 & $\mathrm{Na}$ & 1200 & 6.5 & Fly Ash & 10 & 3 & 75 \\
\hline Option 2 & $\mathrm{Na}$ & 1200 & 6.5 & Slag & 50 & 3 & 75 \\
\hline
\end{tabular}

Following the equations 5.14 through 5.19, factors for option 1 are calculated here.

$$
\begin{gathered}
C_{p H}=11.4 e^{-0.89 p H}=0.0350 \\
C_{t}=0.000125 t^{2}=0.7031 \\
C_{d}=3-1.9 \log (d)=2.093 \\
C_{p c}=C_{1} \rho^{2}+C_{2} \rho+1=0.3515\left(\mathrm{C}_{1}=0.002531 \mathrm{C}_{2}=-0.090159\right)
\end{gathered}
$$

Factors for option 2 are calculated here.

$$
\begin{gathered}
C_{p H}=11.4 e^{-0.89 p H}=0.0350 \\
C_{t}=0.000125 t^{2}=0.7031 \\
C_{d}=3-1.9 \log (d)=2.093 \\
C_{p c}=C_{1} \rho^{2}+C_{2} \rho+1=0.0533\left(C_{1}=0.000342 C_{2}=-0.036034\right)
\end{gathered}
$$

The factors for each option are tabulated here: 


\begin{tabular}{|l|l|l|l|l|l|l|l|}
\hline & $\mathrm{C}_{\mathrm{pH}}$ & $\mathrm{C}_{\mathrm{t}}$ & $\mathrm{C}_{\mathrm{d}}$ & $\mathrm{C}_{\mathrm{pc}}$ & $\mathrm{E}_{0}$ & $\mathrm{C}_{0}$ & $\rho_{\text {crack }}$ \\
\hline Option 1 & 0.0350 & 0.7031 & 2.093 & 0.3515 & 0.0005 & 2437 & 24.76 \\
\hline Option 2 & 0.0350 & 0.7031 & 2.093 & 0.0533 & 0.0003 & 2437 & 2.661 \\
\hline
\end{tabular}

$$
\begin{aligned}
& \rho_{\text {crack }}=C_{p H} C_{t} C_{0} C_{p c} C_{d} E_{0} C_{s}=24.76 \text { (option } 1 \text { ) } \\
& \rho_{\text {crack }}=C_{p H} C_{t} C_{0} C_{p c} C_{d} E_{0} C_{s}=2.661 \text { (option 2) }
\end{aligned}
$$

Let's say the threshold is concrete percentage reaching $5 \%$

$$
\begin{gathered}
t=\sqrt{\frac{C_{t}}{0.000125}}=\sqrt{\frac{\rho_{\text {crack }}}{0.000125 C_{p H} C_{0} C_{p c} C_{d} E_{0} c_{s}}}=34 \text { (option 1) } \\
t=\sqrt{\frac{C_{t}}{0.000125}}=\sqrt{\frac{\rho_{\text {crack }}}{0.000125 C_{p H} C_{0} C_{p c} C_{d} E_{0} c_{s}}}=103 \text { (option 2) }
\end{gathered}
$$

Ex. 2 FDOT is investigating an existing bridge (46 years) in a location with environmental sulfate $\left(\mathrm{Na}^{+}\right)$of $800 \mathrm{ppm}, \mathrm{pH}$ value of 7.0. The bridge is supported by 18 inch driven piles. A total of two (2) cores are sampled and six (6) SEM images are taken at depth of 1, 2, and 3 in. Crack percentages of each image are tabulated below. FDOT would like to use this model to evaluate if it is need to replace the foundation before the end of its service life. It is noted that the mix design of this foundation is unknown.

\begin{tabular}{|l|l|l|}
\hline Sample No. & Depth (inch) & $\begin{array}{l}\text { Crack percentage } \\
(\%)\end{array}$ \\
\hline XX-1-1 & 1 & 3.52 \\
\hline XX-1-2 & 1 & 3.43 \\
\hline XX-2-1 & 2 & 2.95 \\
\hline XX-2-2 & 2 & 2.76 \\
\hline XX-3-1 & 3 & 2.30 \\
\hline XX-3-2 & 3 & 1.98 \\
\hline
\end{tabular}

In order to solve this problem, concrete property factor and expansion rate are firstly needed to be calculated. The information of test samples is tabulated below: 


\begin{tabular}{|l|l|l|l|l|l|l|}
\hline Sample No. & $\begin{array}{l}\text { Sulfate } \\
\text { type }\end{array}$ & $\begin{array}{l}\text { Concentration } \\
(\mathrm{ppm})\end{array}$ & $\mathrm{pH}$ & $\begin{array}{l}\text { Depth } \\
\text { (inch) }\end{array}$ & $\begin{array}{l}\text { Time } \\
\text { (year) }\end{array}$ & $\begin{array}{l}\text { Crack } \\
\text { percentage } \\
(\%)\end{array}$ \\
\hline $\mathrm{XX}-1-1$ & $\mathrm{Na}+$ & 800 & 7.0 & 1 & 46 & 3.52 \\
\hline $\mathrm{XX}-1-2$ & $\mathrm{Na}+$ & 800 & 7.0 & 1 & 46 & 3.43 \\
\hline $\mathrm{XX}-2-1$ & $\mathrm{Na}+$ & 800 & 7.0 & 2 & 46 & 2.95 \\
\hline $\mathrm{XX}-2-2$ & $\mathrm{Na}+$ & 800 & 7.0 & 2 & 46 & 2.76 \\
\hline $\mathrm{XX}-3-1$ & $\mathrm{Na}+$ & 800 & 7.0 & 3 & 46 & 2.30 \\
\hline $\mathrm{XX}-3-2$ & $\mathrm{Na}+$ & 800 & 7.0 & 3 & 46 & 1.98 \\
\hline
\end{tabular}

Expansion rate and concrete property factor is calculated using the given environmental condition and tested crack percentage. The results are tabulated below:

$$
\begin{gathered}
C_{p H}=11.4 e^{-0.89 p H}=0.02245 \\
C_{t}=0.000125 t^{2}=0.2645 \\
C_{d}=3-1.9 \log (d)=3 ; 2.428 ; 2.093 \text { (depth of } 1,2,3 \text { in.) } \\
C_{p c} E_{0}=\frac{\rho_{c r a c k}}{C_{p H} C_{t} C_{0} C_{p c} C_{d} c_{s}}
\end{gathered}
$$

The results are tabulated here:

\begin{tabular}{|l|l|l|l|l|l|l|}
\hline Sample No. & $\mathrm{C}_{\mathrm{pH}}$ & $\mathrm{C}_{\mathrm{t}}$ & $\mathrm{C}_{\mathrm{d}}$ & $\rho_{\text {crack }}$ & $\mathrm{C}_{0}$ & $\mathrm{C}_{\mathrm{pcE} 0}$ \\
\hline XXXXXXX-1-1 & 0.02245 & 0.2645 & 3.000 & 3.52 & 2437 & 0.000101 \\
\hline XXXXXXX-1-2 & 0.02245 & 0.2645 & 3.000 & 3.43 & 2437 & 0.000099 \\
\hline XXXXXXX-2-1 & 0.02245 & 0.2645 & 2.428 & 2.95 & 2437 & 0.000105 \\
\hline XXXXXXX-2-2 & 0.02245 & 0.2645 & 2.428 & 2.76 & 2437 & 0.000098 \\
\hline XXXXXXX-3-1 & 0.02245 & 0.2645 & 2.093 & 2.30 & 2437 & 0.000095 \\
\hline XXXXXXX-3-2 & 0.02245 & 0.2645 & 2.093 & 1.98 & 2437 & 0.000082 \\
\hline \multicolumn{9}{|c}{ Standard Deviation } & 0.000008 \\
\hline
\end{tabular}

Crack percentage of the inspected bridge at the end of service life (75 years) are calculated and tabulated in the following table.

$$
\rho_{\text {crack }}=C_{p H} C_{t} C_{0} C_{p c} C_{d} E_{0} c_{s}=6.33
$$




\begin{tabular}{|l|l|l|l|l|l|l|l|}
\hline $\mathrm{C}_{\mathrm{pH}}$ & $\mathrm{C}_{\mathrm{t}}$ & $\mathrm{C}_{\mathrm{d}}$ & $\mathrm{C}_{\mathrm{pc}} \mathrm{E}_{0}$ & $\mathrm{C}_{0}$ & $\rho_{\text {crack}}($ mean $)$ & $\rho_{\text {crack}}(\max )$ & $\rho_{\text {crack }}(\min )$ \\
\hline 0.02245 & 0.7031 & 2.093 & 0.000098 & 2437 & 6.33 & 6.85 & 5.81 \\
\hline
\end{tabular}

Let's say the threshold is concrete percentage reaching $5 \%$

$$
t=\sqrt{\frac{C_{t}}{0.000125}}=\sqrt{\frac{\rho_{\text {crack }}}{0.000125 C_{p H} C_{0} C_{p c} C_{d} E_{0} c_{s}}}=67
$$

\subsection{References}

1. Atkinson, A., Haxby, A., \& Hearne, J. A. (1988). The chemistry and expansion of limestone-Portland cement mortars exposed to sulphate containing solutions. United Kingdom Nirex, Ltd., Harwell (UK).

2. Brown, P. W. and Taylor, H. F. W. (1999), The Role of Ettringite in External Sulfate Attack, J. Marchand and J. Skalny (eds) Materials Science of Concrete Special Volume: Sulfate Attack Mechanisms, The American Ceramic Society, Westerville, $\mathrm{OH}$, 73-98.

3. Clifton, J. F. (1991). Predicting the remaining service life of concrete (No. NISTIR--4712). National Inst. of Standards and Technology (NML), Gaithersburg, MD (United States). Center for Atomic, Molecular and Optical Physics.

4. Ferraris, C. F., Stutzman, P. E. and Snyder, K. A. (2006), Sulfate Resistance of Concrete: A New Approach, PCA R\&D Serial No. 2486, 93.

5. Frohnsdorf, G. (1998), Modeling Service Life and Life-Cycle Cost of SteelReinforced Concrete, NIST/ACI/ASTM Workshop, Gaithersburg, MD, November 9-10.

6. Gollop, R. S., \& Taylor, H. F. W. (1996). Microstructural and microanalytical studies of sulfate attack. V. Comparison of different slag blends. Cement and Concrete Research, 26(7), 1029-1044.

7. Gollop, R. S., \& Taylor, H. F. W. (1996). Microstructural and microanalytical studies of sulfate attack. IV. Reactions of a slag cement paste with sodium and magnesium sulfate solutions. Cement and Concrete Research, 26(7), 1013-1028.

8. Green, K. M., Hoff, W. D., Carter, M. A., Wilson, M. A., \& Hyatt, J. P. (1999). A high pressure permeameter for the measurement of liquid conductivity of porous construction materials. Review of scientific instruments, 70(8), 3397-3401.

9. Gummerson, R. J., Hall, C., Hoff, W. D., Hawkes, R., Holland, G. N., \& Moore, W. S. (1979). Unsaturated water flow within porous materials observed by NMR imaging. 
10. Hall, C., \& Hoff, W. D. (2011). Water transport in brick, stone and concrete. CRC Press.

11. Hall, C., Hoff, W. D., \& Skeldon, M. (1983). The sorptivity of brick: dependence on the initial water content. Journal of Physics D: Applied Physics, 16(10), 1875.

12. Heaslet, M. A., \& Alksne, A. (1961). Diffusion from a fixed surface with a concentration-dependent coefficient. Journal of the Society for Industrial \& Applied Mathematics, 9(4), 584-596.

13. Hooton, R. D. (2000). High strength concrete as a by-product of design for low permeability. In International Conference on Concrete (pp. 1627-1637).

14. Jason, L., Pijaudier-Cabot, G., Ghavamian, S., \& Huerta, A. (2007). Hydraulic behaviour of a representative structural volume for containment buildings.Nuclear engineering and design, 237(12), 1259-1274.

15. Kumar, A. (2010). Water flow and transport of chloride in unsaturated concrete(Doctoral dissertation, College of Graduate Studies and Research in Partial Fulfillment of the Degree of Master of Science in the Department of Civil and Geological Engineering, University of Saskatchewan).

16. Kurtis, K. E., Monteiro, P. J., \& Madanat, S. M. (2000). Empirical models to predict concrete expansion caused by sulfate attack. ACI Materials Journal, 97(2).

17. Kyritsis, K., Hall, C., Bentz, D. P., Meller, N., \& Wilson, M. A. (2009). Relationship Between Engineering Properties, Mineralogy, and Microstructure in Cement Based Hydroceramic Materials Cured at $200^{\circ}-350^{\circ}$ C. Journal of the American Ceramic Society, 92(3), 694-701.

18. Leech, C., Lockington, D., Hooton, R. D., Galloway, G., Cowin, G., \& Dux, P. (2008). Validation of Mualem's conductivity model and prediction of saturated permeability from sorptivity. ACI Materials Journal, 105(1).

19. Lockington, D., Parlange, J. Y., \& Dux, P. (1999). Sorptivity and the estimation of water penetration into unsaturated concrete. Materials and Structures, 32(5), 342-347.

20. Loosveldt, H., Lafhaj, Z., \& Skoczylas, F. (2002). Experimental study of gas and liquid permeability of a mortar. Cement and Concrete Research, 32(9), 1357-1363.

21. Mehta, P. K. (1983), Mechanism of Sulfate Attack on Portland Cement Concrete — Another Look, Cement and Concrete Research, Vol. 13, No. 3, 401-406.

22. Mehta, P. K. and Haynes, H. (1975), Durability of Concrete in Seawater, Journal of the American Society of Civil Engineers Structural Division 101(ST8), 1679-1686. 
23. Monlouis-Bonnaire, J. P., Verdier, J., \& Perrin, B. (2004). Prediction of the relative permeability to gas flow of cement-based materials. Cement and Concrete Research, 34(5), 737-744.

24. Mualem, Y. (1976). A new model for predicting the hydraulic conductivity of unsaturated porous media. Water resources research, 12(3), 513-522.

25. Navarro, V., Yustres, A., Cea, L., Candel, M., Juncosa, R., \& Delgado, J. (2006). Characterization of the water flow through concrete based on parameter estimation from infiltration tests. Cement and concrete research, 36(9), 1575-1582.

26. Parlance, M. B., Prasad, S. N., Parlange, J. Y., \& Römkens, M. J. M. (1992). Extension of the Heaslet-Alksne Technique to arbitrary soil water diffusivities.Water resources research, 28(10), 2793-2797.

27. Parlange, J. Y. (1972). Theory of Water Movement in Soils: 4. Two and Three Dimensional Steady Infiltration. Soil Science,113(2), 96-101.

28. Philip, J. (1955). Numerical solution of equations of the diffusion type with diffusivity concentration-dependent. Trans. Faraday Soc., 51, 885-892.

29. Philip, J. R. (1957). Numerical Solution of Equations of the Diffusion Type with Diffusivity Concentration? Dependent. II. Australian Journal of Physics, 10(1), 29-42.

30. Philip, J. R. (1957). The theory of infiltration: 1 . The infiltration equation and its solution. Soil science, 83(5), 345-358.

31. Philip, J. R. (1973). Flow in porous media. In Theoretical and applied mechanics (pp. 279-294). Springer Berlin Heidelberg.

32. Pommersheim, J. M., \& Clifton, J. R. (1991). Models of transport processes in concrete. Nuclear Regulatory Commission, Washington, DC (USA). Div. of Engineering.

33. Powers, T. C., \& Brownyard, T. L. (1946, November). Studies of the physical properties of hardened Portland cement paste. In ACI Journal Proceedings(Vol. 43, No. 9). ACI.

34. Richards, L. A. (2004). Capillary conduction of liquids through porous mediums.Journal of Applied Physics, 1(5), 318-333.

35. Savage, B. M., \& Janssen, D. J. (1997). Soil physics principles validated for use in predicting unsaturated moisture movement in portland cement concrete.ACI materials journal, 94(1).

36. Skalny, J. and Pierce, J. (1999), Sulfate Attack: an Overview, Materials Science of Concrete Special Volume: Sulfate Attack Mechanisms, The American Ceramic Society, Westerville, OH, 49-63. 
37. Sposito, G. (1986). The "physics" of soil water physics. Water Resources Research, 22(9S), 83S-88S.

38. Sposito, G. (1990). Lie group invariance of the Richards equation. IN: Dynamics of Fluids in Hierarchical Porous Media. Academic Press, Inc., San Diego, California. 1990. p 327-347, 1 tab, 40 ref, append. NSF Grant.

39. Van Genuchten, M. T. (1980). A closed-form equation for predicting the hydraulic conductivity of unsaturated soils. Soil science society of America journal, 44(5), 892-898.

40. Van Genuchten, M. T., Leij, F. J., \& Yates, S. R. (1991). The RETC code for quantifying the hydraulic functions of unsaturated soils. 


\section{CHAPTER VI}

SUMMARY AND CONCLUSIONS 


\section{CHAPTER VI \\ SUMMARY AND CONCLUSIONS}

\subsection{Summary}

\subsubsection{Use of SEM and EDS in concrete inspection}

SEM with EDS analysis is used in this research and proved to be a very powerful and accurate method in terms of evaluates sulfate penetration and formation of micro cracks. SEM can provide up to thousands times of magnification images that contain rich microstructure information. In this research, 100 times and 200 times magnification SEM images are mostly used. Microcracks can be easily seen and counted on those images. Formation of ettringite can be easily found on 1000 times magnification SEM images.

Sulfate penetration is evaluated using EDS analysis which can provide element atom or weight percentage for certain area or some point. It's accurate enough to analysis the formation of ettringite or other sulfate reaction products by analyzing sulfur content. It is found that the concrete in sulfate and low $\mathrm{pH}$ environment can result of sulfate accumulating deep inside concrete instead of just on surface.

With analysis of both SEM images and EDS sulfur content, it is found that microcrack width and sulfur content is positive correlated.

\subsubsection{Use of cementitious material to resist sulfate attack}

Among fly ash, slag, metakaolin, and silica fume, it is found that slag is the best cementitious material in term of resisting sulfate penetration and attack in sulfate and low pH environmental condition. The expansion amount of HPC with $70 \%$ slag is only about $20 \%$ of HPC with $10 \%$ fly ash during test period and much less than ordinary concrete. 


\subsubsection{Finite element approach in modeling sulfate attack}

Sulfate reaction model using Finite Element Modeling is created using Richards equation based water penetration model and linear reaction rate. Sulfate reaction process is simplified as steps of water penetration, sulfate reaction and accumulation. Multiple conditions and factors are discussed in this model, such as gravity, temperature, sulfate concentration, and so on. FE model is approached by taking 3 steps as sulfate attack to concrete under water level, short term penetration and long term penetration. Model is validated with literatures and finally with in-service field bridge samples.

\subsubsection{Empirical modeling of concrete microcrack development}

The empirical model to predict concrete microcrack development is developed using field exploration and laboratory test data. The environmental conditions and concrete properties are found to be highly correlated to concrete microcrack development. The empirical equations was conducted and validated with field bridges testing data. Results show that the proposed equations compared well with field test results with a maximum deviation of $\pm 20 \%$.

\subsection{Conclusions}

Unlike chloride attack, sulfate attack could result of the formation of gypsum or ettringite that resulted in cracking to form in concrete. As such, existing diffusion or sorption model for calculating concrete service cannot be used. New model based on cracking should be used. As described in Chapter I, the goal of this research was to determine the performance and service life of high-performance concrete (HPC) in sulfate and low $\mathrm{pH}$ environment. To reach this goal, the primary research objective was 
to test the hypothesis that microcracks in HPC exposed to sulfate and low $\mathrm{pH}$ environment can be directly used to predict the ingress of external chemical dissolved in the aqueous solution that is in contact with the concrete.

The research approaches were 1) to evaluate the performance of HPC in these environments using accelerated laboratory testing, and 2) to evaluate the actual concrete structures performance using field cores. The accelerated laboratory testing (methodologies and results shown in Chapter III) was used to determine the effect of cementitious materials supplement such as fly ash, slag, and silica fume on expansion when exposed to sulfate and low $\mathrm{pH}$ environment. This data was used to develop a decision tool to help engineer select appropriate concrete mixture based on the structure exposure level. The field test (methods and findings described in Chapter II) was used to derive a relationship between microcracks in concrete and the ingress of external chemicals.

Based on the experimental and field tests, new equations were proposed based on regression analysis (regression process provided in Chapter V) to predict the crack percentage in concrete exposed to different sulfate and low $\mathrm{pH}$ environment. The crack percentage could be further use to establish a threshold that can be set by bridge owners. Results show that the proposed equations compared well with field test results with a maximum deviation of $\pm 20 \%$.

In conclusion, the proposed approach of relating microcracks to deterioration is a better method than existing diffusion and sorption models since sulfate attack cause cracking in concrete. Imaging technique provided in this study can also be used to quantitatively analyze concrete samples. 
VITA

SHUO ZHANG

2005-2009 B.S., Civil Engineering

Beijing University of Civil Engineering and Architecture

Beijing, China

2008-2009 Research Assistant

Beijing University of Civil Engineering and Architecture

Beijing, China

2009- 2015 Doctoral Candidate

Department of Civil and Environmental Engineering,

Florida International University

Miami, Florida

2009-2010 Teaching Assistant, Department of Civil and Environmental Engineering,

Florida International University

Miami, Florida

2010-2013 Research Assistant, Department of Civil and Environmental Engineering, Florida International University

Miami, Florida

2011-2015 Membership

American Society of Civil Engineers

2011-2015 Membership

American Concrete Institute

2012-2015 Membership

Chi-Epsilon Honor Society of Civil Engineering Honor Society

2013-2015 Geotechnical Engineer, Geosol, Inc.

Miami Lakes, Florida

\section{PUBLICATIONS AND PRESENTATIONS}

Jha, K.K., Zhang, S., Suksawang, N., Wang, T., and Agarwal, A. (2013) "Work-ofindentation as a mean to characterize indenter geometry and load-displacement response of a material” Journal of Physics D: Applied Physics, Vol. 46, No. 41, p. 415501 doi:10.1088/0022-3727/46/41/415501 
Suksawang, N., and Zhang, S. (2013) "Performance of High Performance Concrete HPC in Low pH and Sulfate Environment" Final Report submitted to FDOT, Contract No. BDK 80 977-16, p. 264

Zhang, S. and Suksawang, N. (2012) "Influence of curing on sulfate resistance of highperformance concrete" Structural Fault + Repair 2012 Conference, Edinburgh, Scotland, UK, July 3rd - 5th, 2012.

Zhang, S. and Suksawang, N. (2012) "Evaluation of the performance of precast concrete piles in sulfate environment" 2012 PCI Convention and National Bridge Conference in Nashville, TN, Sept. 29-Oct. 3, 2012

Zhang, S. (2012) "Service Life Modeling of HPC in Low pH and Sulfate Condition", School of Civil Engineering Academic Seminar. Beijing University of Civil Engineering and Architecture, Beijing, China, December 13th, 2012.

Zhang S. and Suksawang, N. "Study of Sulfate-Induced Deterioration of In-Situ Concrete Bridge Foundations", submitted.

Zhang S. and Suksawang, N. "Impact of Pozzolanic Materials for Concrete Exposed to Sulfate and Acidic Environments”, submitted.

Zhang S. and Suksawang, N. "Sulfate mitigation and attack modeling in blended cementbased materials", in progress.

Sun Y., Zhang S., Chen C., Lahiri D., and Agarwal A. "A Comparative Evaluation of Overall Elastic Modulus of Aluminum-SiC Composite through Experimental, Finite Element Analysis, and Micromechanics Models”, in progress. 